\title{
Development of an open loop fuzzy logic urea dosage controller for use with an SCR equipped HDD engine
}

Theodore R. Adams

West Virginia University

Follow this and additional works at: https://researchrepository.wvu.edu/etd

\section{Recommended Citation}

Adams, Theodore R., "Development of an open loop fuzzy logic urea dosage controller for use with an SCR equipped HDD engine" (2008). Graduate Theses, Dissertations, and Problem Reports. 1967.

https://researchrepository.wvu.edu/etd/1967

This Thesis is protected by copyright and/or related rights. It has been brought to you by the The Research Repository @ WVU with permission from the rights-holder(s). You are free to use this Thesis in any way that is permitted by the copyright and related rights legislation that applies to your use. For other uses you must obtain permission from the rights-holder(s) directly, unless additional rights are indicated by a Creative Commons license in the record and/ or on the work itself. This Thesis has been accepted for inclusion in WVU Graduate Theses, Dissertations, and Problem Reports collection by an authorized administrator of The Research Repository @ WVU. For more information, please contact researchrepository@mail.wvu.edu. 


\title{
Development of an Open Loop Fuzzy Logic Urea Dosage Controller for Use with an SCR Equipped HDD Engine
}

By

Theodore R. Adams

\section{THESIS}

Submitted to the College of Engineering \& Mineral Resources at West Virginia University in partial fulfillment of the requirements for the degree of

\author{
Master of Science \\ in \\ Mechanical Engineering
}

\section{Committee Members:}

Mridul Gautam, Ph.D., Chair

Benjamin C. Shade, Ph.D.

Mario Perhinschi, Ph.D.

\author{
Department of Mechanical and Aerospace Engineering \\ Morgantown, West Virginia \\ 2008
}

Keywords: SCR, $\mathrm{NO}_{\mathrm{x}}$, Fuzzy Logic, Urea, Exhaust Aftertreatment Copyright 2008, Theodore R. Adams 


\title{
Development of an Open Loop Fuzzy Logic Urea Dosage Controller For Use with an SCR Equipped HDD Engine
}

\author{
Theodore R. Adams
}

\begin{abstract}
Selective Catalytic Reduction (SCR) has been shown to be the most promising exhaust aftertreatment system for reducing oxides of nitrogen in near term in-use applications. SCRs use the ammonia containing compound urea, as a reducing agent. In order to control the urea dosage during transient operation of the engine, sophisticated control strategies are needed. The goal of this study was to design a controller to achieve the maximum $\mathrm{NO}_{\mathrm{x}}$ emission reduction possible in the transient mode of engine operation, without causing ammonia slip. The development of an open loop, non-sensor based fuzzy logic urea dosage controller is discussed in this thesis. Urea injection values were controlled with 'maps' based upon the engine speed and engine load, and fuzzy logic was employed as a robust artificial intelligence technique to allow for the development of these maps. Fuzzy logic was utilized to model the complex SCR system and predict the efficiency of $\mathrm{NO}_{\mathrm{x}}$ conversion. In order to aid in the development of the fuzzy logic SCR model, other methods for generating urea maps were investigated, as well. The first method was an optimization technique, which involved manual testing of the engine to find the optimal urea injection amount. The other method involved injection of urea based upon the average $\mathrm{NO}_{\mathrm{x}}$ produced. A correction factor was developed and applied to this map to account for losses of ammonia.

The open loop urea map control strategy was implemented without the use of $\mathrm{NO}_{\mathrm{x}}$ or $\mathrm{NH}_{3}$ sensors. The final fuzzy logic urea map created was able to reduce $\mathrm{NO}_{\mathrm{x}}$ by $57 \%$ over the FTP cycle and $60 \%$ over the ETC cycle. This reduction was achieved without causing any significant ammonia slip. The optimized and average $\mathrm{NO}_{\mathrm{x}}$ urea maps reduced $\mathrm{NO}_{\mathrm{x}}$ by $67 \%$ and $66 \%$ over the FTP cycle, but also resulted in large peaks of ammonia slip during the LAFY section. The average $\mathrm{NH}_{3}$ slip seen during the FTP was less than $10 \mathrm{ppm}$, which was deemed acceptable. The optimized map was also used on the ETC cycle and $\mathrm{NO}_{\mathrm{x}}$ was reduced by $65 \%$ with no significant $\mathrm{NH}_{3}$ slip. The urea maps created for this study appeared to be cycle independent and could be used to control $\mathrm{NO}_{\mathrm{x}}$ emissions for any transient mode of engine operation.
\end{abstract}




\section{Table of Contents}

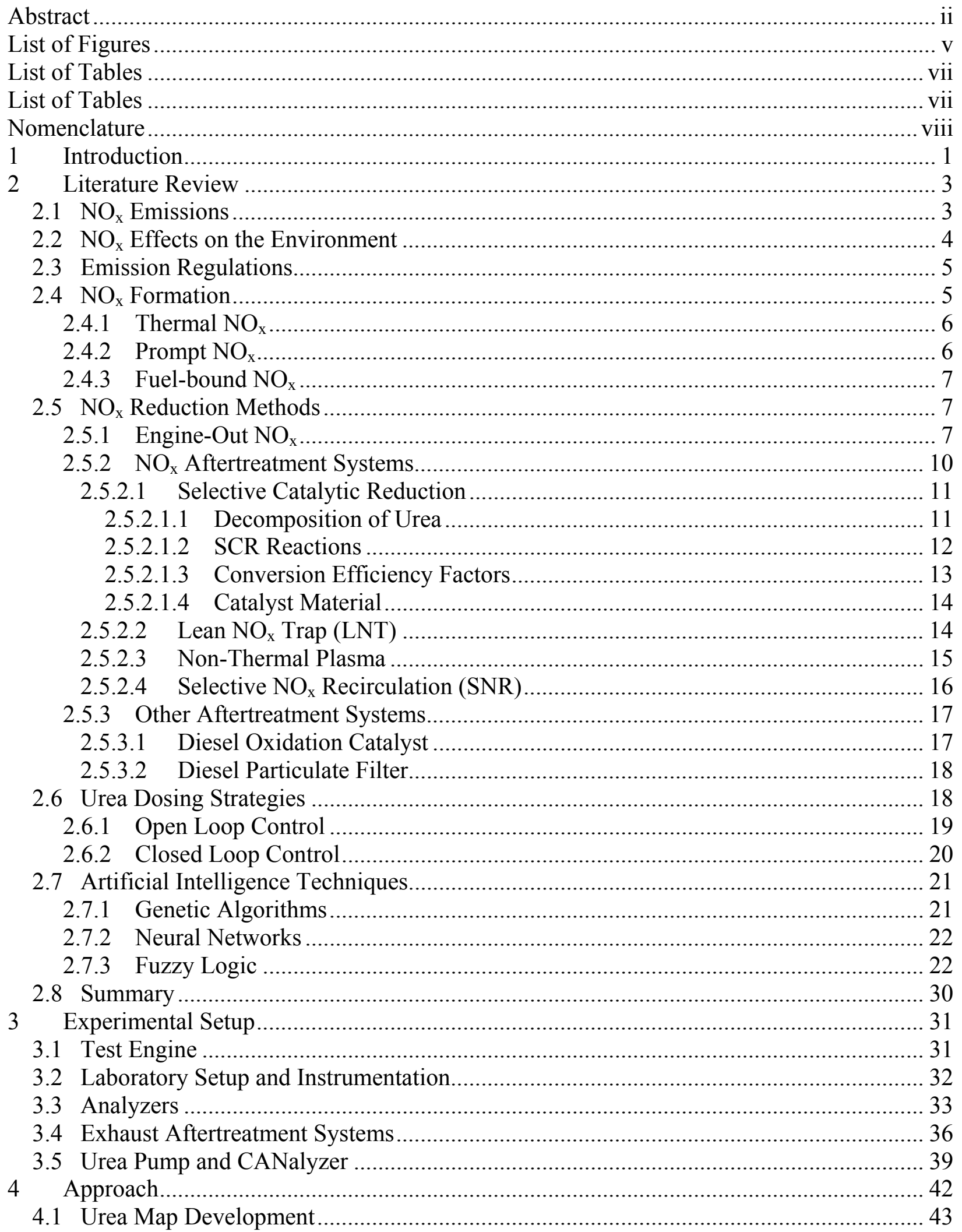




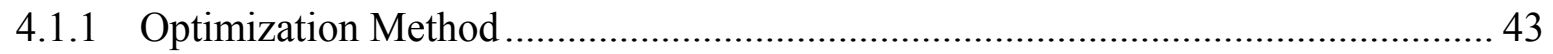

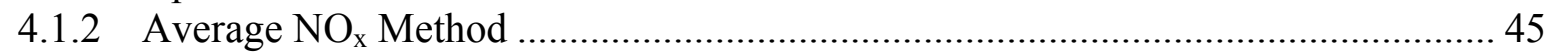

4.1.2.1 Ammonia Adsorption/Desorption Study .................................................... 46

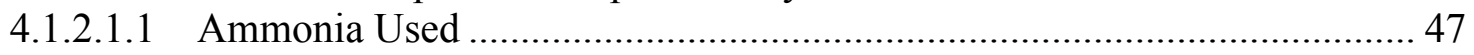

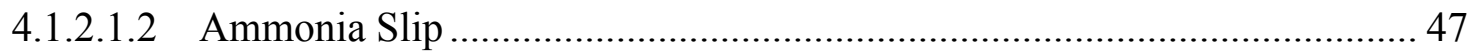

4.1.2.1.3 Ammonia Injection Values ................................................................ 49

4.1.2.1.4 Ammonia Loss .............................................................................. 49

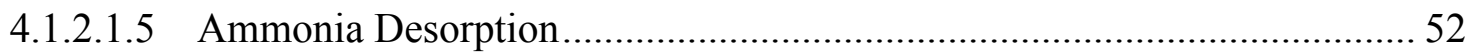

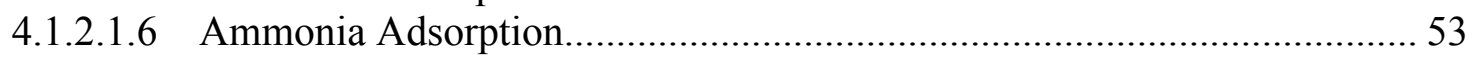

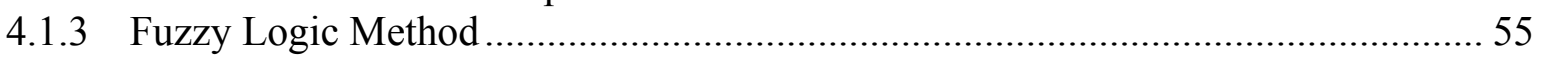

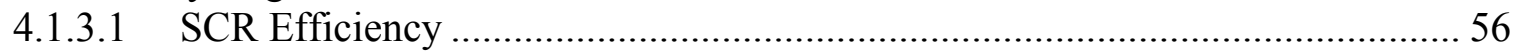

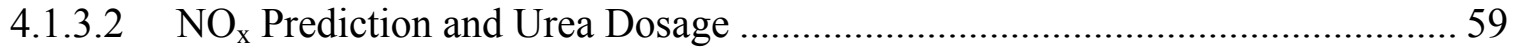

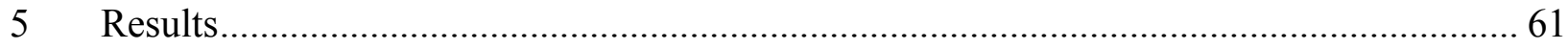

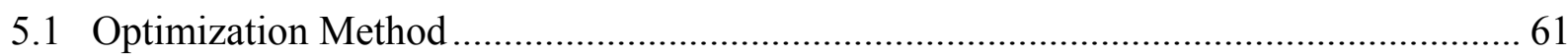

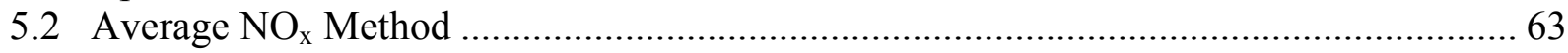

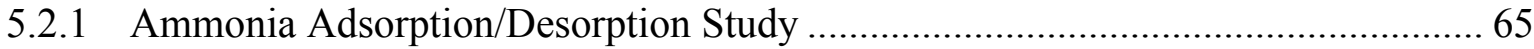

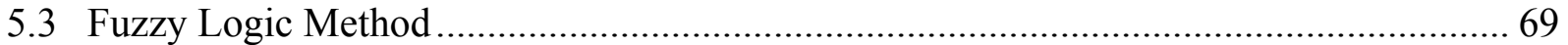

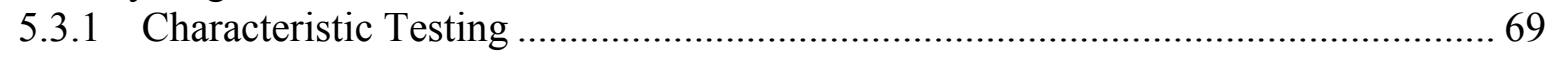

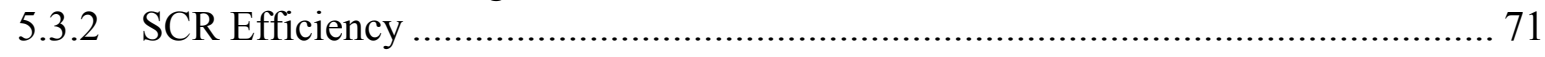

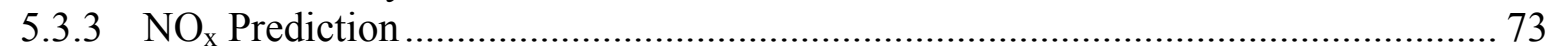

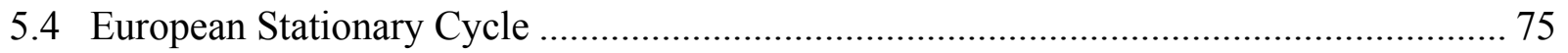

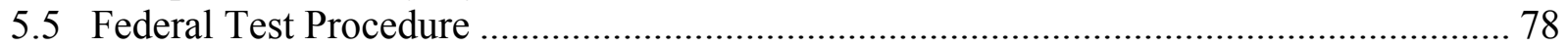

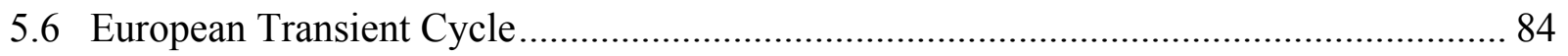

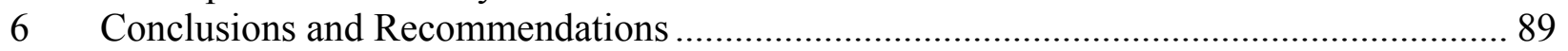

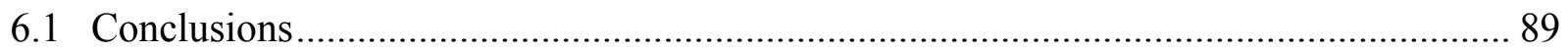

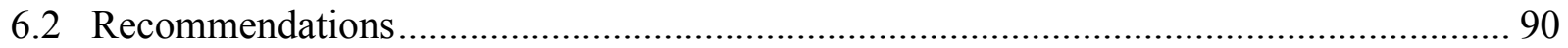

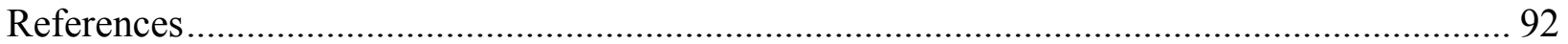

Appendix A - Fuzzy Logic Control Code ............................................................................. 94

Appendix B - CANalyzer Control Code ................................................................................. 102 


\section{List of Figures}

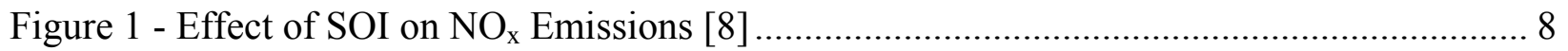

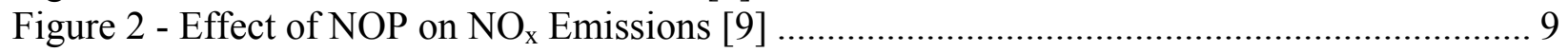

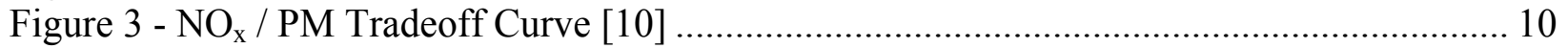

Figure 4 - Plasma Assisted Catalytic Reduction System [13] ...................................................... 16

Figure 5 - Selective $\mathrm{NO}_{\mathrm{x}}$ Recirculation System [7] ............................................................. 17

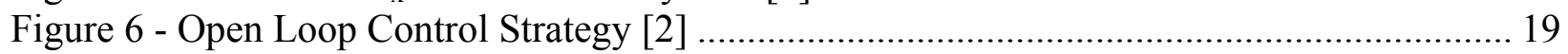

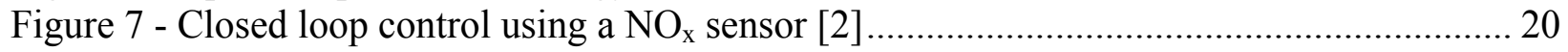

Figure 8 - Fuzzy Logic Based Control Input/Output Mapping [19] .............................................. 23

Figure 9 - General Block Diagram for a Fuzzy Logic Controller [19] ........................................ 24

Figure 10 - Trapezoidal Membership Functions [19] …………………........................................ 25

Figure 11 - Bell-shaped Membership Functions [19] ……….................................................. 25

Figure 12 - Cosinusoidal Membership Functions [19] ………................................................... 26

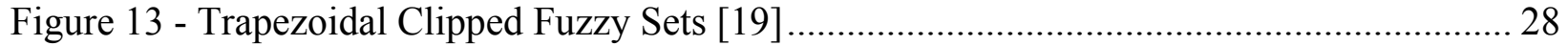

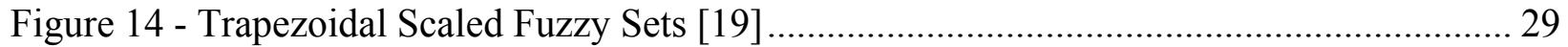

Figure 15 - MY07 Volvo MD11 (339 hp@1800 rpm/1298 lb-ft @1306 rpm).......................... 31

Figure 16 - 800hp DC Dynamometer connected to MY07 Volvo MD11 Engine.......................... 32

Figure 17 - CVS Subsonic Flow Venturi and Dilution Tunnel ................................................... 33

Figure 18 - Variable Speed Blower .................................................................................... 33

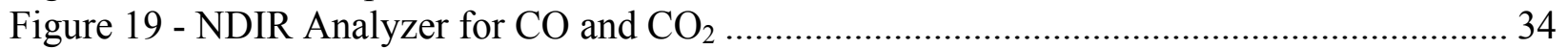

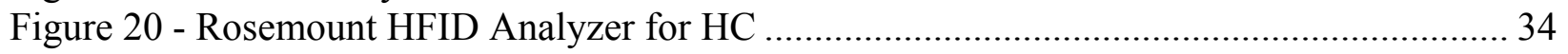

Figure 21 - Ecophysics CLD 822CMH Analyzer for $\mathrm{NO}_{\mathrm{x}}$ and $\mathrm{NO}$............................................. 34

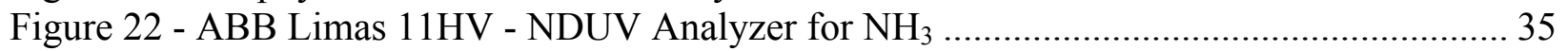

Figure 23 - PM filters (Left: Unused, Right: Engine-Out Test) ………………………................ 36

Figure 24 - PM Filter Box (left) and Filter Holder (right) [22] ................................................... 36

Figure 25 - Fleetguard DOC+DPF Aftertreatment System ...................................................... 37

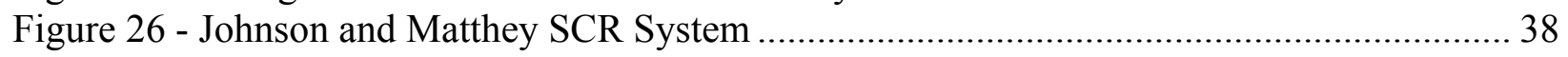

Figure 27 - Exhaust Aftertreatment Systems on the Volvo MD11 Engine .................................. 38

Figure 28 - Urea Pump Hose Connection Diagram .................................................................. 39

Figure 29 - CANalyzer Control Setup Diagram ………............................................................ 40

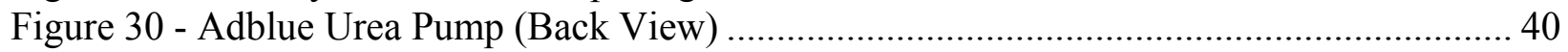

Figure 31 - Adblue Urea Pump (Front View) ………............................................................... 40

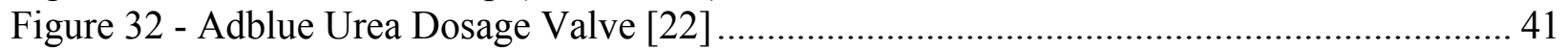

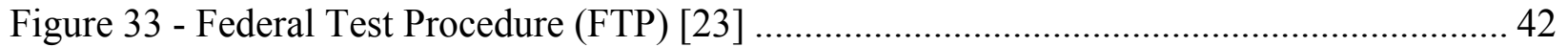

Figure 34 - ESC and AVL Modes Used for Optimization of Urea Injection [21]........................ 44

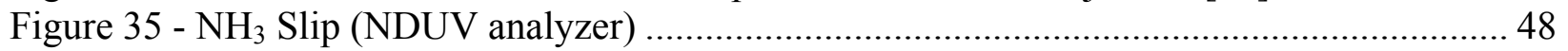

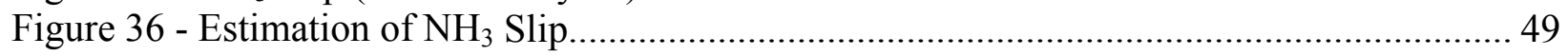

Figure 37 - Urea Pump Calibration (Volvo) [26] ……......................................................... 50

Figure 38 - Urea Pump Calibration Curve ........................................................................... 52

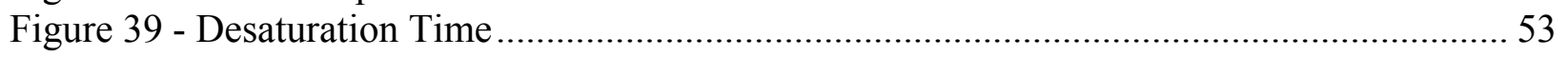

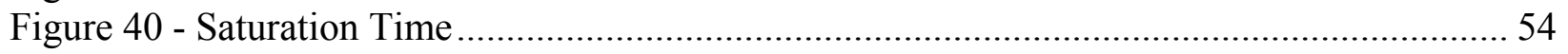

Figure 41 - Open Loop Control Strategy for Urea Dosage........................................................ 55

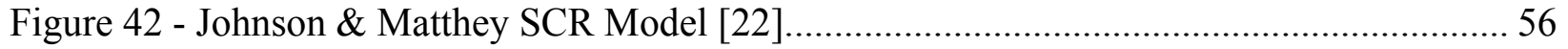

Figure 43 - Temperature Membership Function ................................................................... 57

Figure $44-\mathrm{NO}_{2} / \mathrm{NO}$ Ratio Membership Function................................................................... 57 
Figure 45 - Efficiency Membership Function................................................................... 58

Figure 46 - Initial Optimization Map using interpolation of ESC and AVL modes.................. 61

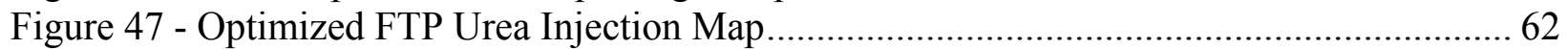

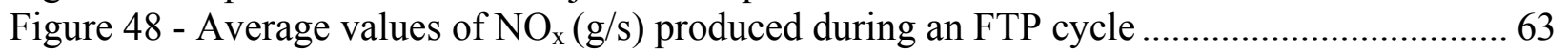

Figure 49 - ESC Mode 8 Ammonia Adsorption/Desorption Study Results .............................. 65

Figure 50 - ESC Mode 10 Ammonia Adsorption/Desorption Study Results ............................ 66

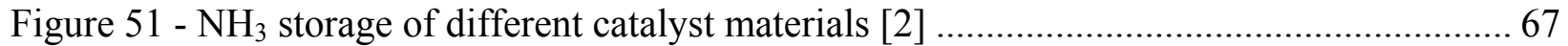

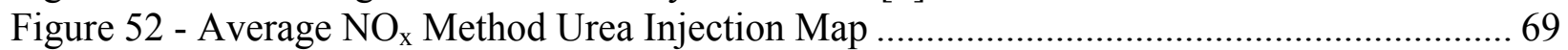

Figure 53 - Fuzzy Logic Controller Behavior with Constant Temperature............................... 70

Figure 54 - Fuzzy Logic Controller Behavior with Constant $\mathrm{NO}_{\mathrm{x}}$ Ratio ............................... 70

Figure 55 - SCR inlet temperature during an FTP cycle .................................................. 71

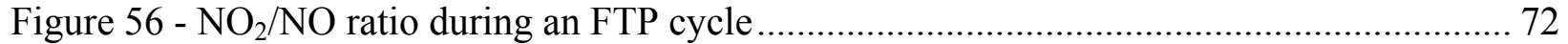

Figure 57 - Predicted SCR efficiency (normalized) over an FTP cycle ................................... 72

Figure 58 - Comparison of Fuzzy Logic Predicted $\mathrm{NO}_{\mathrm{x}}$ and Actual $\mathrm{NO}_{\mathrm{x}}$ over an FTP cycle..... 73

Figure 59 - Fuzzy Logic Method Urea Injection Map ............................................................ 74

Figure $60-\mathrm{NO}_{\mathrm{x}}$ Reduction during an ESC Cycle .............................................................. 76

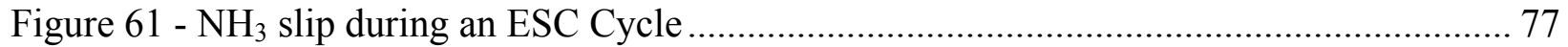

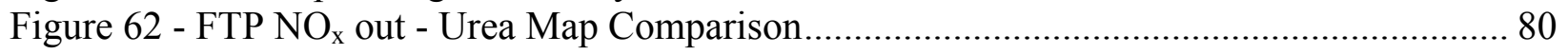

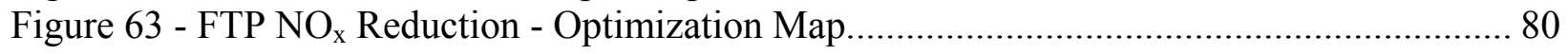

Figure 64 - FTP $\mathrm{NH}_{3}$ slip Values for Different Urea Maps ................................................ 81

Figure 65 - SCR efficiency of each method based on ranges of temperature for an FTP cycle... 82

Figure 66 - SCR efficiency trends for each method during an FTP cycle................................ 83

Figure 67 - SCR efficiency based on temperature using ESC and FTP data (optimized map) .... 83

Figure 68 - ETC $\mathrm{NO}_{\mathrm{x}}$ out -Urea Map Comparison ............................................................... 85

Figure 69 - ETC $\mathrm{NO}_{\mathrm{x}}$ Reduction using FTP Optimization Map.............................................. 85

Figure 70 - ETC $\mathrm{NH}_{3}$ Slip Values for Different Urea Maps................................................. 86

Figure 71 - SCR efficiency based on ranges of temperature for an ETC cycle ......................... 87

Figure 72 - SCR efficiency over the ETC temperature range................................................ 88 


\section{List of Tables}

Table 1 - U.S. Heavy-duty Engine Emission Regulations (g/bhp-hr) [1] .................................. 5

Table 2 - Europe Heavy-duty Engine Emissions Regulations (g/bhp-hr) [1] ........................... 5

Table 3 - Inference Rule Matrix for a Cruise Controller [19] ................................................. 27

Table 4 - Fuzzy Command Matrix using Multiplicative Intersection of Fuzzy Sets [19] ........... 27

Table 5 - Fuzzy Command Matrix using Minimum Intersection of Fuzzy Sets [19]................. 27

Table 6 - Fuzzy Command Matrix Overlaid with Inference Rule Matrix [19] ......................... 28

Table 7 - Volvo MY07 MD11 Engine Specifications [21] ....................................................... 32

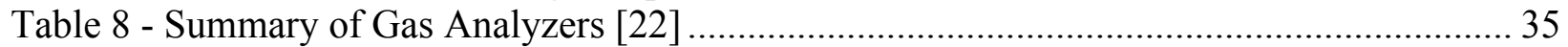

Table 9 - Example of Optimization of a Specific section of the FTP cycle .............................. 45

Table 10 - Example of Average $\mathrm{NO}_{\mathrm{x}}(\mathrm{g} / \mathrm{s})$ Values for an FTP cycle ........................................ 46

Table 11 - Urea Pump Injection Error ................................................................................... 51

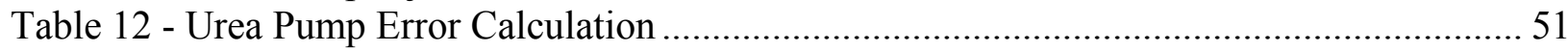

Table 13 - Structure of Fuzzified Input................................................................................... 58

Table 14 - Inference Rule Matrix......................................................................................... 59

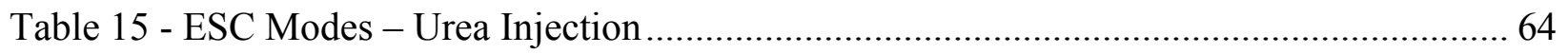

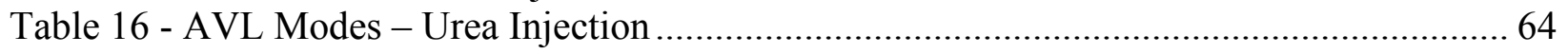

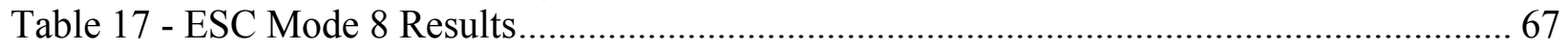

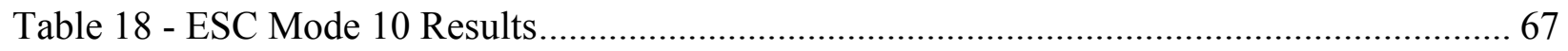

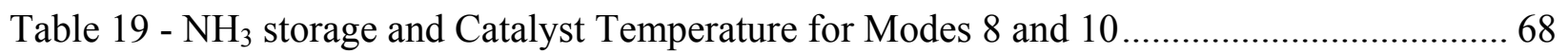

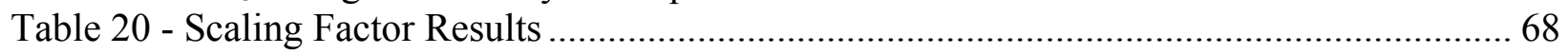

Table 21 - ESC Emissions Summary ................................................................................ 75

Table 22 - ESC modes - Optimization Method Results ................................................... 77

Table 23 - FTP Emission Summary ......................................................................................... 79

Table 24 - FTP Urea Map $\mathrm{NO}_{\mathrm{x}}$ Reduction Comparison ...................................................... 79

Table 25 - ETC Emission Summary ................................................................................. 84

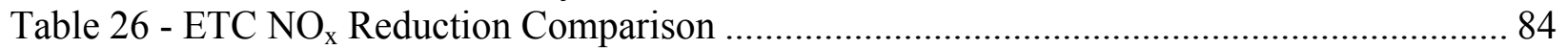




\section{Nomenclature}

\begin{tabular}{|c|c|}
\hline AI & Artificial Intelligence \\
\hline ANN & Artificial Neural Network \\
\hline $\mathrm{BaO}$ & Barium Oxide \\
\hline $\mathrm{C}$ & Carbon \\
\hline $\mathrm{CN}$ & Cetane \\
\hline $\mathrm{CNG}$ & Compressed Natural Gas \\
\hline $\mathrm{CO}$ & Carbon Monoxide \\
\hline $\mathrm{CO}_{2}$ & Carbon Dioxide \\
\hline DOC & Diesel Oxidation Catalyst \\
\hline DPF & Diesel Particulate Filter \\
\hline DRC & Design Requirements and Constraints \\
\hline EGR & Exhaust Gas Recirculation \\
\hline ESC & European Steady Cycle \\
\hline ETC & European Transient Cycle \\
\hline FL & Fuzzy Logic \\
\hline FTP & Federal Test Procedure \\
\hline GA & Genetic Algorithm \\
\hline g/bhp-hr & Grams per Brake Horsepower-hour \\
\hline $\mathrm{H}$ & Hydrogen \\
\hline $\mathrm{H}_{2} \mathrm{O}$ & Water \\
\hline $\mathrm{HC}$ & Hydrocarbon \\
\hline HCCI & Homogenous Charge Compression Ignition \\
\hline $\mathrm{HCN}$ & Hydrogen Cyanide \\
\hline HDDE & Heavy Duty Diesel Engine \\
\hline HECC & High Efficiency Clean Combustion \\
\hline HFID & Heated Flame Ionization Detector \\
\hline $\mathrm{HNCO}$ & Isocyanic Acid \\
\hline $\mathrm{HNO}_{2}$ & Nitrous Acid \\
\hline $\mathrm{HNO}_{3}$ & Nitric Acid \\
\hline LAFY & Los Angeles Freeway \\
\hline LANF & Los Angeles Non-Freeway \\
\hline LNT & Lean NOx Trap \\
\hline MF & Membership Function \\
\hline $\mathrm{N}$ & Monatomic Nitrogen \\
\hline $\mathrm{N}_{2}$ & Diatomic Nitrogen \\
\hline $\mathrm{N}_{2} \mathrm{O}$ & Nitrous Oxide \\
\hline NDIR & Non-dispersive Infrared \\
\hline NDUV & Non-dispersive Ultraviolet \\
\hline $\mathrm{NH}_{3}$ & Ammonia \\
\hline$\left(\mathrm{NH}_{2}\right)_{2} \mathrm{CO}$ & Urea \\
\hline NO & Nitrogen Oxide \\
\hline $\mathrm{NO}_{2}$ & Nitrogen Dioxide \\
\hline $\mathrm{NO}_{\mathrm{x}}$ & Oxides of Nitrogen \\
\hline
\end{tabular}


NOP

NSR

NYNF

$\mathrm{O}$

$\mathrm{O}_{2}$

$\mathrm{O}_{3}$

$\mathrm{OH}$

PACR

PCCI

PM

PPM

SCR

SNR

$\mathrm{SOI}$

$\mathrm{SO}_{2}$

$\mathrm{Ti}$

TWC

$\mathrm{V}$

VGT

W
Needle Opening Pressure

Nominal Stoichiometric Ratio

New York Non-Freeway

Monatomic Oxygen

Diatomic Oxygen

Ozone

Hydroxide

Plasma Assisted $\mathrm{NO}_{\mathrm{x}}$ Reduction

Premixed Charge Compression Ignition

Particulate Matter (soot)

Parts per million

Selective Catalyst Reduction

Selective NOx Recirculation

Start of Injection

Sulfer Dioxide

Titania

Three Way Catalyst

Vanadium

Variable Geometry Turbocharger

Tungsten 


\section{Introduction}

Diesel exhaust emissions are a significant contributor to atmospheric pollution worldwide. Oxides of nitrogen $\left(\mathrm{NO}_{\mathrm{x}}\right)$, one of the major pollutants in diesel exhaust, are very harmful to the environment and pose serious health risks in urban areas. Consequently, $\mathrm{NO}_{\mathrm{x}}$ emission regulations are becoming more and more stringent. Previously, regulations could be met by optimizing engine parameters in order to produce different levels of emission. With the new regulations, engine-out emission strategies alone may not be enough. This has caused engine manufacturers to look for other methods, such as exhaust aftertreatment systems, to reduce $\mathrm{NO}_{\mathrm{x}}$. Of all the exhaust aftertreatment systems for $\mathrm{NO}_{\mathrm{x}}$ reduction that have been developed and investigated, selective catalytic reduction (SCR) is one of the most promising available for near term in-use applications [1].

SCR is an exhaust aftertreatment system that reduces $\mathrm{NO}_{\mathrm{x}}$ through the combination of a catalyst and reducing agent (urea). Urea is a compound that decomposes to form ammonia $\left(\mathrm{NH}_{3}\right)$, which reacts with $\mathrm{NO}_{\mathrm{x}}$ to form nitrogen and water. SCRs are capable of converting a very high percentage of $\mathrm{NO}_{\mathrm{x}}$ during steady state testing [1]. However, transient engine operation creates difficulties, primarily due to problems encountered in controlling the quantity of urea injected. This dictates the need for a urea dosage controller capable of injecting the correct quantities needed to maximize $\mathrm{NO}_{\mathrm{x}}$ reduction without causing ammonia slip. Ammonia slip will occur if an excess of urea is injected and a portion of the unused ammonia 'slips' out in the exhaust stream. To prevent this, many strategies have been tried, including open and closed loop control. Closed loop urea dosage strategies, which rely on real time sensors for feedback, are limited by the technology available. $\mathrm{NO}_{\mathrm{x}}$ sensors are unreliable at very low concentrations and have a cross sensitivity to $\mathrm{NH}_{3}$ in the exhaust. $\mathrm{NH}_{3}$ sensors are also unreliable at low concentrations, have slow response times and exhibit a response to $\mathrm{NO}_{\mathrm{x}}$ levels in the exhaust. Due to these limitations, closed loop strategies have met with limited success. Open loop control strategies typically inject urea based on the $\mathrm{NO}_{\mathrm{x}}$ produced by the engine as well as some type of SCR system model. Problems with high ammonia slip values have led many to believe that open loop control strategies are inadequate to achieve the upcoming emission regulations [2]. Both types of control strategies are limited by the difficulty in modeling the reactions within an SCR. 
The goal of this study was to create a non-sensor based control strategy that will limit the amount of ammonia slip while still reducing a high percentage of $\mathrm{NO}_{\mathrm{x}}$. This was done through the use of an artificial intelligence technique called fuzzy logic. The fuzzy logic method allowed for simple modeling of a highly complex SCR system. The controller used an open loop strategy with urea 'maps' to inject the correct amount based on several engine parameters. The advantage of this approach was that it could be implemented without the use of sensors and without detailed knowledge of the internal workings of an SCR system. To develop the fuzzy logic program and the urea maps, several methods were applied that gave insight into how the SCR system reacts and performs in different circumstances.

This work is significant because it provides a basis for more in-depth development and understanding of the SCR system. It is feasible, that with further development and improvement of the strategy described by this paper, the 2010 emission standards for heavy-duty on-highway diesel engines can be reached. The open loop control strategy could also be adapted to more complex approaches that involve technologies not available as of now. This will allow for a more robust closed loop control strategy that can adjust to variability in the system. 


\section{Literature Review}

In order to effectively reduce $\mathrm{NO}_{\mathrm{x}}$ emissions, it is necessary to have a basic understanding of $\mathrm{NO}_{\mathrm{x}}$ formation and transformation to other species via chemical reactions, catalytic reduction techniques, on-vehicle control strategies and system controls. This section will look at what $\mathrm{NO}_{\mathrm{x}}$ is, how it is formed and its effects on the environment. Also an extensive review of available $\mathrm{NO}_{\mathrm{x}}$ reduction techniques and aftertreatment devices will be presented. A review will also be done of several types of control strategies for urea dosage that have been implemented with SCR exhaust aftertreatment systems. Finally, artificial intelligence techniques that could be used for control purposes will be investigated.

\section{$2.1 \mathrm{NO}_{x}$ Emissions}

Oxides of nitrogen contribute to various forms of pollution such as photochemical smog and acid rain. Because of this, $\mathrm{NO}_{\mathrm{x}}$ emission regulations are becoming more and more stringent. Heavy-duty $\mathrm{NO}_{\mathrm{x}}$ standards in 2010 will be $0.20 \mathrm{~g} / \mathrm{bhp}-\mathrm{hr}$ compared to $2.5 \mathrm{~g} / \mathrm{bhp}$-hr in 2006 [1]. The 2010 standards will be phased in beginning 2007. One of the biggest sources of $\mathrm{NO}_{\mathrm{x}}$ emissions are heavy-duty diesel engines earmarked for on-highway application, such as buses and trucks [6]. To meet these very stringent regulations, companies such as Cummins, Volvo, and Caterpillar, who produce large diesel engines, are actively researching methods to reduce $\mathrm{NO}_{\mathrm{x}}$.

One of the methods of reducing $\mathrm{NO}_{\mathrm{x}}$ emissions is to optimize the combustion process. This is done by changing various engine parameters, such as the amount of exhaust gas recirculation (EGR), needle opening pressure (NOP) and start of injection (SOI). Changing these parameters for optimal combustion allows for reduction of engine-out $\mathrm{NO}_{\mathrm{x}}$. Drawbacks to this approach come in the form of increased fuel consumption and increased particulate matter (PM) emissions [4]. Another way to optimize the combustion process is through advanced combustion techniques such as homogenous charge compression ignition (HCCI), compressed natural gas (CNG), high efficiency clean combustion (HECC) or premixed charge compression ignition (PCCI). These methods are all still being actively researched, and this section will not focus on any one of them. Instead, exhaust aftertreatment systems that have been shown to be viable in the near term will be discussed. 
Exhaust aftertreatment systems may be used to reduce $\mathrm{NO}_{\mathrm{x}}$ by treating the exhaust gases downstream of the engine. There are several types of exhaust aftertreatment systems for $\mathrm{NO}_{\mathrm{x}}$ but the most commonly used is SCR. Other systems include lean $\mathrm{NO}_{\mathrm{x}}$ traps $/ \mathrm{NO}_{\mathrm{x}}$ adsorbers, a nonthermal plasma system and selective $\mathrm{NO}_{\mathrm{x}}$ recirculation. A combination of different engine calibrations and exhaust aftertreatment systems may also be used.

\section{$2.2 \mathrm{NO}_{x}$ Effects on the Environment}

$\mathrm{NO}_{\mathrm{x}}$ is one of the main causes of photochemical smog and it is also a large contributor to acid rain. Smog is a major problem in highly urban areas as it has many health hazards associated with it. Chief among these is damage to lung tissue and reduction in lung function [3]. Children and people with asthma are especially susceptible to this. Smog is also harmful to trees and can cause crop damage [3].

Smog is another way to refer to ground level ozone $\left(\mathrm{O}_{3}\right)$. Photochemical smog is formed when $\mathrm{NO}_{\mathrm{x}}$ reacts with atmospheric air in the presence of sunlight [4]. This causes nitrogen dioxide to decompose into nitrogen oxide, monatomic oxygen and smog. The monatomic oxygen then reacts with oxygen in the atmosphere to form ozone. This is shown in Equations 2.1 and $2.2[4]$.

$$
\begin{array}{ll}
\mathrm{NO}_{2}+\text { Energy_from_sunlight } \rightarrow \mathrm{NO}+\mathrm{O}+\text { smog } & \mathbf{2 . 1} \\
\mathrm{O}+\mathrm{O}_{2} \rightarrow \mathrm{O}_{3} & \mathbf{2 . 2}
\end{array}
$$

Acid rain, another harmful effect of $\mathrm{NO}_{\mathrm{x}}$, is formed when $\mathrm{NO}_{\mathrm{x}}$ reacts with moisture in the atmosphere to form nitric acids. The following reaction shows how nitrogen dioxide reacts with water to form nitrous acid and nitric acid [3].

$$
2 \mathrm{NO}_{2}+\mathrm{H}_{2} \mathrm{O} \rightarrow \mathrm{HNO}_{2}+\mathrm{HNO}_{3}
$$

Acid rain is very harmful to lakes and streams as it can make them acidic and unsuitable for habitation by fish. It also contributes to the deterioration of buildings and historical monuments [3]. 


\subsection{Emission Regulations}

Emissions standards throughout the world are being considerably tightened. In 2007 the U.S. standards for hydrocarbons, oxides of nitrogen and particulate matter were all reduced significantly [1]. The regulations for 2010 are even more stringent and will require more sophisticated strategies and technologies in order to reach. Table 1 shows the past, current and future U.S. emission standards.

Table 1 - U.S. Heavy-duty Engine Emission Regulations (g/bhp-hr) [1]

\begin{tabular}{|c|c|c|c|c|}
\hline Year & HC & CO & NOx+NHWC & Ph \\
\hline $\mathbf{1 9 9 8}$ & 1.3 & 15.5 & 4.0 & 0.10 \\
\hline 2004 & 0.5 & 15.5 & 2.5 & 0.10 \\
\hline 2007 & 0.14 & 15.5 & 1.2 & 0.01 \\
\hline 2010 & 0.14 & 15.5 & 0.2 & 0.01 \\
\hline
\end{tabular}

As seen in Table 1, $\mathrm{NO}_{\mathrm{x}}$ emissions must be reduced from $1.2 \mathrm{~g} / \mathrm{bhp}-\mathrm{hr}$ to $0.20 \mathrm{~g} / \mathrm{bhp}-\mathrm{hr}$ between 2007 and 2010. This presents a very serious challenge to engine developers and researchers. In Europe, the emission limits are similarly low. Table 2 shows the emission regulations for Europe.

Table 2 - Europe Heavy-duty Engine Emissions Regulations (g/bhp-hr) [1]

\begin{tabular}{|c|c|c|c|c|}
\hline Year & HC & CO & NOx+NHMC & PM \\
\hline 2000 (Euro II) & 0.5 & 1.6 & 3.7 & 0.07 \\
\hline 2005 (Euro M) & 0.3 & 1.1 & 2.6 & 0.01 \\
\hline 2008 (Euro W) & 0.19 & 1.1 & 1.5 & 0.01 \\
\hline
\end{tabular}

\section{$2.4 \mathrm{NO}_{x}$ Formation}

Oxides of nitrogen in the exhaust gas are made up mainly of nitrogen oxide (NO) with some nitrogen dioxide $\left(\mathrm{NO}_{2}\right)$ and trace amounts of various other nitrogen and oxygen compounds. These are collectively referred to as $\mathrm{NO}_{\mathrm{x}}[4] . \mathrm{NO}_{\mathrm{x}}$ formed in a diesel engine is mainly due to the dissociation of diatomic nitrogen $\left(\mathrm{N}_{2}\right)$ into monatomic nitrogen $(\mathrm{N})$, which then joins with reacting oxygen. Diatomic nitrogen is normally a very stable element and does not react as readily as monatomic nitrogen, which is very unstable. The very high combustion 
temperatures in an engine cause the dissociation of diatomic nitrogen. The main source of nitrogen for this reaction is the engine intake air. Small amounts of nitrogen can also be present in the diesel fuel, which may contain $\mathrm{NH}_{3}, \mathrm{CN}$ and $\mathrm{HCN}$ [4].

There are three means by which $\mathrm{NO}_{\mathrm{x}}$ is formed in a diesel engine. These include thermal $\mathrm{NO}_{\mathrm{x}}$, prompt $\mathrm{NO}_{\mathrm{x}}$ and fuel-bound $\mathrm{NO}_{\mathrm{x}}$. Thermal $\mathrm{NO}_{\mathrm{x}}$ is caused by oxidation of nitrogen in the post-flame zone and is the largest contributor to the total $\mathrm{NO}_{\mathrm{x}}$ emissions from a diesel engine [5]. Prompt $\mathrm{NO}_{\mathrm{x}}$ is caused by the formation of $\mathrm{NO}_{\mathrm{x}}$ in the flame zone. Fuel-bound $\mathrm{NO}_{\mathrm{x}}$ is caused by oxidation of nitrogen containing compounds that may be in the fuel [6].

\subsubsection{Thermal $\mathrm{NO}_{\mathrm{x}}$}

Thermal $\mathrm{NO}_{\mathrm{x}}$ is the main source of $\mathrm{NO}_{\mathrm{x}}$ emissions and the mechanism by which it is produced is the extended Zeldovich mechanism. This mechanism consists of three reactions, which are shown by Equations 2.4, 2.5 and 2.6: [6]

$$
\begin{array}{ll}
\mathrm{O}+\mathrm{N}_{2} \rightarrow \mathrm{NO}+\mathrm{N} & \mathbf{2 . 4} \\
\mathrm{NO}+\mathrm{O} \rightarrow \mathrm{NO}+\mathrm{O} & \mathbf{2 . 5} \\
\mathrm{N}+\mathrm{OH} \rightarrow \mathrm{NO}+\mathrm{H} & \mathbf{2 . 6}
\end{array}
$$

$\mathrm{NO}_{2}$ typically makes up only a small percentage of the total $\mathrm{NO}_{\mathrm{x}}$ but is formed when $\mathrm{NO}$ further reacts with oxygen. Equations 2.7 and 2.8 show the means by which NO is converted to $\mathrm{NO}_{2}[4]$.

$$
\begin{aligned}
& \mathrm{NO}+\mathrm{H}_{2} \mathrm{O} \rightarrow \mathrm{NO}_{2}+\mathrm{H}_{2} \\
& \mathrm{NO}+\mathrm{O}_{2} \rightarrow \mathrm{NO}_{2}+\mathrm{O}
\end{aligned}
$$

Thermal $\mathrm{NO}_{\mathrm{x}}$ is very temperature dependent and is formed mainly by oxidation of nitrogen found in the combustion air. The rate at which thermal $\mathrm{NO}_{\mathrm{x}}$ is formed depends on both temperature and time. High temperatures and long residence time in the combustion chamber allow for a large amount of thermal $\mathrm{NO}_{\mathrm{x}}$ formation [6].

\subsubsection{Prompt $\mathrm{NO}_{\mathrm{x}}$}

Prompt $\mathrm{NO}_{\mathrm{x}}$ is formed when atmospheric nitrogen $\left(\mathrm{N}_{2}\right)$ reacts with compounds in the fuel such as $\mathrm{C}, \mathrm{CH}$ and $\mathrm{CH}_{2}$. This results in the formation of various other compounds such as $\mathrm{HCN}$, 
$\mathrm{H}_{2} \mathrm{CN}$ and $\mathrm{CN}$ that can then be oxidized to form $\mathrm{NO}$. Prompt $\mathrm{NO}_{\mathrm{x}}$ is a very small contributor to the overall $\mathrm{NO}_{\mathrm{x}}$ and is generally negligible when compared with thermal $\mathrm{NO}_{\mathrm{x}}[6]$.

\subsubsection{Fuel-bound $\mathrm{NO}_{x}$}

Fuel-bound $\mathrm{NO}_{\mathrm{x}}$ is caused by the oxidation of nitrogen containing compounds in the fuel. During the combustion process nitrogen found in the fuel is released and forms $\mathrm{N}_{2}$ and NO. Fuel bound $\mathrm{NO}_{\mathrm{x}}$ is more relevant when combusting oil or coal and in general is not an issue regardind diesel engine combustion [6].

\subsection{NO $\mathrm{Neduction}_{x}$ Methods}

\subsubsection{Engine-Out $\mathrm{NO}_{\mathrm{x}}$}

Reduction of engine-out $\mathrm{NO}_{\mathrm{x}}$ is very important when trying to reach the 2010 emission levels. There are several ways to reduce engine-out $\mathrm{NO}_{\mathrm{x}}$. One option is to optimize the engine combustion parameters in order to produce lower $\mathrm{NO}_{\mathrm{x}}$ levels. This can be done several different ways, including increasing exhaust gas recirculation, retarding the injection timing and reducing the needle opening pressure. The general idea when optimizing engine parameters is to reduce the amount of oxygen available for oxidation of nitrogen and to reduce the temperature of the combustion. High combustion temperatures lead to the dissociation of $\mathrm{N}_{2}$ and higher $\mathrm{NO}_{\mathrm{x}}$ values [4].

Exhaust gas recirculation is one of the best methods to reduce engine-out $\mathrm{NO}_{\mathrm{x}}$. EGR is a method in which a percentage of the exhaust gas is recirculated into the engine intake air. The hydrocarbons and other gases present in the recirculated exhaust gas will reduce the amount of oxygen available for reaction, which will reduce $\mathrm{NO}_{\mathrm{x}}$. Also, the large heat absorbing capacity of $\mathrm{CO}_{2}$ and $\mathrm{H}_{2} \mathrm{O}$ in the exhaust will draw heat away from the combustion in the chamber. This reduces the overall temperature of the combustion, which in turn reduces $\mathrm{NO}_{\mathrm{x}}$ [7]. This comes with a penalty though. Lower combustion temperatures lead to lower thermal efficiency, less power and higher fuel consumption of the engine. It also increases the amount of particulates or soot that is produced by the combustion. EGR may also require a retrofit and can affect the life of the engine [7].

Another parameter that can be optimized for low $\mathrm{NO}_{\mathrm{x}}$ is the injection timing or start of injection (SOI). Retarding the injection timing will reduce the amount of premix burning in the 
combustion chamber. It has been shown that premix burning can account for up to $50 \%$ of the total $\mathrm{NO}_{\mathrm{x}}$ produced [6]. Reducing this amount decreases the total amount of $\mathrm{NO}_{\mathrm{x}}$ created. Renshan and Zhang [8] demonstrated the $\mathrm{NO}_{\mathrm{x}}$ production trend with various injection-timing values for a diesel engine. This is shown in Figure 1.

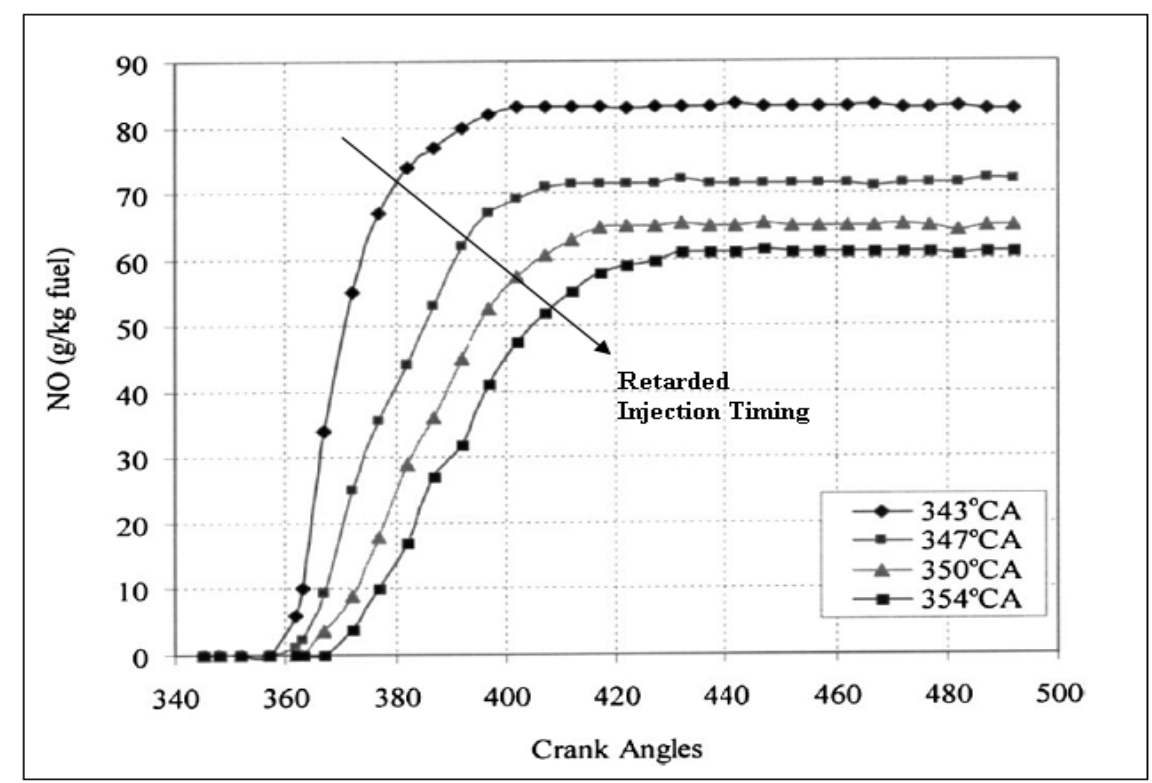

Figure 1 - Effect of SOI on $\mathrm{NO}_{\mathrm{x}}$ Emissions [8]

As evident in the figure, when the injection timing is retarded, $\mathrm{NO}_{\mathrm{x}}$ production is decreased. Another engine parameter that can be optimized is the needle opening pressure. NOP has a direct relationship with $\mathrm{NO}_{\mathrm{x}}$. When NOP is increased, $\mathrm{NO}_{\mathrm{x}}$ increases and when NOP decreases, $\mathrm{NO}_{\mathrm{x}}$ decreases. Increased injection pressure increases mixing velocity and in turn improves fuel atomization and the air/fuel mixing process [9]. This improves the combustion and raises the temperatures. Once again, high combustion temperatures are going to increase the amount of $\mathrm{NO}_{\mathrm{x}}$ produced. Hence, high $\mathrm{NOP}$ means high $\mathrm{NO}_{\mathrm{x}}$. The figure below shows the trend of high $\mathrm{NO}_{\mathrm{x}}$ for high NOP [9]. 


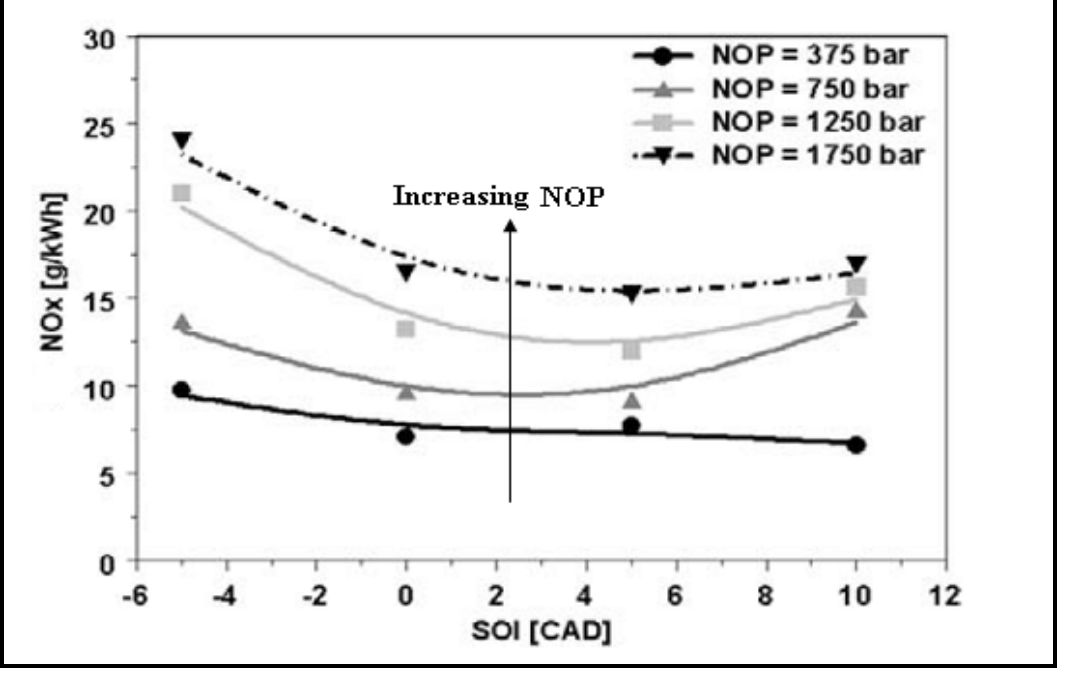

Figure 2 - Effect of NOP on NO ${ }_{x}$ Emissions [9]

$\mathrm{NO}_{\mathrm{x}}$ emissions can also be reduced by employing water injection or humidified inlet air. The idea behind this method is to reduce gas temperatures and oxygen concentration inside the combustion chamber. When water vapor is injected into the combustion chamber it will absorb heat and reduce the combustion temperature, which reduces $\mathrm{NO}_{\mathrm{x}}[7]$.

After looking at the possible methods of reducing engine-out $\mathrm{NO}_{\mathrm{x}}$, it is seen that all of them will have a tradeoff with fuel consumption and particulate matter. A compromise has to be made when dealing with $\mathrm{NO}_{\mathrm{x}}$ emissions. $\mathrm{NO}_{\mathrm{x}}$ can be reduced but the increase in fuel consumption and particulates will require other measures to be taken such as using a diesel particulate filter (DPF) to reduce PM emissions. The tradeoff between $\mathrm{NO}_{\mathrm{x}}$ and $\mathrm{PM}$ is the one of the biggest problems when it comes to reaching 2010 emission regulations. Reducing either one will result in an increase in the other. The figure below shows the tradeoff between them and possible methods to reduce these emissions. 


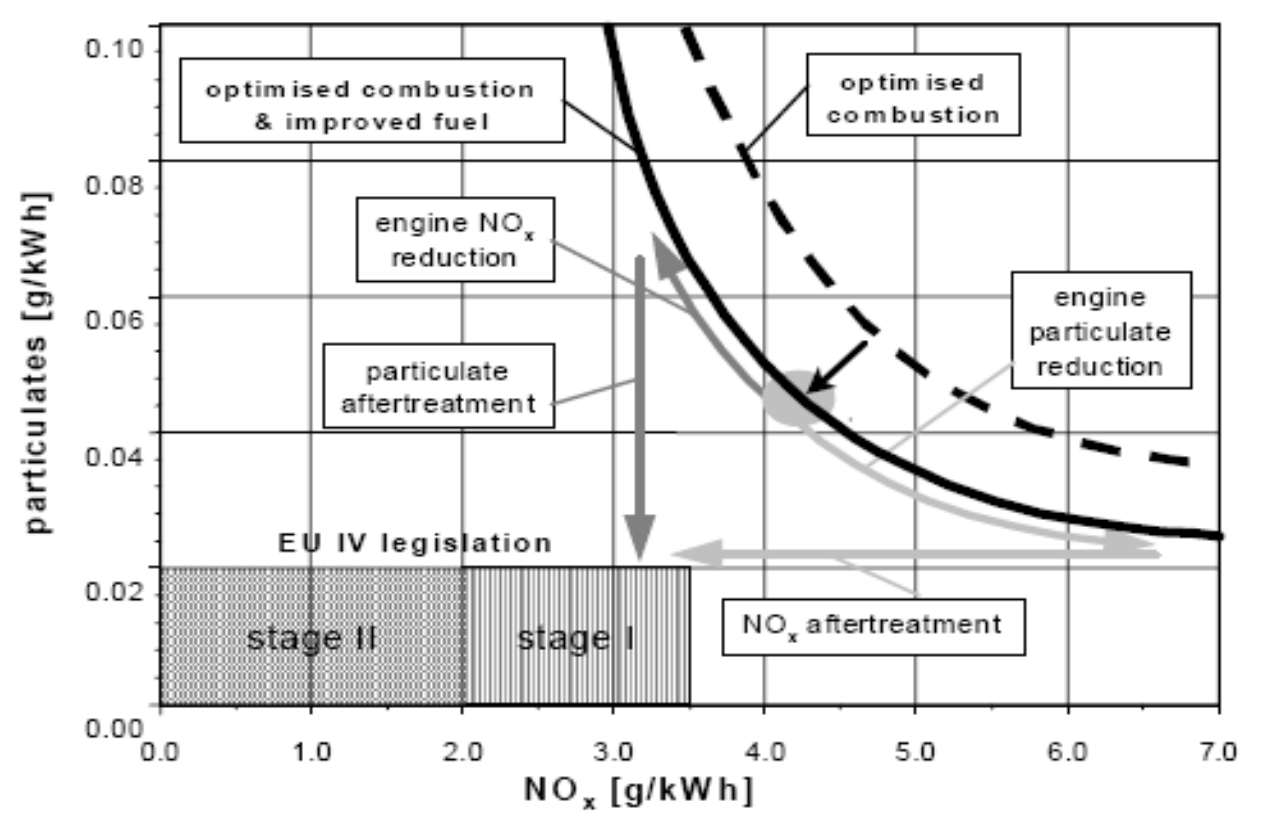

Figure 3 - $\mathrm{NO}_{\mathrm{x}} / \mathrm{PM}$ Tradeoff Curve [10]

It is seen from Figure 3 that optimization of the engine parameters can only reduce emission levels to a certain point. After that point, both $\mathrm{NO}_{\mathrm{x}}$ and $\mathrm{PM}$ exhaust aftertreatment systems will be needed to reach the U.S. 2010 and Euro V limits. Section 2.5.2 will look at various aftertreatment systems for $\mathrm{NO}_{\mathrm{x}}$ and $\mathrm{PM}$.

\subsection{2 $\mathrm{NO}_{\mathrm{x}}$ Aftertreatment Systems}

For spark ignition engines, a three-way catalyst (TWC) is sufficient to reduce $\mathrm{NO}_{\mathrm{x}}$ emissions. For lean burn or diesel engines, they are inadequate because of the higher concentration of oxygen in the exhaust. Due to this, other exhaust aftertreatment systems are being developed for lean burn engines. Each has their advantages and drawbacks. Some require special injection systems for reducing agents while others may occupy a large volume and be very costly. When looking at these systems, it is good to keep in mind that they must be placed on a mobile vehicle application. This necessitates each system to be durable as well as small enough to be placed on the vehicle. Following is a review of the types of $\mathrm{NO}_{\mathrm{x}}$ aftertreatment systems and their advantages. 


\subsubsection{Selective Catalytic Reduction}

Selective catalytic reduction is a very promising technology that has already been implemented on stationary diesel engines used in power plants and marine applications. It is one of the leading technologies being used to meet the stringent 2010 emission levels of $\mathrm{NO}_{\mathrm{x}}$. An SCR system reduces $\mathrm{NO}_{x}$ to $\mathrm{N}_{2}$ and $\mathrm{H}_{2} \mathrm{O}$ by passing lean exhaust gas through a catalyst in the presence of a reducing agent. The reducing agent used can be either anhydrous ammonia or urea. Anhydrous ammonia is very corrosive and hard to disperse [7]. For this reason, it is not practical to use in mobile applications. Urea is much less corrosive and is highly soluble in water. This allows for a safe way to handle and distribute a reducing agent. Because of this an aqueous urea solution is the best choice to incorporate into an SCR system [7]. The most commonly used solution concentration is $32.5 \%$ urea by weight in water, which gives the minimum crystallization point possible of $-11^{\circ} \mathrm{C}[11]$.

\subsection{Decomposition of Urea}

In order to have ammonia available for reaction with $\mathrm{NO}_{\mathrm{x}}$, the urea must first be decomposed. When aqueous urea is injected into the hot exhaust gases of the engine, it undergoes several processes including vaporization, thermolysis and hydrolysis. Vaporization occurs when the temperature of the aqueous urea increases and the water particles are separated. This is shown in the Equation 2.9 [11].

$$
\left(\mathrm{NH}_{2}\right)_{2} \mathrm{CO}(a q) \rightarrow\left(\mathrm{NH}_{2}\right)_{2} \mathrm{CO}+6.9 \mathrm{H}_{2} \mathrm{O}
$$

Next, thermolysis occurs which decomposes the urea into ammonia and isocyanic acid [11].

$$
\left(\mathrm{NH}_{2}\right)_{2} \mathrm{CO} \rightarrow \mathrm{NH}_{3}+\mathrm{HNCO}
$$

Finally, the isocyanic acid is hydrolyzed with water and forms ammonia and carbon dioxide [11].

$$
\mathrm{HNCO}+\mathrm{H}_{2} \mathrm{O} \rightarrow \mathrm{NH}_{3}+\mathrm{CO}_{2}
$$

The processes of vaporization and thermolysis both occur before the catalyst inlet but only a portion of the isocyanic acid is hydrolyzed before entering the catalyst. A large part of the 
hydrolyzation occurs directly on the catalyst surface. Overall, the decomposition process produces two moles of ammonia for each mole of urea that is injected [11].

\subsection{SCR Reactions}

After decomposition, the ammonia produced reacts with $\mathrm{NO}$ and $\mathrm{NO}_{2}$. The $\mathrm{NO}_{\mathrm{x}}$ conversion reactions are well known and are shown in Equations 2.12 to 2.14 [7,12].

$$
\begin{array}{ll}
4 \mathrm{NO}+4 \mathrm{NH}_{3}+\mathrm{O}_{2} \rightarrow 4 \mathrm{~N}_{2}+6 \mathrm{H}_{2} \mathrm{O} & \mathbf{2 . 1 2} \\
2 \mathrm{NO}_{2}+4 \mathrm{NH}_{3}+\mathrm{O}_{2} \rightarrow 3 \mathrm{~N}_{2}+6 \mathrm{H}_{2} \mathrm{O} & \mathbf{2 . 1 3} \\
\mathrm{NO}+\mathrm{NO}_{2}+2 \mathrm{NH}_{3}+\mathrm{O}_{2} \rightarrow 2 \mathrm{~N}_{2}+3 \mathrm{H}_{2} \mathrm{O} & \mathbf{2 . 1 4}
\end{array}
$$

The first reaction, Equation 2.12, is referred to as 'standard SCR', the second reaction is 'slow SCR' and the third reaction is 'fast SCR' [2]. This refers to the speed of the reactions. 'Fast $\mathrm{SCR}$ ' is more desirable as it allows for more reduction of $\mathrm{NO}_{\mathrm{x}}$ but requires a $\mathrm{NO}_{2} / \mathrm{NO}$ ratio equal to unity. 'Standard SCR' is a relatively fast reaction that occurs at high temperatures due to a low $\mathrm{NO}_{2} / \mathrm{NO}$ ratio. The low ratio is caused by the dissociation of $\mathrm{NO}_{2}$ to $\mathrm{NO}$ at the high temperatures. 'Slow SCR' occurs at lower temperatures when the $\mathrm{NO}_{2}$ value exceeds the $\mathrm{NO}$ value. This reaction is very slow and can reduce the efficiency of $\mathrm{NO}_{\mathrm{x}}$ conversion. There are also unwanted reactions that can occur which result in the formation of nitrous oxide $\left(\mathrm{N}_{2} \mathrm{O}\right)$, a greenhouse gas. These reactions are shown in Equation 2.15 and 2.16 [12].

$$
\begin{array}{ll}
2 \mathrm{NH}_{3}+2 \mathrm{NO}_{2} \rightarrow \mathrm{N}_{2} \mathrm{O}+\mathrm{N}_{2}+3 \mathrm{H}_{2} \mathrm{O} & \mathbf{2 . 1 5} \\
4 \mathrm{NH}_{3}+4 \mathrm{NO}+3 \mathrm{O}_{2} \rightarrow 4 \mathrm{~N}_{2} \mathrm{O}+6 \mathrm{H}_{2} \mathrm{O} & \mathbf{2 . 1 6}
\end{array}
$$

Ammonia that is not absorbed by the catalyst, used for $\mathrm{NO}_{\mathrm{x}}$ reduction or slipped in the exhaust can be oxidized to form nitrogen and water. It can also form nitrous oxides depending on the amount of oxygen present in the reaction. The following reactions show the oxidation of ammonia [12]. 


$$
\begin{aligned}
& 4 \mathrm{NH}_{3}+3 \mathrm{O}_{2} \rightarrow 2 \mathrm{~N}_{2}+6 \mathrm{H}_{2} \mathrm{O} \\
& 4 \mathrm{NH}_{3}+4 \mathrm{O}_{2} \rightarrow 2 \mathrm{~N}_{2} \mathrm{O}+6 \mathrm{H}_{2} \mathrm{O}
\end{aligned}
$$

\subsection{Conversion Efficiency Factors}

Several factors, such as $\mathrm{NO}_{2} / \mathrm{NO}$ ratio, ammonia mixing in the exhaust, exhaust temperature and the ratio of ammonia to $\mathrm{NO}_{\mathrm{x}}$ can affect the conversion efficiency of the system. The $\mathrm{NO}_{2} / \mathrm{NO}$ ratio is important because of the speed at which $\mathrm{NO}$ and $\mathrm{NO}_{2}$ react with ammonia. $\mathrm{NO}_{2}$ reacts more slowly than $\mathrm{NO}$ with $\mathrm{NH}_{3}$. Therefore, a high $\mathrm{NO}_{2} / \mathrm{NO}$ ratio will result in a decrease in speed of the reactions and a decrease in efficiency. This gives rise to ammonia slip, which is the release of $\mathrm{NH}_{3}$ with the exhaust gases. Ammonia slip is a big concern of SCR systems and may be minimized by sophisticated urea injection strategies. Usually a ratio of $\mathrm{NO}_{2} / \mathrm{NO}$ equal to one is ideal because both $\mathrm{NO}$ and $\mathrm{NO}_{2}$ react in parallel which reduces the time needed to convert $\mathrm{NO}_{\mathrm{x}}[10] . . \quad \mathrm{A} \mathrm{NO}_{\mathrm{x}}$ ratio higher than one will lead to an increase in low temperature activity of the catalyst because $\mathrm{NO}_{2}$ reacts more readily at low temperature than NO. At high temperatures, a high $\mathrm{NO}_{\mathrm{x}}$ ratio will lead to a decrease in catalyst activity and $\mathrm{NO}_{\mathrm{x}}$ reduction will be significantly reduced [10].

Temperature plays a big role in the conversion efficiency. High temperatures contribute to quicker reactions of $\mathrm{NO}$ with $\mathrm{NH}_{3}$ and higher efficiencies. Also, at high temperatures, the catalyst cannot absorb much ammonia. At low temperatures (less than $250^{\circ} \mathrm{C}$ ) efficiency goes down and ammonia absorbance increases [10]. The operating temperature for a typical SCR system is between $250^{\circ} \mathrm{C}$ and $500^{\circ} \mathrm{C}$ but may be slightly different depending on the material of the catalyst. The amount of urea or ammonia injected is very important as well. Ideal conditions would see 1 mole of $\mathrm{NH}_{3}$ for every mole of $\mathrm{NO}_{\mathrm{x}}$ in the exhaust [11]. This is very hard to achieve, as real time $\mathrm{NO}_{\mathrm{x}}$ sensors have poor resolution when measuring the extremely low levels required by 2010 regulations. This means that the ammonia injected must be based on a model for $\mathrm{NO}_{\mathrm{x}}$ prediction as well as a model of the catalyst. The accuracy of these models will affect the amount of ammonia slip and conversion efficiency of the SCR.

Turbulence in the exhaust system is also being studied to see its effect on mixing. With high turbulence, the $\mathrm{NH}_{3}$ should mix more completely with the exhaust gas and better $\mathrm{NO}_{\mathrm{x}}$ conversion is likely. Complete mixing may not occur. In this case, some $\mathrm{NH}_{3}$ will not react with $\mathrm{NO}_{\mathrm{x}}$ and may contribute to ammonia slip. Using an SCR system, $\mathrm{NO}_{\mathrm{x}}$ conversion rates of up to 
$80 \%$ and $90 \%$ have been achieved [7]. These high efficiency rates are usually seen during steady state testing. During transient testing, low temperatures, poor $\mathrm{NO}_{2} / \mathrm{NO}$ ratio and inexact urea injection strategies combine to reduce the $\mathrm{NO}_{\mathrm{x}}$ conversion efficiency.

\subsection{Catalyst Material}

A range of materials such as vanadium $(\mathrm{V})$, tungsten $(\mathrm{W})$, titania $(\mathrm{Ti})$ and zeolites are used as catalysts. A commonly used type is a mixture of vanadium and titania on a high density honeycomb structure. Zeolites can be used on a ceramic substrate as well. Each material will have slightly different operating temperatures, conversion efficiency and storage capabilities [7].

Overall, a selective catalytic reduction system seems to be one of the best methods for reducing $\mathrm{NO}_{\mathrm{x}}$ emissions. However there are a few concerns with the system such as urea dosage and ammonia slip. Ammonia slip must be kept to a minimum or one pollutant $\left(\mathrm{NO}_{\mathrm{x}}\right)$ will be traded for another $\left(\mathrm{NH}_{3}\right)$. Another important issue is the optimal distribution of urea. In order for trucks to use urea systems, it must be commercially available. This will require a urea infrastructure that may raise the overall cost of implementing SCR systems on diesel vehicles [4]. This may decrease the cost effectiveness of the SCR system and reduce its appeal as the leading $\mathrm{NO}_{\mathrm{x}}$ reduction technology. However, the existence of an adequate urea distribution network and the associated economics are outside the scope of this study. Despite these drawbacks, SCR technology is still very promising and is currently the leading $\mathrm{NO}_{\mathrm{x}}$ aftertreatment system for HDD engines.

\subsubsection{Lean NO $\mathrm{N}_{\mathrm{x}}$ Trap (LNT)}

Another leading $\mathrm{NO}_{\mathrm{x}}$ reduction technology is a lean $\mathrm{NO}_{\mathrm{x}}$ trap, sometimes called a $\mathrm{NO}_{\mathrm{x}}$ adsorber. This type of system removes $\mathrm{NO}_{\mathrm{x}}$ under lean exhaust conditions by adsorbing it into a catalyst. In order to store it, the $\mathrm{NO}$ in the exhaust must first be oxidized to form $\mathrm{NO}_{2}$. This is done by passing the exhaust gas over a Pt-based catalyst [13]. The $\mathrm{NO}_{2}$ is then stored in a metal oxide, such as barium oxide $(\mathrm{BaO})$. The catalyst will eventually reach its maximum storage capacity and once this point is reached, an $\mathrm{HC}$ reductant such as diesel fuel is injected to create a rich exhaust environment. Under these rich operating conditions the $\mathrm{NO}_{2}$ is desorbed from the catalyst and then reduced to $\mathrm{N}_{2}[13]$. 
There are two types of lean $\mathrm{NO}_{\mathrm{x}}$ traps, active and passive. The only difference between them is that the active trap requires additional hydrocarbons to be introduced while the passive trap uses hydrocarbons that are already present in the exhaust. The passive trap may not be as effective, since there may not be enough hydrocarbons present in the exhaust to promote reduction of all the $\mathrm{NO}_{\mathrm{x}}[7,13]$.

A lean $\mathrm{NO}_{\mathrm{x}}$ trap works over a range of $200^{\circ} \mathrm{C}$ to $550^{\circ} \mathrm{C}$ and can have $\mathrm{NO}_{\mathrm{x}}$ conversion rates, as high as $90 \%[7,13]$. Active lean $\mathrm{NO}_{\mathrm{x}}$ traps have a readily available reductant in diesel fuel while passive traps do not require additional reductant. Active trap systems will suffer a fuel consumption penalty by using the diesel fuel for this purpose [7]. A major problem with this type of system is its high vulnerability to sulfur poisoning. Sulfur poisoning occurs when sulfates in the exhaust react with the metal oxide and block the adsorption sites of the catalyst. This causes deactivation of the catalyst, which can occur very rapidly. This is less of a problem with the new requirement of using ultra low sulfur diesel fuel, but will still continue to happen due to the sulfur content of lubrication oil. Because of this, a sulfate trap may be necessary to protect the lean $\mathrm{NO}_{\mathrm{x}}$ trap. However, a sulfate trap will add to the size and cost of this type of system, which could reduce its appeal [13].

\subsubsection{Non-Thermal Plasma}

Non-thermal plasma systems are sometimes referred to as plasma assisted catalytic $\mathrm{NO}_{\mathrm{x}}$ reduction (PACR). It uses an SCR within the system but there is also an additional plasma reactor chamber that is placed in front of it. The exhaust gas is passed through this chamber and a rapid electrical pulse is introduced. The plasma creates electrons and ions in the exhaust that will react with $\mathrm{NO}$ molecules to form $\mathrm{NO}_{2}$ molecules, which are then catalyzed by the SCR $[13,14]$. Figure 4 shows the setup of this type of system [13]. 


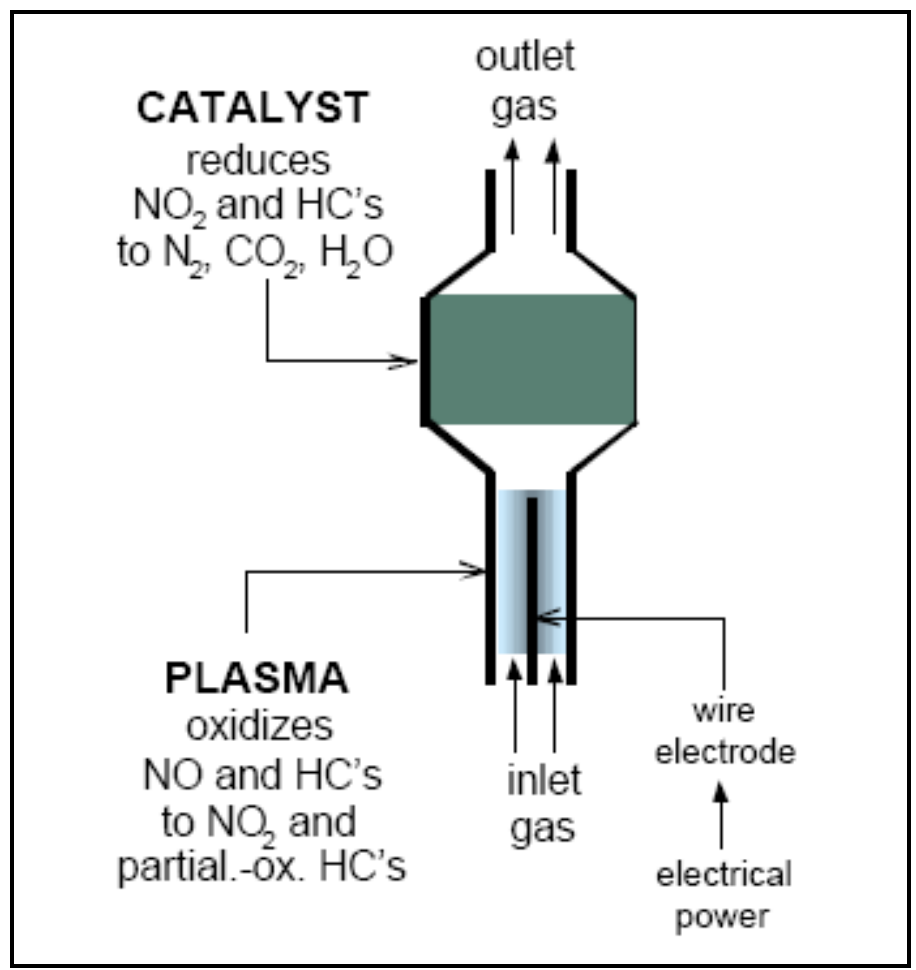

Figure 4 - Plasma Assisted Catalytic Reduction System [13]

There are some advantages to this system. First, this system can help with $\mathrm{NO}_{\mathrm{x}}$ reduction at low temperatures. This is because $\mathrm{NO}_{2}$ reacts more readily at low temperatures than $\mathrm{NO}$ does and this system promotes the formation of $\mathrm{NO}_{2}$ in the exhaust. When coupled with an SCR, this allows for high reduction of $\mathrm{NO}_{\mathrm{x}}$ since an SCR has low efficiency at low temperatures and high efficiency at high temperatures. Some disadvantages with the system are the large volume space required and the additional power needed for the electrical pulse. Also, the plasma does not help the SCR at temperatures above $300^{\circ} \mathrm{C}$ and the large size of this system would create problems when trying to use it for a mobile application [13].

\subsubsection{Selective $\mathrm{NO}_{\mathrm{x}}$ Recirculation (SNR)}

Selective $\mathrm{NO}_{\mathrm{x}}$ recirculation is a technique that incorporates both an aftertreatment system as well as gas recirculation. It involves removal of $\mathrm{NO}_{\mathrm{x}}$ from the cooled exhaust gas by a lean $\mathrm{NO}_{\mathrm{x}}$ adsorber and periodic recirculation of the desorbed $\mathrm{NO}_{\mathrm{x}}$. This is very similar to a passive $\mathrm{NO}_{\mathrm{x}}$ trap. The only difference is the use of high concentration $\mathrm{NO}_{\mathrm{x}}$ recirculation to decompose the $\mathrm{NO}_{\mathrm{x}}$ instead of an $\mathrm{HC}$ reductant to convert $\mathrm{NO}_{\mathrm{x}}$. Figure 5 shows a selective $\mathrm{NO}_{\mathrm{x}}$ 
recirculation system that uses only one passive $\mathrm{NO}_{\mathrm{x}}$ trap. Two traps may be used as well, to improve efficiency [7].

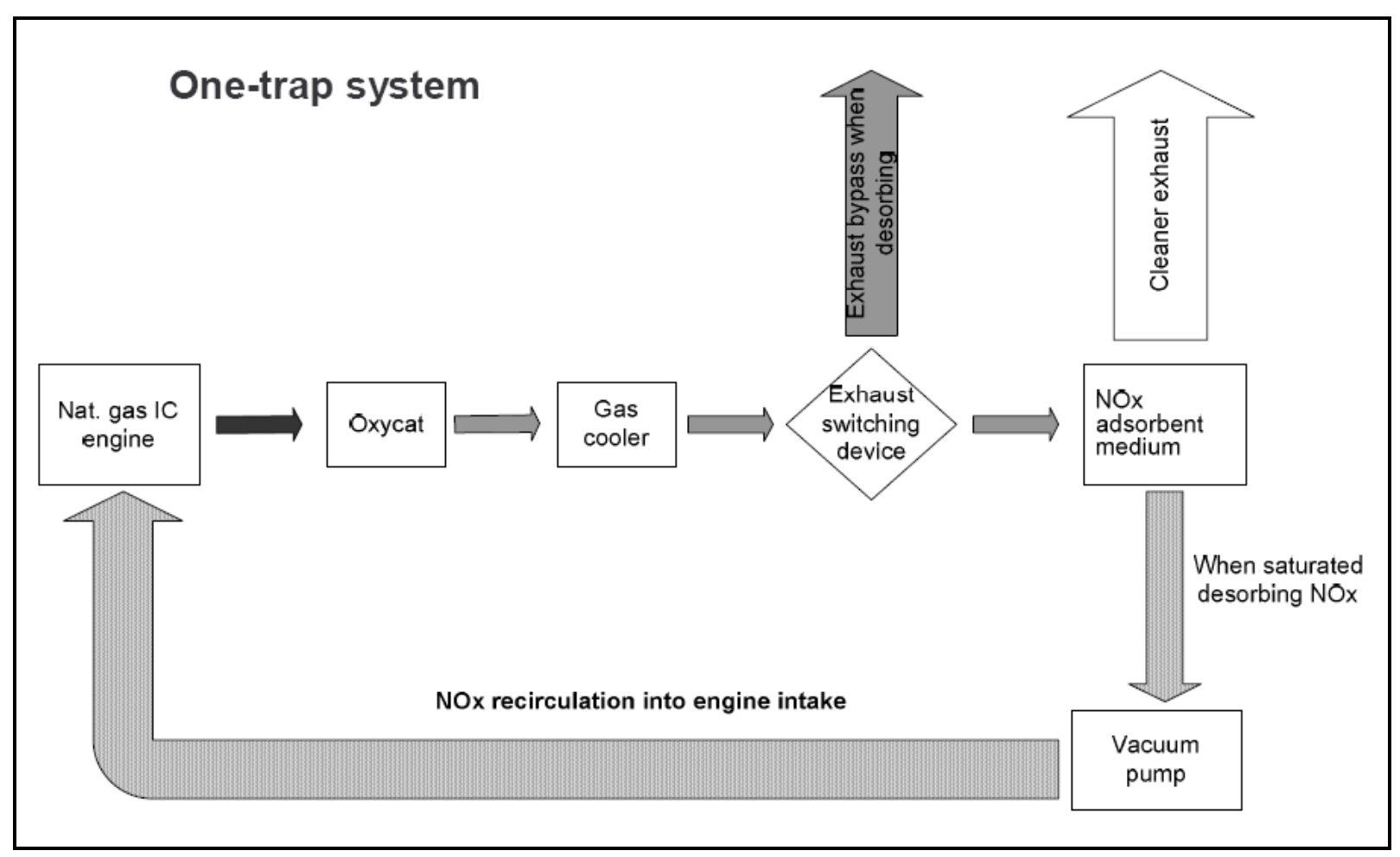

Figure 5 - Selective $\mathrm{NO}_{\mathrm{x}}$ Recirculation System [7]

After the passive trap reaches its storage capacity, $\mathrm{NO}_{\mathrm{x}}$ will be desorbed. The desorbed $\mathrm{NO}_{\mathrm{x}}$ is then sent back into the engine intake air and a large portion of it will be decomposed by the incylinder combustion process. The decomposed $\mathrm{NO}_{\mathrm{x}}$ will then be converted to $\mathrm{N}_{2}, \mathrm{O}_{2}$ or $\mathrm{H}_{2} \mathrm{O}$ in the engine. The $\mathrm{NO}_{\mathrm{x}}$ recirculation will decrease the amount of thermal $\mathrm{NO}_{\mathrm{x}}$ created in the combustion chamber, while increasing the amount of non-thermal NO reactions. This will decrease the amount of overall $\mathrm{NO}_{\mathrm{x}}$ created [7].

\subsubsection{Other Aftertreatment Systems}

\subsubsection{Diesel Oxidation Catalyst}

Diesel oxidation catalysts are used to promote the oxidation of a number of several harmful diesel exhaust components, including hydrocarbons, carbon monoxide and soluble organic fraction of particulate matter [15]. HC reacts with the catalyst to form carbon dioxide and water vapor and $\mathrm{CO}$ reacts with oxygen to form $\mathrm{CO}_{2}$. A drawback is that the catalyst will 
also oxidize sulfur dioxide $\left(\mathrm{SO}_{2}\right)$ to form sulfate particles, which contribute to the overall particulate matter emissions [15]. When used in conjunction with a diesel particulate filter, very good reductions of $\mathrm{CO}, \mathrm{HC}$ and $\mathrm{PM}$ are achieved. Another effect of a DOC is to change the $\mathrm{NO}_{2} / \mathrm{NO}$ ratio while the total $\mathrm{NO}_{\mathrm{x}}$ remains relatively constant. The catalyst will increase the amount of $\mathrm{NO}_{2}$ by oxidation of $\mathrm{NO}$ in the exhaust. When used upstream of an SCR system, the changing $\mathrm{NO}_{\mathrm{x}}$ ratio will have an effect on the efficiency of $\mathrm{NO}_{\mathrm{x}}$ conversion [15]. DOCs can also be used downstream of an SCR system in order 'clean up' or oxidize ammonia slip.

\subsubsection{Diesel Particulate Filter}

Diesel particulate filters or traps are a means of capturing diesel particulate matter in the exhaust stream. They trap particulates through surface type and deep bed filtration mechanisms [16]. Thermal regeneration is used to remove excessive particulate matter deposited on the filter. This can be done either actively or passively. For active regeneration, fuel is injected in the exhaust stream to raise the temperature high enough to burn off the deposited soot [16]. Passive regeneration will occur periodically without the use of additional fuel or an auxiliary heat source. DPFs are combined with DOCs in many cases, which will reduce many of the key emissions that are regulated. Many times DPFs are used in conjunction with an SCR system in order to remove both $\mathrm{PM}$ and $\mathrm{NO}_{\mathrm{x}}$. This is becoming the case more and more frequently as the 2010 emissions standards are extremely low for both $\mathrm{PM}$ and $\mathrm{NO}_{\mathrm{x}}$.

\subsection{Urea Dosing Strategies}

In order for an SCR to be effective, a robust and flexible urea dosage strategy is essential. Depending on the complexity of the approach, a dosage strategy may take into account a large number of factors including ammonia slip, ammonia adsorption/desorption, catalyst temperature, $\mathrm{NO}_{\mathrm{x}}$ ratio, $\mathrm{NO}_{\mathrm{x}}$ out, SCR reactions and others [2]. The two main approaches are open loop and closed loop control strategies. Each of these has their advantages and drawbacks. Closed loop control usually requires a slightly more complex model in order to be efficient. Open loop strategies may require significantly more calibration time [2]. Also, open loop control may not always be adequate to reduce $\mathrm{NO}_{\mathrm{x}}$ while preventing ammonia slip. Following is a review of some of the strategies that have been implemented. 


\subsubsection{Open Loop Control}

Most open loop strategies are relatively simple. They usually use a $\mathrm{NO}_{\mathrm{x}}$ prediction model, a urea injection map based on stoichiometry, and some type of a correction factor. An example of this is a study done by TNO Automotive in which the following open loop control strategy was used [2].

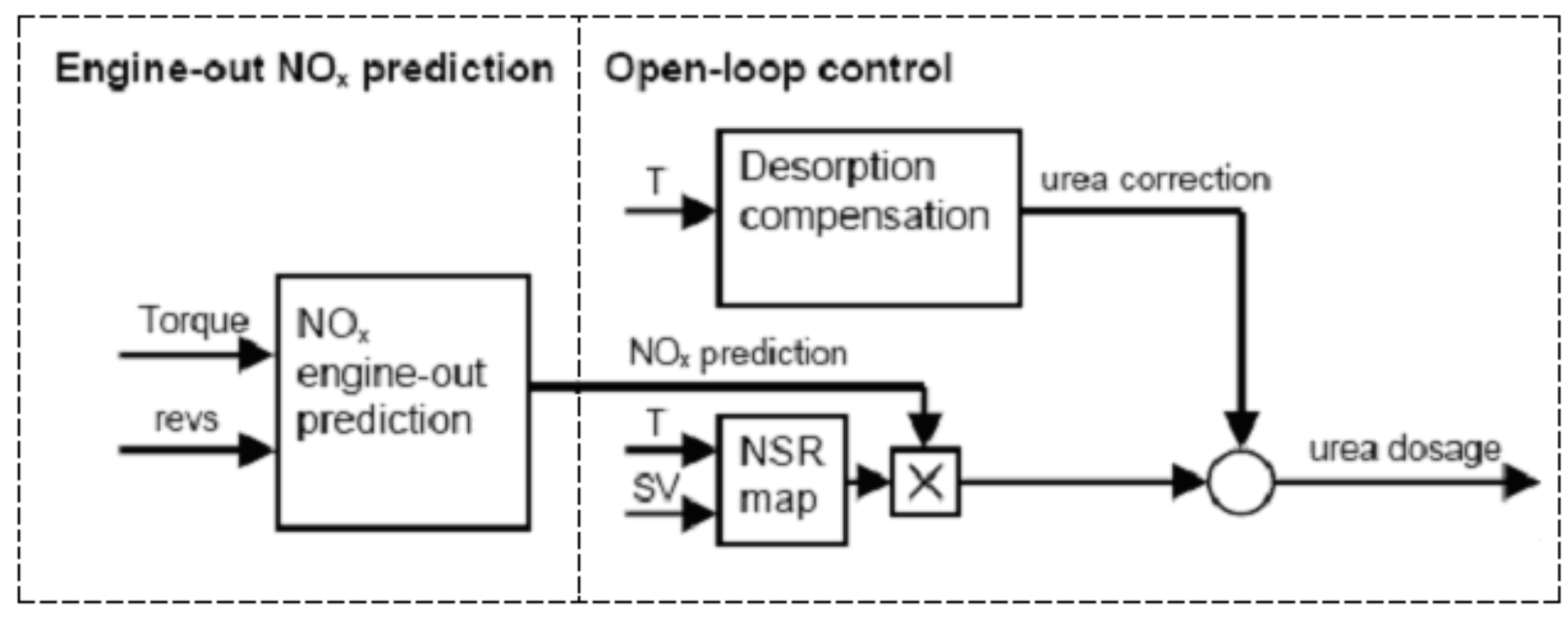

Figure 6 - Open Loop Control Strategy [2]

In this strategy, $\mathrm{NO}_{\mathrm{x}}$ prediction was based upon engine speed and torque. A nominal $\mathrm{NH}_{3} / \mathrm{NO}_{\mathrm{x}}$ ratio that allows for no more than $10 \mathrm{ppm}$ ammonia slip and is based on catalyst temperature and surface coverage was found using the nominal stoichiometric ratio (NSR) map [2]. The predicted $\mathrm{NO}_{\mathrm{x}}$ multiplied by the $\mathrm{NH}_{3} / \mathrm{NO}_{\mathrm{x}}$ ratio gives the amount of urea that should be injected. This value is then corrected based on a desorption compensation model to get the final injection value [2]. Another factor that could be included in this strategy would be a $\mathrm{NO}_{\mathrm{x}}$ out target that would limit the urea dosage in order to reach the correct value. An SCR efficiency model that takes into account the condition of the SCR system for $\mathrm{NO}_{\mathrm{x}}$ conversion could also be used. In general, this is a very typical open loop strategy used for SCR urea dosage. Open loop strategies often require a large amount of calibration time and require periodic calibrations over time to account for changes in the system such as catalyst ageing. Open loop strategies have been shown to achieve high $\mathrm{NO}_{\mathrm{x}}$ conversion, but suffer from excessive ammonia slip [2]. Balancing the two is one of the challenges of this approach. Also, open loop is usually very effective for steady state engine operation, but becomes significantly more arduous with transient operation. 


\subsubsection{Closed Loop Control}

Closed loop SCR control typically consists of the following aspects: $\mathrm{NO}_{\mathrm{x}}$ sensors before and after the SCR, an ammonia adsorption/desorption or surface coverage model and some type of temperature correction factor. The temperature can be used to predict SCR conversion efficiency, adsorption/desorption or even the amount of $\mathrm{NO}_{\mathrm{x}}$ being produced. Sometimes an $\mathrm{NH}_{3}$ sensor is used to keep track of ammonia slip values. An $\mathrm{NH}_{3}$ sensor may allow for simpler urea dosage control because it can replace complex adsorption/desorption models [17].

In reality, most closed loop control strategies are not purely closed loop [2]. They usually employ some sort of feed-forward or open loop control aspect. This is evident in Figure 7, which is a closed loop strategy that was implemented by TNO automotive [2].

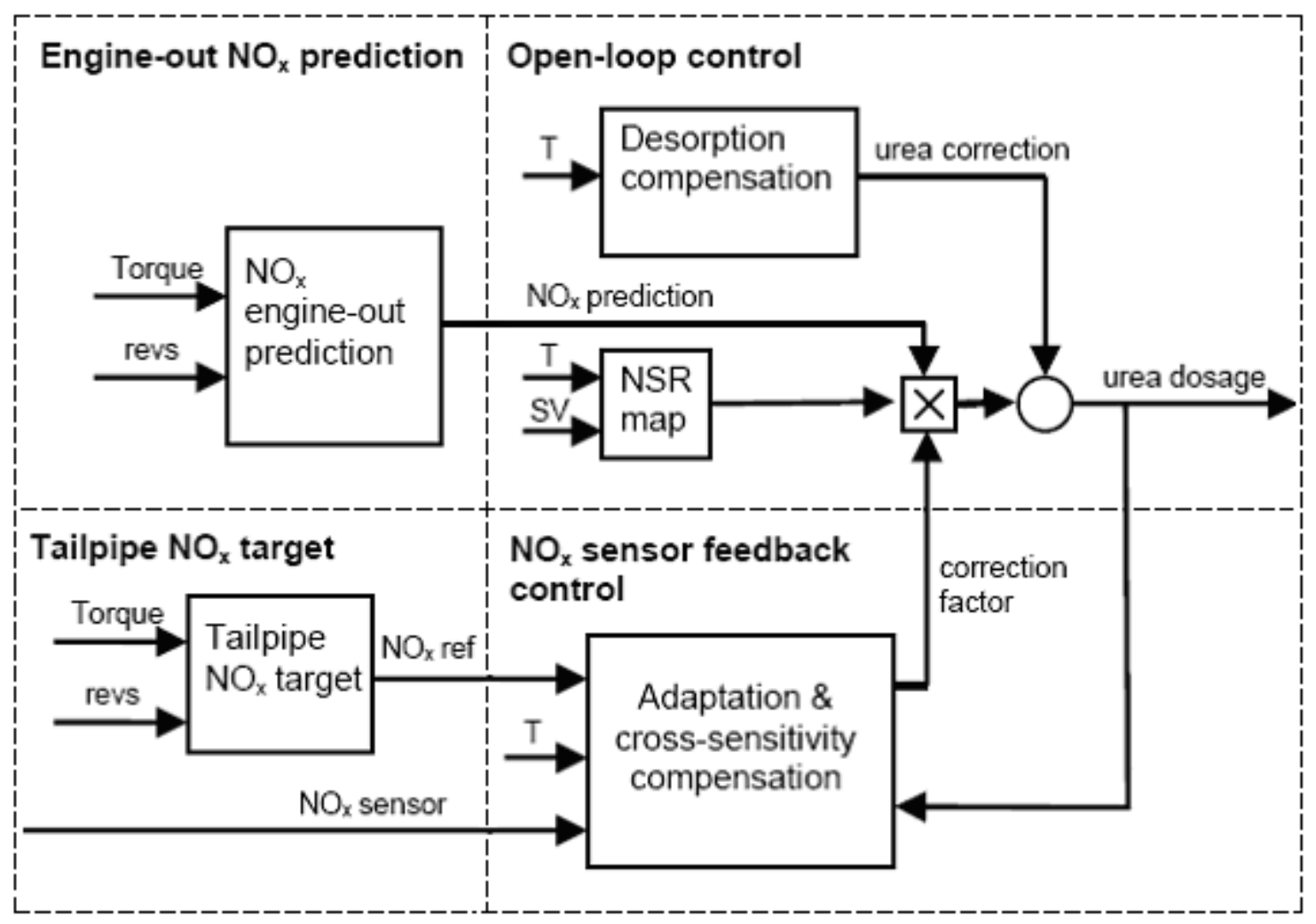

Figure 7 - Closed loop control using a $\mathrm{NO}_{\mathrm{x}}$ sensor [2]

The strategy shown above is one that uses a $\mathrm{NO}_{\mathrm{x}}$ sensor in the feedback portion. It also predicts the engine-out $\mathrm{NO}_{\mathrm{x}}$ instead of measuring it directly with a sensor. As seen in Figure 7, there is a cross-sensitivity compensation for the $\mathrm{NO}_{\mathrm{x}}$ sensor. Cross-sensitivity and poor resolution of $\mathrm{NO}_{\mathrm{x}}$ sensors at very low concentrations are a major limitation of closed loop control strategies. An 
often used $\mathrm{NO}_{\mathrm{x}}$ smart sensor developed by Siemens VDO/NGK has a resolution of $\pm 10 \mathrm{ppm}$ at 0 ppm concentration [18]. In regards to the 2010 emissions limits, an error of 10 ppm is very significant. Other limitations of a closed loop SCR strategy may be attributed to the time delay of the urea dosage system and slow catalyst dynamics. Slow catalyst dynamics make an adsorption/desorption model very important for closed loop control. An advantage of closed loop control is its ability to account for system variations such as catalyst ageing and engine-out $\mathrm{NO}_{\mathrm{x}}$ variations [2].

\subsection{Artificial Intelligence Techniques}

Artificial Intelligence (A.I.) is the ability of a computer to imitate intelligent processes of humans such as reasoning, generalization and adaptation [19]. A.I. techniques can be used in a wide variety of ever-increasing fields, including pattern recognition, adaptive control, machine vision, machine learning, decision-making and many others [19]. There are two types of A.I. techniques, conventional A.I. and computational A.I. Conventional techniques include case based reasoning, expert systems and behavior based A.I. Computational techniques include genetic algorithms, neural networks and fuzzy logic systems. This thesis will focus on computational A.I. methods. Following is a review of these methods.

\subsubsection{Genetic Algorithms}

Genetic algorithms (GA), also called evolutionary algorithms, are a parameter optimization technique. GAs are modeled after Darwin's evolution of species and survival of the fittest concept. A solution space is defined and then searched iteratively based on biological processes. An individual is a possible solution of the model and is a part of a population or set of solutions. Design requirements and constraints (DRC) act as the environment. Each individual in a population is evaluated and given a degree to which it meets the DRC. This degree determines the individual's survivability [19]. Once this is done, a new set of solutions is formed through genetic mutation and crossover of the individuals. This process is done a specified number of times or as much as is needed to fulfill certain design requirements. Allowing the program to search an unspecified number of times may result in long computational times ranging from a few hours to a few days [19]. Genetic algorithms are very helpful when it comes to optimizing parameters and have been used to solve complex and nonlinear problems. They 
are also very useful since they can perform a search of the solution space in two directions unlike other methods, which can only search in one direction [19]. GAs can also handle large quantities of parameters and objectives. A disadvantage of GAs is the large computational time needed to solve problems. Depending on the complexity of the problem, it may take several days to get a solution. This prevents GAs from being used for real time control [19].

\subsubsection{Neural Networks}

Artificial Neural Networks (ANN or NN) are based on processes of the human brain. Specifically, ANNs use the operation and structure of the central nervous system and biological neurons as the starting point to model a system [19]. Actual operation of a human brain is infinitely more complicated than any ANN that has been created. The brain and all its processes are not even fully understood as of yet. What is known is that the brain works on a parallel architecture and it is this that the artificial neural networks attempt to emulate. ANN changes both its structure and parameters during training, which allow it to be an adaptive system. They are used to model very complex input/output relationships and can approximate arbitrary functions with a good degree of accuracy [19]. ANNs are applicable in many areas including function approximation, data processing/filtering, classification and others. ANNs have the advantage of being able to adaptively learn as well as being very robust systems. They can operate at a fairly high level of speed as well. Disadvantages of ANNs are the need for adequate sets of input/output training data and proper structure. They can be very complicated and must be modeled carefully in order to get good results [19].

\subsubsection{Fuzzy Logic}

Fuzzy logic is an artificial intelligence technique first developed by Lotfi Zadeh, a professor at the University of California at Berkeley. Zadeh was looking to mimic the human ability for highly adaptive reasoning and control. He saw that people do not need clear inputs in order to adaptively reason. He reasoned that if this could be programmed into a feedback controller, then the controller would be able to deal with very noisy and imprecise inputs [20,19]. This would allow for easier implementation of feedback control and may be more effective as well. Fuzzy logic is a very robust type of artificial intelligence that can be implemented in any number of applications. In the diesel engine field it has been applied to air-fuel ratio control, idle speed control and failure detection, among other things. An advantage of fuzzy logic is that it 
can control non-linear systems that do not have any readily available mathematical model. This makes it ideal for controlling an SCR system because these systems are highly complex and not fully understood. Another benefit of fuzzy logic control is the fact that the output will be a relatively smooth function despite large variations of input parameters [20,19].

Fuzzy logic is another way of looking at classic binary logic. Binary logic requires that a statement be either true or false with no other alternative. Fuzzy logic allows a statement to be both, as well as anywhere in between. This leads to degrees of truth or partial membership of a function. This is what allows the control to accept very noisy inputs. It is based on a simple rule based approach, if $\mathrm{X}$ and $\mathrm{Y}$ then $\mathrm{Z}$. Rules are based on the programmer's experience or expert knowledge rather than a very strict mathematical model. Because of this, a thorough technical understanding of the system and all processes occurring is not needed. Instead, a programmer can create a general model and then make minor modifications that can significantly improve performance. Fuzzy logic allows for multiple inputs, which produce a single output, whereas in classic control theory there is a single input and a single output [19]. To produce good results using classic control theory, the model must be very accurate. Fuzzy logic reduces this need and allows for simple models of very complex systems. Figure 8 shows the fuzzy logic based control theory [19].

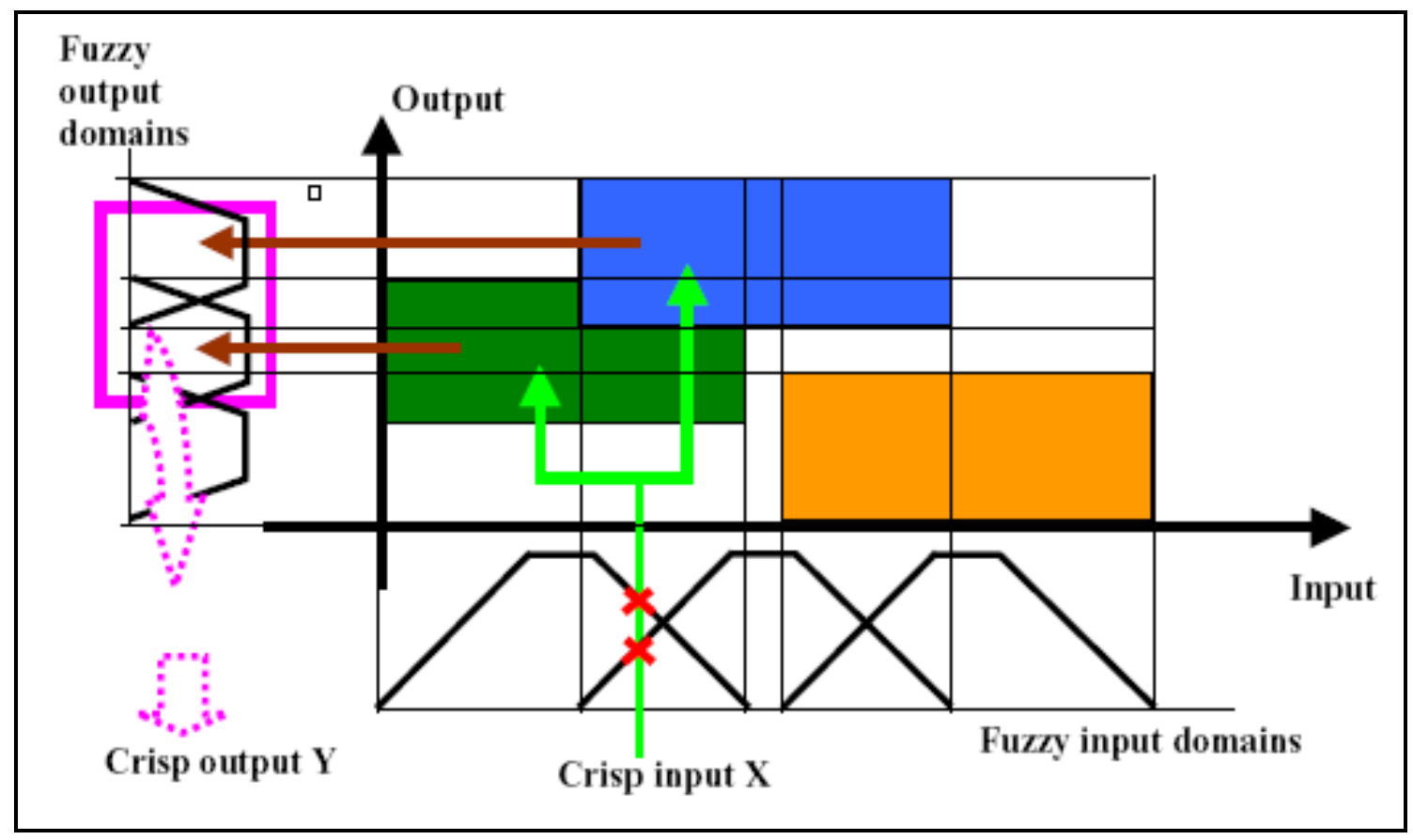

Figure 8 - Fuzzy Logic Based Control Input/Output Mapping [19] 
As seen in Figure 8, a crisp input comes into the system and is fuzzified into multiple values through the use of membership functions (MF). Membership functions determine the degree to which an input belongs to a particular fuzzy set. These values are then sent into an inference rule matrix, which applies the If_Then statements determined by the programmer. The inference rules produce a fuzzy output, which can be defuzzified through various methods. This produces a crisp output that can be used to control whatever is needed. Overall a fuzzy logic program is a relatively simple method. This can be seen in Figure 9, which shows the general structure of a fuzzy logic program.

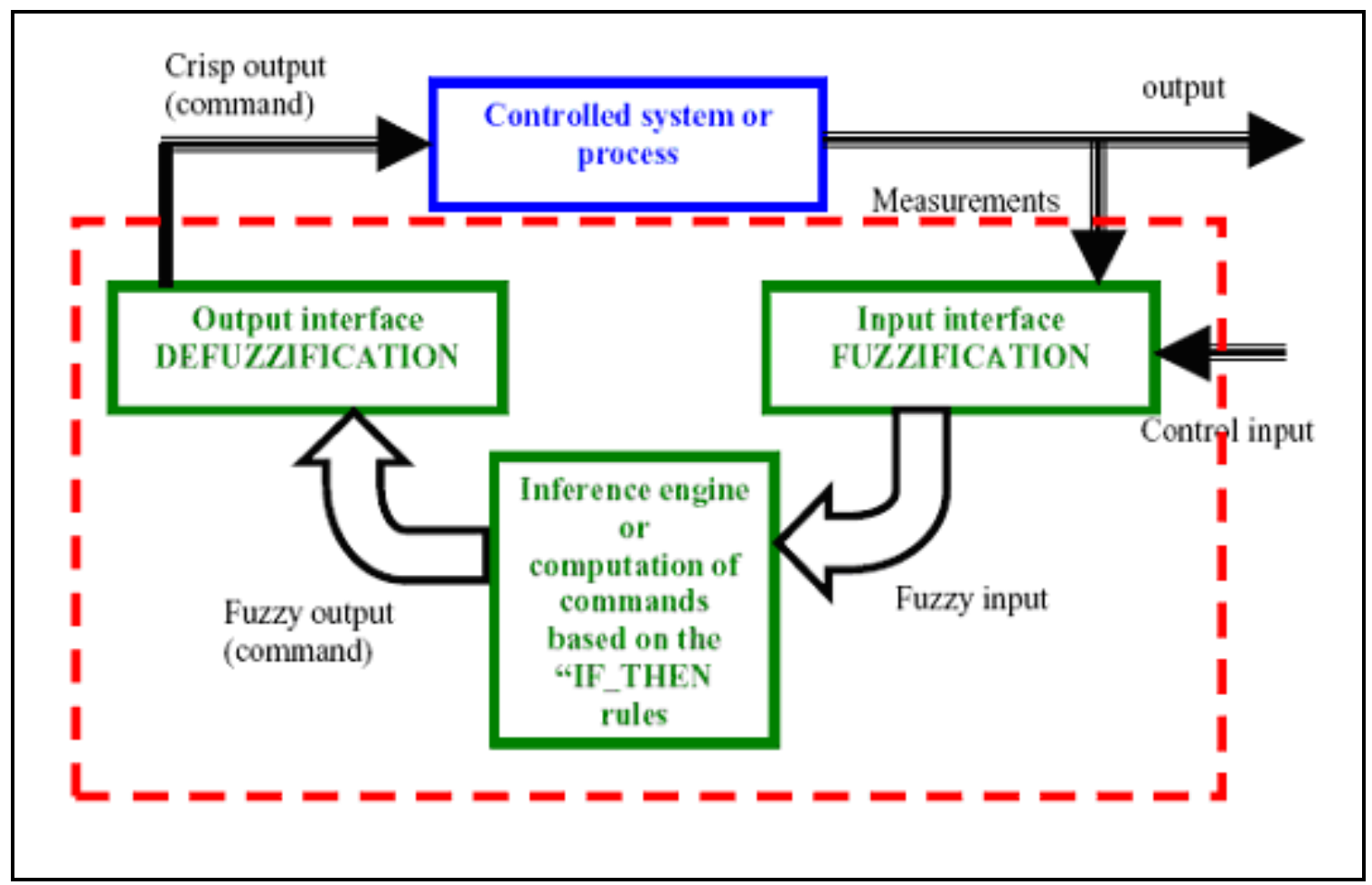

Figure 9 - General Block Diagram for a Fuzzy Logic Controller [19]

To understand how a fuzzy logic program works, a look at each block in Figure 9 is needed. The first block is the 'fuzzification' model. To create this model a couple of things are needed. These include linguistic variables, linguistic values and membership functions. A linguistic variable is a physical variable or input such as temperature, speed or pressure. A linguistic value is something assigned to a linguistic variable to describe its characteristics. For example, if temperature is the linguistic variable, linguistic values of very low, low, medium and high can be assigned. Together these form a membership function. The range of the 
membership function should take into account the entire range of possibilities for the input variable. Figure 10 is an example of a membership function using trapezoidal members.

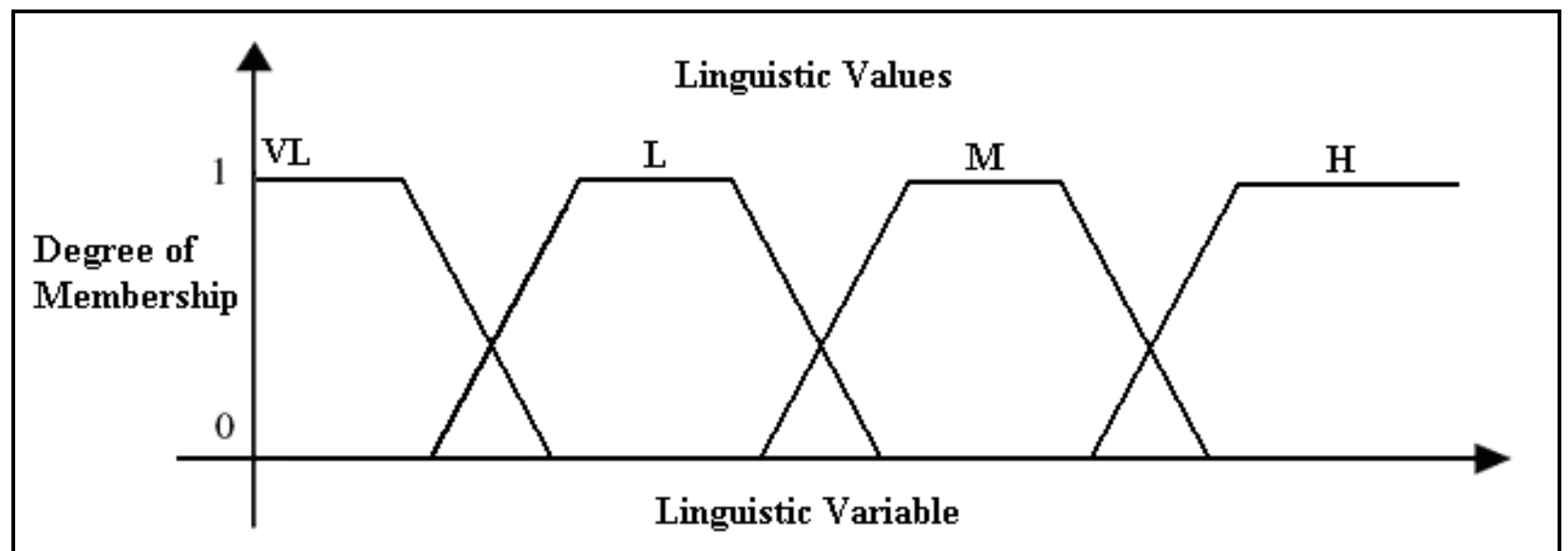

Figure 10 - Trapezoidal Membership Functions [19]

Other shapes can be used for the functions such as triangular, bell-shaped and cosinusoidal. Trapezoidal and triangular membership functions are very commonly used but can have discontinuities because of their shape. Bell-shaped and cosinusoidal membership functions are smooth curves without any discontinuities. Figure 11 and Figure 12 show the bell-shaped and cosinusoidal membership functions, respectively [19].

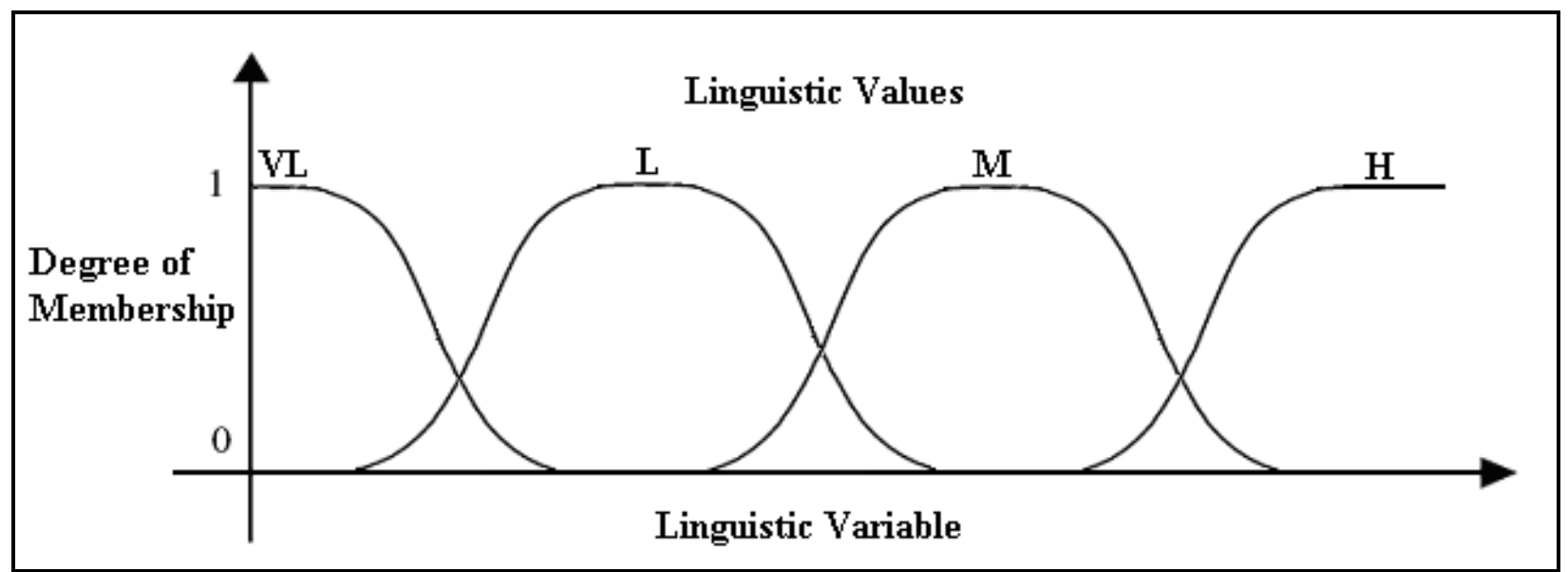

Figure 11 - Bell-shaped Membership Functions [19] 


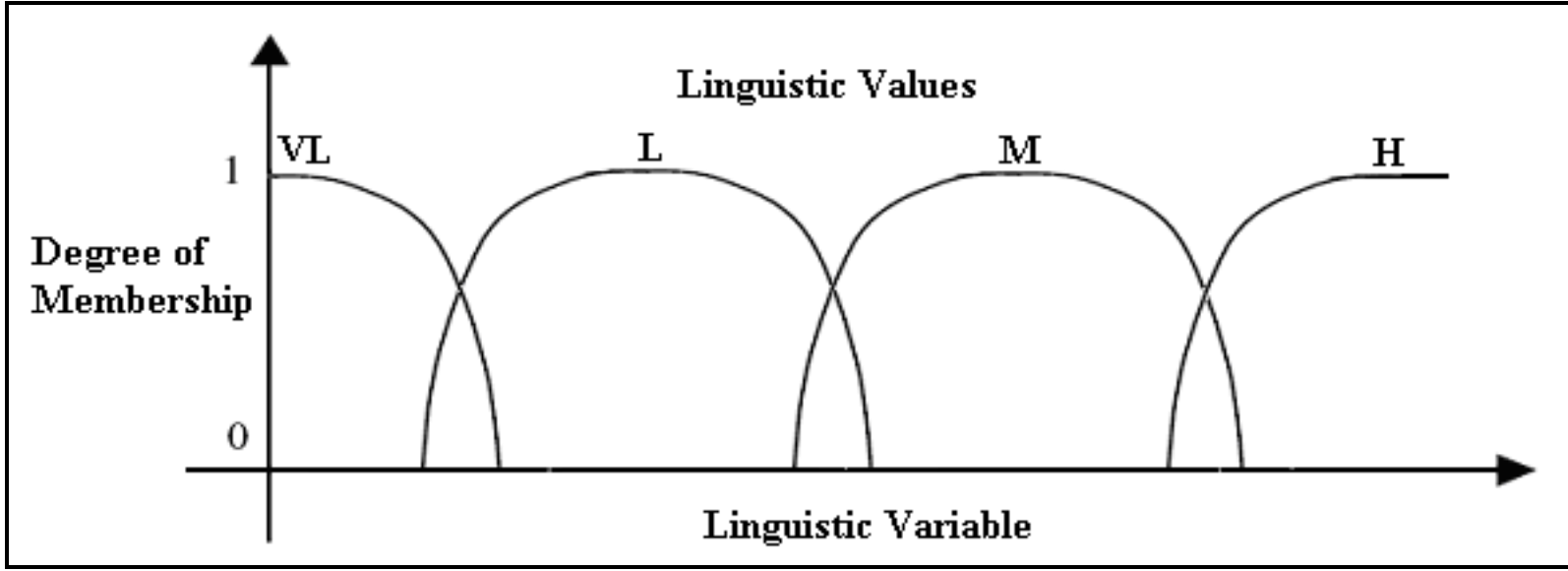

Figure 12 - Cosinusoidal Membership Functions [19]

A crisp input is entered into the membership function, which then returns a degree of membership for each linguistic value. This array of values will be the fuzzy input or set. Continuing with the temperature membership function, assume a temperature that lies somewhere between medium and high. The degrees of membership would be zero for both 'very low' (VL) and 'low' (L) but would be somewhere between zero and one for 'medium' (M) and 'high' $(\mathrm{H})$. The fuzzy input would then be something similar to $[0,0,1,0.5]$. This corresponds to degrees of membership equal to $0 \mathrm{VL}, 0 \mathrm{~L}, 1 \mathrm{M}$ and $0.5 \mathrm{H}$. Now if there were two linguistic variables, there would be two fuzzy sets for each point. These can be put together in one matrix through the use of definitions of the intersection of fuzzy sets. The two most common methods are multiplicative and minimum intersection. These are defined by Equations 2.19 and 2.20, where $A$ and $B$ are fuzzy sets and $\mu_{A \cap B}$ represents the intersection between them [19].

\section{Multiplicative Intersection of Fuzzy Sets}

$$
A \cap B=\left\{x \mid \mu_{A \cap B}=\mu_{A}(x) \cdot \mu_{B}(x)\right\}
$$

Minimum Intersection of Fuzzy Sets

$$
A \cap B=\left\{x \mid \mu_{A \cap B}=\min \left(\mu_{A}(x), \mu_{B}(x)\right\}\right.
$$

This produces the fuzzy command matrix. The number of linguistic variables and linguistic values determine the size of the matrix. If there are two inputs and four linguistic values then the fuzzy input command will be a $4 \times 4$ matrix. This matrix is then overlaid on the inference rule matrix, which must be of the same size, to produce the final fuzzy command matrix. This can be seen more clearly through an example of the design of a cruise controller for a vehicle [19]. The 
inputs are acceleration and speed error with linguistic values of large negative (LN), small negative (SN), zero (Z), small positive (SP) and large positive (LP). The output will be changes to the speed of the vehicle. An inference rule matrix for these inputs is shown in Table 3 [19].

Table 3 - Inference Rule Matrix for a Cruise Controller [19]

\begin{tabular}{|c|c|c|c|c|c|}
\hline \multirow{2}{*}{ Acceleration } & \multicolumn{5}{|c|}{ Speed Error } \\
\cline { 2 - 6 } & LN & SN & Z & SP & LP \\
\hline LN & $Z$ & $S P$ & $S P$ & $L P$ & $L P$ \\
\hline SN & SN & $Z$ & $S P$ & $S P$ & $L P$ \\
\hline$Z$ & $S N$ & $S N$ & $Z$ & $S P$ & $S P$ \\
\hline SP & $L N$ & $S N$ & $S N$ & $Z$ & $S P$ \\
\hline LP & $L N$ & $L N$ & $S N$ & $S N$ & $Z$ \\
\hline
\end{tabular}

Now, assume the fuzzy sets or inputs for the acceleration and speed error are equal to the following vectors:

$$
\begin{aligned}
& \text { Acceleration }=\left[\begin{array}{lllll}
0 & 0 & 1 & 0.33 & 0
\end{array}\right] \\
& \text { Speed Error }=\left[\begin{array}{lllll}
0 & 0 & 0.25 & 1 & 0
\end{array}\right]
\end{aligned}
$$

Next, we can form fuzzy input command matrices using the definition of intersection of fuzzy sets. Using the multiplicative method would give the matrix in Table 4 and using the minimum intersection method would give the matrix in Table 5 [19].

Table 4 - Fuzzy Command Matrix using Multiplicative Intersection of Fuzzy Sets [19]

\begin{tabular}{|c|c|c|c|c|c|}
\hline \multirow{2}{*}{ Acceleration } & \multicolumn{5}{|c|}{ Speed Error } \\
\cline { 2 - 6 } & $\mathbf{0}$ & $\mathbf{0}$ & $\mathbf{0 . 2 5}$ & $\mathbf{1}$ & $\mathbf{0}$ \\
\hline $\mathbf{0}$ & 0 & 0 & 0 & 0 & 0 \\
\hline $\mathbf{0}$ & 0 & 0 & 0 & 0 & 0 \\
\hline $\mathbf{1}$ & 0 & 0 & 0.25 & 1 & 0 \\
\hline $\mathbf{0 . 3 3}$ & 0 & 0 & 0.082 & 0.33 & 0 \\
\hline $\mathbf{0}$ & 0 & 0 & 0 & 0 & 0 \\
\hline
\end{tabular}

Table 5 - Fuzzy Command Matrix using Minimum Intersection of Fuzzy Sets [19]

\begin{tabular}{|c|c|c|c|c|c|}
\hline \multirow{2}{*}{ Acceleration } & \multicolumn{5}{|c|}{ Speed Error } \\
\cline { 2 - 6 } & $\mathbf{0}$ & $\mathbf{0}$ & $\mathbf{0 . 2 5}$ & $\mathbf{1}$ & $\mathbf{0}$ \\
\hline $\mathbf{0}$ & 0 & 0 & 0 & 0 & 0 \\
\hline $\mathbf{0}$ & 0 & 0 & 0 & 0 & 0 \\
\hline $\mathbf{1}$ & 0 & 0 & 0.25 & 1 & 0 \\
\hline $\mathbf{0 . 3 3}$ & 0 & 0 & 0.25 & 0.33 & 0 \\
\hline $\mathbf{0}$ & 0 & 0 & 0 & 0 & 0 \\
\hline
\end{tabular}


In order to fire the inference rules, the fuzzy command matrix must be overlaid with the inference rule matrix. Using the multiplicative method with the inference rule matrix would give the following result:

Table 6 - Fuzzy Command Matrix Overlaid with Inference Rule Matrix [19]

\begin{tabular}{|c|c|c|c|c|c|}
\hline \multirow{2}{*}{ Acceleration } & \multicolumn{5}{|c|}{ Speed Error } \\
\cline { 2 - 6 } & $\mathbf{0}$ & $\mathbf{0}$ & $\mathbf{0 . 2 5}$ & $\mathbf{1}$ & $\mathbf{0}$ \\
\hline $\mathbf{0}$ & 0 & 0 & 0 & 0 & 0 \\
\hline $\mathbf{0}$ & 0 & 0 & 0 & 0 & 0 \\
\hline $\mathbf{1}$ & 0 & 0 & $0.25(Z)$ & $1(\mathrm{SP})$ & 0 \\
\hline $\mathbf{0 . 3 3}$ & 0 & 0 & $0.082(\mathrm{SN})$ & $0.33(\mathrm{Z})$ & 0 \\
\hline $\mathbf{0}$ & 0 & 0 & 0 & 0 & 0 \\
\hline
\end{tabular}

In words, this corresponds to a command of $0.25 \mathrm{Z}, 1.0 \mathrm{SP} 0.082 \mathrm{SN}$ and $0.33 \mathrm{Z}$. This is the fuzzy output, which needs to be defuzzified in order to get a crisp output. The values in the command are considered heights of fuzzy sets in the membership functions. The fuzzy sets can either be clipped or scaled according to these heights. Figure 13 and Figure 14 show how this is done.

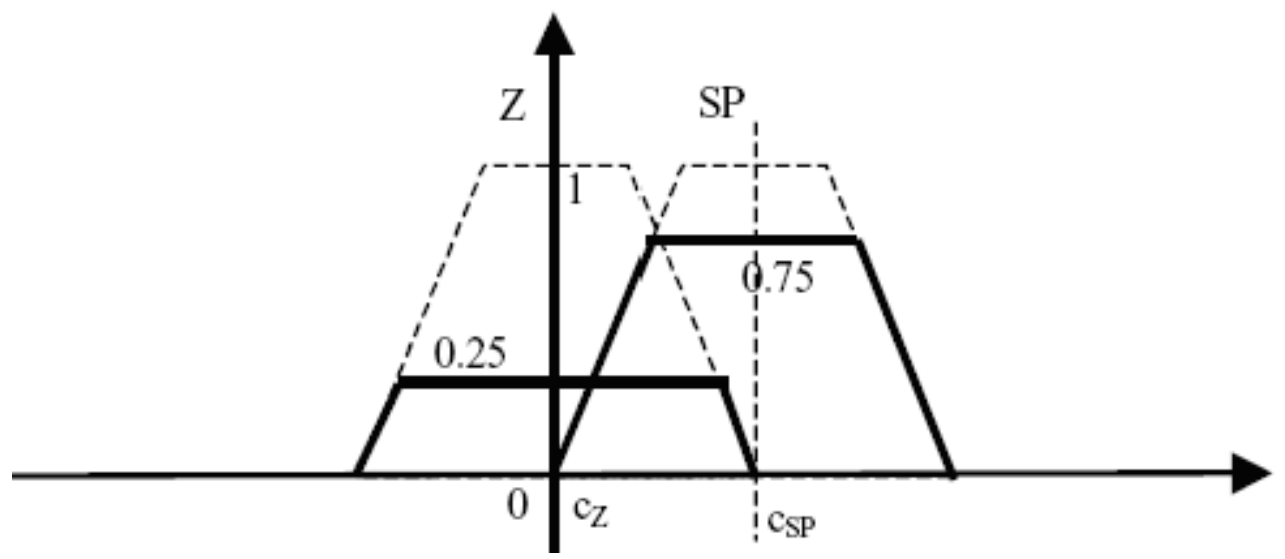

Figure 13 - Trapezoidal Clipped Fuzzy Sets [19] 


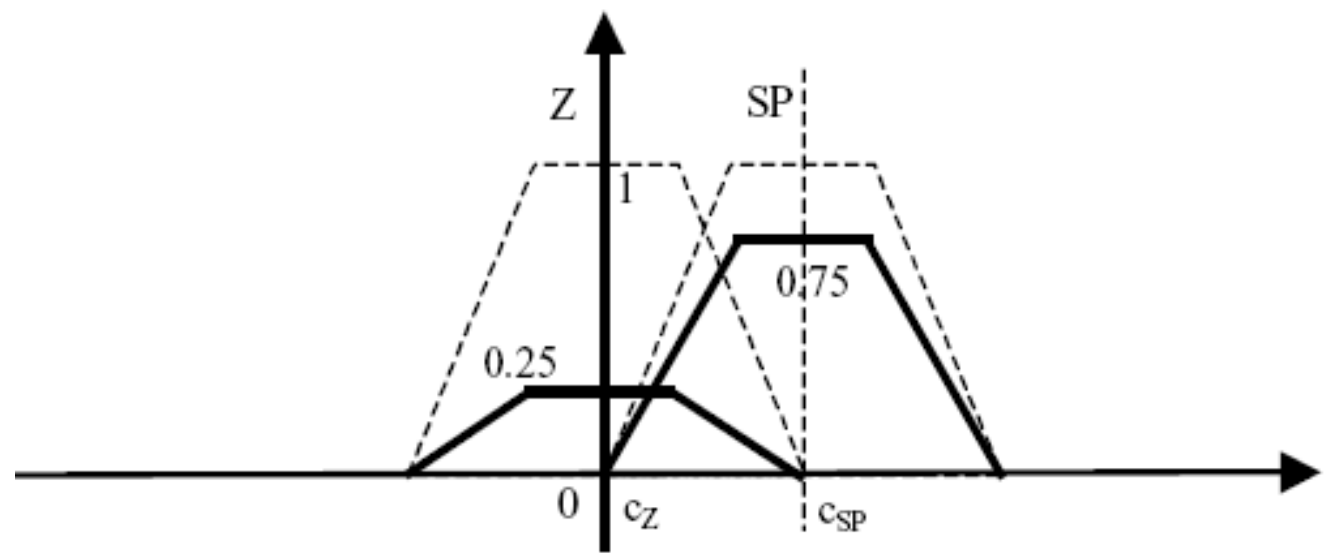

Figure 14 - Trapezoidal Scaled Fuzzy Sets [19]

Defuzzification can now be done based on the clipped or scaled fuzzy sets using various methods. Some of the most common methods are shown below. They are based on the area, height, and centers of the fuzzy sets. The defuzzification outputs a single crisp value, which is the actual command generated by the fuzzy logic program [19].

\section{Center of Sum Defuzzification}

$$
u=\frac{\sum_{i=1}^{n} \sum_{j=1}^{n} c_{i j} A_{i j}}{\sum_{i=1}^{n} \sum_{j=1}^{n} A_{i j}}
$$

Height at Lower Value Defuzzification

$$
u=\frac{\sum_{i=1}^{n} \sum_{j=1}^{n} c_{i j-\min } d_{i j}}{\sum_{i=1}^{n} \sum_{j=1}^{n} d_{i j}}
$$

Height at Peak Value Defuzzification

$$
u=\frac{\sum_{i=1}^{n} \sum_{j=1}^{n} c_{i j} d_{i j}}{\sum_{i=1}^{n} \sum_{j=1}^{n} d_{i j}}
$$


The above defuzzification methods are very similar and using one or another will not change the result in any drastic way. Despite this, there are several things that can be done in order to 'tune' or improve a fuzzy logic system. First, the number and type of membership functions can be changed. Usually a membership function will have four or five linguistic values. Increasing this number will increase computation time but will also improve the system. The type of membership function can also have an effect. Trapezoidal and triangular membership functions have discontinuities in their derivative, which can cause discontinuities in the command values. Using continuous membership functions such as bell-shaped or cosinusoidal will remove any problems due to discontinuities. The size of the inference matrix, which is directly affected by the size of the membership functions, is an important factor in the performance and stability of a fuzzy logic system. In most cases, an increase in the size of the inference matrix will result in an improvement of the system.

\subsection{Summary}

After reviewing the problems and effects associated with $\mathrm{NO}_{\mathrm{x}}$ emissions, it is clear that the reduction of $\mathrm{NO}_{\mathrm{x}}$ to 2010 standards is a priority. It is also evident, that in order to meet these standards, engine-out $\mathrm{NO}_{\mathrm{x}}$ reduction techniques are insufficient without advanced engine combustion techniques or exhaust aftertreatment systems. SCRs are the most promising exhaust aftertreatment systems but require sophisticated urea injection strategies. Closed loop control strategies are limited by the availability of high-resolution $\mathrm{NO}_{\mathrm{x}}$ sensors without excessive crosssensitivity to $\mathrm{NH}_{3}$ or vice versa. Due to this, an open loop control strategy that can be adapted in the future for feedback control is an attractive option. A.I. techniques can be used in conjunction with open loop control strategies to develop a simple, yet effective method of reducing diesel engine $\mathrm{NO}_{\mathrm{x}}$ emissions. Fuzzy logic is the best-suited A.I. technique for this purpose, because of its robust nature and straightforward implementation. 


\section{Experimental Setup}

\subsection{Test Engine}

The test engine used was a MY07 Volvo MD11 production series engine. This 11-liter heavy-duty diesel engine commonly used for refuse collection and services, is earmarked by Volvo [21]. The engine is shown below in Figure 15.

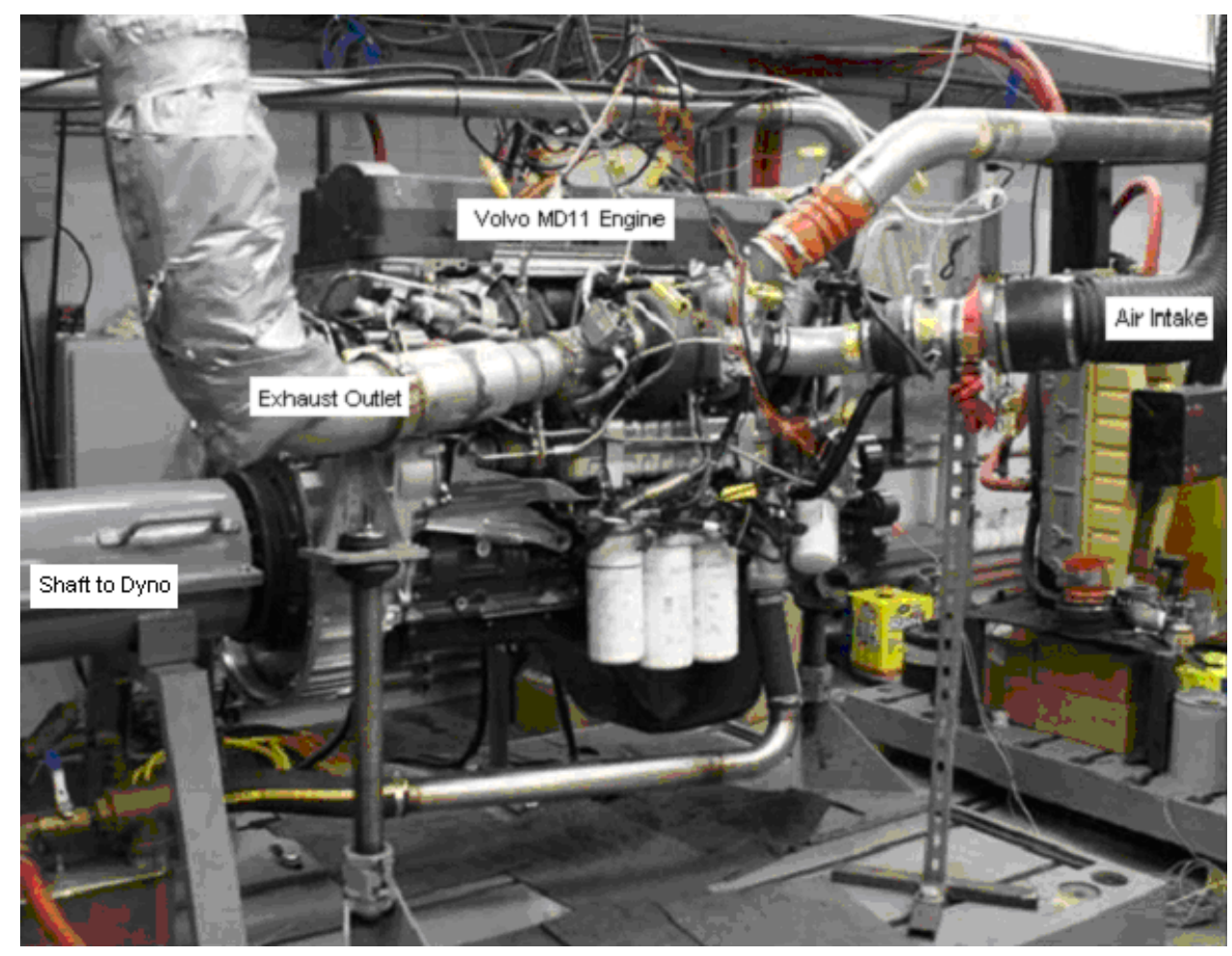

Figure 15 - MY07 Volvo MD11 (339 hp@1800 rpm/1298 lb-ft@1306 rpm)

The engine is equipped with a high-pressure loop EGR system that is cooled by an air-to-liquid heat exchanger. It also has a variable geometry turbocharger (VGT) with a sliding nozzle. It also comes equipped with a seventh injector for use with a diesel particulate filter. The engine specifications are shown below in Table 7. 
Table 7 - Volvo MY07 MD11 Engine Specifications [21]

\begin{tabular}{|c|c|}
\hline Power & $\begin{array}{l}253 \mathrm{~kW} 01800 \mathrm{rpm} \\
(939 \mathrm{hp} 1800 \mathrm{pm})\end{array}$ \\
\hline Torque & $\begin{array}{l}1760 \mathrm{Nm} @ 1306 \mathrm{pm} \\
(1298 \mathrm{lt}-\mathrm{ft} 1306 \mathrm{rmm})\end{array}$ \\
\hline Base Configuration & 4 cycle, In-line E cylinder \\
\hline Aspiration & Sliding Nozzle Variable Turbocharger \\
\hline Injection System & Dual Solenoid Electronic Unit Injector \\
\hline Displacement, cu. In. (L) & $661(10.8)$ \\
\hline Compression Ratio & 16:01 \\
\hline Bore \& Stroke, in. (mm) & $4.84 \times 5.98$ \\
\hline Cylinder Spacing, in. (mm) & $6.06(154)$ \\
\hline
\end{tabular}

\subsection{Laboratory Setup and Instrumentation}

The test cell used for this study is designed according to the emission measurement regulations of the Code of Federal Regulations (CFR) 40, parts 86, 89, 92 and 1065. The test cell is equipped with an $800 \mathrm{hp} \mathrm{DC}$ dynamometer, which was used for testing and is shown connected to the engine in Figure 16.

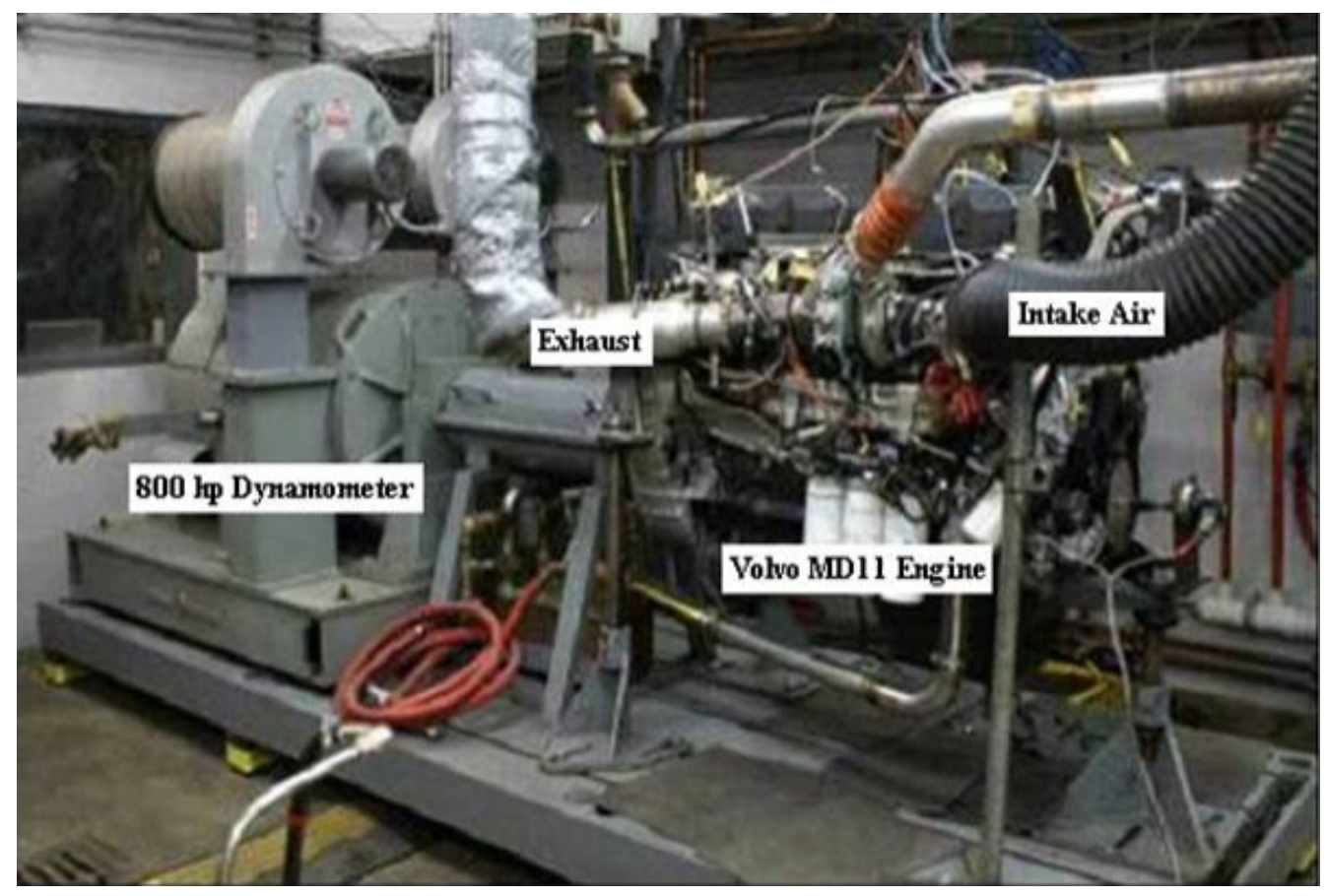

Figure 16 - 800hp DC Dynamometer connected to MY07 Volvo MD11 Engine 
The exhaust of the engine is routed to a full-scale dilution tunnel. The tunnel uses a CVS subsonic flow venturi compliant with CFR 40, part 86 . The venturi has a variable speed blower that is controlled according to CFR 40 part 1065. The dilution air is filtered with HEPA filters, and is temperature and humidity controlled. The venturi, dilution tunnel and variable speed blower are shown in Figure 17 and Figure 18, respectively.

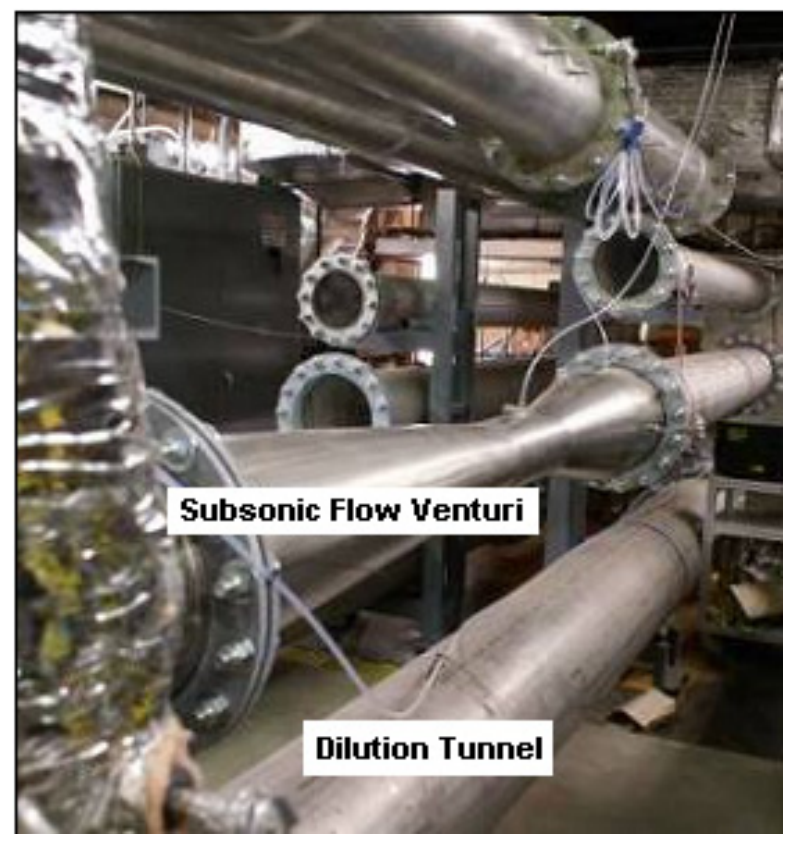

Figure 17 - CVS Subsonic Flow Venturi and Dilution Tunnel

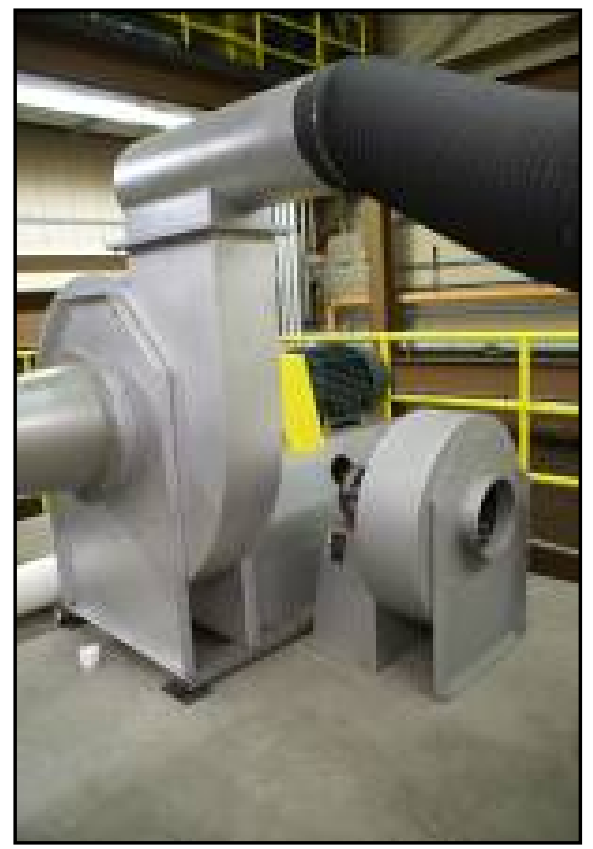

Figure 18 - Variable Speed Blower

\subsection{Analyzers}

All gaseous analyzers were set up to acquire emission measurements in accordance with requirements of CFR 40, part 1065. Each of the analyzers was calibrated on a eleven-point curve $(0 \%-100 \%)$ with at least 30 seconds stability time at each point. Prior to each engine test, all analyzers were zero/spanned to ensure the accuracy of the emission measurements. Nondispersive infrared (NDIR) analyzers were used for measuring carbon monoxide (CO) and carbon dioxide $\left(\mathrm{CO}_{2}\right)$. The NDIR analyzers were manufactured by Horiba and are shown in Figure 19. A heated flame ionization detector (HFID) manufactured by Rosemount, was used to measure hydrocarbons and is shown in Figure 20. 


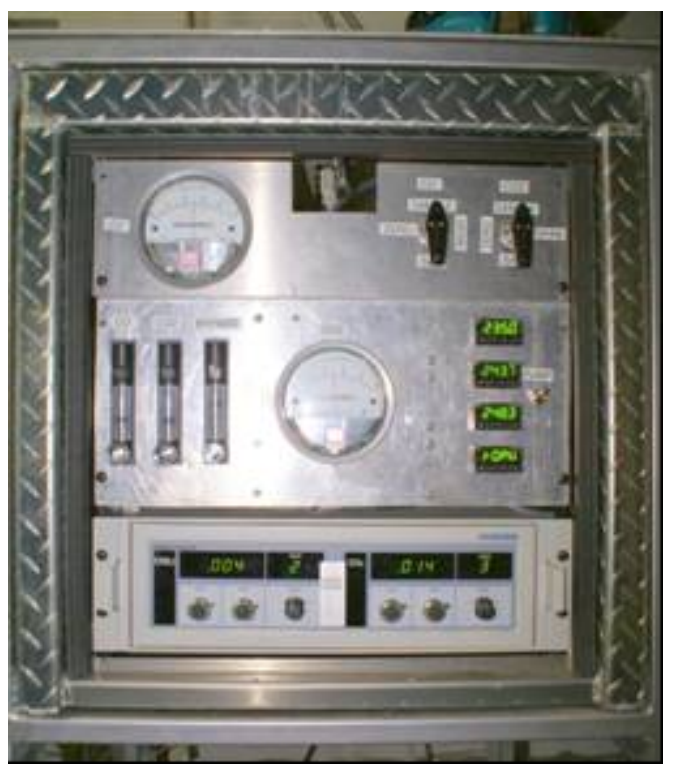

Figure 19 - NDIR Analyzer for $\mathrm{CO}$ and $\mathrm{CO}_{2}$

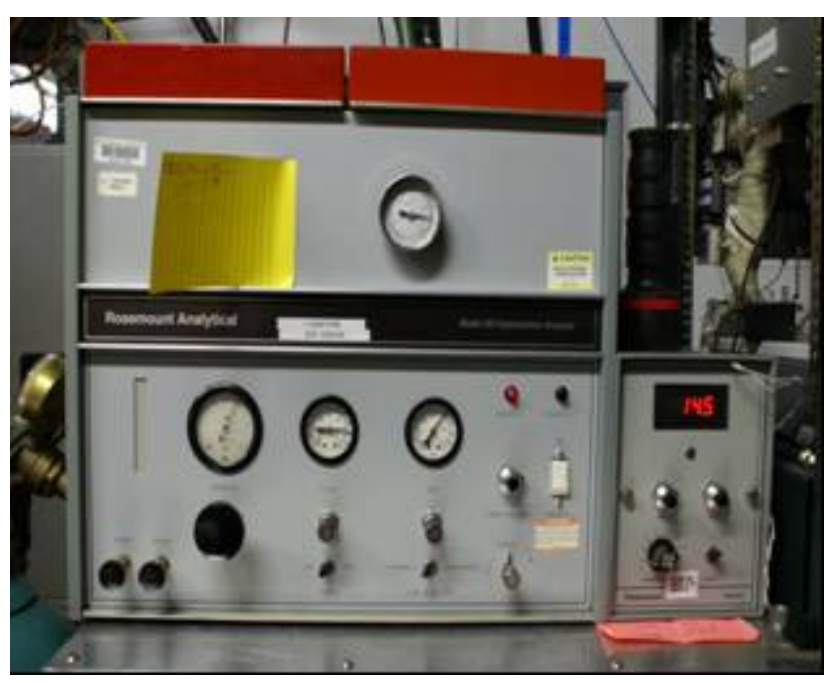

Figure 20 - Rosemount HFID Analyzer for HC

Two analyzers were used for the measurement of $\mathrm{NO}_{\mathrm{x}}$. The first is a chemiluminescent detector manufactured by Ecophysics, which was set up to measure $\mathrm{NO}_{\mathrm{x}}$ and $\mathrm{NO}$. The second was a non-dispersive ultraviolet (NDUV) analyzer manufactured by Limas, which could measure $\mathrm{NO}, \mathrm{NO}_{2}$ and $\mathrm{NH}_{3}$. The NDUV analyzer was used to measure ammonia slip values and served as a comparison for $\mathrm{NO}_{\mathrm{x}}$ measurements from the Ecophysics analyzer. The chemiluminescent and NDUV analyzers are shown in Figure 21 and Figure 22, respectively.

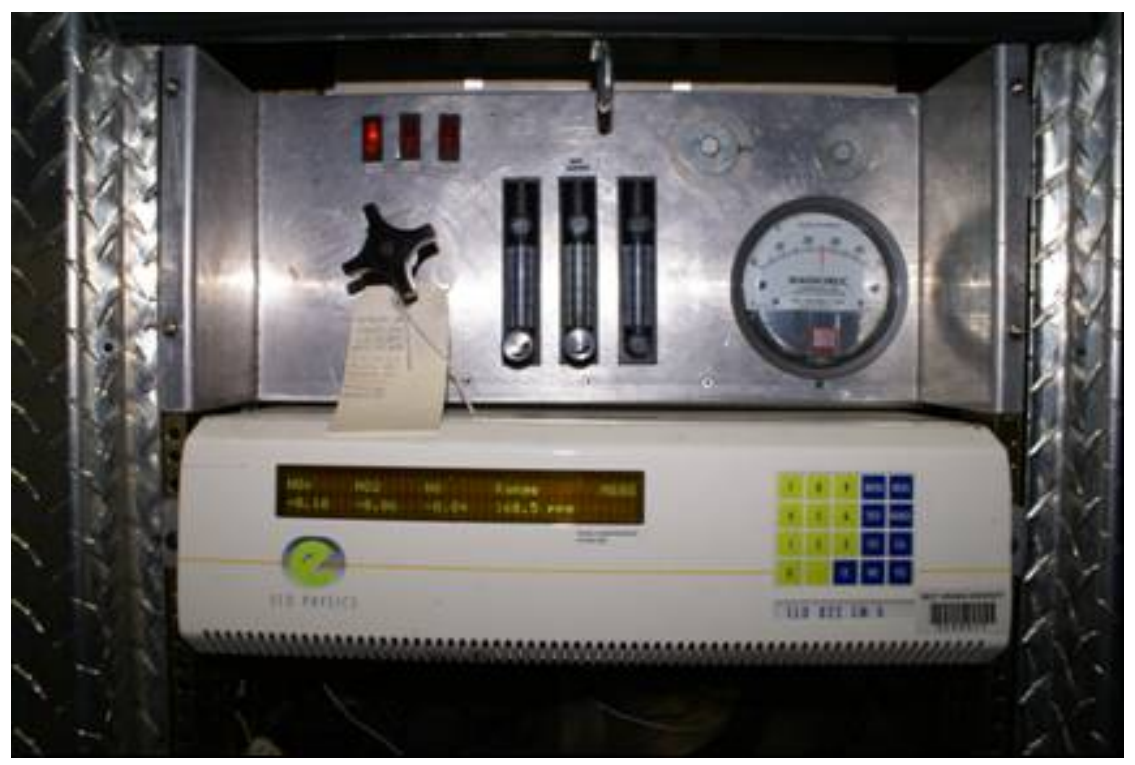

Figure 21 - Ecophysics CLD 822CMH Analyzer for $\mathrm{NO}_{\mathrm{x}}$ and NO 


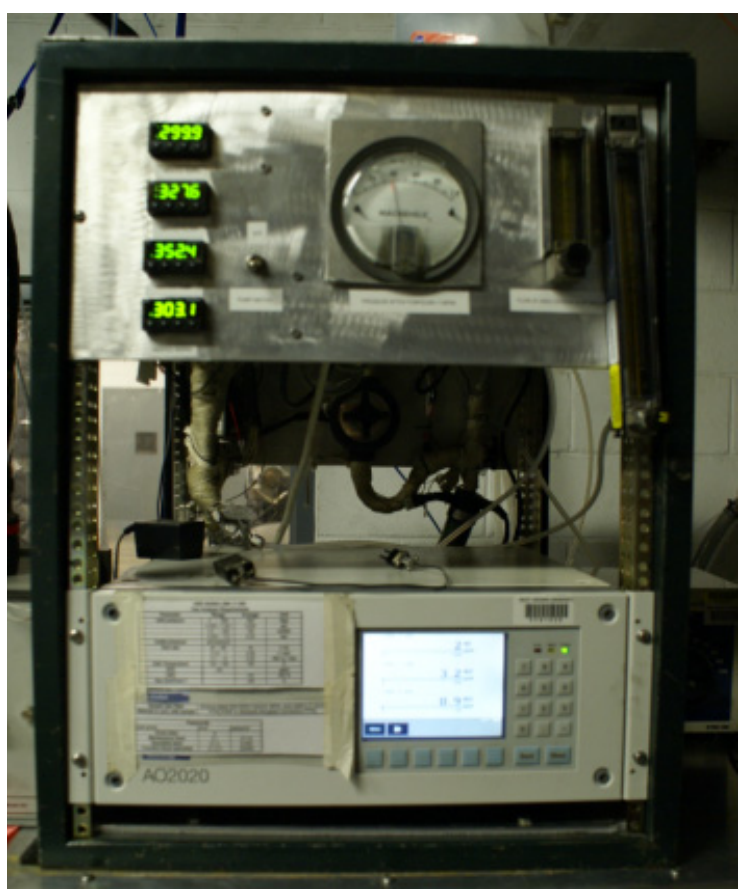

Figure 22 - ABB Limas 11HV - NDUV Analyzer for $\mathrm{NH}_{3}$

Table 8 gives a summary of the type and model of each gaseous analyzer used for measurement of engine emissions during this study.

Table 8 - Summary of Gas Analyzers [22]

\begin{tabular}{|c|c|c|}
\hline Emission & Manufacturer & Model No. \\
\hline THC & Rosemount & 402 \\
\hline CO & Horiba & AIA-220 \\
\hline CO $_{2}$ & Horiba & AIA-220 \\
\hline NO $_{\mathbf{x}} / \mathbf{N O}$ & Eco Physics & CLD822CMh \\
\hline NDUV & ABB Limas11HV & AO2020 \\
\hline
\end{tabular}

Particulate matter was collected on $47 \mathrm{~mm}$ Teflo filters (see Figure 23) after the filters were equilibrated and pre-weighed using a high precision microbalance. Filters were placed in a holder and then within a 'PM box' to collect samples during the test (see Figure 24). Afterward, the filters were removed and equilibrated again in a temperature and humidity controlled room. Once properly conditioned, filters were post-weighed. This was done according to specifications laid out in CFR 40, part 1065. 


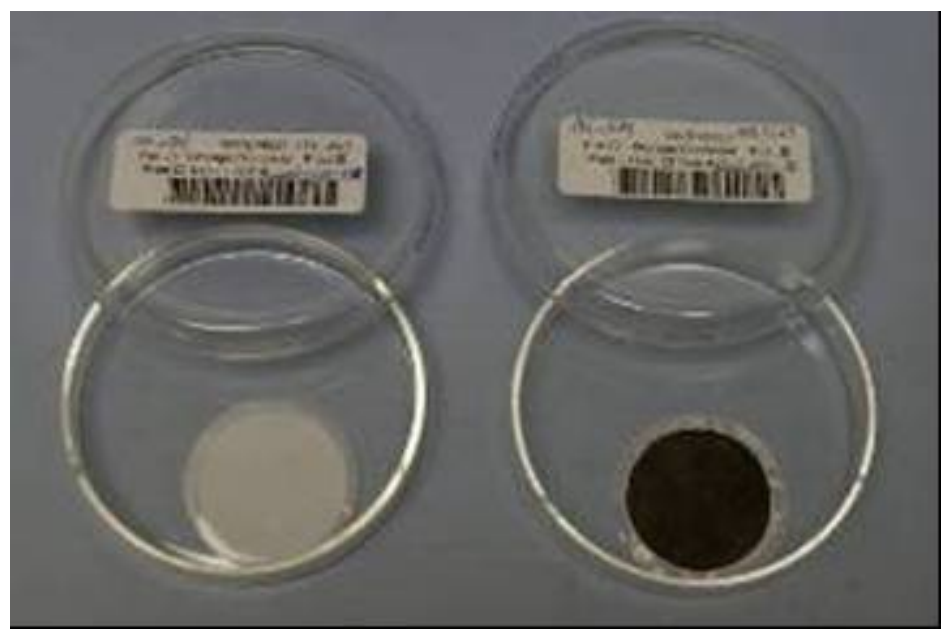

Figure 23 - PM filters (Left: Unused, Right: Engine-Out Test)

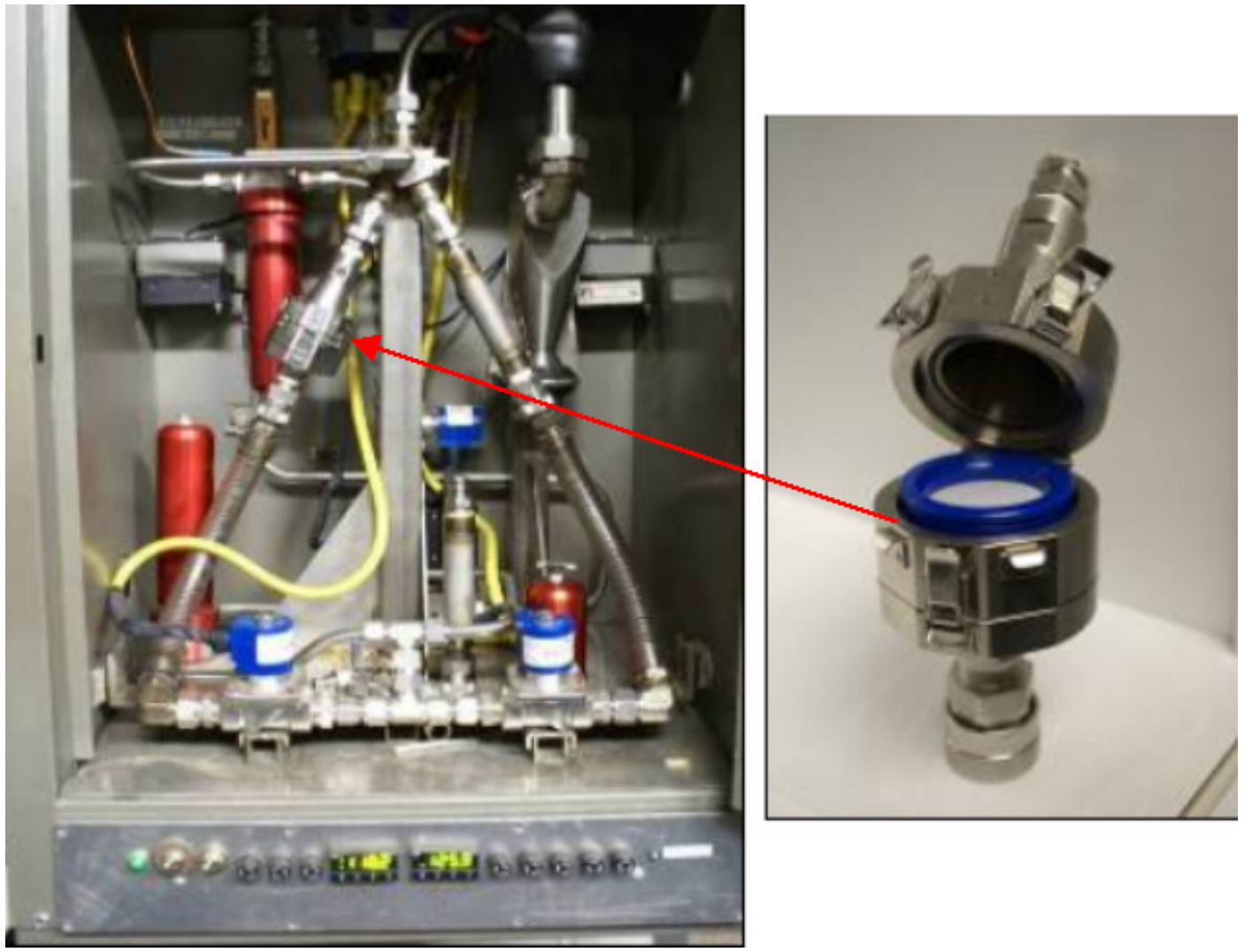

Figure 24 - PM Filter Box (left) and Filter Holder (right) [22]

\subsection{Exhaust Aftertreatment Systems}

The exhaust aftertreatment system was comprised of a diesel oxidation catalyst, a diesel particulate filter and a selective catalytic reduction system. The DPF and DOC are packaged into one unit to save space and were manufactured by Fleetguard. The DOC located upstream of the 
DPF in the system was designed to enhance generation of $\mathrm{NO}_{2}$, which enabled soot ignition at temperatures as low as $250^{\circ} \mathrm{C}$. Additionally, the $\mathrm{NO}_{2} / \mathrm{NO}$ ratio as initiated by the $\mathrm{DOC}$ is critical for efficient operation of the SCR system. The DPF and DOC are shown in Figure 25. The engine was also equipped with a seventh injector for active regeneration of the DPF system. This is done by injection of hydrocarbons, diesel fuel in this case, into the exhaust gas to raise the temperature high enough to initiate oxidation of the soot. For this study, the seventh injector was not used and the DPF was allowed to passively regenerate.

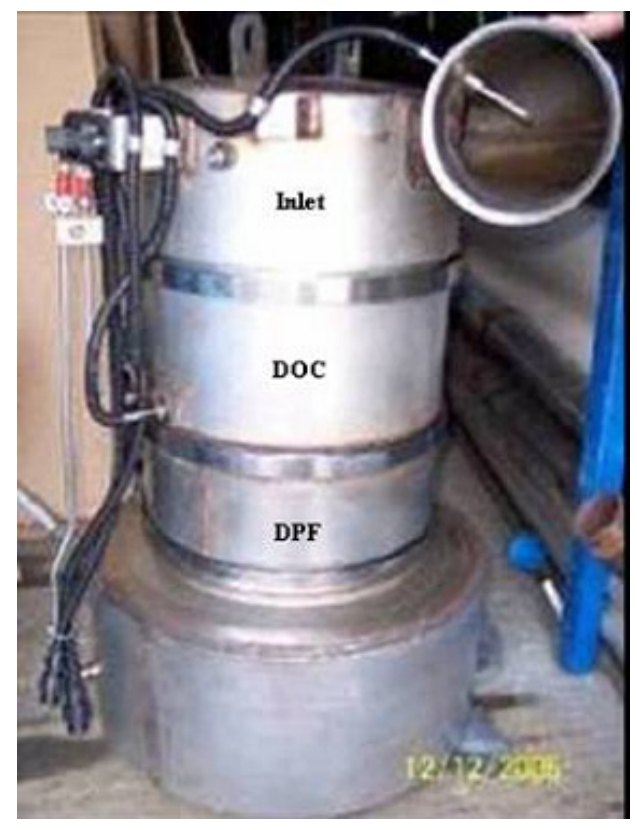

Figure 25 - Fleetguard DOC+DPF Aftertreatment System

The SCR system manufactured by Johnson and Matthey, uses aqueous urea as a reducing agent. It is equipped with an oxidation catalyst, which allows for oxidation of ammonia that breaks through the SCR substrate. Urea by itself is very corrosive; hence, it is mixed in a solution with water in order to use for automotive applications. The solution used, called Adblue, is $32.5 \%$ urea and $67.5 \%$ water by weight. This mixture allows for the lowest crystallization point possible at $-11^{\circ} \mathrm{C}$. The urea solution is distributed to the SCR through a urea pump and injector. The urea dosage is managed by a controller, which is driven by the software program CANalyzer. This program allowed for the implementation of the urea dosing strategy using urea maps. The SCR system is shown in Figure 26. The DPF and SCR system were mounted on a cart and then attached to the exhaust outlet of the Volvo MD11 engine. The 
system is shown completely assembled in Figure 27. The DPF+DOC combination is upstream of the SCR.

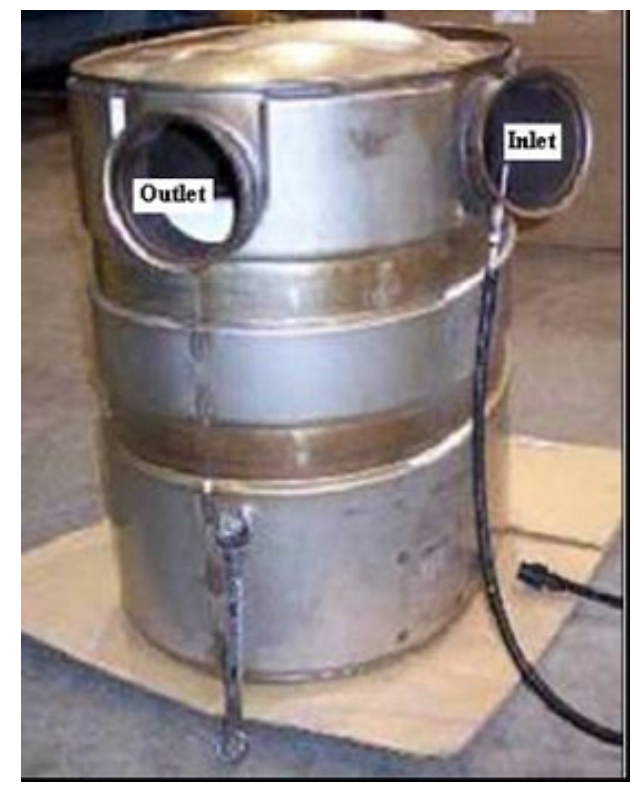

Figure 26 - Johnson and Matthey SCR System

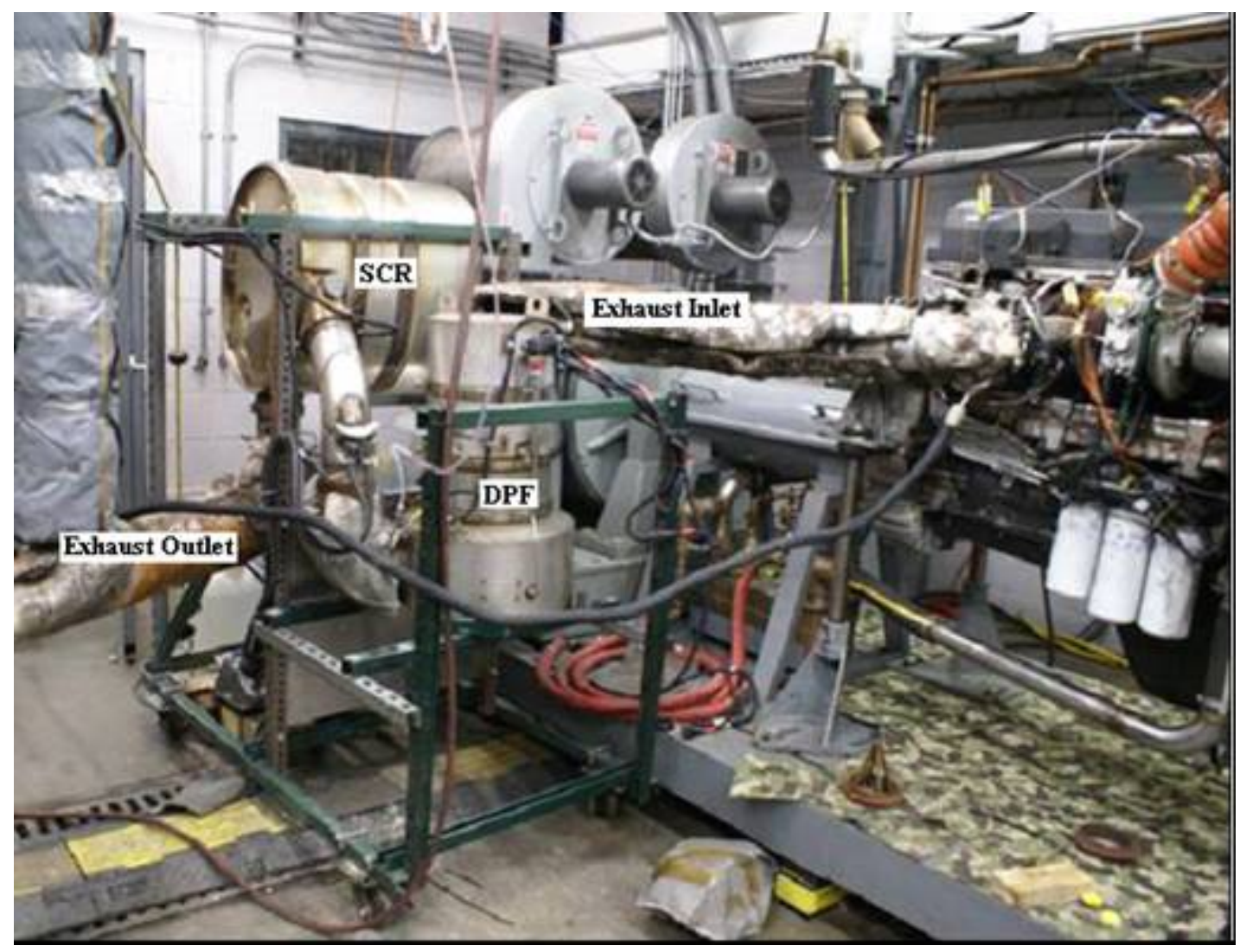

Figure 27 - Exhaust Aftertreatment Systems on the Volvo MD11 Engine 


\subsection{Urea Pump and CANalyzer}

The urea pump and injector used for this project were designed and manufactured by Volvo. The pump is very small and compact and can be used in mobile applications. It operates at a pressure of $500 \mathrm{kpa}$ for injection. Figure 28 shows how the urea pump was connected to both the urea injector and the urea tank.

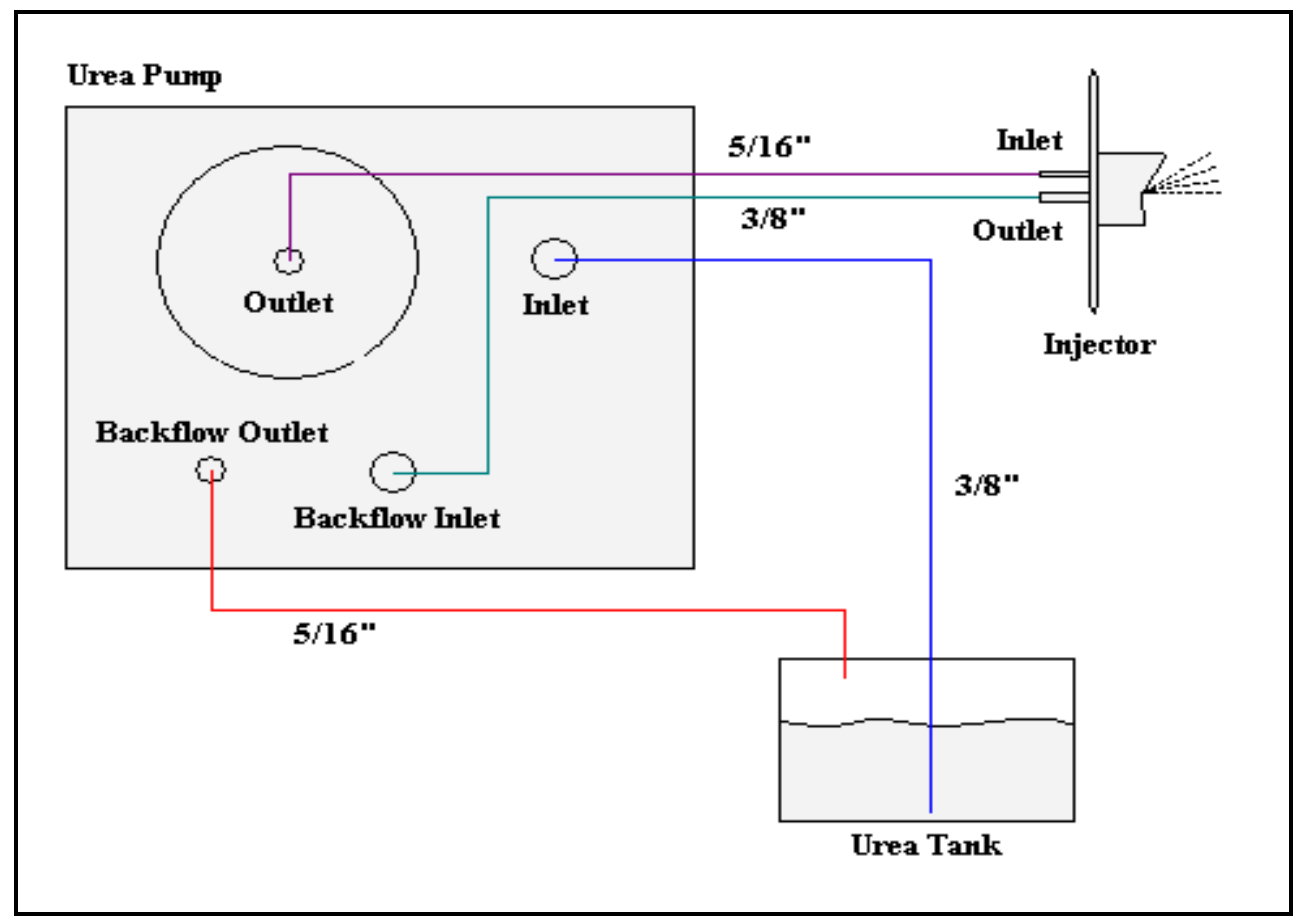

Figure 28 - Urea Pump Hose Connection Diagram

Figure 28 shows that the pump draws urea from the tank, sends it to the injector and then returns the backflow. When the pump was turned off, it purged itself and pumped any residual ammonia back into the urea tank. Through CANalyzer, it was possible to have real time values of various engine parameters such as engine speed, throttle percentage and temperature. Figure 29 shows the schematic of the control setup using CANalyzer. 


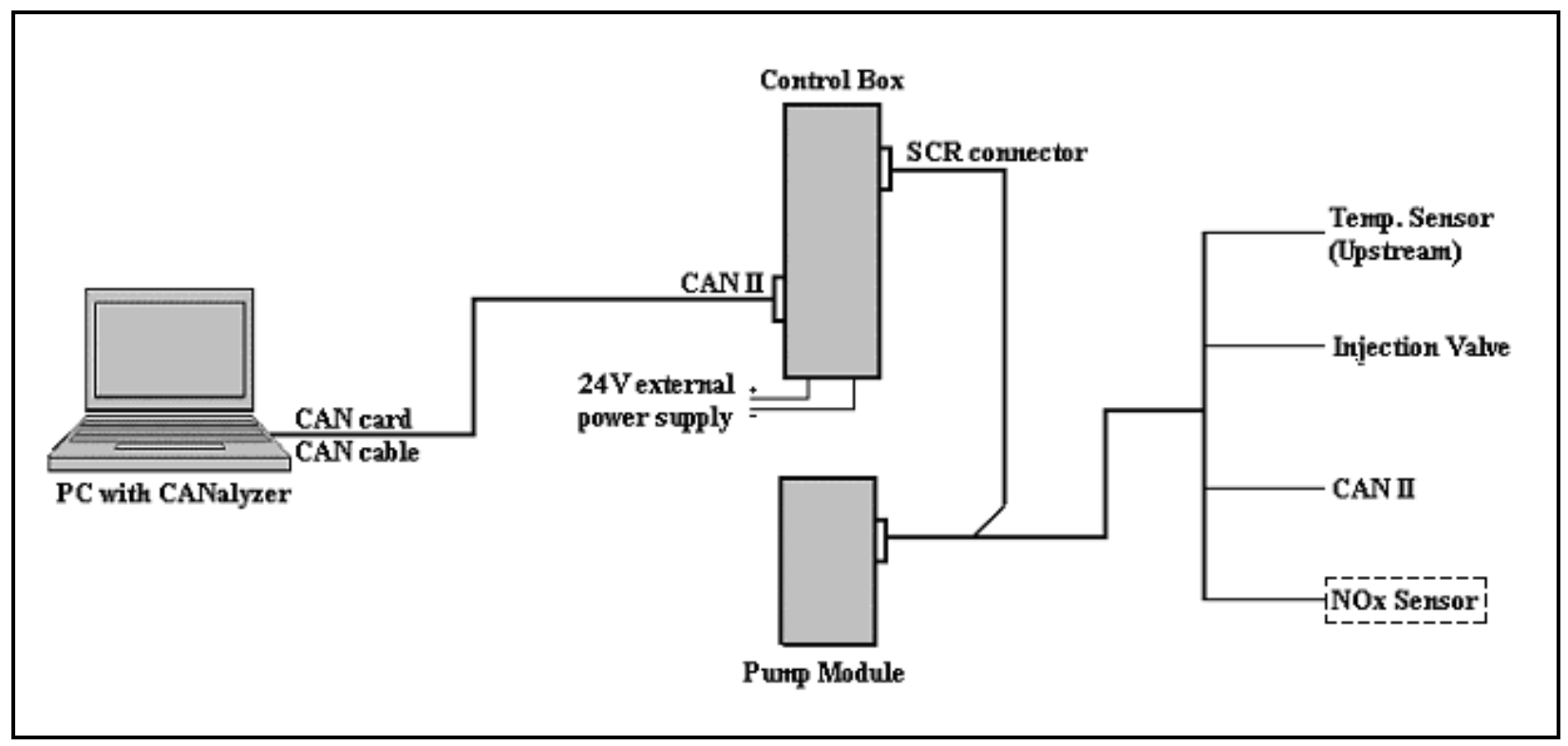

Figure 29 - CANalyzer Control Setup Diagram

A separate computer was needed to operate CANalyzer. A network or CAN card and cable were used to connect to the control box, which relayed the CANalyzer commands. A simple program written within CANalyzer produced the urea injection commands based upon the engine speed and engine torque. The control box was then connected to the pump as well as any sensors used. Figure 30 and Figure 31 show different views of the urea pump used for this study.

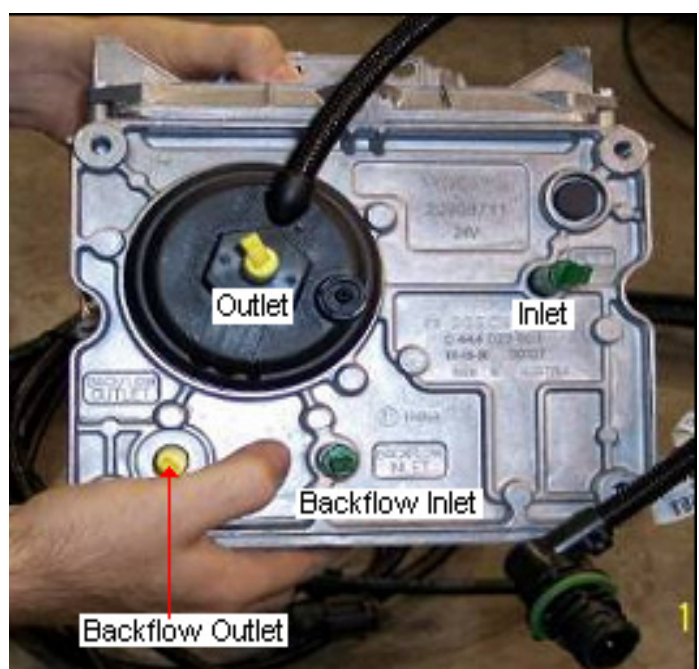

Figure 30 - Adblue Urea Pump (Back View)

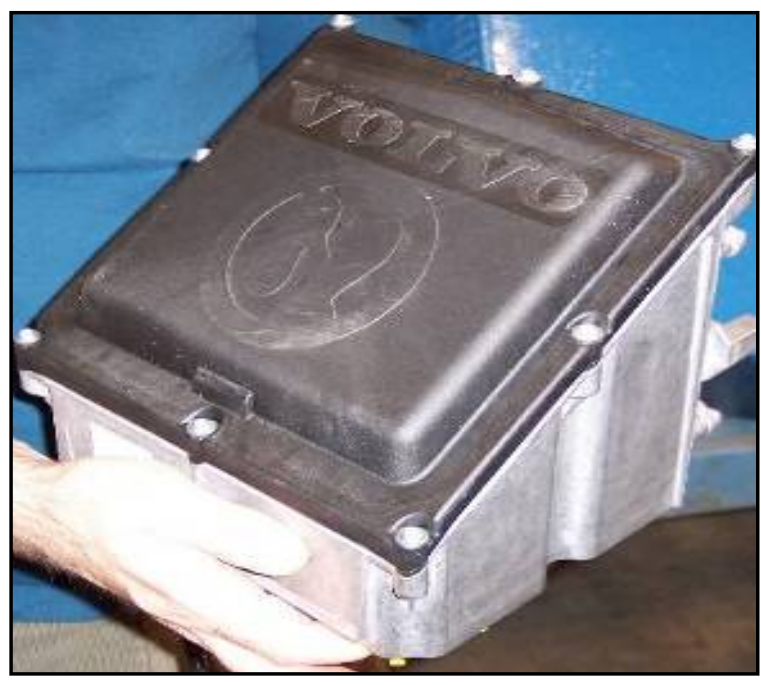

Figure 31 - Adblue Urea Pump (Front View) 
Volvo manufactured the urea pump shown above. The urea injector is used in conjunction with the urea pump is shown in Figure 32.

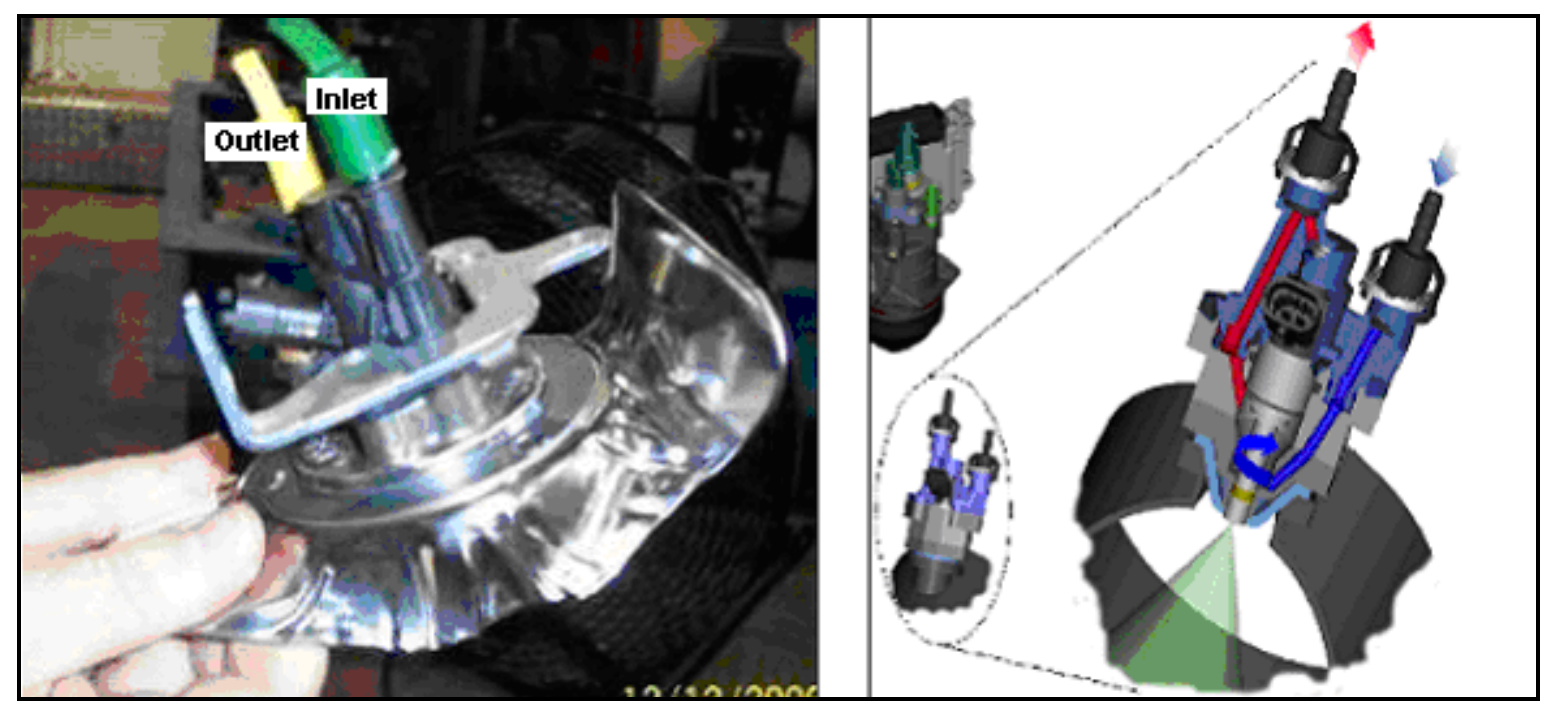

Figure 32 - Adblue Urea Dosage Valve [22] 


\section{Approach}

SCR is the leading $\mathrm{NO}_{\mathrm{x}}$ reduction technology, which is being adopted to meet the stringent 2010 emission regulations and was used in this study. The urea dosage strategy that was implemented took into account the temperature of the SCR catalyst, $\mathrm{NO}_{2} / \mathrm{NO}$ ratio, engine speed and engine load. An open loop control strategy was implemented because of its ability to reach high levels of $\mathrm{NO}_{\mathrm{x}}$ reduction without the use of $\mathrm{NO}_{\mathrm{x}}$ or $\mathrm{NH}_{3}$ sensors. These sensors have several limitations for controlling urea dosage at very low $\mathrm{NO}_{\mathrm{x}}$ concentrations. The engine used for this study produced only $1.0 \mathrm{~g} / \mathrm{bhp}-\mathrm{hr}$ of $\mathrm{NO}_{\mathrm{x}}$ without aftertreatment [21]. With the exhaust aftertreatment, the $\mathrm{NO}_{\mathrm{x}}$ concentration was sufficiently low as to rule out the possibility of using a $\mathrm{NO}_{\mathrm{x}}$ sensor. The open loop strategy used a urea dosage map that injected a specific amount based on the engine speed and load of the engine at any given time. Three different methods were used to create these maps and each was applied on the Federal Test Procedure (FTP). The FTP cycle for a heavy-duty diesel engine is shown in Figure 33.

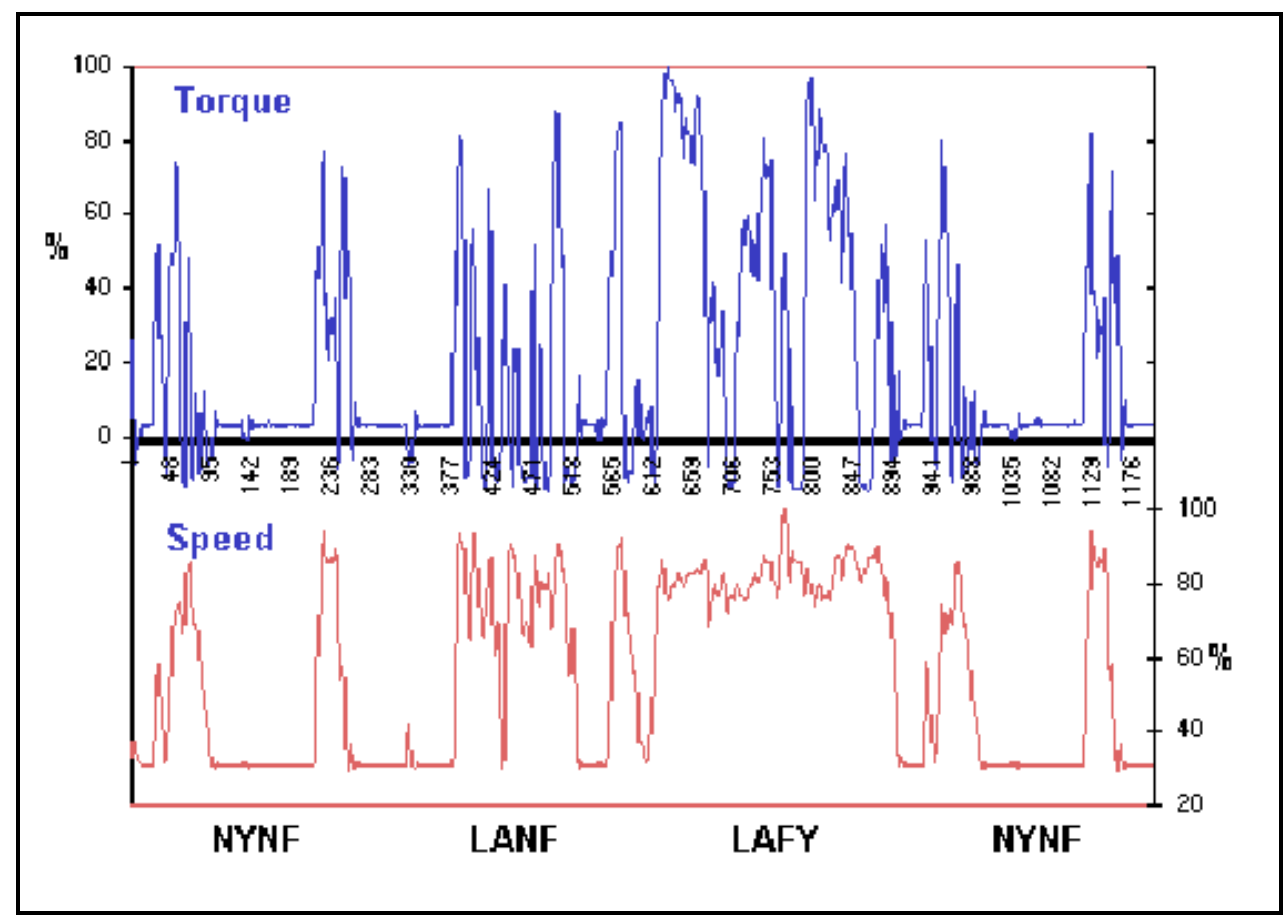

Figure 33 - Federal Test Procedure (FTP) [23]

The FTP is a transient cycle that is comprised of four different sections. As seen in Figure 33, the FTP is made up of four five-minute sections, which include the New York non-freeway 
(NYNF), Los Angeles non-freeway (LANF) and Los Angeles freeway (LAFY). The NYNF is the first section and is repeated after the LA portions of the test. Two of the urea maps were also evaluated on the European Transient Cycle (ETC) to ensure that the maps were not cycle specific to the FTP. The optimization method was also implemented on the 13 modes of the European Stationary Cycle (ESC). The ESC is a steady state cycle that runs the engine at three different speeds and various engine loads. This was done to gain insight into the difference of the behavior of the system during steady state and transient engine operation.

\subsection{Urea Map Development}

In order to develop an open loop urea dosage map, three different approaches were used. The three methods were (1) optimization, (2) average $\mathrm{NO}_{\mathrm{x}}$ and (3) fuzzy logic. The optimization method was used to get the maximum amount of $\mathrm{NO}_{\mathrm{x}}$ reduction possible with only minimal regard to ammonia slip. By creating this map, it was possible to get a good understanding of the system and its limitations. The average $\mathrm{NO}_{\mathrm{x}}$ method is an approach that was used to dramatically reduce the amount of testing needed when compared with the optimization method. This approach allowed for similar reduction percentage as the optimization map without extensive testing time. The fuzzy logic method was an approach that also required little testing time, but was aimed towards reducing ammonia slip values while still achieving high $\mathrm{NO}_{\mathrm{x}}$ reduction. The fuzzy logic method was an improvement upon the average $\mathrm{NO}_{\mathrm{x}}$ method and takes into account an SCR efficiency model. The SCR efficiency model was created with knowledge that was gained during the creation of the optimization map. Following is an in-depth look at each of the three methods.

\subsubsection{Optimization Method}

The first method used was a simple optimization strategy. A decision was made to optimize a specific set of engine operation points, and interpolate these values to the rest of the urea injection map. The operation points used included the thirteen steady state modes of the ESC cycle and the AVL 8 modes that are representative of the emissions over an FTP cycle [24]. Testing of each mode had to be done at steady state conditions. Although done at steady state, the results gave valuable knowledge about the system and the amount of urea that is needed. The ESC and AVL modes are shown in Figure 34 under the lug curve for the Volvo test engine. 


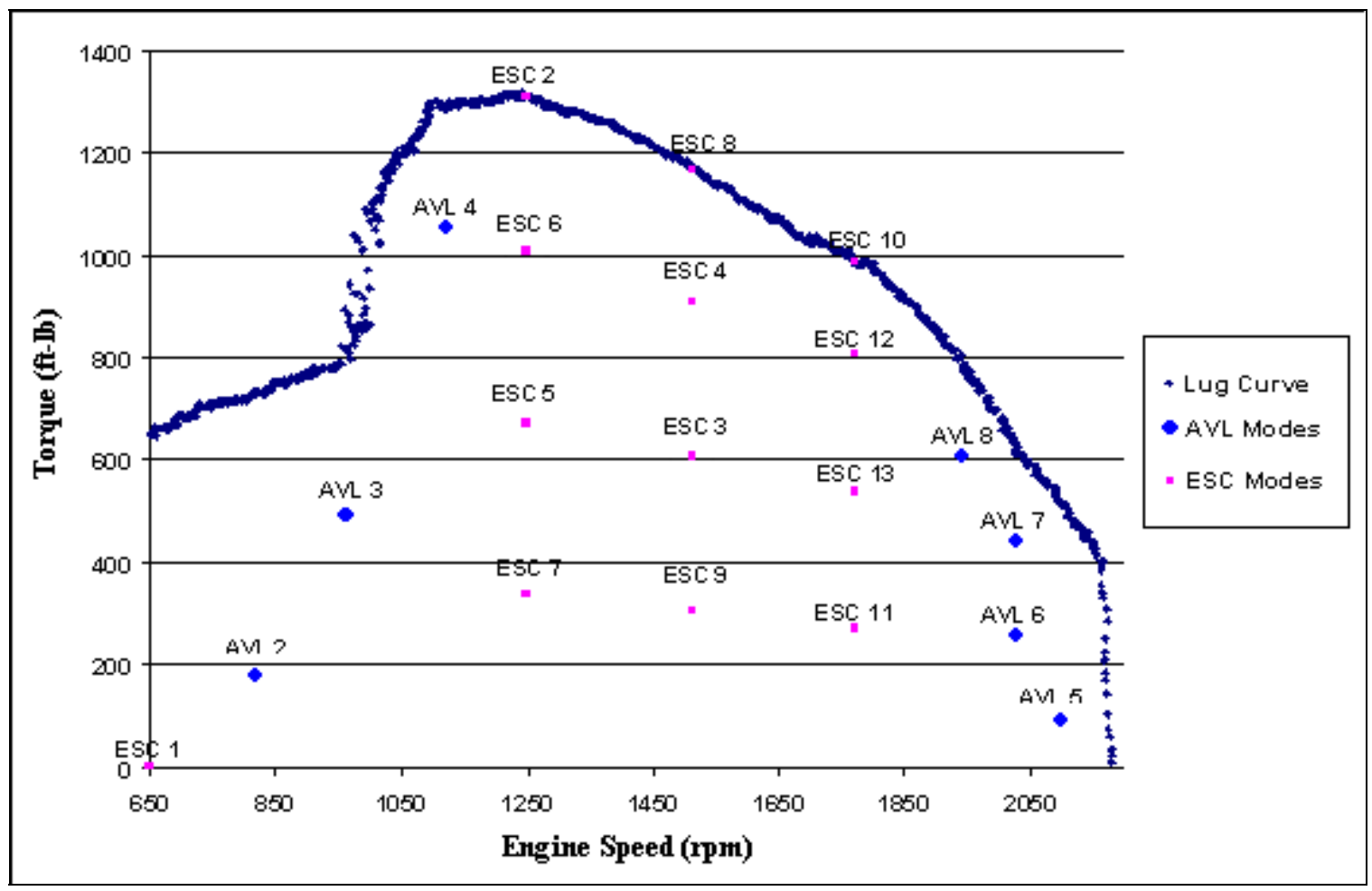

Figure 34 - ESC and AVL Modes Used for Optimization of Urea Injection [21]

The AVL 8-mode cycle is comprised of 8 steady state modes, each of them are assigned a specific weight in order to correspond to emissions produced during an FTP. To create an optimized urea map the engine was operated at each mode, and then urea was injected manually at a low level and increased until the best $\mathrm{NO}_{\mathrm{x}}$ reduction was observed without a significant amount of ammonia slip. Ammonia slip was observed as an increase in the $\mathrm{NO}_{\mathrm{x}}$ level of the chemiluminescent analyzer. This is due to the cross-sensitivity of $\mathrm{NO}_{\mathrm{x}}$ analyzers with $\mathrm{NH}_{3}$. The optimized values found were then interpolated to the rest of the map and provided a basis to start testing. Further adjustments were done by making changes in the map according to specific portions of the FTP. In order to reduce the amount of time and number of tests needed to optimize the entire cycle, the test was broken down into its five-minute sections. By focusing on a single section, optimization could be done more efficiently.

An example of this method is the Los Angeles Freeway (LAFY) section, shown in Figure 33. The engine speed ranges from 70 to 90 percent of the maximum and also has large variations in torque. This is a critical section of the FTP because it produces the largest amount of $\mathrm{NO}_{\mathrm{x}}$. By changing parts of the map corresponding to the engine speed and torque of this section, 
greater optimization and reduction of $\mathrm{NO}_{\mathrm{x}}$ was achieved. Table 9 shows the portion of the urea dosage map that was optimized in order to reduce $\mathrm{NO}_{\mathrm{x}}$ during the Los Angeles freeway section.

Table 9 - Example of Optimization of a Specific section of the FTP cycle

\begin{tabular}{|c|c|c|c|c|c|c|c|c|c|c|}
\hline \multirow{2}{*}{$\begin{array}{c}\text { Engine } \\
\text { Speed }\end{array}$} & \multicolumn{9}{|c|}{ Enqine Load (\%) } \\
\hline & 10 & 20 & 30 & 40 & 50 & 60 & 70 & 80 & 90 & 100 \\
\hline 650 & 0 & 0 & 0 & 0 & 0 & 0 & 0 & 0 & 0 & 0 \\
\hline 700 & 0 & 0 & 1 & 1 & 1 & 0 & 0 & 0 & 0 & 0 \\
\hline 800 & 0 & 0 & 0 & 2 & 1 & 2 & 0 & 0 & 0 & 0 \\
\hline 900 & 0 & 0 & 2 & 1 & 2 & 2 & 2 & 0 & 0 & 0 \\
\hline 1000 & 0 & 1 & 1 & 4 & 3 & 3 & 3 & 2 & 0 & 0 \\
\hline 1100 & 0 & 1 & 1 & 4 & 3 & 3 & 3 & 3 & 3 & 0 \\
\hline 1200 & 0 & 0 & 0 & 2 & 2 & 3 & 3 & 3 & 2 & 2 \\
\hline 1300 & 0 & 0 & 0 & 1 & 2 & 3 & 3 & 2 & 3 & 2 \\
\hline 1400 & 0 & 0 & 1 & 2 & 3 & 3 & 3 & 2 & 3 & 2 \\
\hline 1500 & 0 & 1 & 1 & 1 & 2 & 2 & 2 & 3 & 3 & 3 \\
\hline 1600 & 0 & 0 & 1 & 1 & 1 & 2 & 2 & 3 & 3 & 3 \\
\hline 1700 & 0 & 0 & 1 & 1 & 1 & 1 & 2 & 2 & 2 & 2 \\
\hline 1800 & 0 & 0 & 1 & 1 & 1 & 1 & 1 & 1 & 2 & 2 \\
\hline 1900 & 0 & 1 & 1 & 1 & 1 & 1 & 1 & 2 & 1 & 0 \\
\hline 2000 & 0 & 1 & 1 & 1 & 1 & 1 & 1 & 0 & 0 & 0 \\
\hline
\end{tabular}

Table 9 is in terms of urea dosage steps, where a single step is equal to $0.36 \mathrm{~kg} / \mathrm{hr}$. From the figure, it is seen that a specific section of the map can be targeted to reduce large peaks in $\mathrm{NO}_{\mathrm{x}}$. By using this method, high $\mathrm{NO}_{\mathrm{x}}$ conversion was achieved. Although testing the specific portions of the FTP reduced the time and amount of tests needed, it still led to a large number of tests in order to fully optimize the urea dosage. The upside to performing this method was the knowledge gained as to the behavior and limitations that could be expected from the SCR system.

\subsubsection{Average $\mathrm{NO}_{\mathrm{x}}$ Method}

The second method used to create a urea injection map was based on the amount of $\mathrm{NO}_{\mathrm{x}}$ produced by the engine at different engine speeds and load. To do this, $\mathrm{NO}_{\mathrm{x}}$ data from an FTP was averaged based upon ranges of engine speed and load. The $\mathrm{NO}_{\mathrm{x}}$ data from the analyzers have a deskew time of seven seconds when compared with the engine speed and load recorded by the data acquisition system. In order to average the $\mathrm{NO}_{\mathrm{x}}$ based on these parameters, this was corrected within the data. Finally, a map was created that gave the rate of $\mathrm{NO}_{\mathrm{x}}$ production in terms of mass flowrate. An example of this is shown in Table 10. 
Table 10 - Example of Average $\mathrm{NO}_{\mathrm{x}}(\mathrm{g} / \mathrm{s})$ Values for an FTP cycle

\begin{tabular}{|c|c|c|c|c|c|c|c|c|c|c|}
\hline \multirow{2}{*}{$\begin{array}{c}\text { Engine } \\
\text { Speed }\end{array}$} & \multicolumn{9}{|c|}{ Enqine Load (\%) } \\
\hline & 10 & 20 & 30 & 40 & 50 & 60 & 70 & 80 & 90 & 100 \\
\hline 650 & 0 & 0 & 0 & 0 & 0 & 0 & 0 & 0 & 0 & 0 \\
\hline 700 & 0.01 & 0.02 & 0.07 & 0.06 & 0.08 & 0 & 0 & 0 & 0 & 0 \\
\hline 800 & 0.02 & 0.02 & 0.01 & 0.16 & 0.09 & 0.17 & 0 & 0 & 0 & 0 \\
\hline 900 & 0.02 & 0.02 & 0.15 & 0.13 & 0.14 & 0.20 & 0.22 & 0 & 0 & 0 \\
\hline 1000 & 0.03 & 0.06 & 0.10 & 0.37 & 0.28 & 0.28 & 0.23 & 0.23 & 0 & 0 \\
\hline 1100 & 0.02 & 0.03 & 0.11 & 0.41 & 0.29 & 0.27 & 0.27 & 0.24 & 0.23 & 0 \\
\hline 1200 & 0.01 & 0.01 & 0.01 & 0.17 & 0.20 & 0.24 & 0.25 & 0.23 & 0.19 & 0.20 \\
\hline 1300 & 0.01 & 0.01 & 0.02 & 0.05 & 0.14 & 0.24 & 0.26 & 0.21 & 0.26 & 0.18 \\
\hline 1400 & 0.02 & 0.03 & 0.04 & 0.15 & 0.25 & 0.32 & 0.25 & 0.21 & 0.25 & 0.22 \\
\hline 1500 & 0.02 & 0.03 & 0.06 & 0.12 & 0.16 & 0.20 & 0.17 & 0.24 & 0.23 & 0.25 \\
\hline 1600 & 0.01 & 0.01 & 0.07 & 0.10 & 0.13 & 0.21 & 0.22 & 0.23 & 0.25 & 0.25 \\
\hline 1700 & 0.01 & 0.02 & 0.06 & 0.09 & 0.09 & 0.10 & 0.13 & 0.15 & 0.15 & 0.23 \\
\hline 1800 & 0.01 & 0.02 & 0.05 & 0.07 & 0.08 & 0.09 & 0.11 & 0.13 & 0.14 & 0.17 \\
\hline 1900 & 0.02 & 0.03 & 0.05 & 0.07 & 0.07 & 0.10 & 0.10 & 0.13 & 0.13 & 0 \\
\hline 2000 & 0.01 & 0.05 & 0.06 & 0.08 & 0.09 & 0.12 & 0.10 & 0 & 0 & 0 \\
\hline
\end{tabular}

The $\mathrm{NO}_{\mathrm{x}}$ values are then converted to moles of $\mathrm{NO}_{\mathrm{x}}$ and matched to $\mathrm{NH}_{3}$ values. For ideal reduction, 1 mole of $\mathrm{NH}_{3}$ should be present for each mole of $\mathrm{NO}_{\mathrm{x}}$ in the exhaust. This comes from the stoichiometric reactions of $\mathrm{NH}_{3}$ and $\mathrm{NO}_{\mathrm{x}}$, which are shown in section 2.5.2.1. After matching these values, the ammonia is converted back into the amount of urea solution that needed to be injected. Due to losses from urea hydrolysis, urea pump injection error, ammonia absorbance, incomplete vaporization of urea and unwanted reactions of ammonia, there is less ammonia available for reduction at the SCR inlet than the amount that was injected. In order to correct this difference, a scaling factor had to be found based upon the ratio between ammonia injected and actual ammonia available for reaction. This was then used to correct the urea dosage to attain 1 mole of $\mathrm{NH}_{3}$ available for each mole of $\mathrm{NO}_{\mathrm{x}}$ produced. A study was done on ammonia adsorption/desorption within the SCR, which allowed for calculation of a scaling factor.

\subsubsection{Ammonia Adsorption/Desorption Study}

A simple study was conducted to provide an estimate of the difference between the set $\mathrm{NH}_{3}$ injection value and actual $\mathrm{NH}_{3}$ available for reaction. This study also estimated the amount of ammonia adsorbed and desorbed by the catalyst during steady state modes. The full study was done on two high load modes, each with a different engine speed. The modes used were 
ESC mode 8 (1258 rpm /100\% Load) and ESC mode 10 (1516 rpm / 100\% Load). The modes were chosen since they produce high amounts of $\mathrm{NO}_{\mathrm{x}}$, which allows for variation in the amount of urea injected to see its effect on the data collected. The procedure for the experiment was as follows: First the engine was brought from idle to the selected mode. The $\mathrm{NO}_{\mathrm{x}}$ value was then allowed to reach its maximum value and stabilize. No urea was injected until the SCR brick had been completely desorbed of any residual ammonia. When the brick was 'empty' and the $\mathrm{NO}_{\mathrm{x}}$ level had stabilized, urea was injected. Enough urea was injected so as to cause ammonia slip. The $\mathrm{NO}_{\mathrm{x}}$ level was reduced to a minimum value, and then eventually began to increase when the brick became full and ammonia began 'slipping' out into the exhaust. The increase in $\mathrm{NO}_{\mathrm{x}}$ level was indicative of ammonia slip due to the cross-sensitivity of the $\mathrm{NO}_{\mathrm{x}}$ analyzer to $\mathrm{NH}_{3}$ in the exhaust. Once the $\mathrm{NO}_{\mathrm{x}}$ level stabilized again, urea injection was stopped and $\mathrm{NO}_{\mathrm{x}}$ returned to its original value. The engine was run for a short period after this to ensure the SCR brick was desorbed of any residual ammonia.

Several factors had to be determined in order to estimate the actual ammonia available at the SCR inlet. These factors included the ammonia used for reduction of $\mathrm{NO}_{\mathrm{x}}$, ammonia slip, ammonia adsorbed and ammonia desorbed. The process by which these values were found is discussed below.

\subsection{Ammonia Used}

The stoichiometric equations for $\mathrm{NO}_{\mathrm{x}}$ reduction through the use of ammonia show that 1 mole of $\mathrm{NH}_{3}$ is needed for each mole of $\mathrm{NO}_{\mathrm{x}}$ that is produced. It stands to reason then, that the number of moles of ammonia used for reduction of $\mathrm{NO}_{\mathrm{x}}$ is equal to the number of moles of $\mathrm{NO}_{\mathrm{x}}$ reduced. This was found by the difference between $\mathrm{NO}_{\mathrm{x}}$-in and $\mathrm{NO}_{\mathrm{x}}$-out of the $\mathrm{SCR}$. The $\mathrm{NO}_{\mathrm{x}}-$ in value is the steady state value of $\mathrm{NO}_{\mathrm{x}}$ produced by the engine. The $\mathrm{NO}_{\mathrm{x}}$-out value is the recorded amount of $\mathrm{NO}_{\mathrm{x}}$ at the SCR outlet.

$$
N H_{3-\text { used }}=N O_{x-\text { in }}-N O_{x-o u t}
$$

Eq. 4.1

\subsection{Ammonia Slip}

$\mathrm{NH}_{3}$ slip was measured with the NDUV analyzer but due to problems with the analyzer such as strong $\mathrm{NO}_{\mathrm{x}}$ interference and slow response time, this value was deemed unreliable at low levels of $\mathrm{NH}_{3}$ slip. Figure 35 shows that the $\mathrm{NH}_{3}$ value was strongly affected by the $\mathrm{NO}_{\mathrm{x}}$ level. 


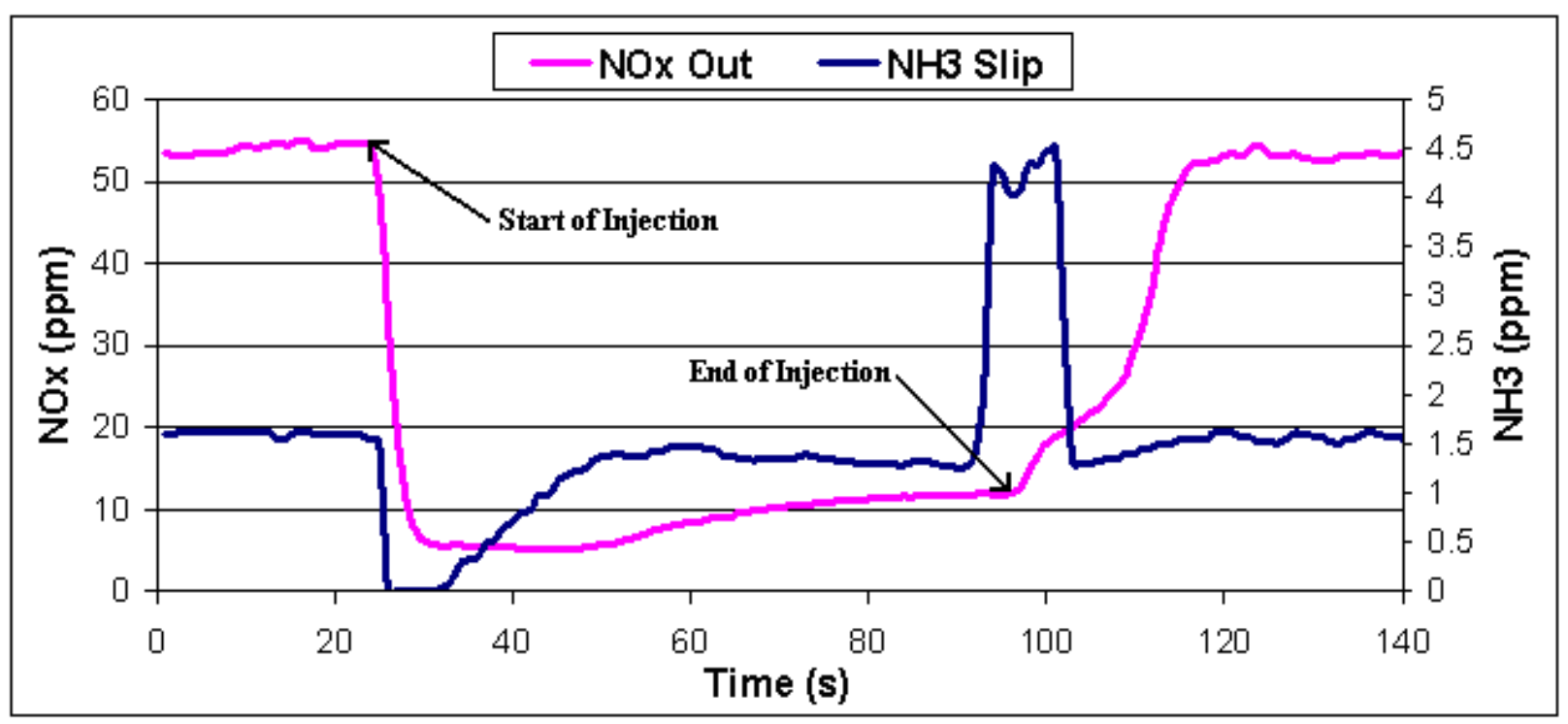

Figure $35-\mathrm{NH}_{3}$ Slip (NDUV analyzer)

The $\mathrm{NH}_{3}$ level shows a response to the $\mathrm{NO}_{\mathrm{x}}$ levels in the exhaust gases and does not correspond with the beginning and end of urea injection as expected. The $\mathrm{NH}_{3}$ reading initially drops as the $\mathrm{NO}_{\mathrm{x}}$ level decreases, but then returns to its original level although the $\mathrm{NO}_{\mathrm{x}}$ does not. Just as the $\mathrm{NO}_{\mathrm{x}}$ level increases to its original value, there is a corresponding spike in the $\mathrm{NH}_{3}$ level. The $\mathrm{NH}_{3}$ level then returns and stabilizes at its initial value. The $\mathrm{NH}_{3}$ analyzer shows a cross-sensitivity with $\mathrm{NO}_{\mathrm{x}}$ which gives a false reading of the $\mathrm{NH}_{3}$ slip in the exhaust. Due to this, the $\mathrm{NH}_{3}$ analyzer data was deemed unreliable and was estimated by other means. The ammonia slip was found to vary in sympathy with $\mathrm{NO}_{\mathrm{x}}$ values. Hence, $\mathrm{NH}_{3}$ was estimated to be proportional to the $\mathrm{NO}_{\mathrm{x}}$ out variation, which was the difference between the $\mathrm{NO}_{\mathrm{x}}$ levels during urea injection, and the minimum $\mathrm{NO}_{\mathrm{x}}$ level achieved. This is shown in Equation 4.2.

$$
N H_{3-\text { slip }}=N O_{x-\text { out }}-N O_{x-\min }
$$

Eq. 4.2

This value was not the actual ammonia slip value but was assumed to have the same trend, and was therefore scaled to get an estimated value. In Figure 36, it can be seen that the $\mathrm{NO}_{\mathrm{x}}$ level was reduced to a minimum value and then increased slowly after approximately 20 seconds. The time when $\mathrm{NO}_{\mathrm{x}}$ began to increase was determined to be the start of ammonia slip. 


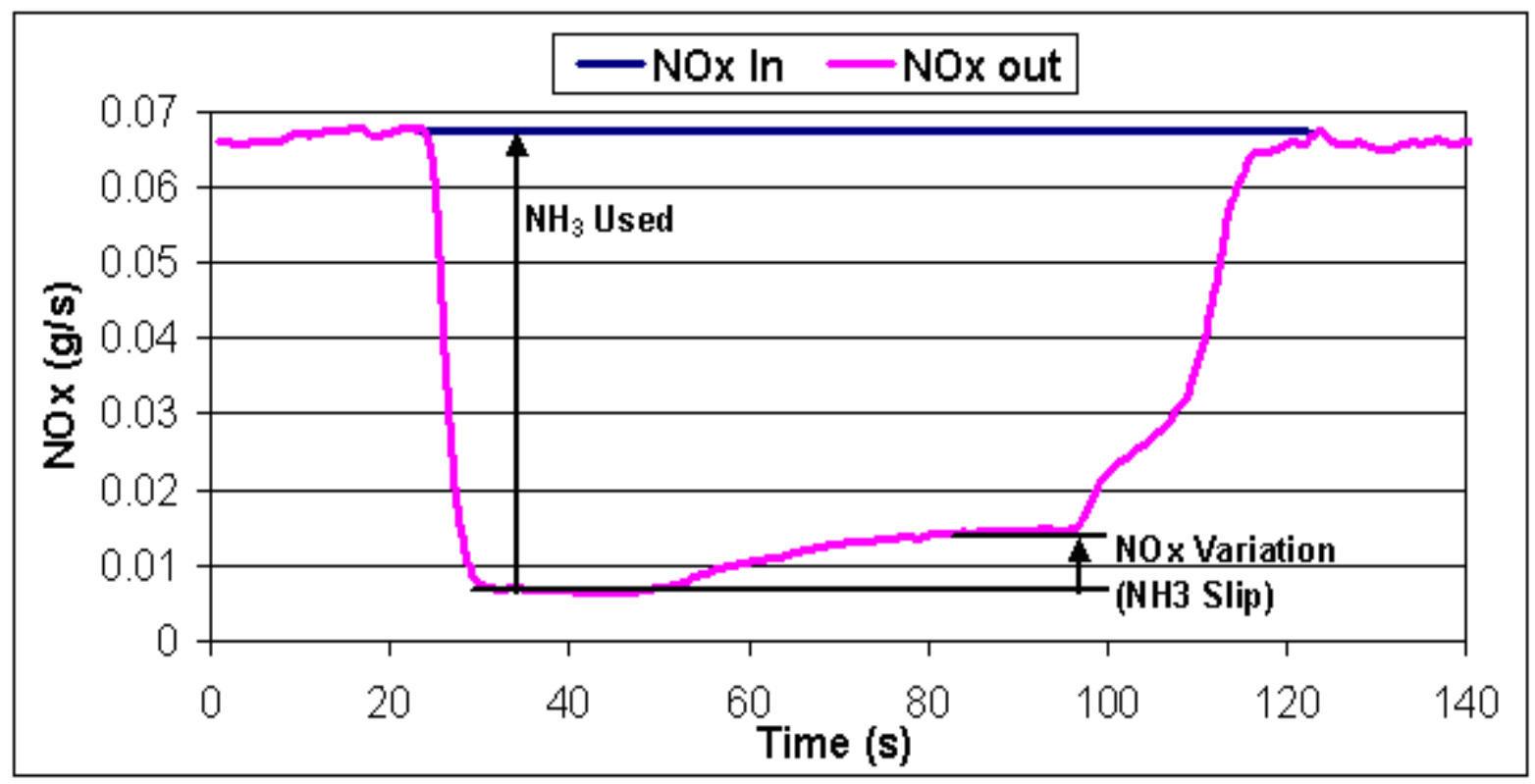

Figure 36 - Estimation of $\mathrm{NH}_{3}$ Slip

\subsection{Ammonia Injection Values}

Taking the set urea injection value and converting it to ammonia yielded the set or nominal ammonia injection value. This was done knowing that the solution was $32.5 \%$ urea by weight. Also, by stoichiometry it was seen that 1 mole of urea produced 2 moles of ammonia. Using the molecular weights of $60 \mathrm{~g} / \mathrm{mol}$ urea and $17 \mathrm{~g} / \mathrm{mol} \mathrm{NH}_{3}$, it is calculated that 1.76 grams of urea produces 1 gram of ammonia. This value was not equal to the ammonia available for reaction since there were losses due to a few different factors. The actual ammonia available was estimated by adding the maximum value of slip to the ammonia used. When the $\mathrm{NH}_{3}$ slip was at its maximum, the catalyst was no longer adsorbing any ammonia, so it was assumed that the total ammonia in the system was equal to the $\mathrm{NH}_{3}$ slip added to the $\mathrm{NH}_{3}$ utilized for reduction of $\mathrm{NO}_{\mathrm{x}}$. Once again, this value is lower than the set ammonia injection value due to losses, which can be attributed to hydrolysis and other factors, as discussed below.

$$
N H_{3-\text { Avail. }}=N H_{3-\text { used }}+N H_{3-\max \text { slip }}
$$

\subsection{Ammonia Loss}

Factors that can be attributed to ammonia loss include hydrolysis conversion efficiency, urea pump injection error, undesirable SCR reactions, and incomplete vaporization. Urea 
solution that does not fully vaporize may condense prior to the SCR and would not contribute to $\mathrm{NO}_{\mathrm{x}}$ conversion or $\mathrm{NH}_{3}$ adsorption within the catalyst. Hydrolysis is part of the decomposition of urea. When urea is decomposed it forms 1 mole of $\mathrm{NH}_{3}$ and 1 mole of isocyanic acid (HNCO). HNCO must then be hydrolyzed to produce another mole of $\mathrm{NH}_{3}$. This means that the hydrolysis of $\mathrm{HNCO}$ accounts for $50 \%$ of the $\mathrm{NH}_{3}$ produced from a mole of urea. A large percentage of this hydrolysis occurs directly on the catalyst surface. This conversion is never $100 \%$ efficient and incomplete hydrolysis results in a loss of ammonia available for reaction [25]. Undesirable reactions can also occur within the SCR system, which produce nitrous oxide. $\mathrm{N}_{2} \mathrm{O}$ can be formed by a reaction between $\mathrm{NH}_{3}$ and $\mathrm{NO}$ or $\mathrm{NO}_{2}$. $\mathrm{NH}_{3}$ can also react with different amounts of $\mathrm{NO}_{\mathrm{x}}$ to form either nitrogen or nitrous oxide and water. These reactions, which are shown in Section 2.5.2.1, can account for a small percentage loss of ammonia available [25]. Another factor that can account for less ammonia available than injected is pump injection error. Volvo initially calibrated the urea pump used in this study. The results of this calibration are shown in Figure 37 [26].

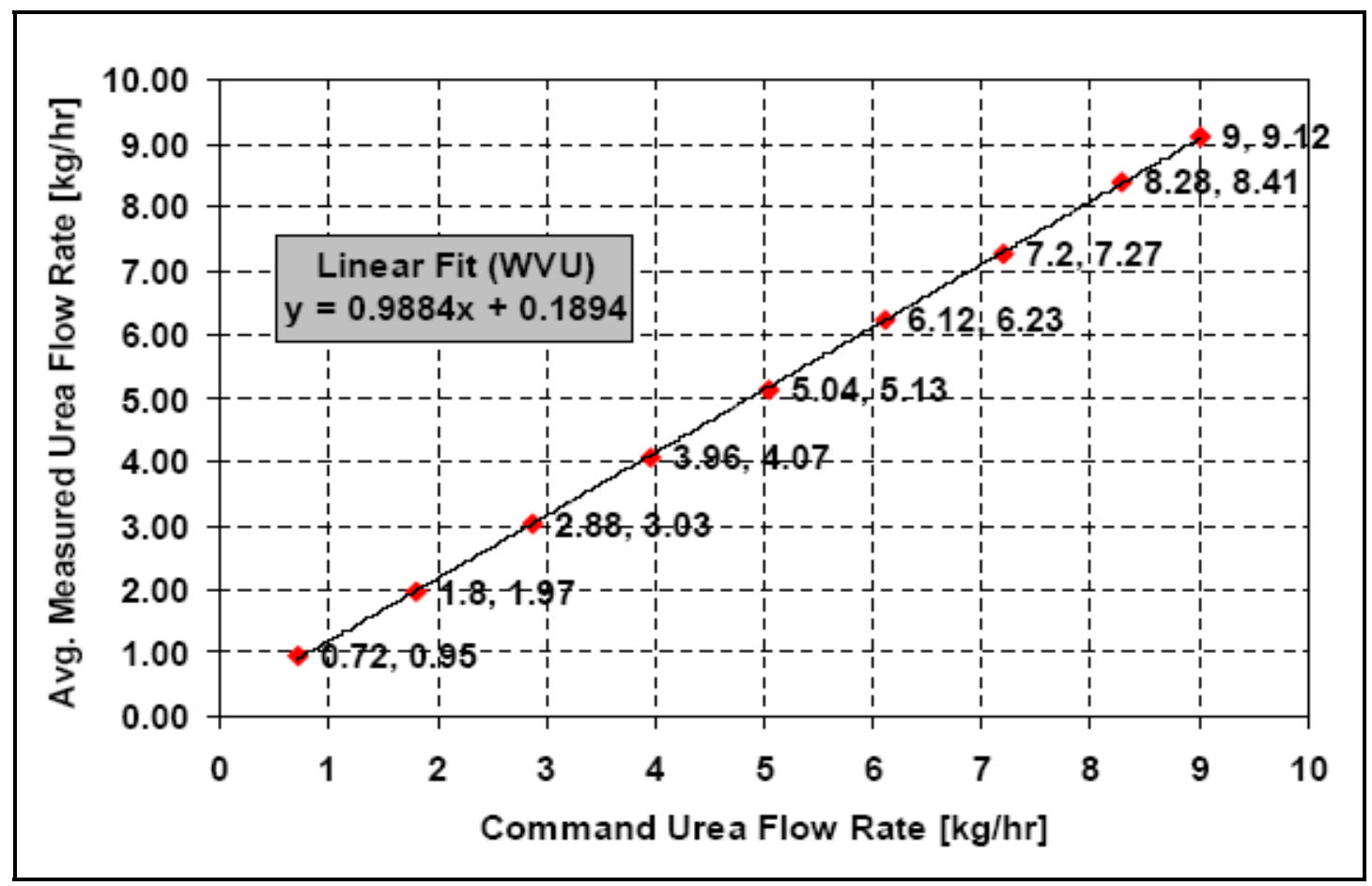

Figure 37 - Urea Pump Calibration (Volvo) [26]

Figure 37 shows that the pump had an acceptable linear fit. It is also seen that there was greater error at lower injection values. Table 11 shows the error associated with each point in Figure 37. 
Table 11 - Urea Pump Injection Error

\begin{tabular}{|c|c|c|c|}
\hline Test \# & $\begin{array}{c}\text { Set Urea } \\
\text { Injection } \\
\mathbf{~ k g} / \mathbf{h r}\end{array}$ & $\begin{array}{c}\text { Measured Urea } \\
\text { Injection } \\
\mathbf{k g} / \mathbf{h r}\end{array}$ & \begin{tabular}{c} 
Error \\
\hline
\end{tabular} \\
\hline $\mathbf{1}$ & 0.72 & 0.95 & $32 \%$ \\
\hline 2 & 1.80 & 1.97 & $9 \%$ \\
\hline 3 & 2.88 & 3.03 & $5 \%$ \\
\hline 4 & 3.96 & 4.07 & $3 \%$ \\
\hline 5 & 5.04 & 5.13 & $2 \%$ \\
\hline 6 & 6.12 & 6.23 & $2 \%$ \\
\hline 7 & 7.20 & 7.27 & $1 \%$ \\
\hline 8 & 8.28 & 8.41 & $2 \%$ \\
\hline 9 & 9.00 & 9.12 & $1 \%$ \\
\hline & & Average Error $=$ & $\mathbf{6 . 3} \%$ \\
\hline
\end{tabular}

Overall, there was tolerable average error of $6.3 \%$. The largest error occurs at very low injection values and significantly decreases at higher injection values. At the set value of $0.72 \mathrm{~kg} / \mathrm{hr}$ urea injection rate the error was $32 \%$. The FTP cycle does not produce large amounts of $\mathrm{NO}_{\mathrm{x}}$; therefore, it requires low urea injection values. Also, the engine calibration used for this study was a low $\mathrm{NO}_{\mathrm{x}}$ calibration, and a large error at very low injection values may inhibit the efficiency of the entire system. For this reason, the pump injection was calibrated for low values of urea using a step of $0.36 \mathrm{~kg} / \mathrm{hr}$. The urea pump was calibrated by injecting into a graduated cylinder for a set amount of time. The weight of urea injected over the time gave the actual rate of injection. This was repeated three times at each point. Table 12 shows the results of the urea pump error calculations.

Table 12 - Urea Pump Error Calculation

\begin{tabular}{|c|c|c|c|}
\hline Test $H$ & $\begin{array}{c}\text { Set Ure a } \\
\text { Injection }\end{array}$ & $\begin{array}{c}\text { Mleasured Urea } \\
\text { Injection }\end{array}$ & Error \\
\hline & $\mathbf{k g} / \mathbf{h r}$ & $\mathbf{k g} / \mathbf{h r}$ & $\%$ \\
\hline 1 & 0.36 & 0.46 & $27 \%$ \\
\hline 2 & 0.72 & 0.85 & $18 \%$ \\
\hline 3 & 1.08 & 1.18 & $9 \%$ \\
\hline 4 & 1.44 & 1.57 & $9 \%$ \\
\hline 5 & 1.80 & 1.96 & $9 \%$ \\
\hline 6 & 2.16 & 2.29 & $6 \%$ \\
\hline 7 & 2.52 & 2.68 & $6 \%$ \\
\hline & & Average Error $=$ & $\mathbf{1 2 . 1 \%}$ \\
\hline
\end{tabular}


Table 12 shows that there is still a large error at urea injection rates of $0.72 \mathrm{~kg} / \mathrm{hr}$ or lower. Higher error percentages at low injection values may be attributed to inaccuracies of the graduated cyclinder method of calibration. Overall, there was an average error of $12.1 \%$. Figure 38 shows a plot of the actual urea injected versus the set urea injection rate.

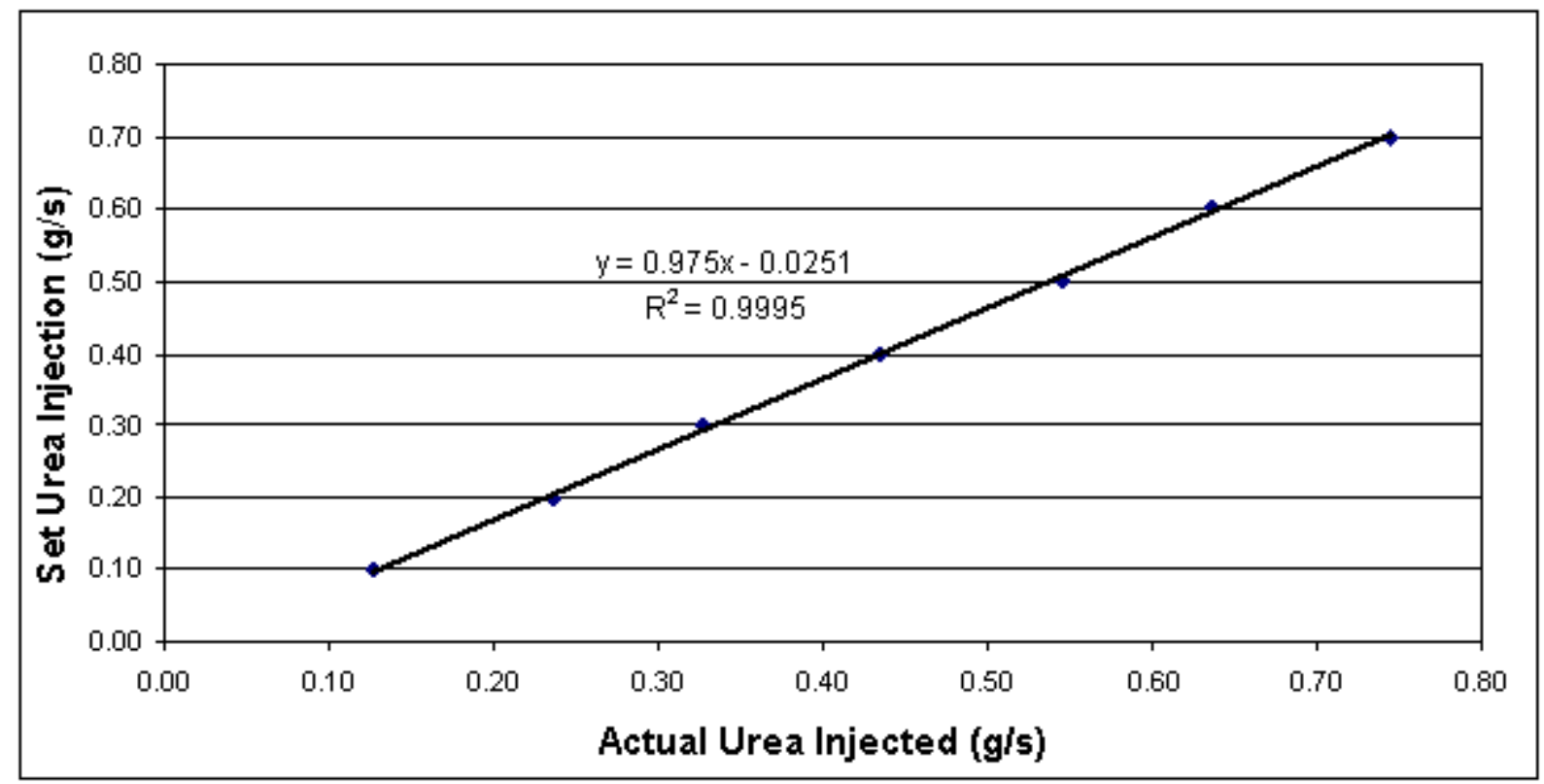

Figure 38 - Urea Pump Calibration Curve

In the FTP cycle, $0.36 \mathrm{~kg} / \mathrm{hr}$ and $0.72 \mathrm{~kg} / \mathrm{hr}$ was the most common injection rate. These were the injection points with the highest error percentage. This contributed to the differences between the amount of ammonia available and the set injection value.

\subsection{Ammonia Desorption}

The amount of ammonia desorbed from the catalyst is equal to the amount of ammonia used during the desaturation time period. The desaturation time is the time from the end of urea injection until $\mathrm{NO}_{\mathrm{x}}$ returns to it original value. Since no urea was being injected during this period, the $\mathrm{NO}_{\mathrm{x}}$ reduction was provided solely by ammonia available from the catalyst. The ammonia can only become available by desorption from the catalyst. Therefore, the ammonia desorbed was equal to the ammonia used during the desaturation time. The desaturation time is shown in Figure 39. 


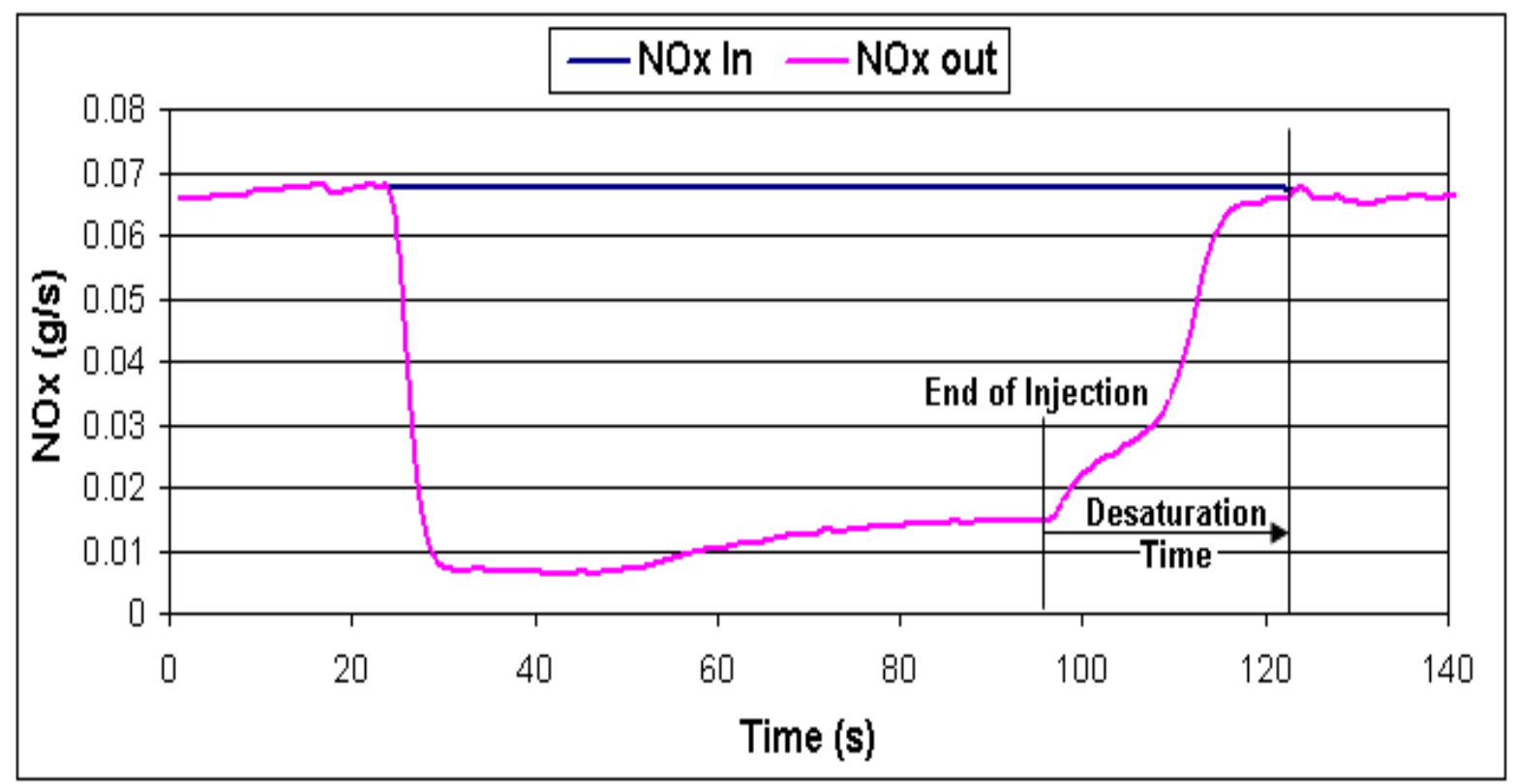

Figure 39 - Desaturation Time

The desorption rate of the catalyst can be found by dividing the total $\mathrm{NH}_{3}$ desorbed by the desaturation time. This rate was used to find a scaling factor that was then used to estimate the ammonia slip and ammonia adsorbed by the catalyst.

$$
\text { Desorption_Rate }=\mathrm{NH}_{3-\text { desorb }} / t_{\text {desat. }} \quad \text { Eq. } 4.4
$$

\subsection{Ammonia Adsorption}

Several factors were assumed to account for all the ammonia available for reaction within the SCR system. These factors included the ammonia used, the ammonia slip and the ammonia adsorbed by the catalyst. If its assumed that the total amount of ammonia in the system is equal to the amount of ammonia available, which was previously found, the ammonia adsorbed by the catalyst can be found. Subtracting the ammonia used and ammonia slip from the ammonia available gives the ammonia adsorbed. This is shown in the equation below.

$$
\mathrm{NH}_{3-\text { adsorb }}=\mathrm{NH}_{3-\text { Avail. }}-\left(\mathrm{NH}_{3-\text { used }}+\mathrm{NH}_{3-\text { slip }}\right) \quad \text { Eq. } 4.5
$$

Next, the saturation time was found by considering it to be the time it takes from start of injection to when the ammonia slip stabilizes. The total $\mathrm{NH}_{3}$ adsorbed was then divided by the saturation time to get a rate of adsorption. This was the initial adsorption rate and had to be 
recalculated after a scaling factor was found. Equation 4.6 shows the calculation of the adsorption rate and Figure 40 shows the saturation time.

$$
\text { Adsorption_Rate }=\mathrm{NH}_{3-\text { adsorb }} / t_{\text {sat. }} \quad \text { Eq. } 4.6
$$

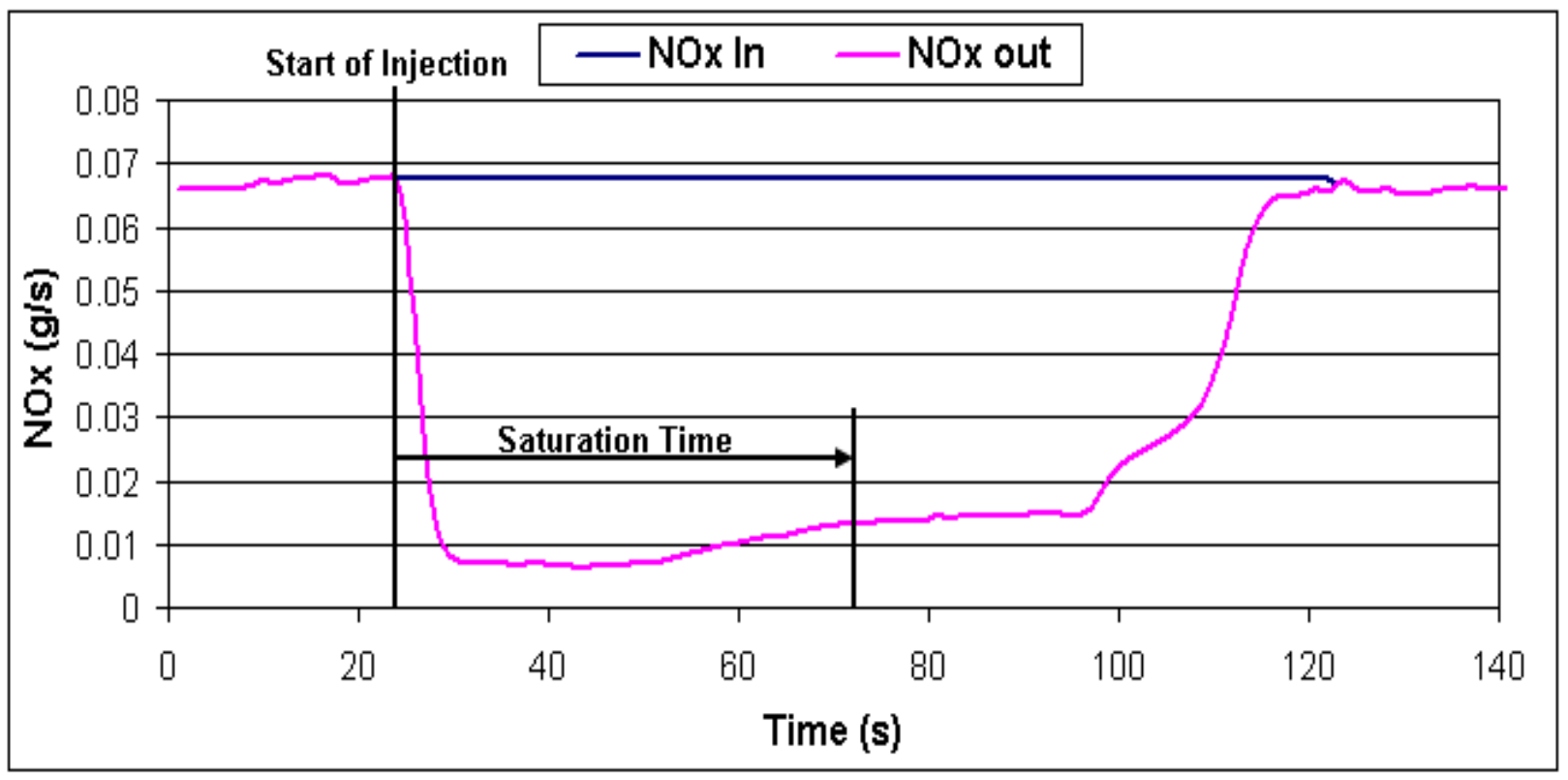

Figure 40 - Saturation Time

The values found for the ammonia slip and ammonia adsorbed must be scaled in order to account for all the ammonia desorbed by the catalyst. This can be done by assuming the total amount of ammonia adsorbed is equal to the total amount of ammonia desorbed by the catalyst. With this assumption, a new ammonia adsorption rate can be calculated based upon the saturation time and the new value for the ammonia adsorbed. Dividing the new adsorption rate by the previous adsorption rate produced a factor that can be used to scale the ammonia slip. This gave a new maximum value of ammonia slip, which was then used to recalculate the ammonia adsorbed. Now with these values, the actual amount of ammonia available was recalculated to get the final result. The difference between the nominal ammonia injection and the actual ammonia available was used as an estimation of the losses in the system. The ratio between these values was then used as a scaling factor for the urea map based on average $\mathrm{NO}_{\mathrm{x}}$ values. 


\subsubsection{Fuzzy Logic Method}

After reviewing the different types of Artificial Intelligence (A.I.) techniques, it was decided that fuzzy logic best suited the application. GAs require too much computational time and ANNs may be too complex for the modeling of an SCR system. Fuzzy logic is ideal to model the SCR for several reasons. The main reason is that the reactions within an SCR are very complicated and hard to model. Fuzzy logic allows for a simple model of the system based on human experience rather than strict mathematical relationships. It is also a very robust type of modeling that can deal with large variations of the input data. This is essential because of the large changes in $\mathrm{NO}_{2} / \mathrm{NO}$ ratio during transient operation of an engine. When used in conjunction with an open loop control strategy, fuzzy logic allows for a simple but effective method to control urea dosage. Another advantage is that it can easily be adapted to a more complex control strategy in the future.

The fuzzy logic program consists of two main parts. The first part is an SCR efficiency model based on the SCR inlet temperature and $\mathrm{NO}_{2} / \mathrm{NO}$ ratio. The second part is a $\mathrm{NO}_{\mathrm{x}}$ prediction model based on engine speed and load. Together these will output a point-by-point value for urea injection of an FTP. These values were then averaged over the entire cycle based on engine speed and load. This produced the final urea injection map used to control the dosage. A block diagram of this open loop control strategy is shown in Figure 41.

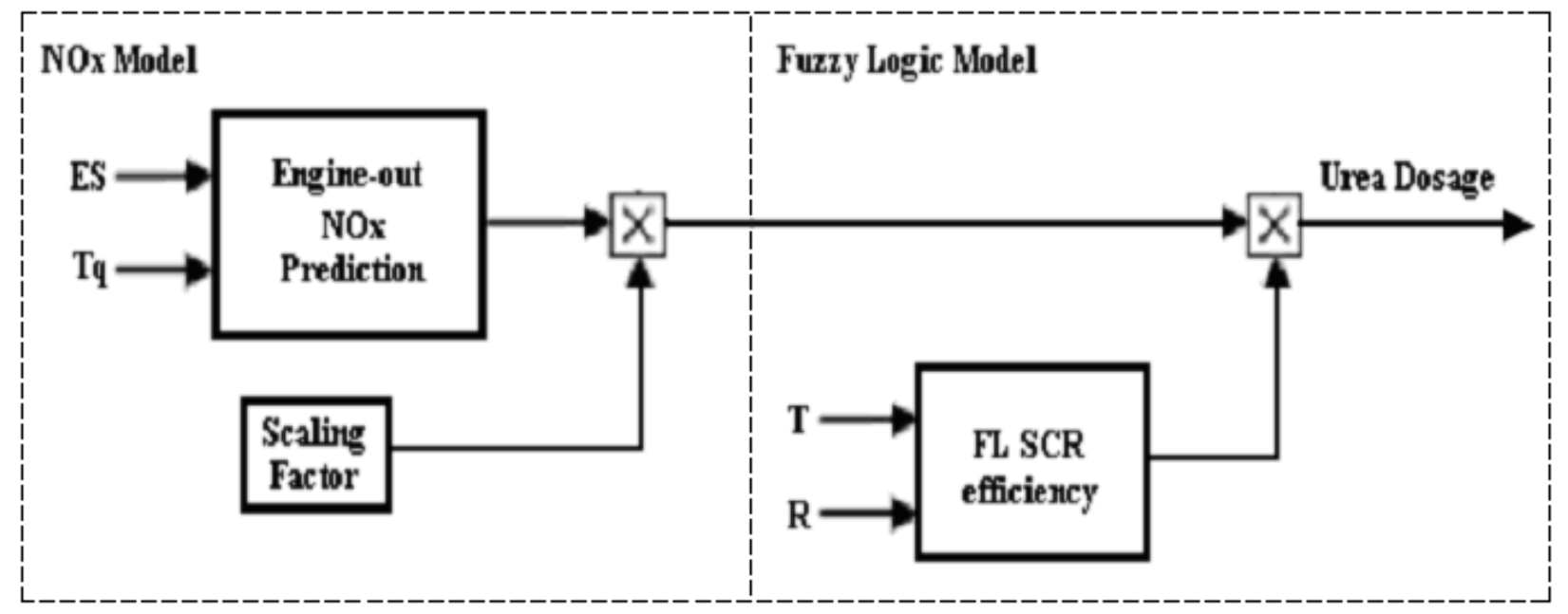

Figure 41 - Open Loop Control Strategy for Urea Dosage 


\subsubsection{SCR Efficiency}

In certain conditions, an SCR system is able to convert $\mathrm{NO}_{\mathrm{x}}$ much more effectively. The predicted SCR efficiency yielded a factor that allowed more urea injection when ideal conditions were present. If the condition of the SCR was less than ideal for $\mathrm{NO}_{\mathrm{x}}$ conversion, the predicted efficiency limited the amount of urea that was injected. Temperature and $\mathrm{NO}_{2} / \mathrm{NO}$ ratio are factors that are very representative of the condition of the SCR system. For this reason, they were chosen as the factors used in the fuzzy logic model of the SCR. In order to implement fuzzy logic, membership functions (MF) for temperature, $\mathrm{NO}_{2} / \mathrm{NO}$ ratio and SCR efficiency must first be created.

\section{Membership Functions}

It was decided to use trapezoidal membership functions. Trapezoidal MFs are very common and can be implemented with minimal complications. The linguistic variables are temperature, $\mathrm{NO}_{2} / \mathrm{NO}$ ratio and $\mathrm{SCR}$ efficiency. The linguistic values chosen for temperature and $\mathrm{NO}_{2} / \mathrm{NO}$ ratio are low, medium and high. For SCR efficiency, the linguistic values are very low, low, medium and high. Temperature and $\mathrm{NO}_{2} / \mathrm{NO}$ ratio MFs are used to fuzzify the inputs and the SCR efficiency MF is used to calculate the output. In order to create the input membership functions the following figure, provided by Johnson and Matthey, was used.

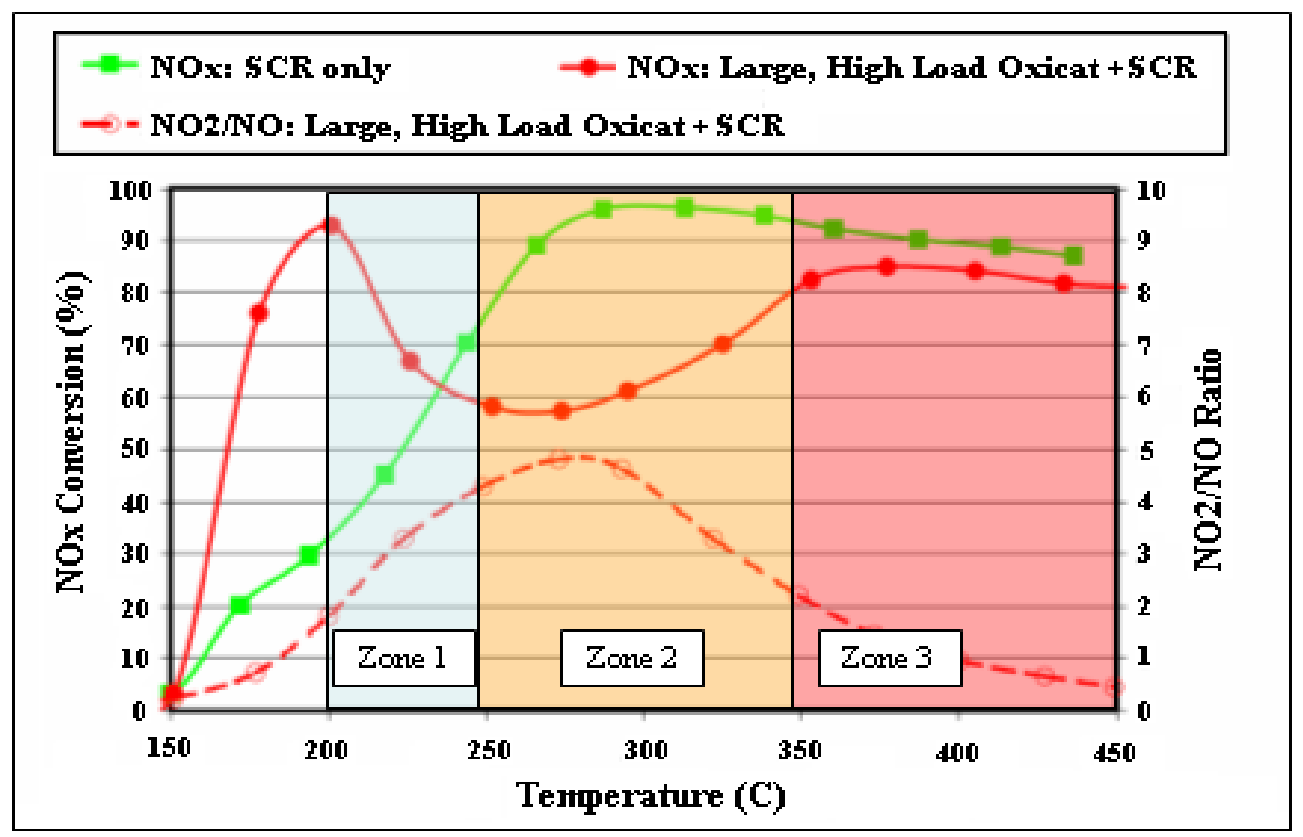

Figure 42 - Johnson \& Matthey SCR Model [22] 
In Figure 42, it is seen that there are several temperature zones that will have an effect on the efficiency of the SCR. Typically, higher temperatures will increase the efficiency of the $\mathrm{SCR}$. The temperature also has an effect on the $\mathrm{NO}_{2} / \mathrm{NO}$ ratio, which will determine the type of reaction occurring within the SCR. An $\mathrm{NO}_{2} / \mathrm{NO}$ ratio near one will result in 'fast SCR' which allows for reaction of $\mathrm{NO}$ and $\mathrm{NO}_{2}$ simultaneously. A low $\mathrm{NO}_{2} / \mathrm{NO}$ ratio will result in the 'standard SCR' reaction, which is between $\mathrm{NO}$ and $\mathrm{NH}_{3}$. High $\mathrm{NO}_{2} / \mathrm{NO}$ ratios result in the reaction of $\mathrm{NO}_{2}$ and $\mathrm{NH}_{3}$, which is termed 'slow SCR'. These reactions are given in section 2.5.2.1. Different combinations of temperature and $\mathrm{NO}_{2} / \mathrm{NO}$ ratio will result in better performance of the SCR. The input membership functions were designed to take this into account. Shown in Figure 43 is the temperature membership function, which has three parts, each representing a temperature zone from Figure 42. Figure 44 shows the $\mathrm{NO}_{2} / \mathrm{NO}$ ratio membership function, which represents 'standard', 'fast' and 'slow' SCR reactions.

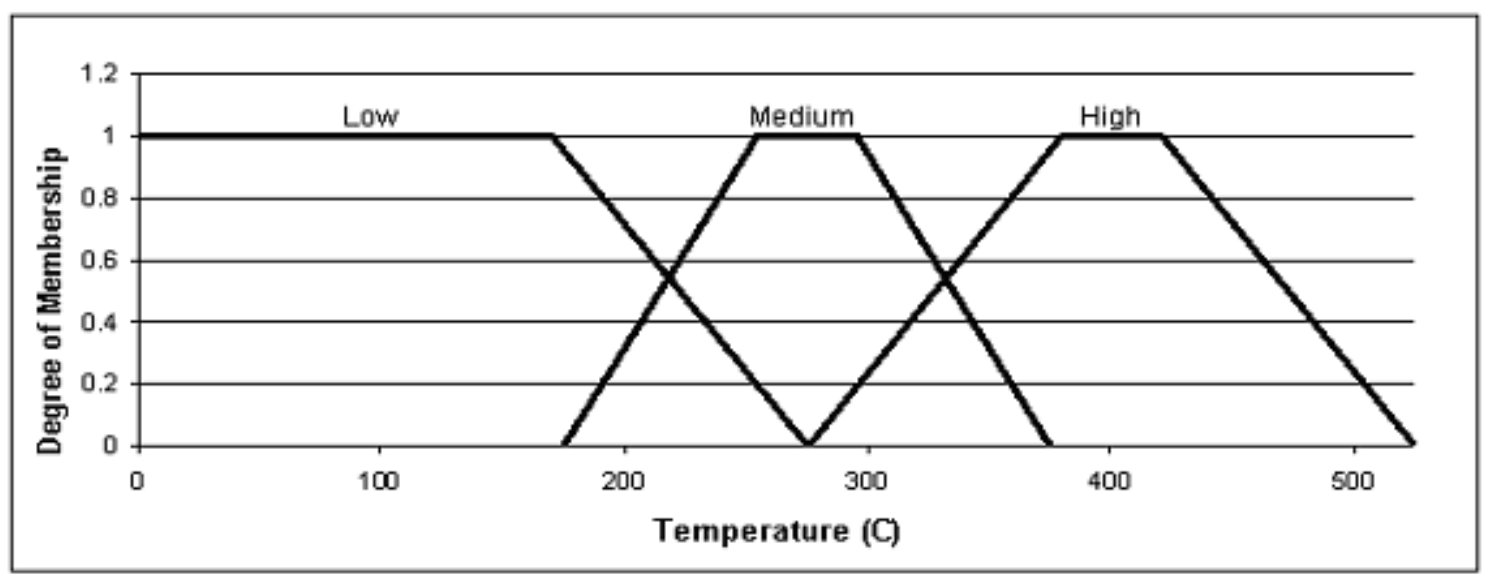

Figure 43 - Temperature Membership Function

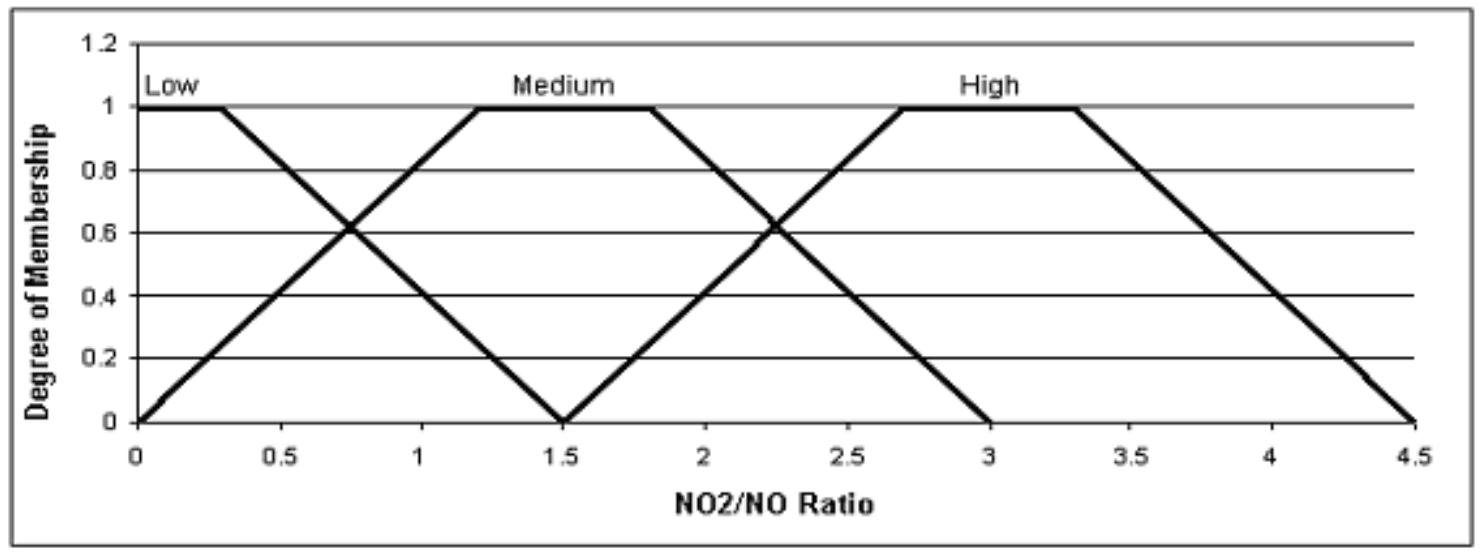

Figure $44-\mathrm{NO}_{2} / \mathrm{NO}$ Ratio Membership Function 
Each crisp input value for temperature and $\mathrm{NO}_{2} / \mathrm{NO}$ ratio will be fuzzified to form a fuzzy set consisting of three values each. Each value in the fuzzy set is a degree of membership for one of the linguistic values. These values are then combined into a $3 \times 3$ matrix using the multiplicative method of the intersection of fuzzy sets. The matrix formed by the intersection of fuzzy sets is shown in Table 13.

Table 13 - Structure of Fuzzified Input

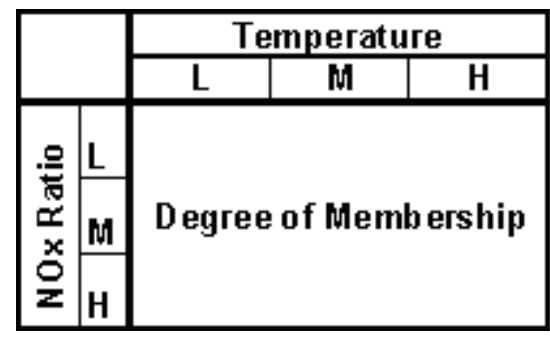

\section{Inference Rule Matrix}

In order to compute the fuzzy output command, the fuzzy input matrix must be overlaid with the inference rule matrix. The inference rule matrix determines the degree to which the input value belongs to each linguistic value of the output, which is the SCR efficiency. The membership function for SCR efficiency is shown in Figure 45.

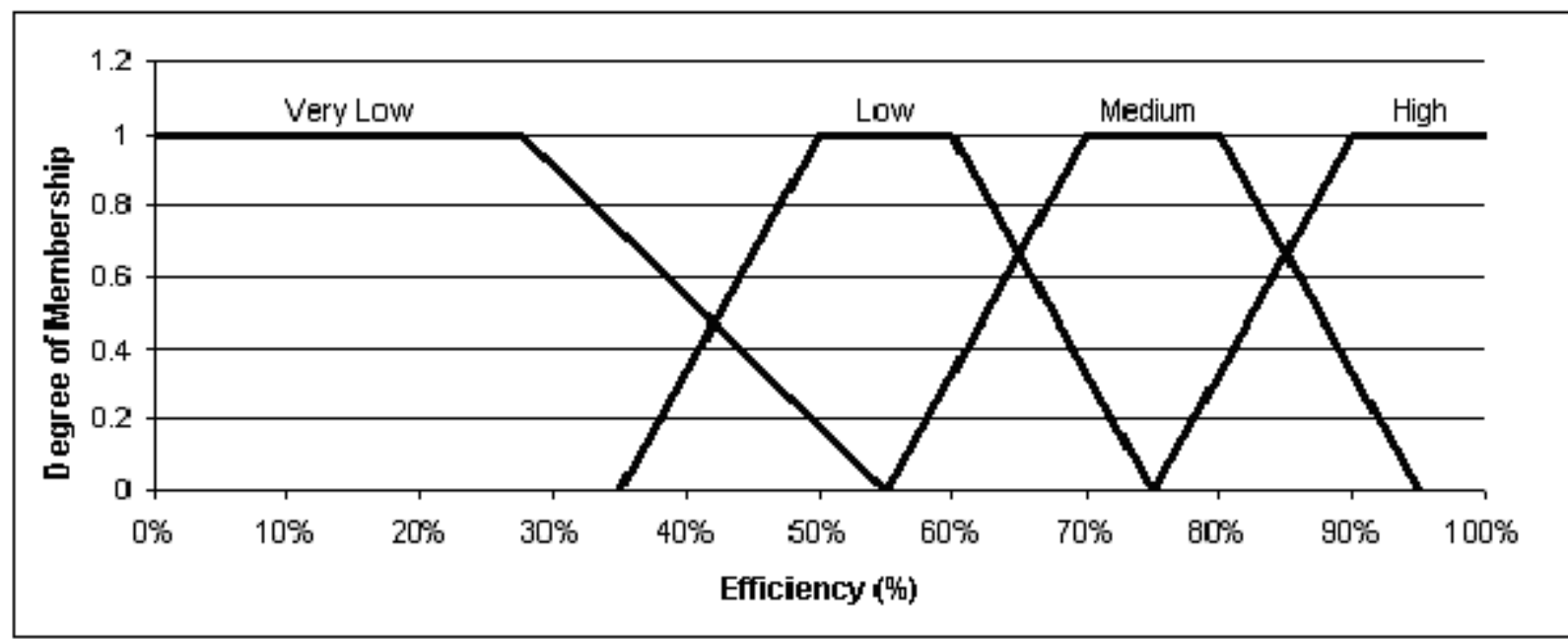

Figure 45 - Efficiency Membership Function 
The inference rule matrix was determined based on the expected efficiency of the SCR with different combinations of temperature and $\mathrm{NO}_{2} / \mathrm{NO}$ ratio. Table 14 shows the inference rules that were chosen.

Table 14 - Inference Rule Matrix

\begin{tabular}{|c|c|c|c|c|}
\hline & \multicolumn{3}{|c|}{ Temperature } \\
\hline & & $\bar{L}$ & $\bar{M}$ & $\bar{H}$ \\
\hline \multirow{3}{*}{\multicolumn{2}{|c|}{ 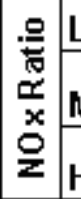 }} & v & M & M \\
\hline & & $\mathbf{L}$ & $\mathbf{H}$ & $\mathbf{H}$ \\
\hline & & L & $\mathbf{M}$ & M \\
\hline
\end{tabular}

From the inference rule matrix, it is seen that medium and high temperatures along with a $\mathrm{NO}_{2} / \mathrm{NO}$ ratio near unity will result in the highest efficiency possible for the SCR. The lowest efficiency is at low temperatures and low $\mathrm{NO}_{2} / \mathrm{NO}$ ratio. At low temperatures, $\mathrm{NO}_{2}$ reacts much more readily than NO. The dominant reaction occurring at low temperature is 'slow SCR,' which accounts for the very low efficiency at low temperatures.

\section{Defuzzification}

The overlaid inference rules and fuzzy input matrix result in the fuzzy output command, which can be defuzzified through various methods. The center-of-sums defuzzification method along with scaled fuzzy sets was chosen to defuzzify the output command. Definitions for center of sums defuzzification and scaled fuzzy sets are shown in section 2.7.3. The defuzzification of the fuzzy output command results in a single crisp output for each input of temperature and $\mathrm{NO}_{2} / \mathrm{NO}$ ratio.

\subsubsection{2 $\mathrm{NO}_{\mathrm{x}}$ Prediction and Urea Dosage}

A simple $\mathrm{NO}_{\mathrm{x}}$ prediction model can be created using the average $\mathrm{NO}_{\mathrm{x}}$ method shown previously in section 4.1.2. The $\mathrm{NO}_{\mathrm{x}}$ produced during an engine cycle was averaged down according to ranges of engine speed and load. This gave a table or 'map' of the rate of $\mathrm{NO}_{\mathrm{x}}$ production at different engine operating conditions. To calculate the amount of urea to be injected, $\mathrm{NO}_{\mathrm{x}}$ levels were matched to $\mathrm{NH}_{3}$ levels and then converted $\mathrm{NH}_{3}$ to urea. The ammonia was converted to urea using the fact that 1 mole of urea produces 2 moles of ammonia. When this was converted to grams using molecular weights of $60 \mathrm{~g} / \mathrm{mol}$ urea and $17 \mathrm{~g} / \mathrm{mol} \mathrm{NH}_{3}$, it was 
seen that 1.76 grams of urea produces 1 gram of $\mathrm{NH}_{3}$. This value was then corrected using the same scaling factor that was found in the estimation of losses study (section 4.1.2.1). This was done to ensure that the amount of ammonia available was as close to $1: 1$ with $\mathrm{NO}_{\mathrm{x}}$ as possible. Assuming the correct amount of ammonia was available for reaction with $\mathrm{NO}_{\mathrm{x}}$, the injection value was then adjusted according to the condition of the SCR system. The SCR efficiency produced by the fuzzy logic method was multiplied by the urea injection value found by the $\mathrm{NO}_{\mathrm{x}}$ prediction model. This restricts the amount of urea injected and reduces the amount of ammonia slip due to poor conditions of the $\mathrm{SCR}$ for $\mathrm{NO}_{\mathrm{x}}$ conversion. This produced a urea injection value for each point of the engine cycle. In order to produce a urea injection map, these values were then averaged down based on engine speed and load of the engine. The urea map produced was in terms of mass flow rate, and had to be converted to a urea step value that could be implemented by the CANalyzer program. One step was equal to $0.36 \mathrm{~kg} / \mathrm{hr}$ of aqueous urea. 


\section{Results}

Determination of urea dosage during transient operation of the engine was one of the specific objectives of this study. For this reason, each of the methods described in the approach section were applied to the FTP cycle. For comparison, the FTP optimization and fuzzy logic maps were then tested on the ETC. The optimization method was also used on the ESC in order to characterize the SCR system. For FTP and ESC test cycles, the engine calibration used was a low $\mathrm{NO}_{\mathrm{x}}$ calibration that produced approximately $1.0 \mathrm{~g} / \mathrm{bhp}-\mathrm{hr}$ of $\mathrm{NO}_{\mathrm{x}}$ emissions. The same calibration was used on the ETC but it produced $1.16 \mathrm{~g} / \mathrm{bhp}-\mathrm{hr}$ of $\mathrm{NO}_{\mathrm{x}}$. Specifics of this calibration and how it was developed are described elsewhere [21].

\subsection{Optimization Method}

The optimization method was applied by manually injecting urea at a range of engine operation points. The ESC and AVL modes were used for this purpose. The urea solution was injected in steps of $0.36 \mathrm{~kg} / \mathrm{hr}$, as discussed in Chapter 4. After optimizing the ESC and AVL modes, the values found were interpolated to the rest of the urea map. The resulting map is shown in Figure 46.

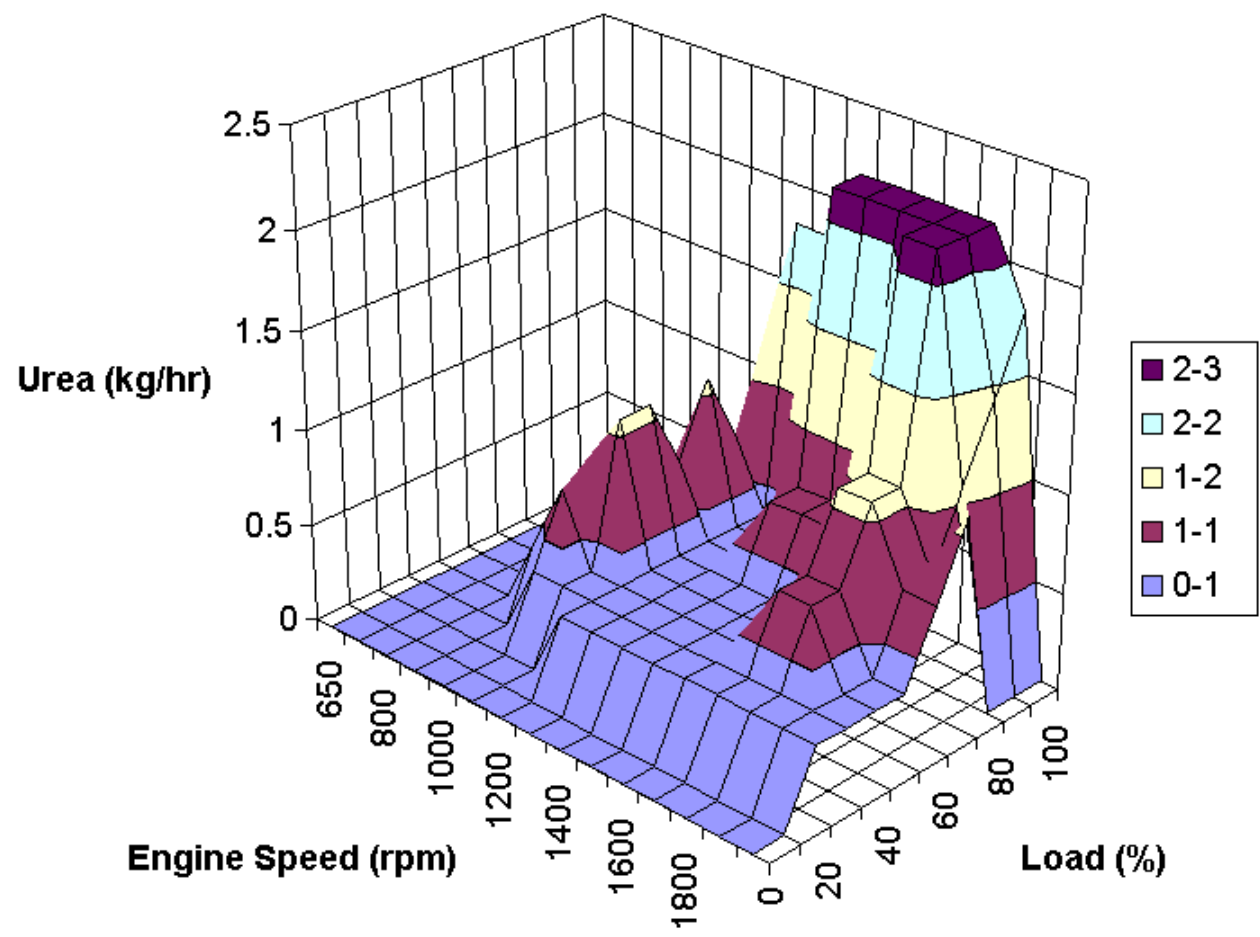

Figure 46 - Initial Optimization Map using interpolation of ESC and AVL modes 
The resulting urea injection values were much higher than the expected values. The values were expected to be at or just above stoichiometric levels. The map in Figure 46 was used as a starting point for optimization of the FTP cycle. After isolating specific sections for optimization and running a large number of tests, the final optimized FTP urea injection map was created. This map is shown in Figure 47.

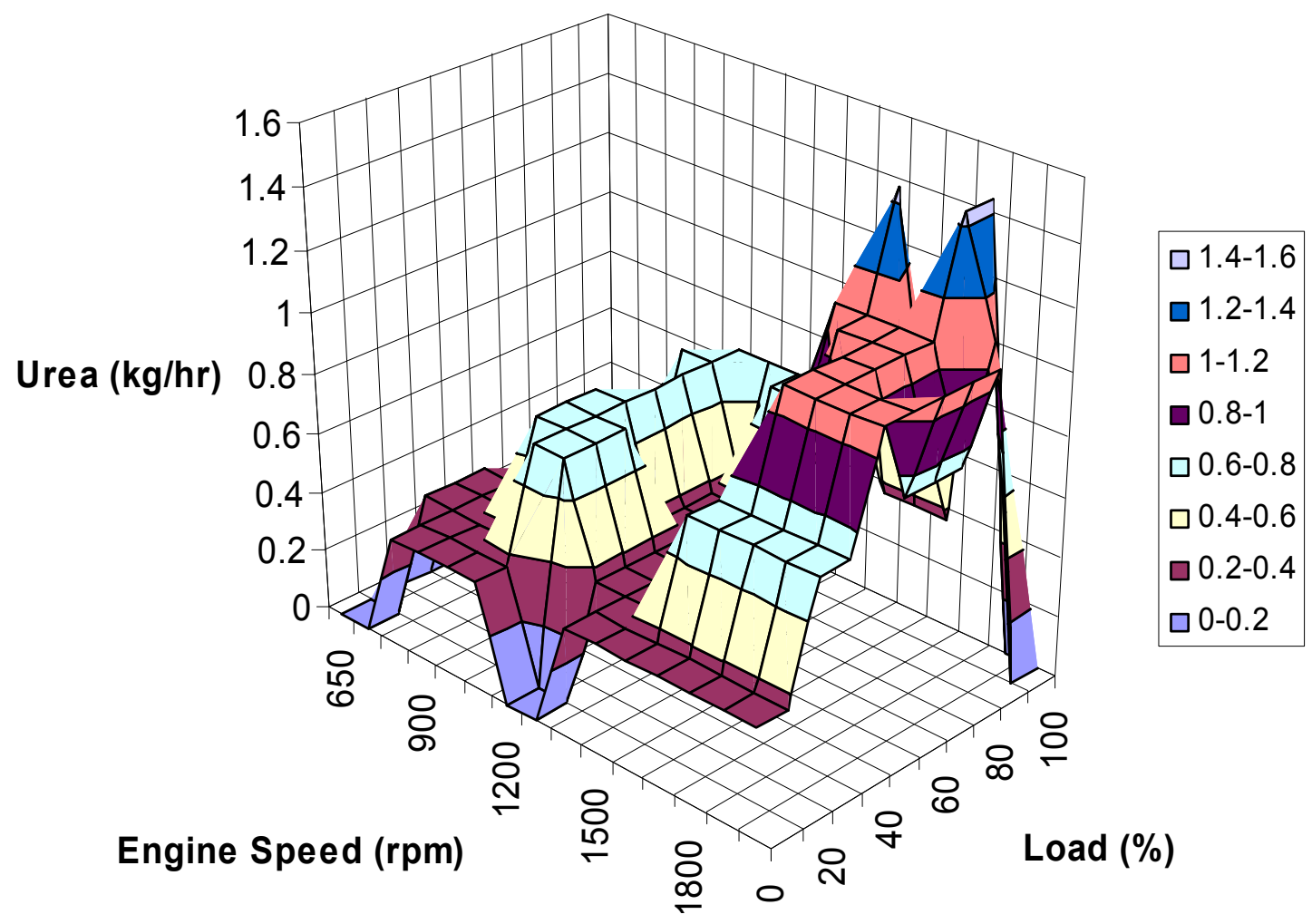

Figure 47 - Optimized FTP Urea Injection Map

The final urea map was significantly different than the initial map shown in Figure 46. This was due to the fact that the optimization points were being tested at steady state modes of engine operation, which produces much higher amounts of $\mathrm{NO}_{\mathrm{x}}$ than transient operation. The urea injection values found for the steady state modes were used only as a starting point for the optimization of the map. Transient operation covered a larger spectrum of engine speed and load and did not require urea injection values as large as those found for high load steady state points. Values used in the map were optimized to get very high $\mathrm{NO}_{\mathrm{x}}$ reduction without significant amounts of ammonia slip. This map was tested on the FTP and the ETC. 


\subsection{Average $\mathrm{NO}_{x}$ Method}

As discussed in section 4.1.2, the average $\mathrm{NO}_{\mathrm{x}}$ method was based upon the average $\mathrm{NO}_{\mathrm{x}}$ produced by the engine. The $\mathrm{NO}_{\mathrm{x}}$ produced was averaged based upon ranges of engine speed and load and the following map was created (see Figure 48).

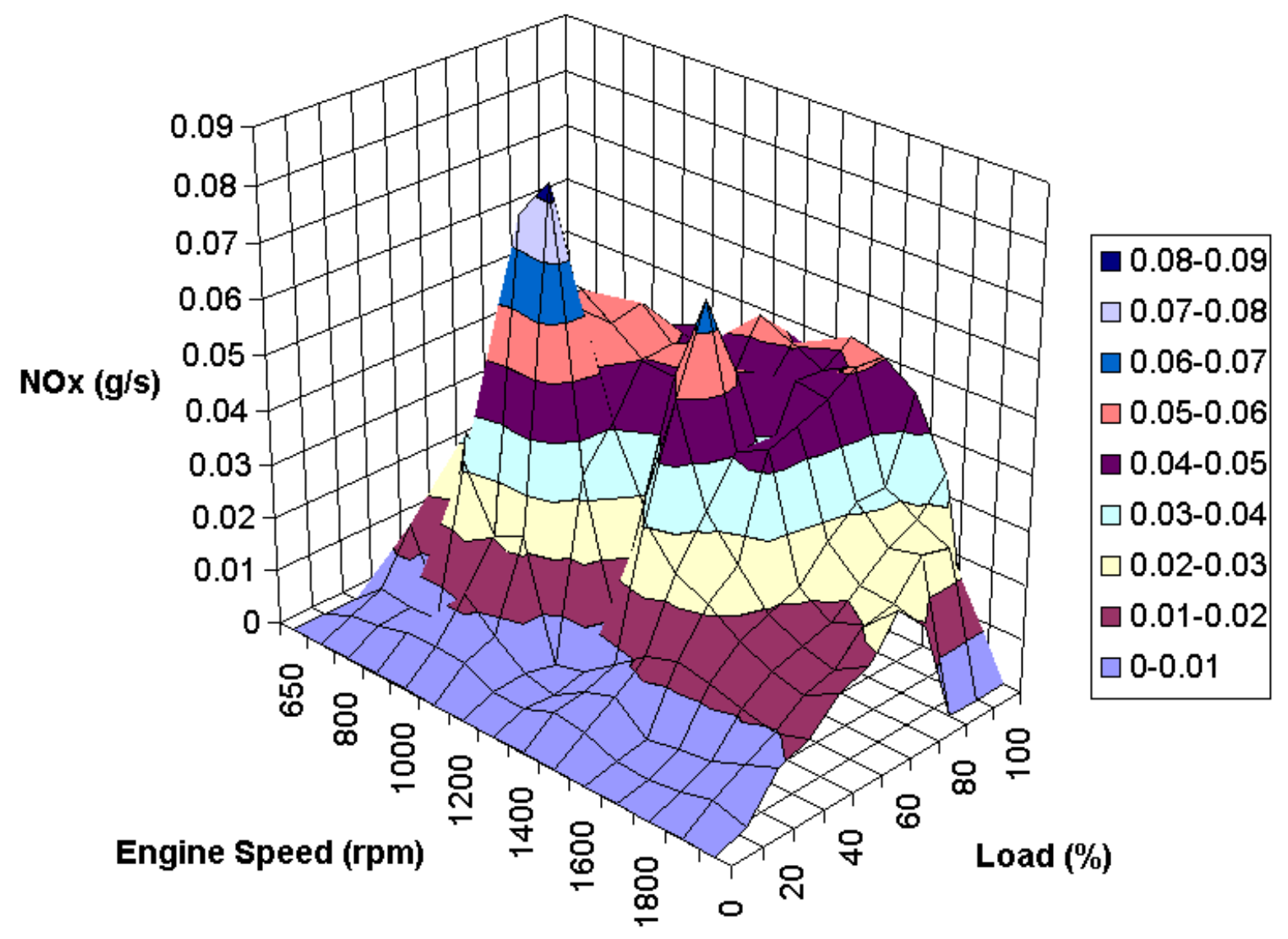

Figure 48 - Average values of $\mathrm{NO}_{\mathrm{x}}(\mathrm{g} / \mathrm{s})$ produced during an FTP cycle

Figure 48 shows that there are two points near $60 \%$ load that create very large peaks in $\mathrm{NO}_{\mathrm{x}}$. The optimization method did not find these peaks and they were not taken into account in the optimized map. By averaging the $\mathrm{NO}_{\mathrm{x}}$ level, the FTP $\mathrm{NO}_{\mathrm{x}}$ production can be more easily seen and accounted for. The $\mathrm{NO}_{\mathrm{x}}$ map above was converted using stoichiometry to get the correct values of urea to inject but from the optimization method, it was seen that injecting at stoichiometric levels was inadequate. By finding the ratio between the actual urea injected and the stoichiometric urea value, the amount of urea injection actually needed for reduction of $\mathrm{NO}_{\mathrm{x}}$ can be estimated. Calculating this ratio for the optimized ESC and AVL modes resulted in Table 15 and Table 16. 
Table 15 - ESC Modes - Urea Injection

\begin{tabular}{|c|c|c|c|c|c|c|}
\hline Mode & $\begin{array}{c}\text { Engine } \\
\text { Speed }\end{array}$ & Torque & $\mathbf{N 0 \times}$ In & $\begin{array}{c}\text { Stoich. Urea } \\
\text { Injection }\end{array}$ & $\begin{array}{c}\text { Actual Urea } \\
\text { Injected }\end{array}$ & $\begin{array}{c}\text { Act Urea Inj./ } \\
\text { St. Urea Inj. }\end{array}$ \\
\hline & $\mathbf{r p m}$ & $\mathbf{f t - l b}$ & $\mathbf{p p m}$ & $\mathbf{k g} / \mathbf{h r}$ & $\mathbf{k g} \mathbf{h r}$ & \\
\hline 1 & 651 & 0 & - & - & - & - \\
\hline 2 & 1258 & 1251 & 48.6 & 0.6647 & 1.80 & 2.70 \\
\hline 3 & 1516 & 587 & 10.7 & 0.1466 & 0.36 & 2.45 \\
\hline 4 & 1516 & 857 & 16.3 & 0.2228 & 0.36 & 1.61 \\
\hline 5 & 1258 & 601 & 10.6 & 0.1455 & 0.36 & 2.47 \\
\hline 6 & 1258 & 904 & 13.3 & 0.1825 & 0.36 & 1.97 \\
\hline 7 & 1258 & 299 & 3.6 & 0.0493 & 0.36 & 7.30 \\
\hline 8 & 1516 & 1106 & 86.6 & 1.1834 & 2.16 & 1.82 \\
\hline 9 & 1516 & 291 & 5.5 & 0.0747 & 0.36 & 4.81 \\
\hline 10 & 1773 & 932 & 77.1 & 1.0542 & 2.16 & 2.04 \\
\hline 11 & 1773 & 244 & 14.8 & 0.2022 & 0.36 & 1.78 \\
\hline 12 & 1773 & 729 & 28.4 & 0.3878 & 1.08 & 2.78 \\
\hline 13 & 1773 & 497 & 17.9 & 0.2442 & 0.36 & 1.47 \\
\hline & & & & & Average $=$ & 2.77 \\
\hline
\end{tabular}

Table 15 shows that an average of 2.77 times the stoichiometric amount of urea was injected for the ESC modes. A similar factor was found for the AVL modes. This is shown in Table 16 below.

Table 16 - AVL Modes - Urea Injection

\begin{tabular}{|c|c|c|c|c|c|c|}
\hline Mode & $\begin{array}{c}\text { Engine } \\
\text { Speed }\end{array}$ & Torque & $\mathbf{N O x} \mathbf{~ I n}$ & $\begin{array}{c}\text { Stoich. Urea } \\
\text { Injection }\end{array}$ & $\begin{array}{c}\text { Actual Urea } \\
\text { Injected }\end{array}$ & $\begin{array}{c}\text { Act Urea Inj./ } \\
\text { St. Urea Inj. }\end{array}$ \\
\hline & $\mathbf{r p m}$ & $\mathbf{f t - l \mathbf { b }}$ & $\mathbf{p p m}$ & $\mathbf{k g} / \mathbf{h r}$ & $\mathbf{k g} / \mathbf{h r}$ & \\
\hline 1 & 651 & 0 & - & - & - & - \\
\hline 2 & 818 & 177 & 2 & 0.0273 & - & - \\
\hline 3 & 962 & 487 & 6.5 & 0.0889 & 0.36 & 4.05 \\
\hline 4 & 1120 & 1052 & 31 & 0.4238 & 0.72 & 1.69 \\
\hline 5 & 2100 & 92 & 2 & 0.0273 & - & - \\
\hline 6 & 2028 & 254 & 8.8 & 0.1203 & 0.36 & 2.99 \\
\hline 7 & 2028 & 439 & 6.4 & 0.0875 & 0.36 & 4.11 \\
\hline 8 & 1942 & 605 & 19 & 0.2598 & 0.72 & 2.77 \\
\hline & & & & & Average $=$ & 3.12 \\
\hline
\end{tabular}

Several of the AVL modes did not produce enough $\mathrm{NO}_{\mathrm{x}}$ to allow for urea injection. In the modes that did, an average of 3.12 times the stoichiometric amount of urea was injected. Since more than the stoichiometric value of urea is needed, a scaling factor was used to correct the amount of urea injected based on the average $\mathrm{NO}_{\mathrm{x}}$ produced. The scaling factor was calculated through the ammonia adsorption/desorption study described in Section 4.1.2.1. Table 15 and 
Table 16 also show that the smallest urea step of $0.36 \mathrm{~kg} / \mathrm{hr}$ was found to be too large for the $\mathrm{NO}_{\mathrm{x}}$ produced by some of the modes but had to be used in order to achieve $\mathrm{NO}_{\mathrm{x}}$ reduction. This may have caused some over-injection of urea and created ammonia slip.

\subsubsection{Ammonia Adsorption/Desorption Study}

The ammonia adsorption/desorption study was conducted on ESC modes 8 and 10. The study estimated not only the amount of ammonia stored but also the actual ammonia available for $\mathrm{NO}_{\mathrm{x}}$ reduction. The ratio of the set ammonia injection to the ammonia available gives the scaling factor that was used. The scaling factor was used to increase the amount of urea injected to have 1 mole of $\mathrm{NH}_{3}$ available in the SCR for each mole of $\mathrm{NO}_{x}$ produced by the engine. Figure 49 shows the results for ESC mode 8.

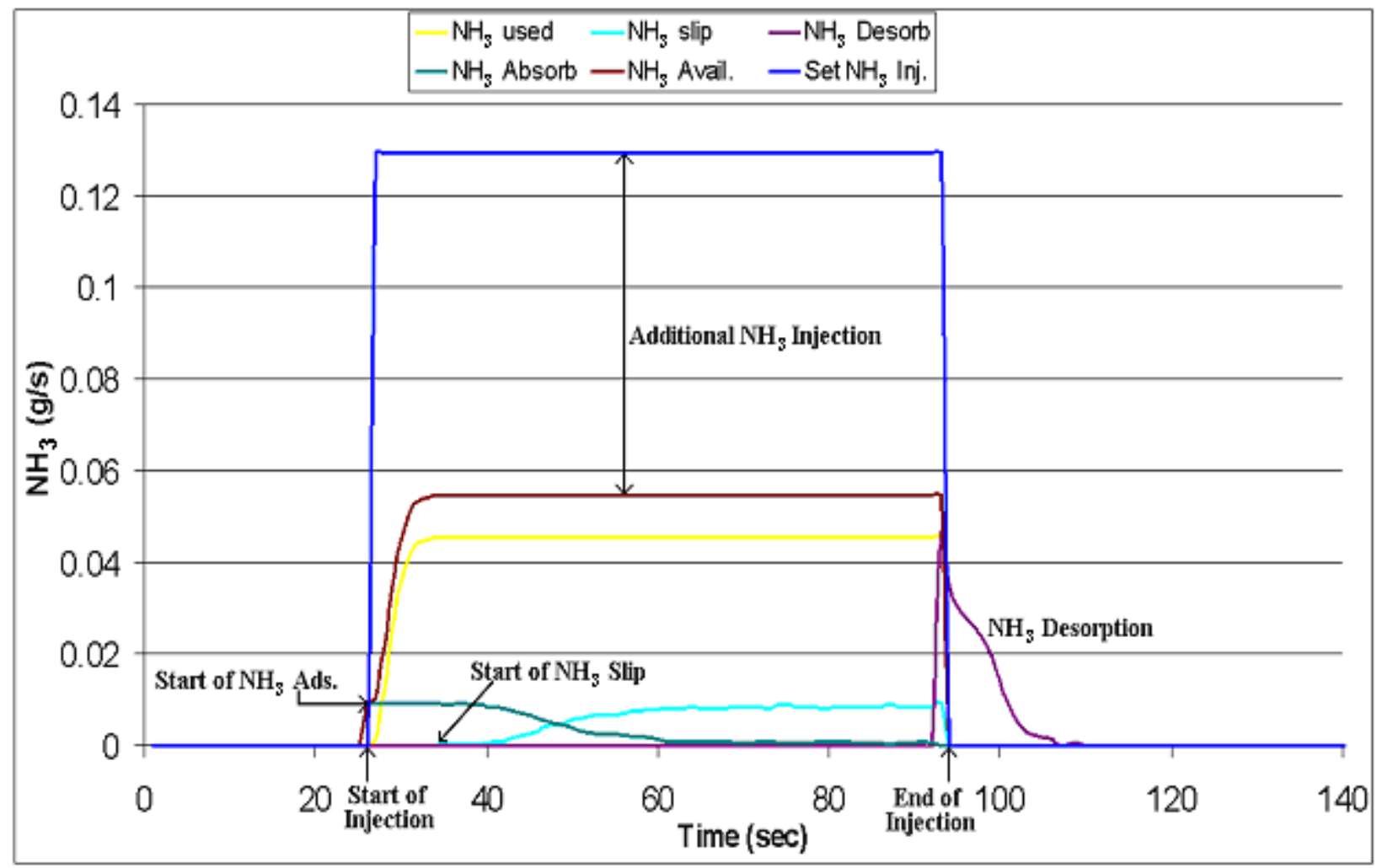

Figure 49 - ESC Mode 8 Ammonia Adsorption/Desorption Study Results

Figure 49 shows that from the start of injection, the catalyst absorbed ammonia for approximately 10 seconds prior to the onset ammonia slip. After this point, ammonia adsorption decreases slowly while the ammonia slip starts increasing. Once the catalyst is completely saturated with ammonia, all the excess becomes ammonia slip. Desorption of the ammonia 
begins at the end of urea injection and at a higher rate than the adsorption. The additional $\mathrm{NH}_{3}$ injection is the difference between the available $\mathrm{NH}_{3}$ and the set $\mathrm{NH}_{3}$ injection level. As seen in Figure 49, the difference in these values is very large. Much of the loss of ammonia can be credited to incomplete urea hydrolysis and vaporization, pump injection error and undesired SCR reactions. Also, the total amount of ammonia available is not completely utilized due to the conversion efficiency of the SCR system. Figure 50 shows the adsorption/desorption study results of ESC mode 10.

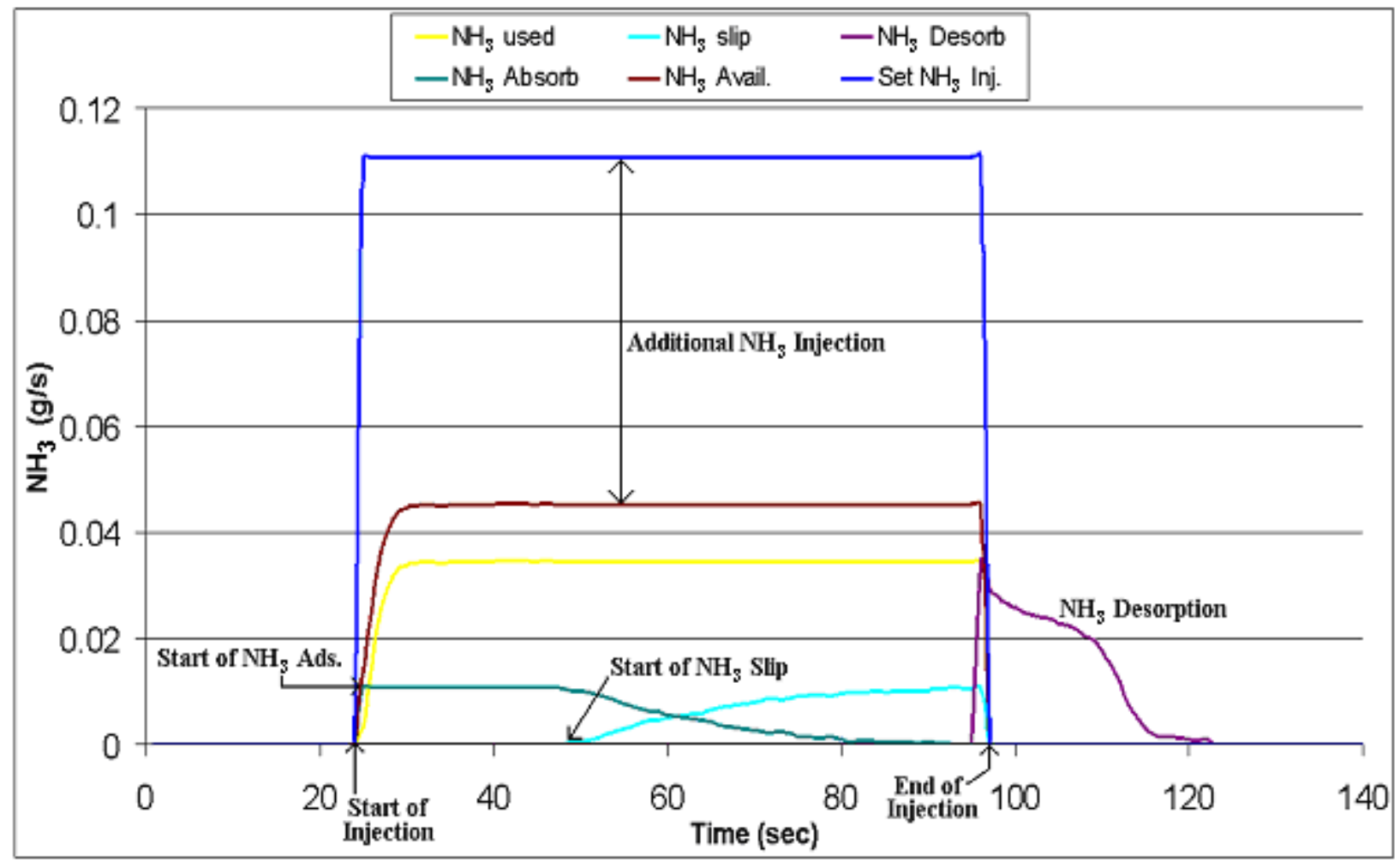

Figure 50 - ESC Mode 10 Ammonia Adsorption/Desorption Study Results

Figure 49 and Figure 50 show that modes 8 and 10 have similar results despite having different urea injection rates. Each of them has long saturation times and short desaturation times, as well as a large difference in set $\mathrm{NH}_{3}$ injection and $\mathrm{NH}_{3}$ available. The estimation of $\mathrm{NH}_{3}$ available was possible because of the assumption that the total amount of ammonia adsorbed is equal to the total amount desorbed by the catalyst. The total ammonia adsorbed/desorbed as well as the saturation and desaturation times for modes 8 and 10 is shown in Table 17 and Table 18, respectively. 
Table 17 - ESC Mode 8 Results

\begin{tabular}{|l|c|c|}
\hline \multicolumn{3}{|c|}{ Mode 8 (1258 rpm/100\% Tq) } \\
\hline NH3 Adsorbed & 0.245 & $\mathrm{~g}$ \\
\hline Saturation Time & 44 & $\mathrm{sec}$ \\
\hline Adsorption Rate & 0.006 & $\mathrm{~g} / \mathrm{s}$ \\
\hline HH3 Desorbed & 0.245 & $\mathrm{~g}$ \\
\hline Desaturation Time & 17 & $\mathrm{sec}$ \\
\hline Desorption Rate & 0.014 & $\mathrm{~g} / \mathrm{s}$ \\
\hline Temperature & 391 & $\mathrm{C}$ \\
\hline
\end{tabular}

Table 18 - ESC Mode 10 Results

\begin{tabular}{|l|c|c|}
\hline \multicolumn{3}{|c|}{ Mode 10 (1516 rpm/100\% TO) } \\
\hline HH3 Adsorbed & 0.418 & $\mathrm{~g}$ \\
\hline Saturation Time & 60 & $\mathrm{sec}$ \\
\hline Adsorption Rate & 0.007 & $\mathrm{~g} / \mathrm{s}$ \\
\hline NH3 Desorbed & 0.419 & $\mathrm{~g}$ \\
\hline Desaturation Time & 27 & $\mathrm{sec}$ \\
\hline Desorption Rate & 0.015 & $\mathrm{~g} / \mathrm{s}$ \\
\hline Temperature & 356 & $\mathrm{C}$ \\
\hline
\end{tabular}

Table 17 and Table 18 show that the SCR inlet temperature of mode 10 is $35^{\circ} \mathrm{C}$ less than in mode 8. The SCR temperature plays an important role in the adsorption/desorption of ammonia by the catalyst. High temperatures lead to fast adsorption/desorption mechanisms and reduce the amount of ammonia storage possible. Ammonia storage reduces exponentially with increasing temperature of the catalyst. This is shown in Figure 51 [2]. Table 17 and Table 18 show that mode 10, which had a lower SCR inlet temperature, was able to absorb a larger amount of ammonia. Mode 10 also had longer saturation and desaturation time periods. The adsorption rates of each mode were similar at $0.006 \mathrm{~g} / \mathrm{s}$ for mode 8 and $0.007 \mathrm{~g} / \mathrm{s}$ for mode 10 . The desorption rates of each mode were similar and were higher than their corresponding adsorption rates. Figure 58 shows results of a study done on the ammonia storage of various catalyst materials based upon temperature.

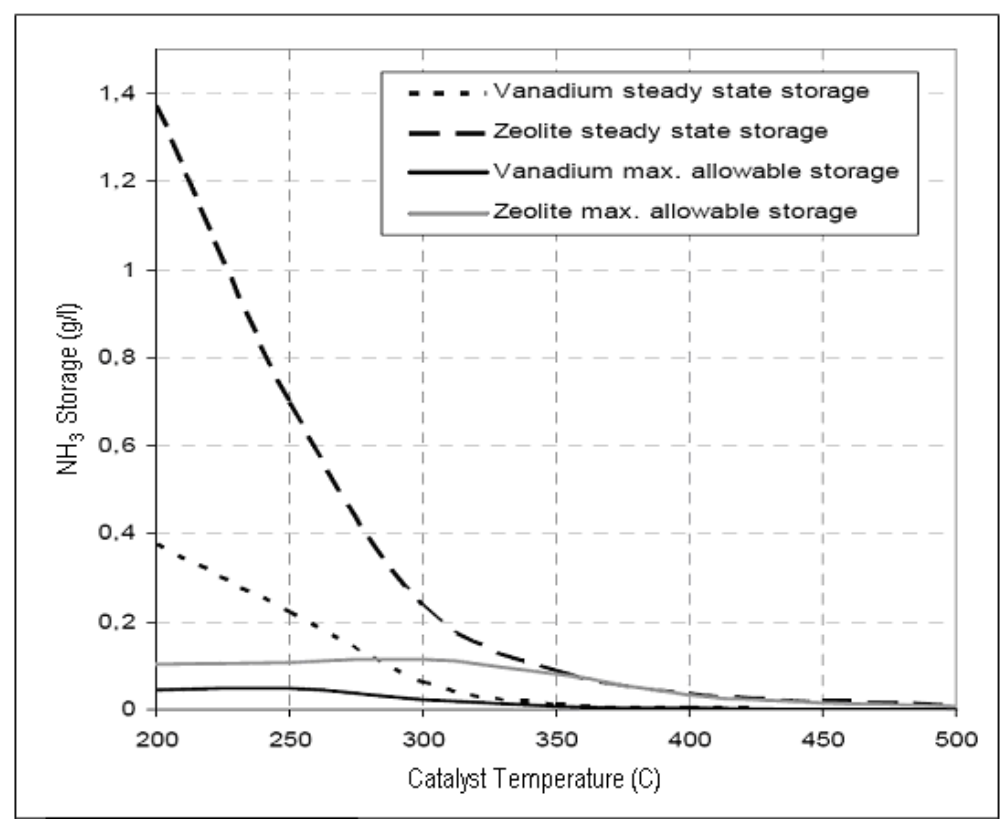

Figure $51-\mathrm{NH}_{3}$ storage of different catalyst materials [2] 
Figure 51 shows the ammonia storage in grams per liter of four types of catalysts. Vanadium based catalysts can store the largest amount of ammonia by a fair margin, specifically at low temperatures. It is also seen that the ammonia storage is significantly reduced at high temperatures. To compare the catalyst, the ammonia storage was calculated with 9 liters being the size of the catalyst and expressed as volumetric flowrate. The $\mathrm{NH}_{3}$ storage for modes 8 and 10 are shown in Table 19.

Table $19-\mathrm{NH}_{3}$ storage and Catalyst Temperature for Modes 8 and 10

\begin{tabular}{|c|c|c|}
\hline Hode & HH3 Storage & $\begin{array}{c}\text { SCR Inlet } \\
\text { Temp }\end{array}$ \\
\hline- & g/I & C \\
\hline ESC G & 0.027 & 391 \\
\hline ESC 10 & 0.046 & 356 \\
\hline
\end{tabular}

Comparing the values found in Table 19 to Figure 51, it is seen that very similar ammonia storage results were obtained. Also, the values correspond to a vanadium based catalyst material. The final value calculated for each mode was the scaling factor. Once again, the scaling factor is found as the ratio of set urea injection over the ammonia available for $\mathrm{NO}_{\mathrm{x}}$ reduction. Table 20 shows the result of this calculation.

Table 20 - Scaling Factor Results

\begin{tabular}{|l|c|}
\hline Mode & Scaling Factor \\
\hline ESC8 & 2.430 \\
\hline ESC 10 & 2.499 \\
\hline Average $=$ & 2.465 \\
\hline
\end{tabular}

The scaling factors found for each mode were very similar, with an average value of 2.465 . This value is approximately $11 \%$ less than the factors found in the optimization study for the ESC and AVL modes. The correction factor was then multiplied by the stoichiometric values found from the average $\mathrm{NO}_{\mathrm{x}}$ produced during an FTP. This generated the final urea injection map. Figure 52 shows the urea dosage map created for the average $\mathrm{NO}_{\mathrm{x}}$ method. 


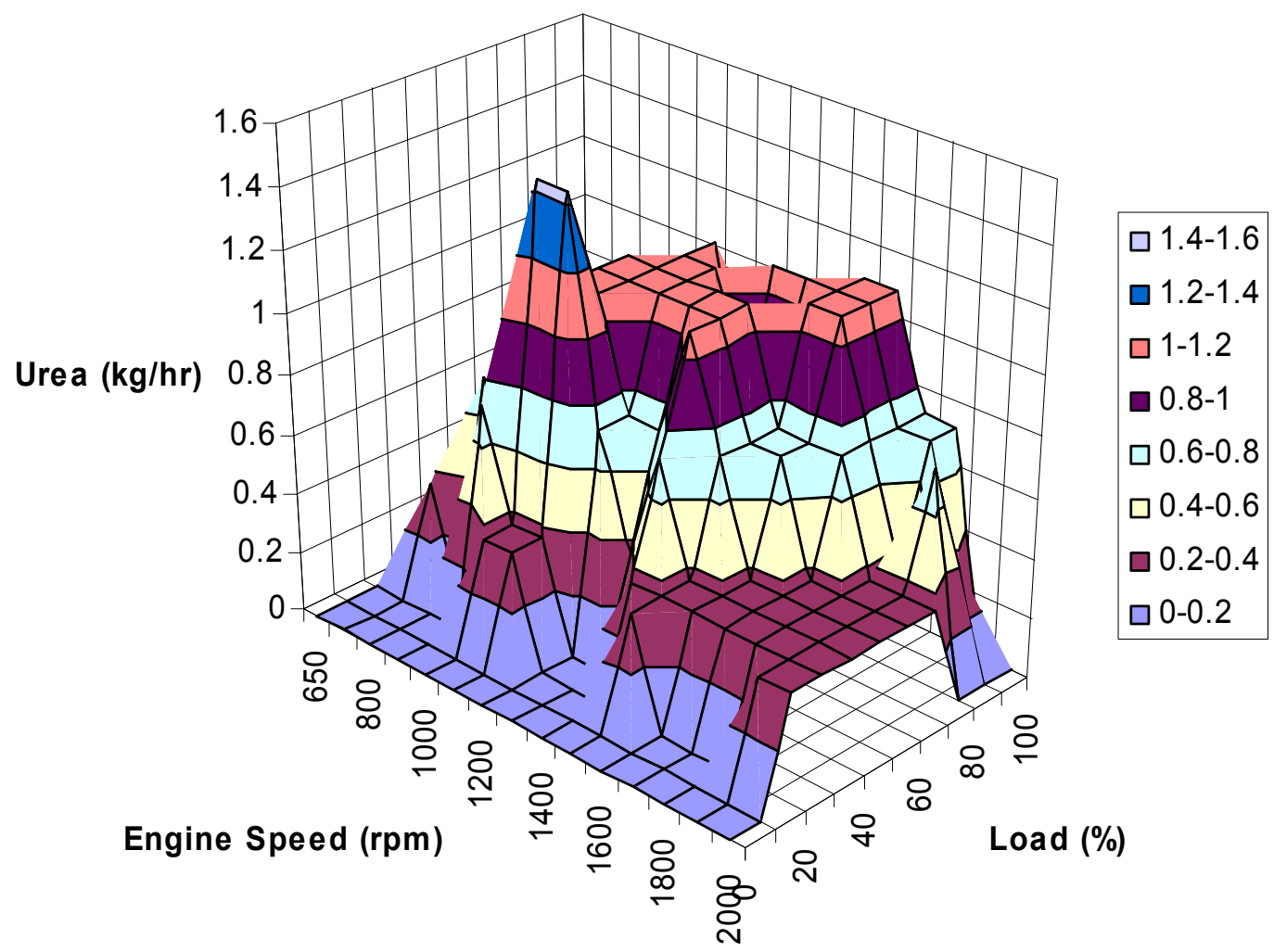

Figure 52 - Average $\mathrm{NO}_{\mathrm{x}}$ Method Urea Injection Map

\subsection{Fuzzy Logic Method}

\subsubsection{Characteristic Testing}

Before the fuzzy logic method was applied to an FTP cycle, the behavior of the controller was investigated. This was done by setting the inlet SCR temperature at a constant value and varying the $\mathrm{NO}_{2} / \mathrm{NO}$ ratio as well as the $\mathrm{NO}_{\mathrm{x}}$ level. The temperature was set to $300^{\circ} \mathrm{C}$ and the $\mathrm{NO}_{2} / \mathrm{NO}$ ratio was increased steadily from zero to 2.2. The $\mathrm{NO}_{\mathrm{x}}$ level was also increased from zero up to $0.12 \mathrm{~g} / \mathrm{s}$. The behavior of the controller with these values is shown in Figure 53. The figure shows that the ammonia injected increases in sympathy with the rising $\mathrm{NO}_{\mathrm{x}}$ level. 


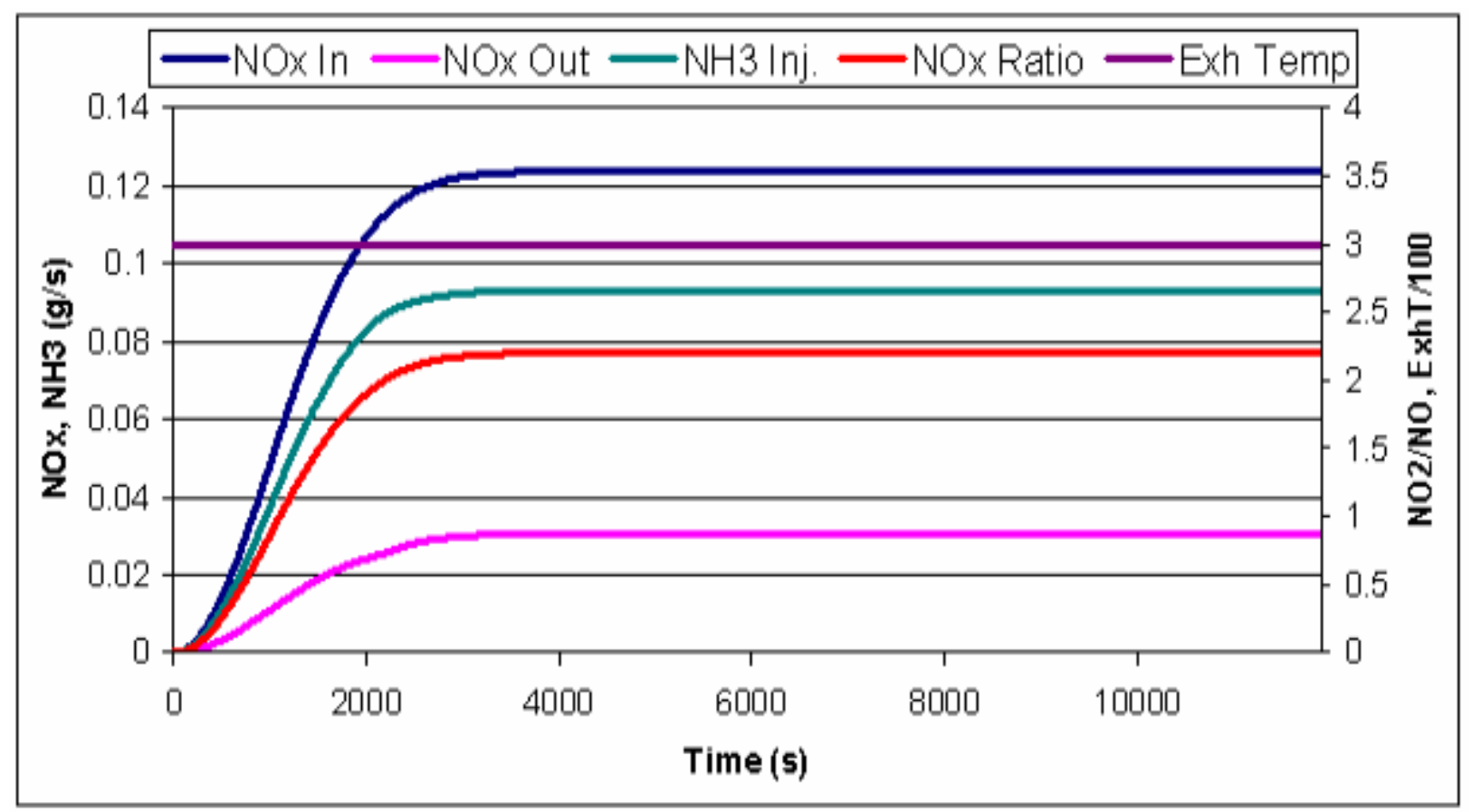

Figure 53 - Fuzzy Logic Controller Behavior with Constant Temperature

As seen in the figure, the controller behaves correctly with a set temperature and increasing $\mathrm{NO}_{\mathrm{x}}$ level. For the next characteristic test, the $\mathrm{NO}_{\mathrm{x}}$ and $\mathrm{NO}_{2} / \mathrm{NO}$ ratio were held constant while varying the temperature from $0^{\circ} \mathrm{C}$ to $350^{\circ} \mathrm{C}$. This is shown in Figure 54 .

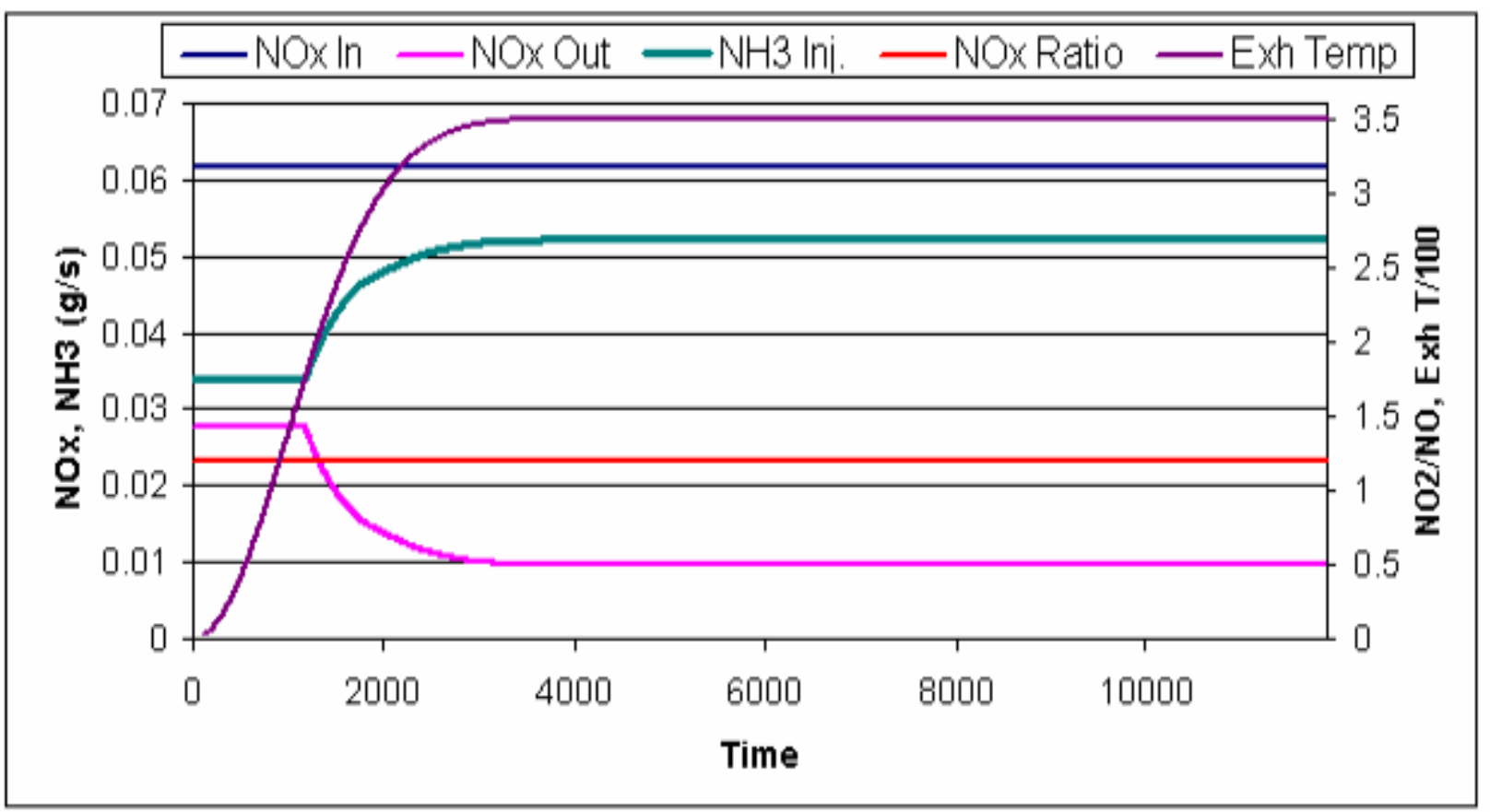

Figure 54 - Fuzzy Logic Controller Behavior with Constant $\mathrm{NO}_{\mathrm{x}}$ Ratio 
In Figure 54, the effect of SCR efficiency on the amount of ammonia injected can be seen. The ammonia injected begins at a very low level because of the initial low temperature of the system, which reduces efficiency of the SCR. The efficiency increases as the temperature increases and allows for more urea injection as the system temperature increases.

\subsubsection{SCR Efficiency}

To estimate the SCR efficiency over an FTP, the SCR inlet temperature and $\mathrm{NO}_{2} / \mathrm{NO}$ ratio are needed. After inputting these values, the fuzzy logic program uses the inference rule matrix shown in Table 14 to calculate the SCR efficiency. The temperature and $\mathrm{NO}_{2} / \mathrm{NO}$ ratio produced by the Volvo engine during an FTP cycle are shown in Figure 55 and Figure 56, respectively.

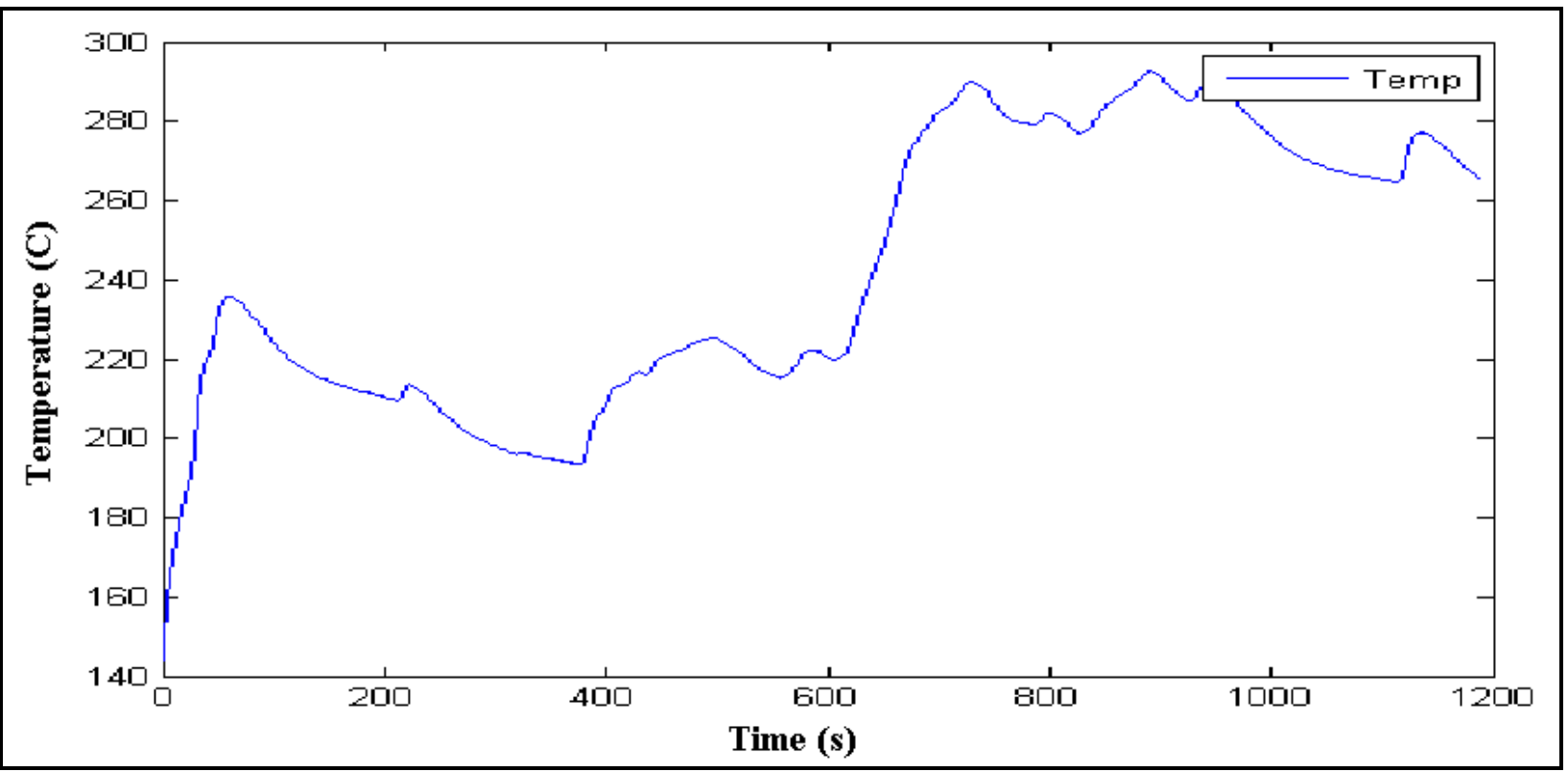

Figure 55 - SCR inlet temperature during an FTP cycle 


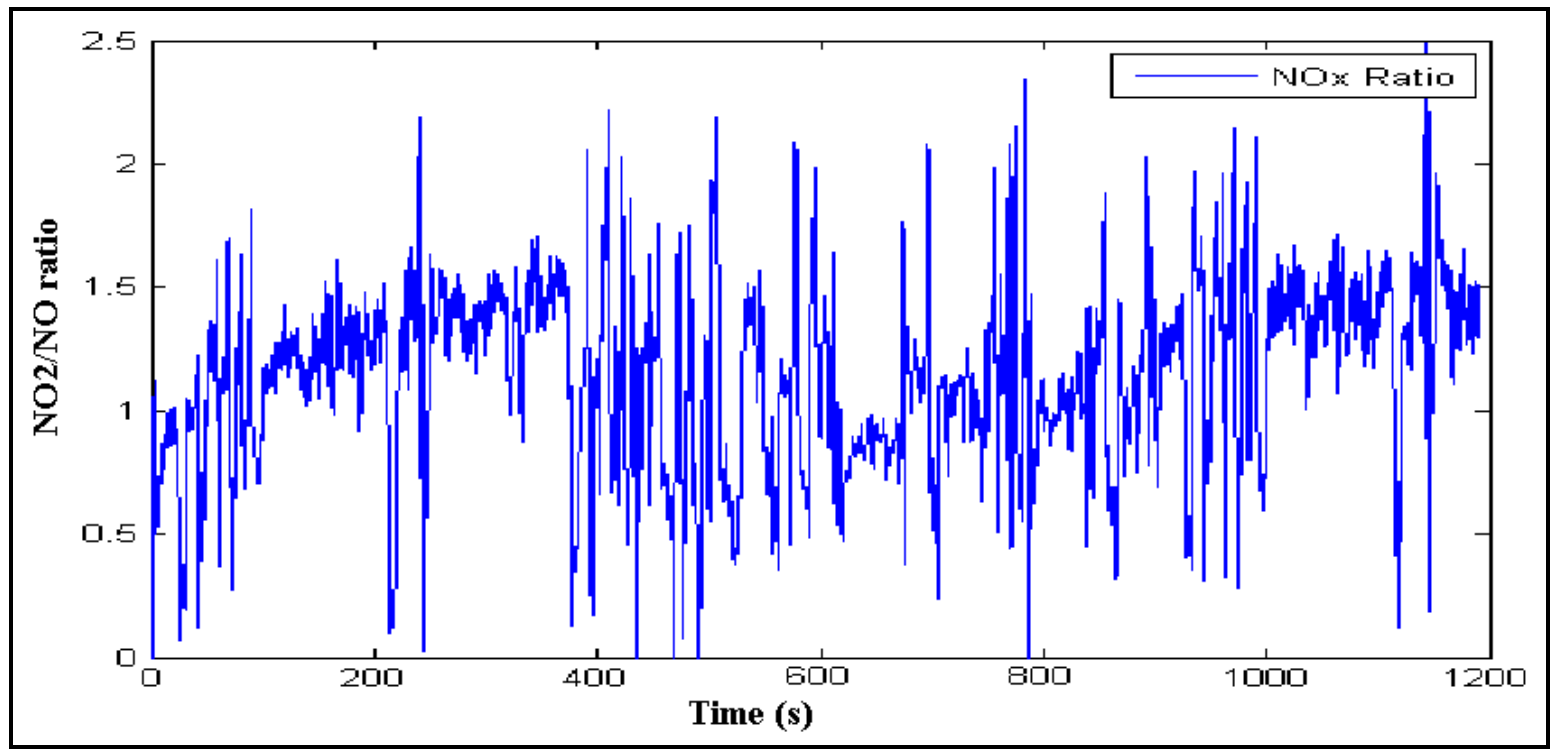

Figure $56-\mathrm{NO}_{2} / \mathrm{NO}$ ratio during an $\mathrm{FTP}$ cycle

Figure 55 shows that the temperature increases by a large amount just after 600 seconds. This corresponds to the Los Angeles freeway section of the FTP, which is a more load intensive section. The estimated SCR efficiency increases at this point as well. At higher temperatures, 'standard' and 'fast SCR' reactions dominate, which increases the overall efficiency of the system. The high temperature of this section also leads to less ammonia storage and quicker $\mathrm{NO}_{\mathrm{x}}$ conversion by the catalyst. The correlation of the inlet SCR temperature and the SCR efficiency can be seen in Figure 57.

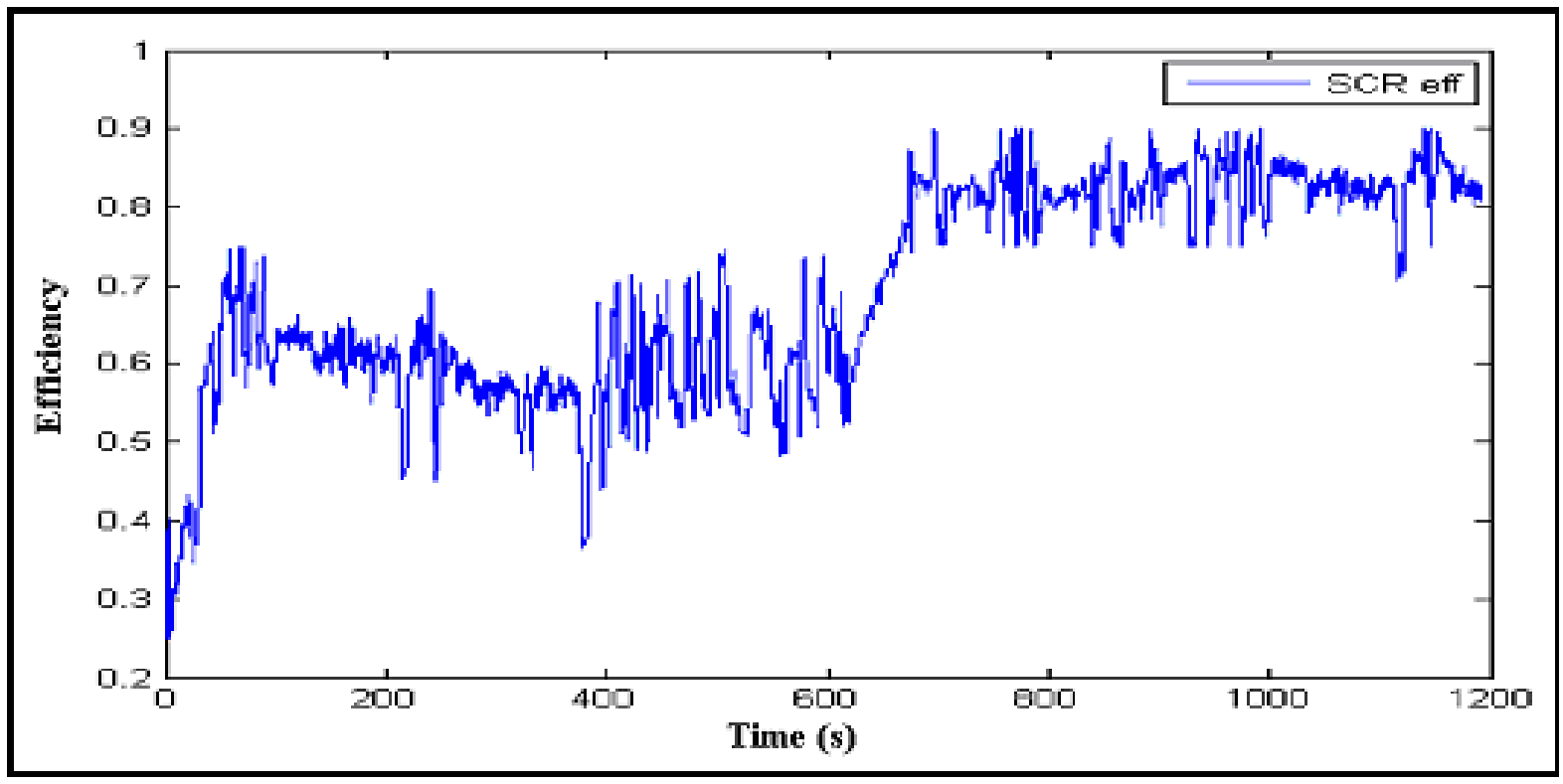

Figure 57 - Predicted SCR efficiency (normalized) over an FTP cycle 
The figure above shows the predicted SCR efficiency during an FTP cycle. The efficiency is based on the temperature and $\mathrm{NO}_{2} / \mathrm{NO}$ ratio of Figure 55 and Figure 56, respectively. The $\mathrm{NO}_{2} / \mathrm{NO}$ ratio varied only minimally, and remained between 0.5 and 1.5 for the majority of the test. Because of this, the SCR efficiency followed the trend of the temperature more than the $\mathrm{NO}_{2} / \mathrm{NO}$ ratio. The smaller variations in SCR efficiency are due to the $\mathrm{NO}_{2} / \mathrm{NO}$ ratio.

\subsection{3 $\mathrm{NO}_{\mathrm{x}}$ Prediction}

The $\mathrm{NO}_{\mathrm{x}}$ prediction model was based on a map of $\mathrm{NO}_{\mathrm{x}}$ produced according to engine speed and load. Figure 48 shows the average $\mathrm{NO}_{\mathrm{x}}$ produced during an FTP cycle. Figure 58 is a comparison of the actual $\mathrm{NO}_{\mathrm{x}}$ produced and that predicted by the $\mathrm{NO}_{\mathrm{x}}$, model during an FTP.

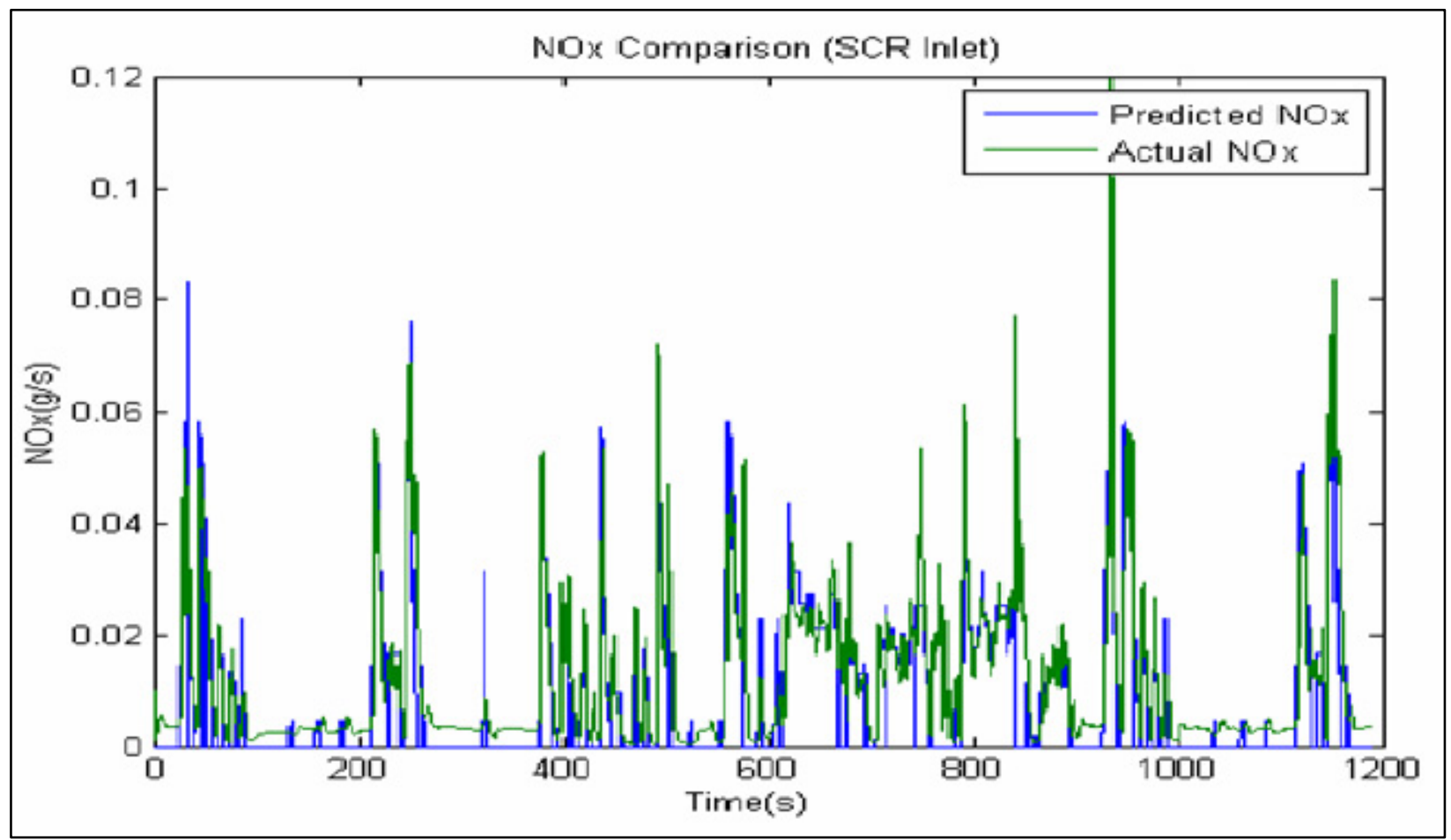

Figure 58 - Comparison of Fuzzy Logic Predicted $\mathrm{NO}_{\mathrm{x}}$ and Actual $\mathrm{NO}_{\mathrm{x}}$ over an FTP cycle

Figure 58 shows the predicted $\mathrm{NO}_{\mathrm{x}}$ is very similar to the actual $\mathrm{NO}_{\mathrm{x}}$ produced during the FTP. The largest difference between the two occurs when the engine is idling. This is irrelevant since there is insufficient $\mathrm{NO}_{\mathrm{x}}$ produced at idle to allow for urea injection. There is an acceptable average error of $5 \%$ between the predicted $\mathrm{NO}_{\mathrm{x}}$ and the actual $\mathrm{NO}_{\mathrm{x}}$, excluding idle. The predicted $\mathrm{NO}_{\mathrm{x}}$ value was then converted into the amount of urea that should be injected and 
scaled using the same methodology as used to produce the average $\mathrm{NO}_{\mathrm{x}}$ urea injection map. This was done to ensure that the $\mathrm{NH}_{3}$ to $\mathrm{NO}_{\mathrm{x}}$ ratio at the $\mathrm{SCR}$ is as close to $1: 1$ as possible. The details of this are shown in section 5.2. The SCR efficiency is now used to correct the urea injection value based upon the condition of the $\mathrm{SCR}$ for $\mathrm{NO}_{\mathrm{x}}$ conversion. Once again, at higher temperatures and optimal $\mathrm{NO}_{2} / \mathrm{NO}$ ratio, the SCR is able to convert a higher percentage of $\mathrm{NO}_{\mathrm{x}}$ produced. In order to reduce the $\mathrm{NH}_{3}$ slip while still having high $\mathrm{NO}_{\mathrm{x}}$ reduction percentages, the predicted SCR efficiency was multiplied by the scaled urea injection value found. This will allow for more or less urea injection depending on the condition of the system. The urea injection map produced by the combination of the fuzzy logic model and $\mathrm{NO}_{\mathrm{x}}$ prediction is shown in Figure 59.

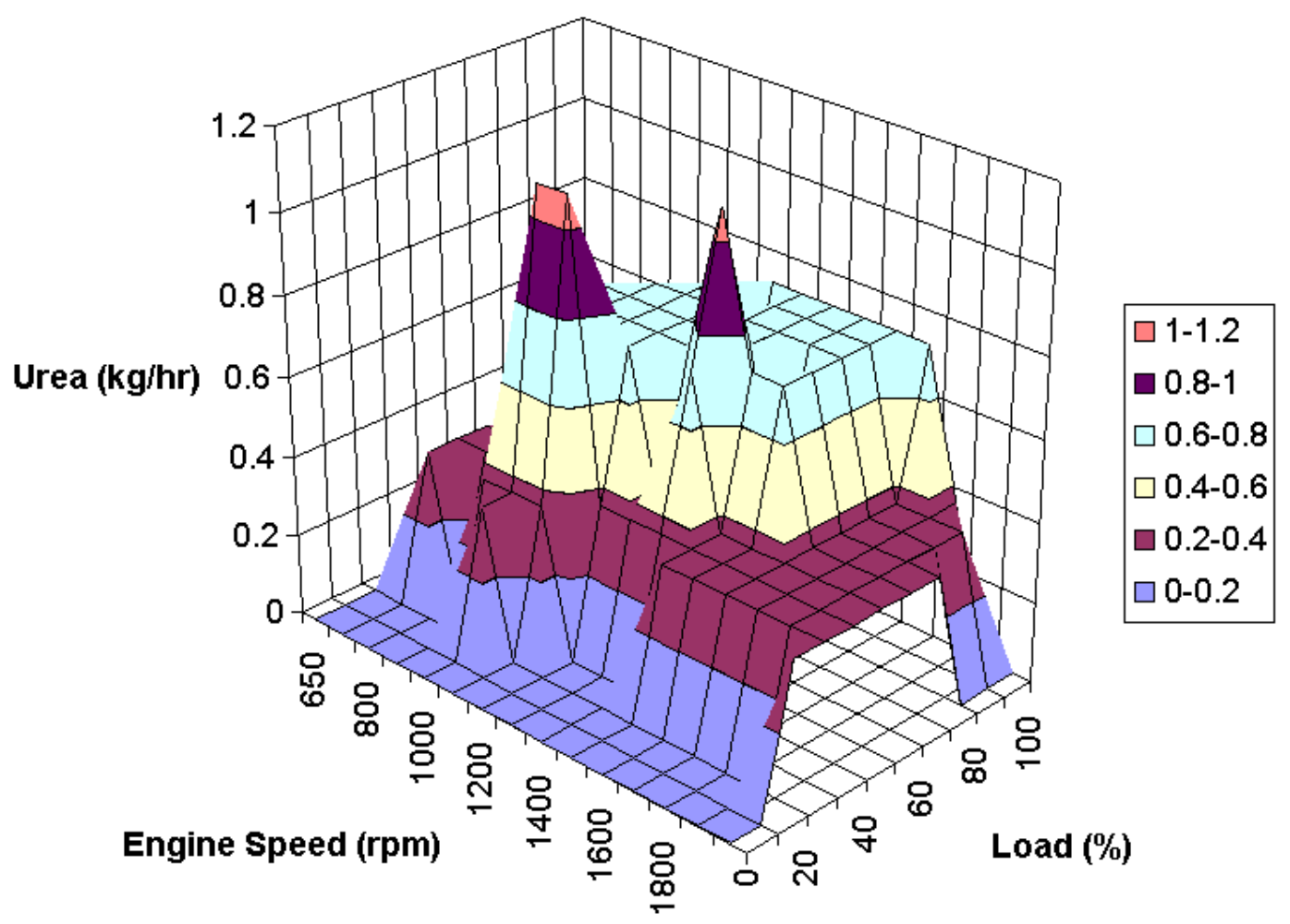

Figure 59 - Fuzzy Logic Method Urea Injection Map

The fuzzy logic map in Figure 59 injected less urea than the average $\mathrm{NO}_{\mathrm{x}}$ map in Figure 52. This is due to the SCR efficiency restricting the amount of urea injection when conditions are unfavorable for high $\mathrm{NO}_{\mathrm{x}}$ conversion. Also, both the average $\mathrm{NO}_{\mathrm{x}}$ and fuzzy logic maps were very different than the optimized map due to the testing at steady state modes that was used for the development of optimized map. The steady state testing resulted in higher injection values 
and allowed the exhaust temperature of the engine to stabilize. The average $\mathrm{NO}_{\mathrm{x}}$ and fuzzy logic maps were created using transient operation of the engine, which produced less $\mathrm{NO}_{\mathrm{x}}$ and did not allow for stabilization of the exhaust temperature.

\subsection{European Stationary Cycle}

The ESC cycle was employed with the optimization method only. It was run to have a basis of understanding for the SCR and a starting point for the optimized FTP urea map. The ESC cycle was first tested without an SCR to characterize the emissions of the engine. After this was done, the SCR was attached and urea was injected. Table 21 summarizes the average values from three hot starts ESC tests.

Table 21 - ESC Emissions Summary

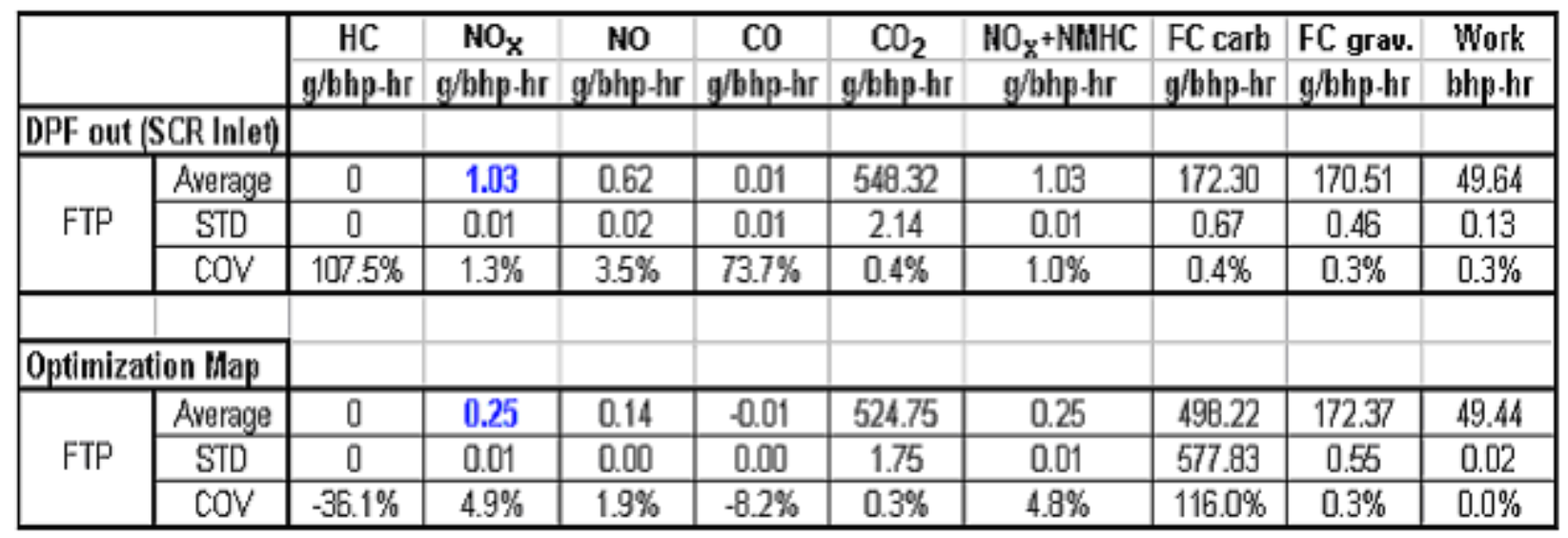

Table 21 shows that the engine produced $1.03 \mathrm{~g} / \mathrm{bhp}-\mathrm{hr}$ of $\mathrm{NO}_{\mathrm{x}}$ without urea injection. With urea injection, the $\mathrm{NO}_{\mathrm{x}}$ was reduced to $0.25 \mathrm{~g} / \mathrm{bhp}-\mathrm{hr}$. This is an overall $\mathrm{NO}_{\mathrm{x}}$ reduction of $76 \%$ for the steady state cycle. The standard deviation and coefficient of variation (COV) of the $\mathrm{NO}_{\mathrm{x}}$ entering the SCR were 0.01 and $1.3 \%$, respectively. When urea was injected, the standard deviation remained the same but the COV increased to $4.9 \%$. The increase in COV comes from inconsistencies of the complex reactions occurring within the SCR system. Overall the $\mathrm{NO}_{\mathrm{x}}$ levels were relatively constant. Figure 60 shows a continuous plot of the $\mathrm{NO}_{\mathrm{x}}$-in and $\mathrm{NO}_{\mathrm{x}}$-out of the SCR during the ESC cycle. 


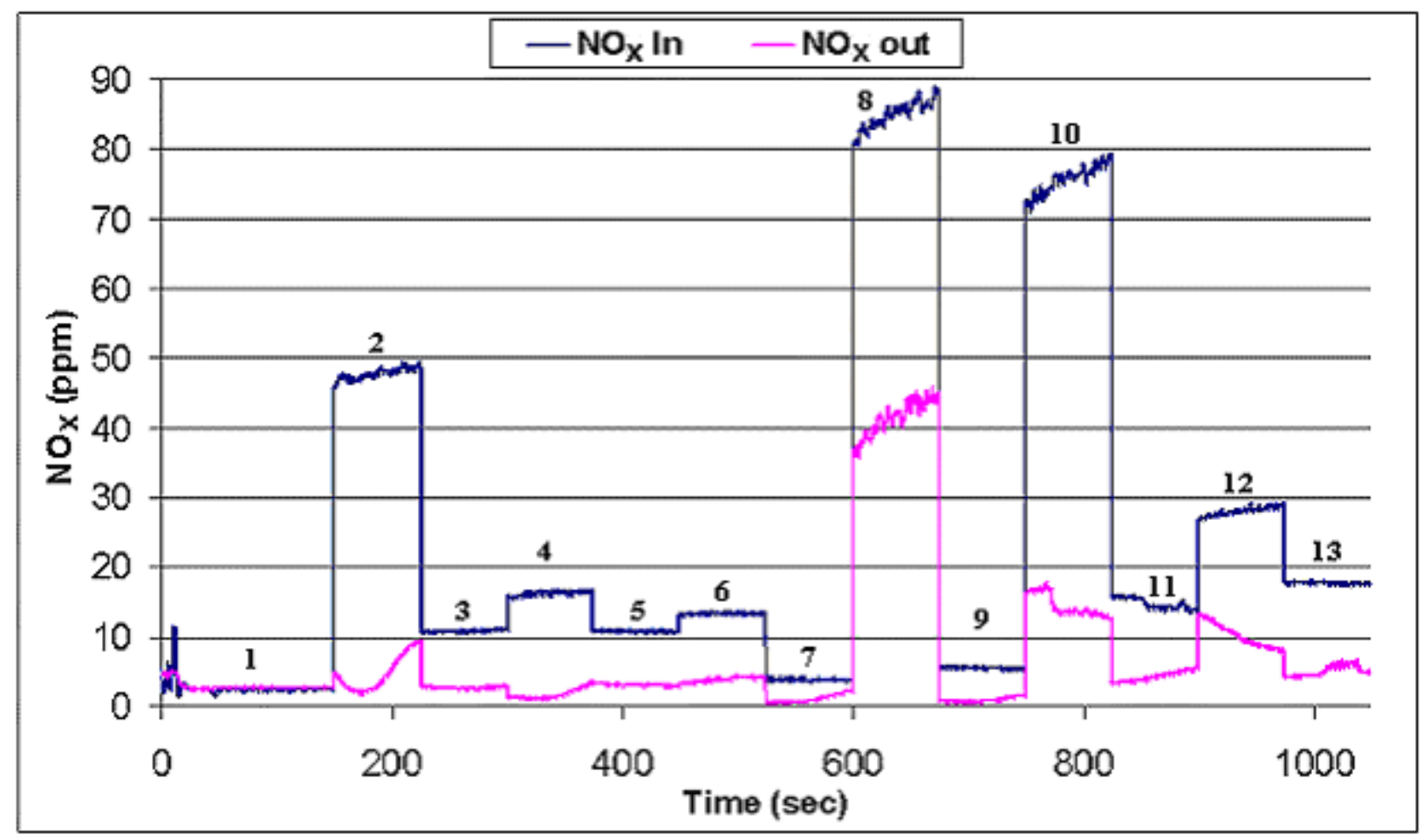

Figure 60 - $\mathrm{NO}_{\mathrm{x}}$ Reduction during an ESC Cycle

Figure 60 shows the $\mathrm{NO}_{\mathrm{x}}$ reduction of each mode of the ESC cycle. It is seen that there are several very high $\mathrm{NO}_{\mathrm{x}}$ producing modes. The three modes that produce the most are 2, 8 and 10, which are all at 100\% load but with different engine speeds. As seen in the figure, the highest $\mathrm{NO}_{\mathrm{x}}$ producing mode had very poor reduction. Poor mixing of urea in the exhaust may be a cause of this. Also affected by mixing is the conversion of $\mathrm{NO}_{\mathrm{x}}$ during high engine speed modes. This would apply to modes 10 through 13, which are at an engine speed of 1773 rpms. At high speed, the urea injected into the exhaust may not have enough time to mix properly before entering the SCR. Also seen from the figure, the $\mathrm{NO}_{\mathrm{x}}$-out level started increasing during engine operation at some of the modes. This is especially evident in mode 2 . The increase in $\mathrm{NO}_{\mathrm{x}}$ is indicative of ammonia slip but can also be attributed to the increasing temperature of the mode. Attempts were made to keep $\mathrm{NH}_{3}$ slip to a minimum while still trying to achieve maximum $\mathrm{NO}_{x}$ reduction. The resulting $\mathrm{NH}_{3}$ slip values and SCR temperatures are shown in Figure 61. 


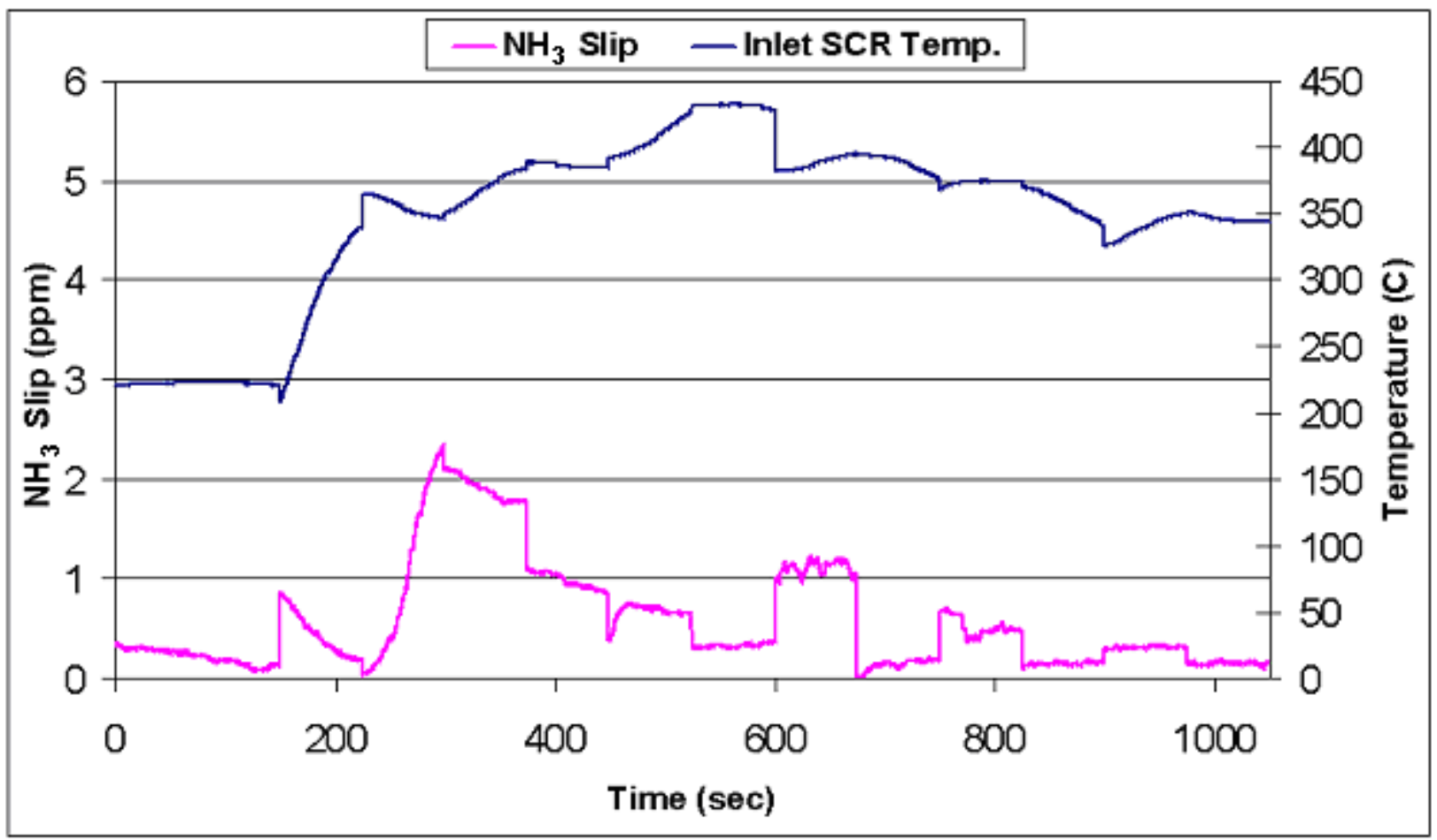

Figure $61-\mathrm{NH}_{3}$ slip during an ESC Cycle

The peak $\mathrm{NH}_{3}$ slip value of $2.3 \mathrm{ppm}$ occurred in mode 4. The average $\mathrm{NH}_{3}$ slip for each mode never exceeded $2 \mathrm{ppm}$. This is well below the $10 \mathrm{ppm}$ level that is generally used as a limit. Table 22 gives mode-by-mode results for $\mathrm{NH}_{3}$ slip and $\mathrm{NO}_{\mathrm{x}}$ reduction percentage.

Table 22 - ESC modes - Optimization Method Results

\begin{tabular}{|c|c|c|c|c|c|c|c|c|c|}
\hline Mode & $\begin{array}{c}\text { Engine } \\
\text { Speed }\end{array}$ & Torque & $\mathbf{N O}_{\mathbf{x}}$ In & $\mathbf{N O}_{\mathbf{x}}$ out & $\mathbf{N O}_{\mathbf{2}} /$ NO & $\begin{array}{c}\text { Inlet SCR } \\
\text { Temp. }\end{array}$ & $\begin{array}{c}\text { Urea Soln } \\
\text { Injected }\end{array}$ & NH $_{\mathbf{3}}$ Slip & Reduction \\
\hline & $\mathbf{r p m}$ & $\mathbf{f t - l \mathbf { b }}$ & $\mathbf{p p m}$ & $\mathbf{p p m}$ & - & $\mathbf{C}$ & $\mathbf{k g} / \mathbf{h r}$ & $\mathbf{p p m}$ & $\%$ \\
\hline 1 & 651 & 0 & - & - & - & 223 & - & - & - \\
\hline 2 & 1258 & 1251 & 48.6 & 9.4 & 0.41 & 287 & 1.80 & 0.44 & $81 \%$ \\
\hline 3 & 1516 & 587 & 10.7 & 4.3 & 0.53 & 355 & 0.36 & 1.02 & $60 \%$ \\
\hline 4 & 1516 & 857 & 16.3 & 3.1 & 0.44 & 369 & 0.36 & 1.91 & $81 \%$ \\
\hline 5 & 1258 & 601 & 10.6 & 2.0 & 0.38 & 387 & 0.36 & 0.98 & $81 \%$ \\
\hline 6 & 1258 & 904 & 13.3 & 1.8 & 0.26 & 407 & 0.36 & 0.68 & $86 \%$ \\
\hline 7 & 1258 & 299 & 3.6 & 0.4 & 0.24 & 431 & 0.36 & 0.33 & $89 \%$ \\
\hline 8 & 1516 & 1106 & 86.6 & 36.9 & 0.59 & 388 & 2.16 & 1.11 & $57 \%$ \\
\hline 9 & 1516 & 291 & 5.5 & 0.5 & 0.48 & 389 & 0.36 & 0.14 & $91 \%$ \\
\hline 10 & 1773 & 932 & 77.1 & 12.7 & 0.83 & 374 & 2.16 & 0.53 & $84 \%$ \\
\hline 11 & 1773 & 244 & 14.8 & 3.1 & 0.89 & 358 & 0.36 & 0.15 & $79 \%$ \\
\hline 12 & 1773 & 729 & 28.4 & 9.0 & 1.07 & 340 & 1.08 & 0.31 & $68 \%$ \\
\hline 13 & 1773 & 497 & 17.9 & 3.8 & 1.00 & 346 & 0.36 & 0.15 & $79 \%$ \\
\hline
\end{tabular}


Table 22 shows that the highest average $\mathrm{NH}_{3}$ slip of $1.91 \mathrm{ppm}$, occurred in mode 4 . This mode also had the highest peak $\mathrm{NH}_{3}$ level. The highest reduction came in mode 9, which reduced 91 percent of the $\mathrm{NO}_{\mathrm{x}}$. Mode 8 reduced the least $\mathrm{NO}_{\mathrm{x}}$ with only 57 percent. The cause for this is not immediately clear since the temperature was $388^{\circ} \mathrm{C}$ and the $\mathrm{NO}_{2} / \mathrm{NO}$ ratio was 0.59. The combination of these values should have allowed for good $\mathrm{NO}_{\mathrm{x}}$ reduction. The low $\mathrm{NO}_{\mathrm{x}}$ reduction may be attributed to poor mixing of urea due to reduced mixing times at the higher engine speeds. Mode 8 produces a large amount of $\mathrm{NO}_{\mathrm{x}}$; hence, requires high urea injection values. With such high levels of $\mathrm{NO}_{\mathrm{x}}$ and urea in the exhaust stream, mixing becomes very important and directly impacts the efficiency of the system. The majority of modes had high reduction values and the average conversion was 78 percent. The interaction of many factors, including SCR inlet temperature, $\mathrm{NO}_{2} / \mathrm{NO}$ ratio, urea injection, urea adsorption and mixing of urea with the exhaust can affect the conversion efficiency of the SCR system. Engine speed and load affect these factors and in turn affect the efficiency as well. By looking at the ESC cycle results, the interaction of these factors and their affect on the efficiency can be seen. For example, the high speed modes had an ideal $\mathrm{NO}_{2} / \mathrm{NO}$ ratio of approximately 1 but did not have higher efficiencies than the low speed modes. This may be due to slightly lower temperatures or to poor mixing of the urea in the exhaust. The highest reduction percentages occurred with low $\mathrm{NO}_{2} / \mathrm{NO}$ ratio and temperature near $400^{\circ} \mathrm{C}$. The lowest occurred with low temperatures and varying $\mathrm{NO}_{2} / \mathrm{NO}$ ratios. All these observations suggest the dependency of conversion efficiency of the system on the temperature and to a lesser extent, the $\mathrm{NO}_{2} / \mathrm{NO}^{2}$ atio. This information was very useful for the fuzzy logic program, which predicts the SCR efficiency.

\subsection{Federal Test Procedure}

All three methods to create urea injection maps were applied to the FTP cycle. The optimization method resulted in the highest $\mathrm{NO}_{\mathrm{x}}$ reduction, but had an undesirable peak ammonia slip value. The average $\mathrm{NO}_{\mathrm{x}}$ method had similar $\mathrm{NO}_{\mathrm{x}}$ reduction and ammonia slip levels as the optimization method. The fuzzy logic method had a lower $\mathrm{NO}_{\mathrm{x}}$ conversion efficiency but reduced the ammonia slip considerably. The average values for three hot start FTP tests are summarized in the following table. 
Table 23 - FTP Emission Summary

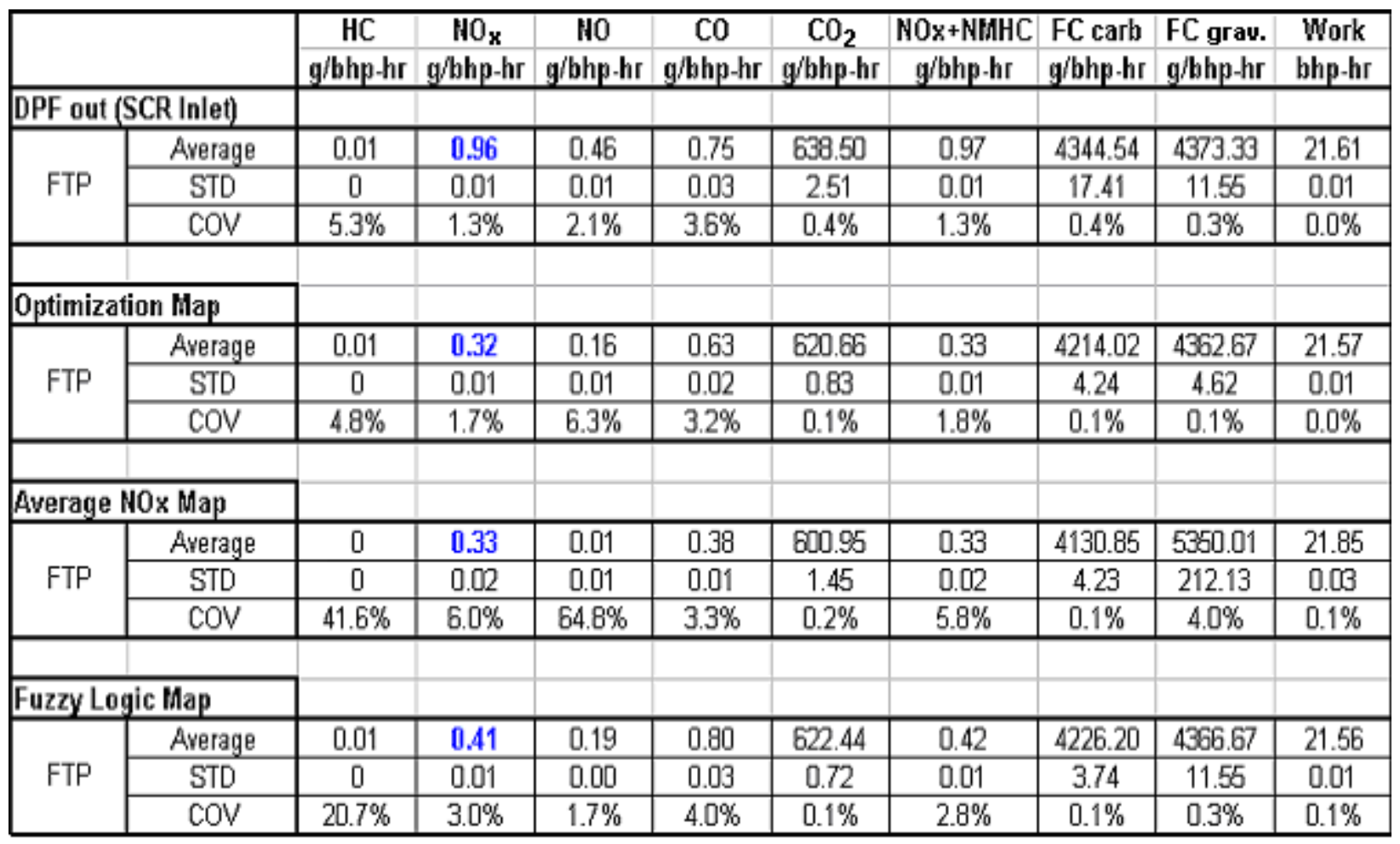

In Table 23, it is seen that without urea injection the engine produced $0.96 \mathrm{~g} / \mathrm{bhp}-\mathrm{hr}$ of $\mathrm{NO}_{\mathrm{x}}$. This value had a COV of $1.3 \%$ and a standard deviation of 0.01 . The optimization method reduced the $\mathrm{NO}_{\mathrm{x}}$ from $0.96 \mathrm{~g} / \mathrm{bhp}-\mathrm{hr}$ to $0.32 \mathrm{~g} / \mathrm{bhp}-\mathrm{hr}$, and the average $\mathrm{NO}_{\mathrm{x}}$ method reduced it to $0.33 \mathrm{~g} / \mathrm{bhp}-\mathrm{hr}$. The fuzzy logic map resulted in the least $\mathrm{NO}_{\mathrm{x}}$ reduction and produced 0.41 g/bhp-hr. Table 24 shows the reduction percentage of each method.

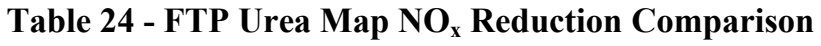

\begin{tabular}{|c|c|c|c|}
\hline $\begin{array}{c}\text { Urea Map } \\
\text { Method }\end{array}$ & NOx In & NOx Out & Reduction \\
\cline { 2 - 4 } g/bhp-hr & g/bhp-hr & $\%$ \\
\hline Optimization & 0.961 & 0.32 & $67 \%$ \\
\hline Average NOx & 0.961 & 0.33 & $66 \%$ \\
\hline Fuzzy Logic & 0.961 & 0.41 & $57 \%$ \\
\hline
\end{tabular}

The optimization and average $\mathrm{NO}_{\mathrm{x}}$ method resulted in nearly the same reduction percentages with $67 \%$ and $66 \%$, respectively. This is significant because the average $\mathrm{NO}_{\mathrm{x}}$ method achieved the same results as the optimization method without the cost and time that was involved in creating the optimized urea map. The fuzzy logic urea map reduced the $\mathrm{NO}_{\mathrm{x}}$ by $57 \%$. Figure 62 
shows the FTP $\mathrm{NO}_{\mathrm{x}}$ emissions for each of the three methods, and Figure 63 shows the engine-out and SCR-out $\mathrm{NO}_{\mathrm{x}}$ for the optimization method.

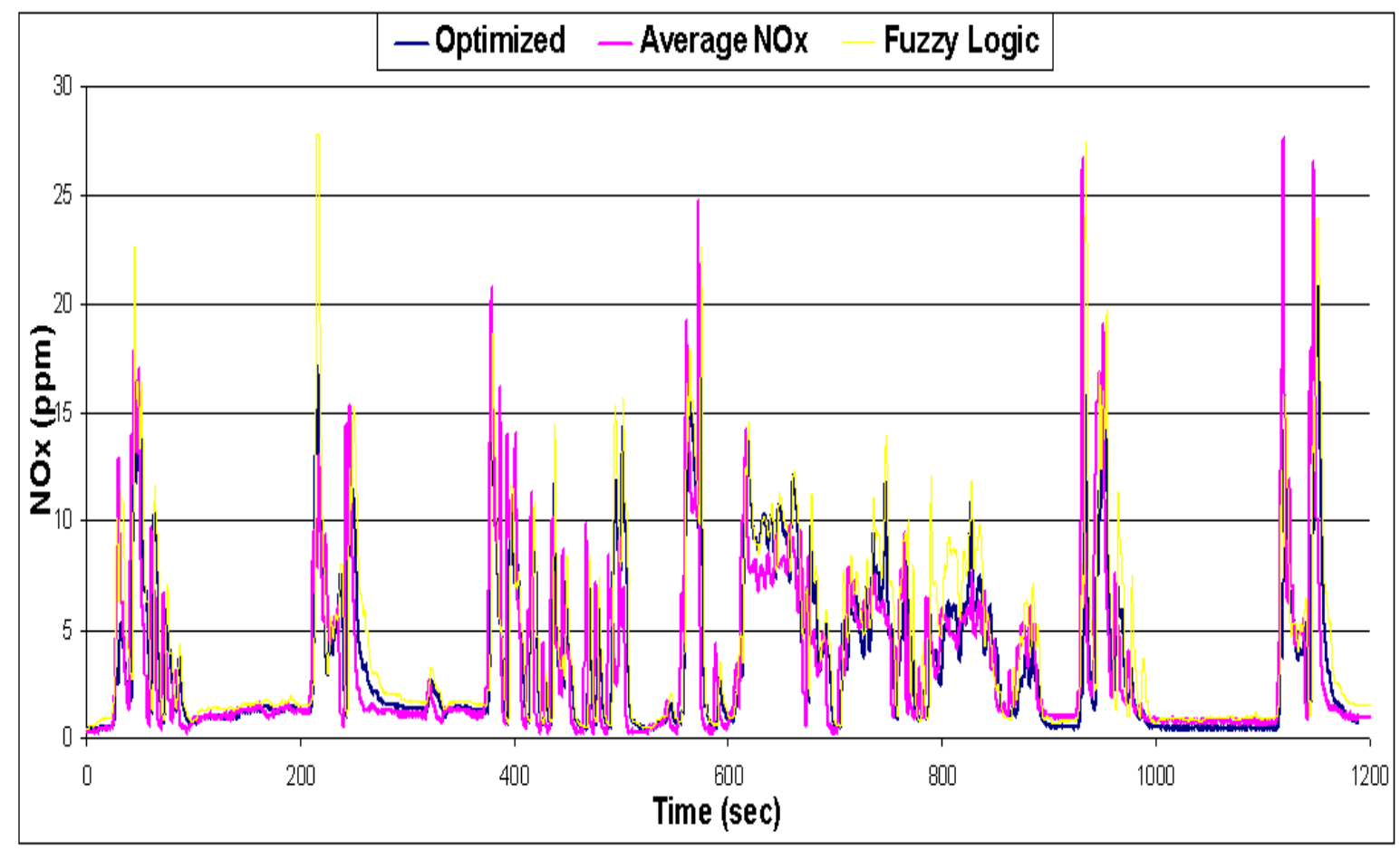

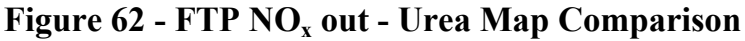

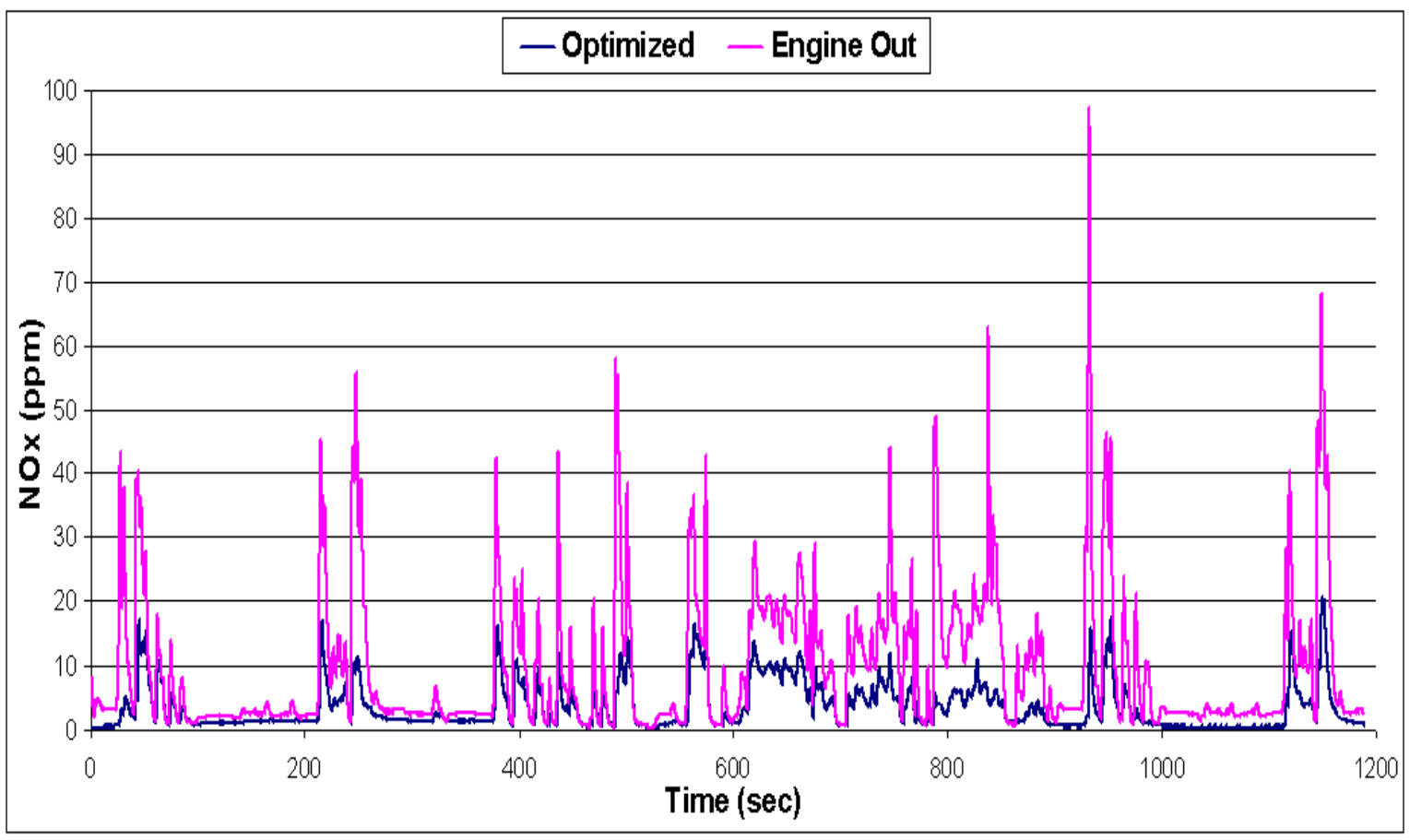

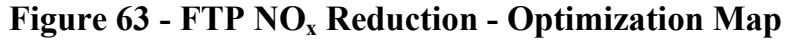


In Figure 62, it is seen that the optimization and average $\mathrm{NO}_{\mathrm{x}}$ methods had the highest reduction of $\mathrm{NO}_{\mathrm{x}}$. Figure 62 and Figure 63 show that the $\mathrm{NO}_{\mathrm{x}}$-out level for the second $\mathrm{New}$ York non-freeway section is higher than the first. The engine is hotter during the second NYNF section, which contributes to the higher $\mathrm{NO}_{\mathrm{x}}$ level. The higher temperatures lead to a higher SCR efficiency, which is the reason that the $\mathrm{NO}_{\mathrm{x}}$-out level during the second NYNF does not increase.

Although the optimization and average $\mathrm{NO}_{\mathrm{x}}$ methods had the highest reduction of $\mathrm{NO}_{\mathrm{x}}$, they also had high peaks in ammonia slip during the Los Angeles freeway section of the FTP. The fuzzy logic method, while not yielding as high percentage of reduction, reduced the ammonia slip completely. Figure 64 shows the ammonia slip of each method along with the SCR inlet temperature.

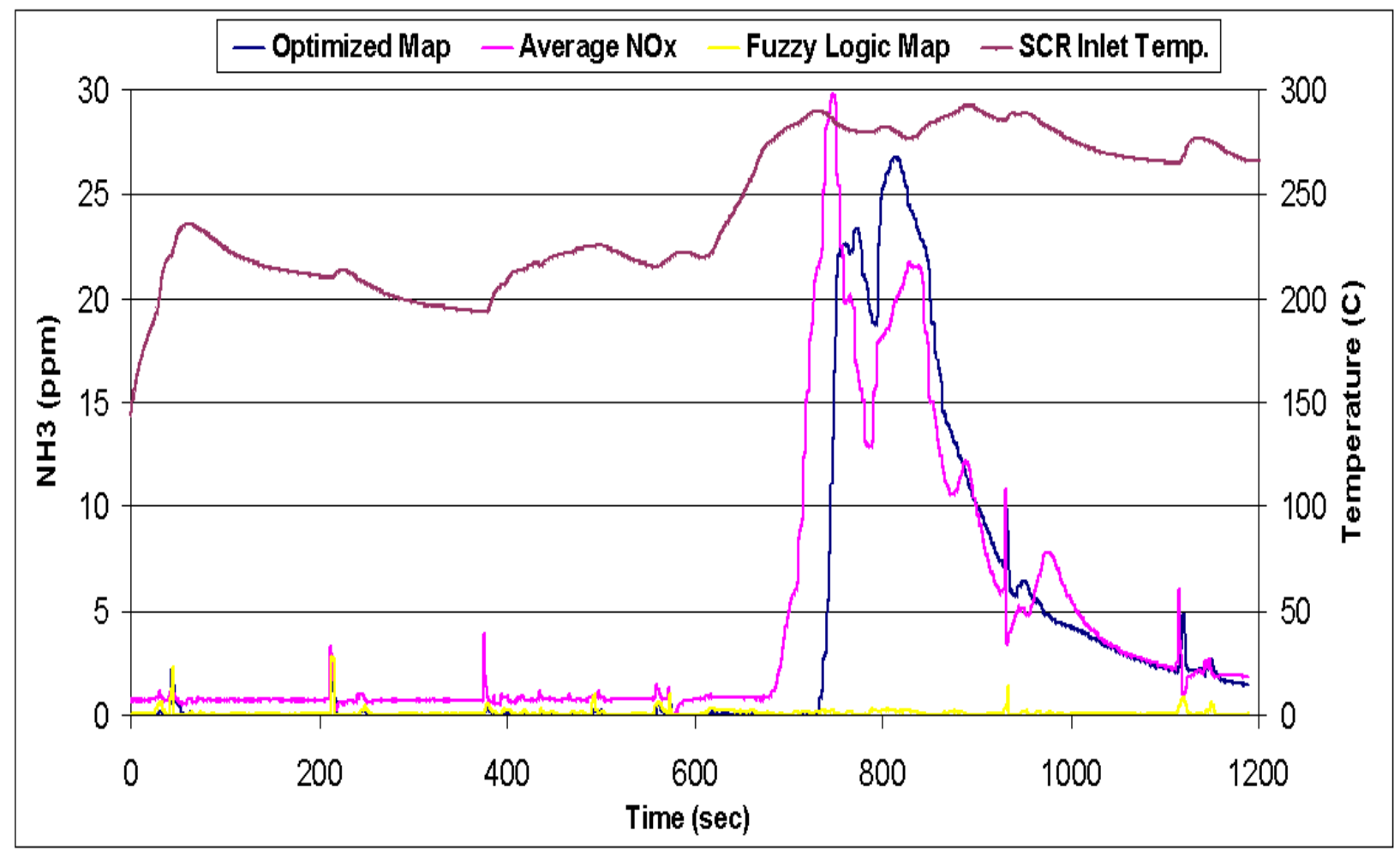

Figure 64 - FTP $\mathrm{NH}_{3}$ slip Values for Different Urea Maps

Figure 64 shows that the optimization and average $\mathrm{NO}_{\mathrm{x}}$ maps cause peaks of ammonia slip of approximately $30 \mathrm{ppm}$. It can also be seen that the ammonia slip occurs just as the SCR inlet temperature increases above $250^{\circ} \mathrm{C}$. The increase in temperature during the LAFY section 
causes the stored ammonia in the catalyst to be released. The ammonia slip level produced using the fuzzy logic method is completely negligible. Considering the results, it is seen that the average $\mathrm{NO}_{\mathrm{x}}$ method and the fuzzy logic method achieved the goals that were set for them. The average $\mathrm{NO}_{\mathrm{x}}$ was able to achieve similar reductions to the optimized map without the investment of time and engine testing. The fuzzy logic method was able to reduce a significant portion of the $\mathrm{NO}_{\mathrm{x}}$ while still completely reducing ammonia slip.

With the results found, an SCR model can be created similar to Johnson and Matthey's, which is shown in Figure 42. The model was created using the $\mathrm{SCR}$ efficiency, $\mathrm{NO}_{2} / \mathrm{NO}$ ratio and the SCR inlet temperature. The SCR efficiency and the $\mathrm{NO}_{2} / \mathrm{NO}$ ratio were averaged over an FTP cycle based upon ranges of the SCR inlet temperature. This was done for each method and the results are shown in the figure below.

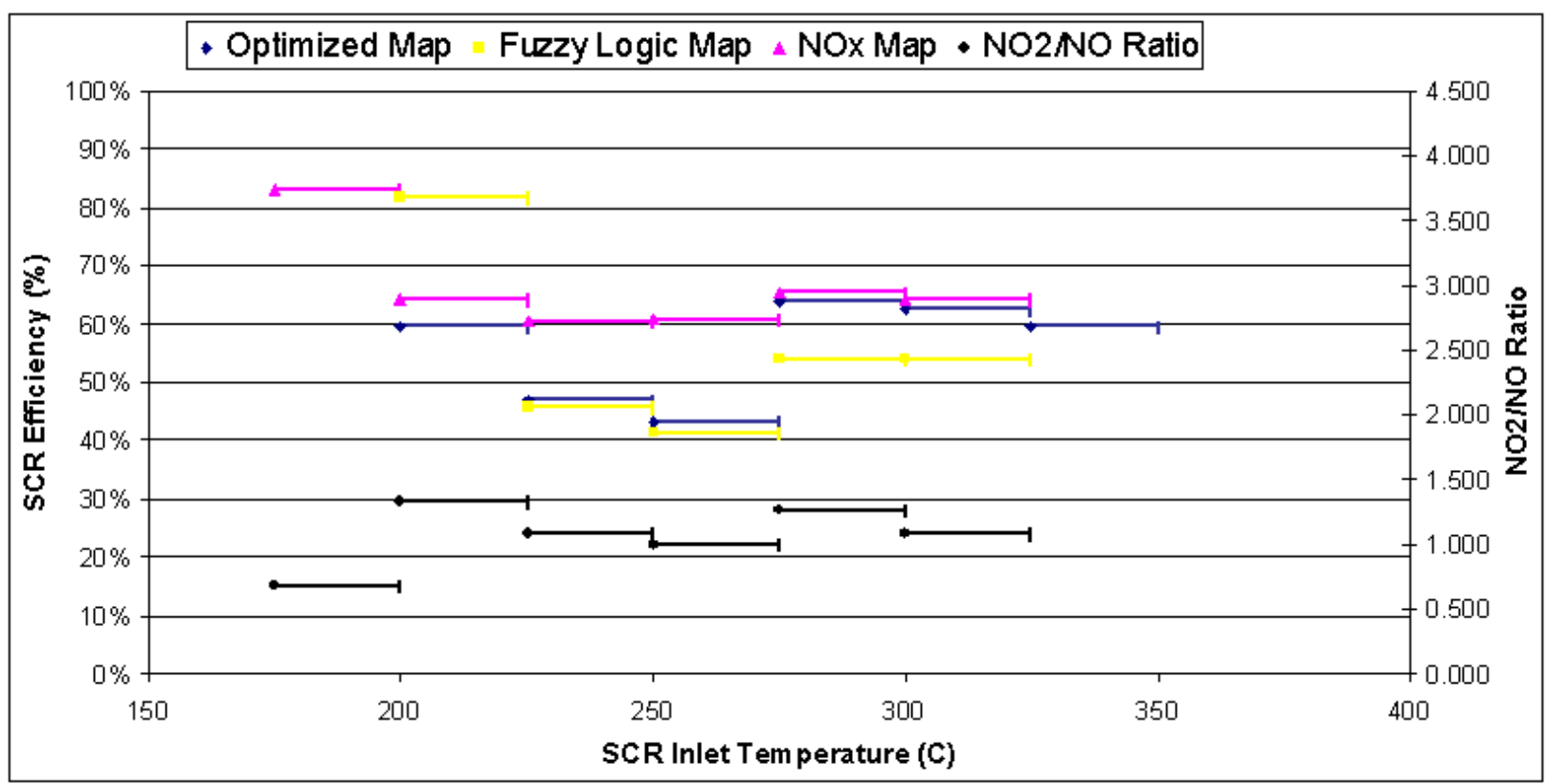

Figure 65 - SCR efficiency of each method based on ranges of temperature for an FTP cycle

Figure 65 shows the average values of the SCR efficiency and $\mathrm{NO}_{2} / \mathrm{NO}$ ratio for various temperature ranges during an FTP cycle. Using these values, a trend can be found for each of the methods, which will allow for the creation of an SCR model. This was done and is shown in Figure 66, below. 


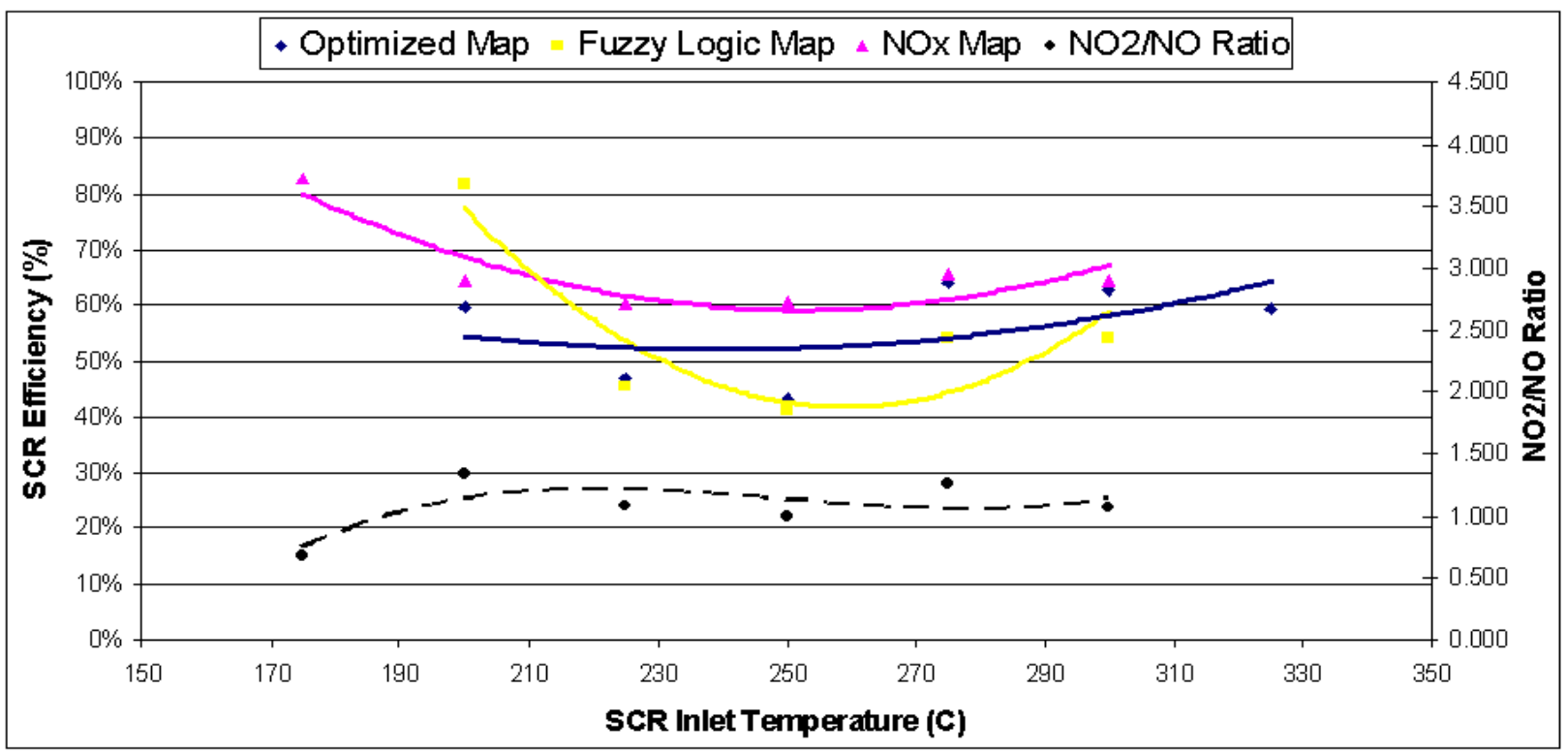

Figure 66 - SCR efficiency trends for each method during an FTP cycle

Figure 66 could be used in place of the model that was used to predict the fuzzy logic efficiency. One problem with using this model is the temperature of the FTP only ranges from $180^{\circ} \mathrm{C}$ to $300^{\circ} \mathrm{C}$, while the model used within the fuzzy logic program had a much broader temperature range. In order to get a wider temperature range, the FTP data based on temperature can be combined with the ESC data for the optimized map. The ESC cycle has a wider temperature range and gives a more representative model of the SCR system over a larger range.

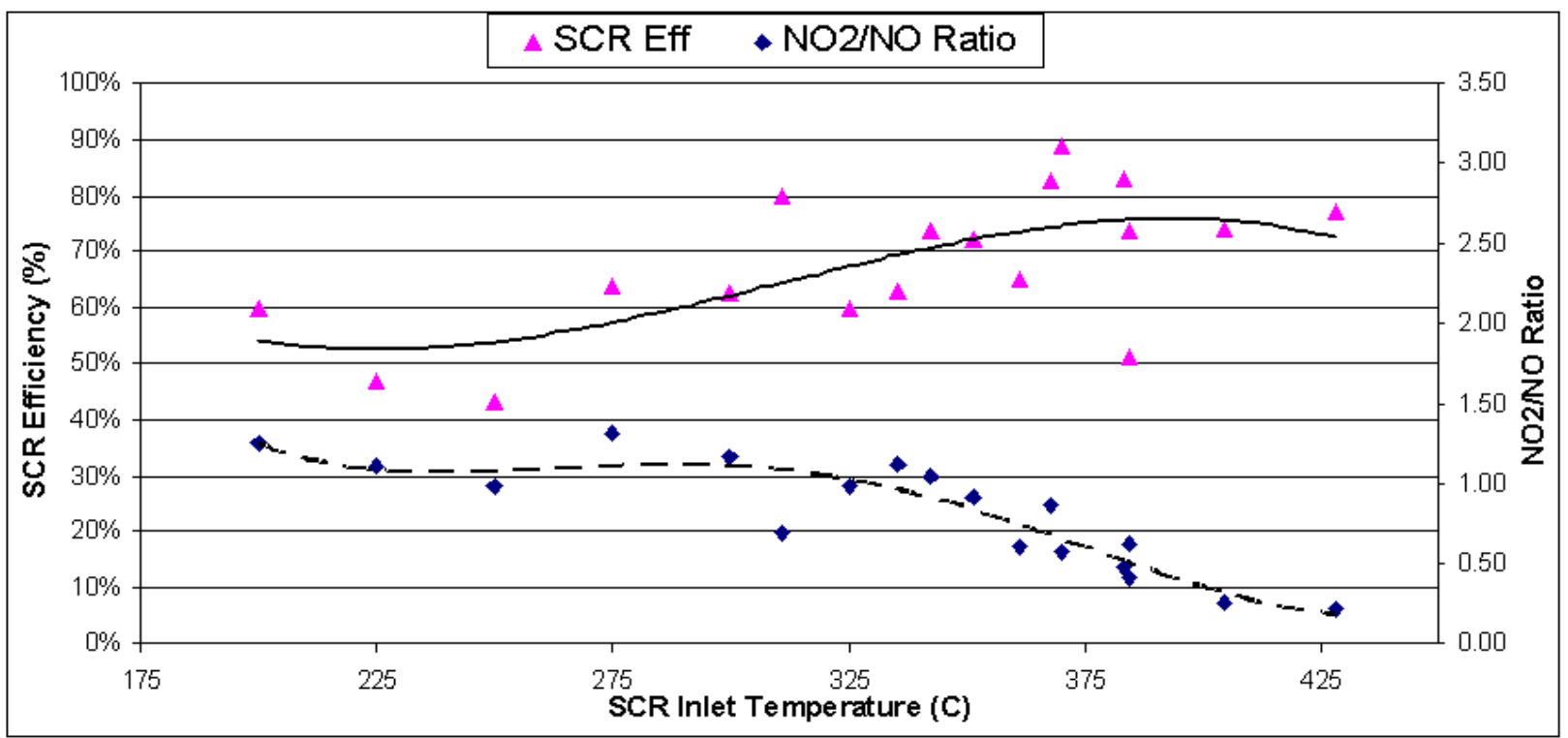

Figure 67 - SCR efficiency based on temperature using ESC and FTP data (optimized map) 
Figure 67 gives an SCR model with a temperature range of $180^{\circ} \mathrm{C}$ to $425^{\circ} \mathrm{C}$. This is a much wider range than with the FTP data alone and provides a good model to use in order to further optimize the fuzzy logic method.

\subsection{European Transient Cycle}

To investigate whether or not the urea injection maps created are cycle specific, both the optimized FTP urea map and the fuzzy logic FTP urea map were tested on the ETC cycle. The ETC is a much higher load intensive transient cycle than the FTP. It is longer and produces more $\mathrm{NO}_{\mathrm{x}}$ emissions. Table 25 summarizes the emissions produced during the ETC cycle.

Table 25 - ETC Emission Summary

\begin{tabular}{|c|c|c|c|c|c|c|c|c|c|c|}
\hline & & \begin{tabular}{|c|}
$\mathrm{HC}$ \\
$\mathrm{g} / \mathrm{bhp}-\mathrm{hr}$
\end{tabular} & $\begin{array}{c}\text { NOx } \\
\text { g/bhp-hr }\end{array}$ & $\begin{array}{c}\text { NO } \\
\text { g/bhp-hr }\end{array}$ & $\begin{array}{c}\text { CO } \\
\text { g/bhp-hr }\end{array}$ & $\begin{array}{c}\mathrm{CO}_{2} \\
\mathrm{~g} / \mathrm{bhp}-\mathrm{hr}\end{array}$ & $\begin{array}{c}\mathrm{NO}+\mathrm{N} \text { HHC } \\
\mathrm{g} / \mathrm{bhp}-\mathrm{hr}\end{array}$ & $\begin{array}{l}\text { FC carb } \\
\text { g/bhp-hr }\end{array}$ & $\begin{array}{l}\text { FC grav. } \\
\text { g/bhp-hr }\end{array}$ & $\begin{array}{c}\text { Work } \\
\text { bhp-hr }\end{array}$ \\
\hline \multicolumn{11}{|c|}{ DPF out (SCR Inlet) } \\
\hline ETC & Average & 0 & 1.16 & 0.58 & 0.17 & 541.17 & 1.17 & 9366.37 & 9680.00 & 55.05 \\
\hline \multicolumn{11}{|c|}{ Optimization Map } \\
\hline \multirow{3}{*}{ ETC } & Average & 0 & 0.41 & 0.17 & 0.13 & 544.70 & 0.41 & 9434.32 & 9660.00 & 55.10 \\
\hline & STD & 0 & 0.03 & 0.01 & 0.07 & 0.57 & 0.03 & 7.14 & 0.00 & 0.05 \\
\hline & $\mathrm{COV}$ & $140.1 \%$ & $7.1 \%$ & $6.9 \%$ & $53.7 \%$ & $0.1 \%$ & $7.3 \%$ & $0.1 \%$ & $0.0 \%$ & $0.1 \%$ \\
\hline \multicolumn{11}{|c|}{ Fuzzy Logic Map } \\
\hline \multirow{3}{*}{ ETC } & Average & 0 & 0.47 & 0.16 & 0.13 & 546.58 & 0.47 & 9459.42 & 9660.00 & 55.05 \\
\hline & STD & 0 & 0.02 & 0.01 & 0.02 & 0.36 & 0.02 & 6.45 & 20.00 & 0.01 \\
\hline & $\mathrm{COV}$ & $13.5 \%$ & $5.2 \%$ & $3.2 \%$ & $11.6 \%$ & $0.1 \%$ & $5.2 \%$ & $0.1 \%$ & $0.2 \%$ & $0.0 \%$ \\
\hline
\end{tabular}

From Table 25, it is seen that the engine produces $1.16 \mathrm{~g} / \mathrm{bhp}$-hr over the ETC compared to 0.96 $\mathrm{g} / \mathrm{bhp}$-hr during the FTP. Using the optimized and fuzzy logic FTP maps on the ETC cycle resulted in $\mathrm{NO}_{\mathrm{x}}$ reductions down to $0.41 \mathrm{~g} / \mathrm{bhp}-\mathrm{hr}$ and $0.47 \mathrm{~g} / \mathrm{bhp}-\mathrm{hr}$, respectively. Table 26 summarizes the $\mathrm{NO}_{\mathrm{x}}$ reduction for the ETC cycle.

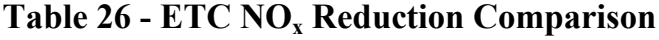

\begin{tabular}{|c|c|c|c|}
\hline $\begin{array}{c}\text { Urea Map } \\
\text { Method }\end{array}$ & NOx In & NOx Out & Reduction \\
\cline { 2 - 4 } & $\mathbf{g} / \mathbf{b h p}-\mathbf{h r}$ & $\mathbf{g} / \mathbf{b h p}-\mathbf{h r}$ & $\%$ \\
\hline Optimization & 1.16 & 0.41 & $65 \%$ \\
\hline Fuzzy Logic & 1.16 & 0.47 & $60 \%$ \\
\hline
\end{tabular}

As seen in the table, the optimized urea map reduced $\mathrm{NO}_{\mathrm{x}}$ by $65 \%$, which is $2 \%$ less than for the FTP. The fuzzy logic urea map reduced $\mathrm{NO}_{\mathrm{x}}$ by $60 \%$, which is $3 \%$ more reduction than on the 
FTP. A fuzzy logic map using ETC data could be created to further optimize the urea injection values. Also, the FTP and ETC data could be averaged together to get a map that may more accurately represent the transient operation range of the engine. A similar reduction of $\mathrm{NO}_{\mathrm{x}}$ on the ETC and FTP leads to the conclusion that the maps created for the FTP could be applied to other certification cycles. It is likely that these maps may be applied to any transient engine operation. The $\mathrm{NO}_{\mathrm{x}}$ produced during the ETC with the different urea injection maps is shown in Figure 68. Figure 69 shows the reduction of engine-out $\mathrm{NO}_{\mathrm{x}}$ by the optimized FTP urea map.

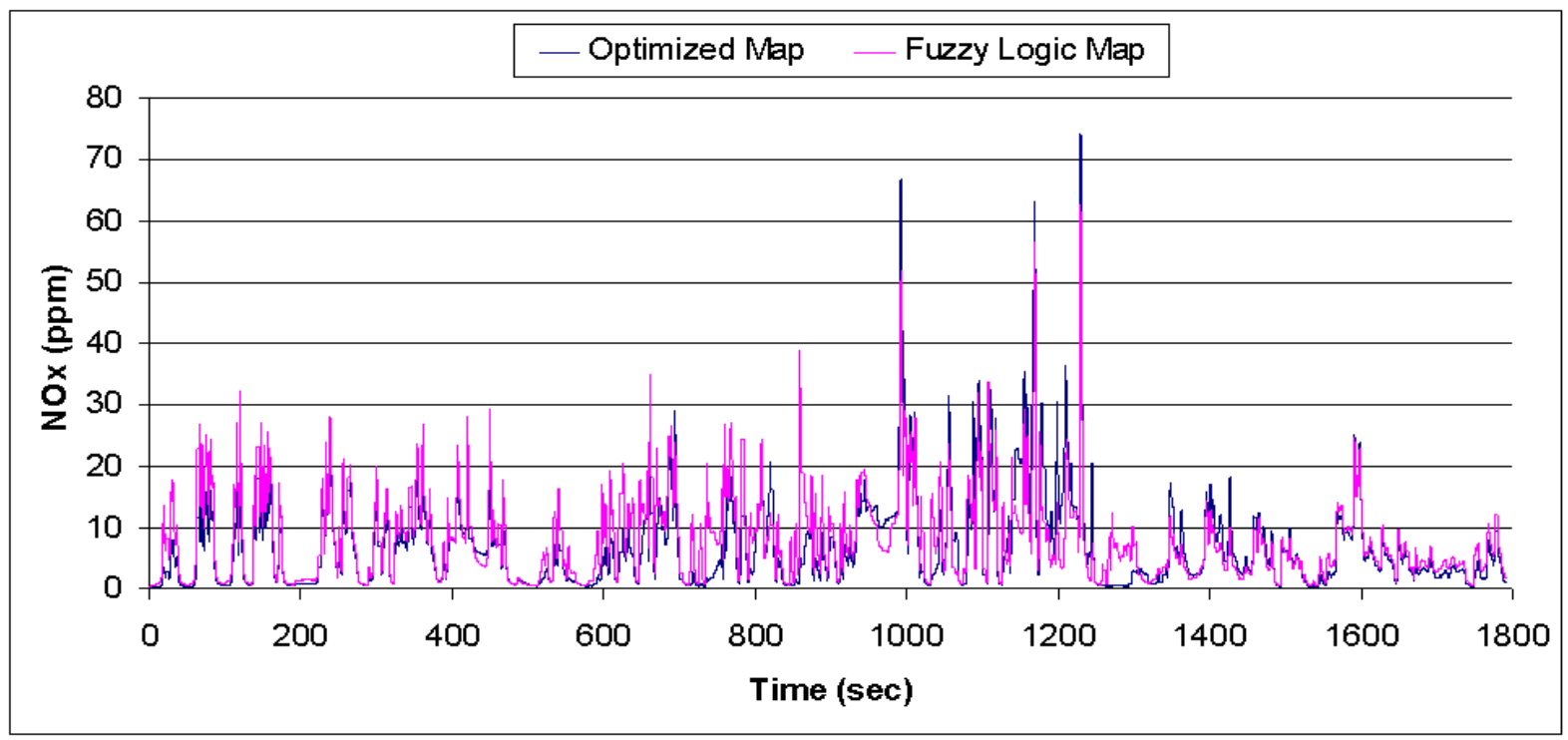

Figure 68 - ETC NO out -Urea Map Comparison

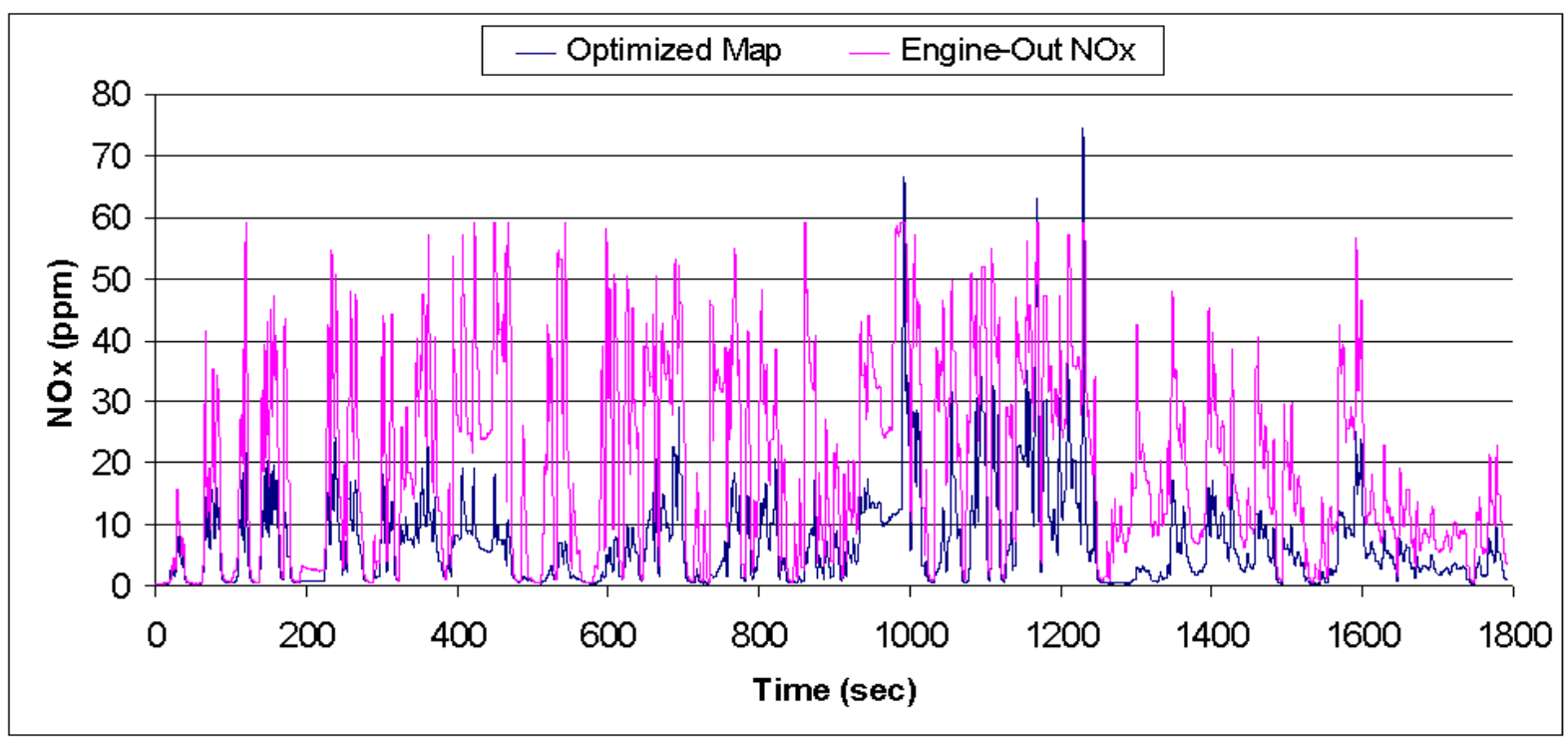

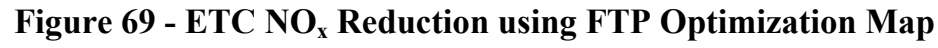


Figure 68 and Figure 69 show that the ETC consistently produces a higher level of $\mathrm{NO}_{\mathrm{x}}$ than the FTP. It is also seen that the fuzzy logic map allows for higher and more variable $\mathrm{NO}_{\mathrm{x}}$-out levels than the optimized map. Higher injection values of the optimized map allow for more $\mathrm{NH}_{3}$ adsorption by the catalyst. The adsorbed $\mathrm{NH}_{3}$ is then desorbed and utilized for conversion of $\mathrm{NO}_{\mathrm{x}}$ when there is a shortage of available ammonia. This reduces the variations of $\mathrm{NO}_{\mathrm{x}}$ that are seen with the fuzzy logic urea map. Neither the optimized nor the fuzzy logic map caused a significant amount of $\mathrm{NH}_{3}$ slip over the ETC cycle. This can be seen in Figure 70 below.

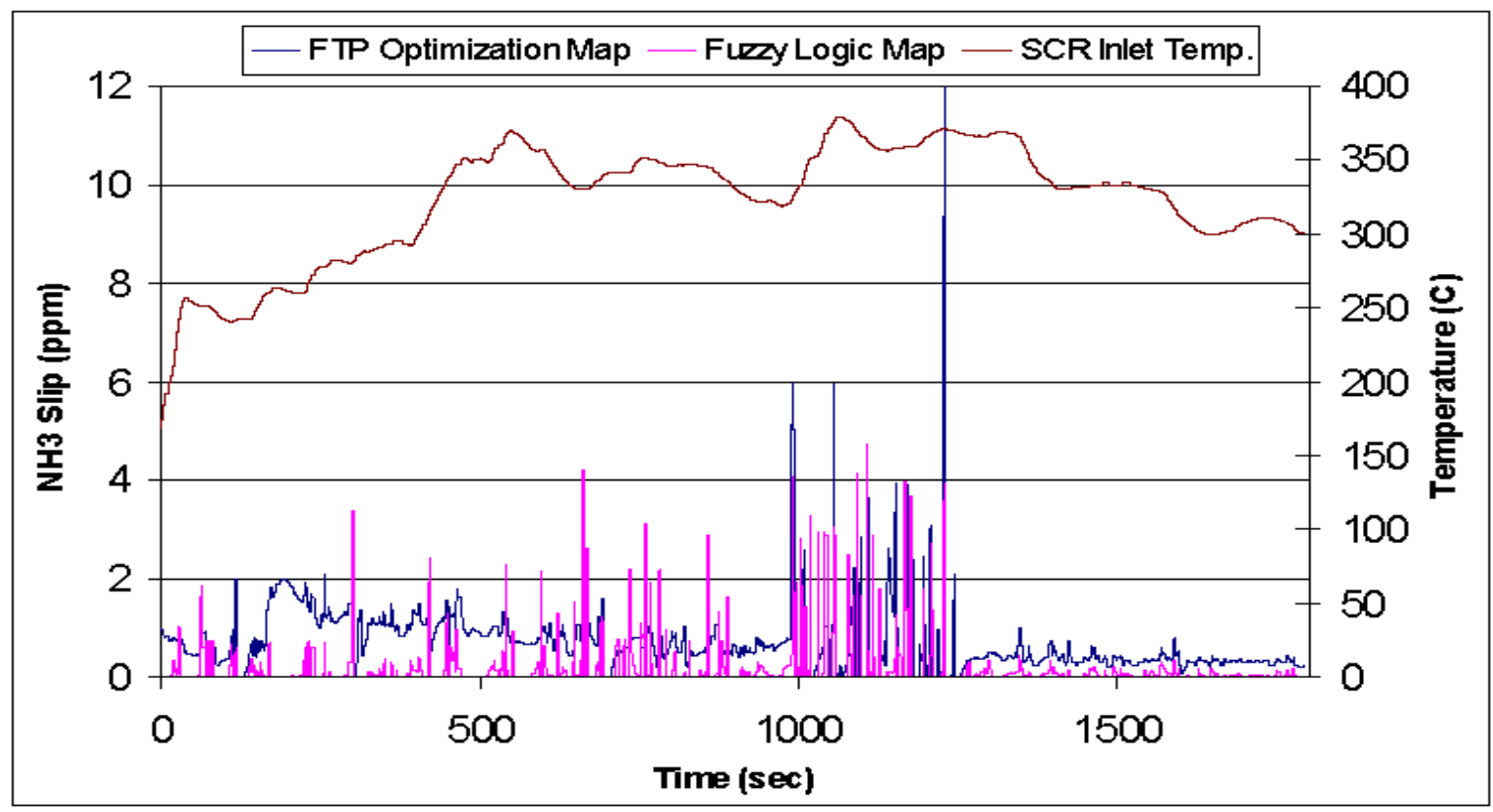

Figure 70 - ETC $\mathrm{NH}_{3}$ Slip Values for Different Urea Maps

In the figure above, it is seen that the $\mathrm{NH}_{3}$ slip of the fuzzy logic method is nearly negligible. There are a few peaks near 5 ppm but the average slip is negligible. The optimized map created slightly more $\mathrm{NH}_{3}$ slip with one peak reaching $12 \mathrm{ppm}$ but still had a very low average $\mathrm{NH}_{3}$ slip. Overall, the $\mathrm{NH}_{3}$ slip caused by each urea map is within acceptable levels of less than $10 \mathrm{ppm}$ average. Also, it is seen that the temperature at the SCR inlet is higher during an ETC cycle than the FTP. The temperature only gets to a maximum of about $300^{\circ} \mathrm{C}$ during the FTP. During the ETC, the temperature reaches $375^{\circ} \mathrm{C}$ and is above $300^{\circ} \mathrm{C}$ for the majority of the cycle. The minimal $\mathrm{NH}_{3}$ slip seen during the ETC can be partly due to the very high temperatures of the cycle. The catalyst is unable to absorb a large amount of ammonia at high temperatures; therefore, will not have any large releases of ammonia. In the FTP, the catalyst absorbs 
significant levels of $\mathrm{NH}_{3}$ during the first half of the test when the temperature is below $250^{\circ} \mathrm{C}$. Then the temperature rises and the $\mathrm{NH}_{3}$ is released. This does not happen in the ETC since the temperature stays above $300^{\circ} \mathrm{C}$ for most of the test.

An SCR model can be created using the ETC data in the same way as done for the FTP. The ETC has a wider range of temperatures and gives a more complete model than the FTP by itself. Figure 72 shows the average SCR efficiency values for various temperature ranges during the ETC cycle.

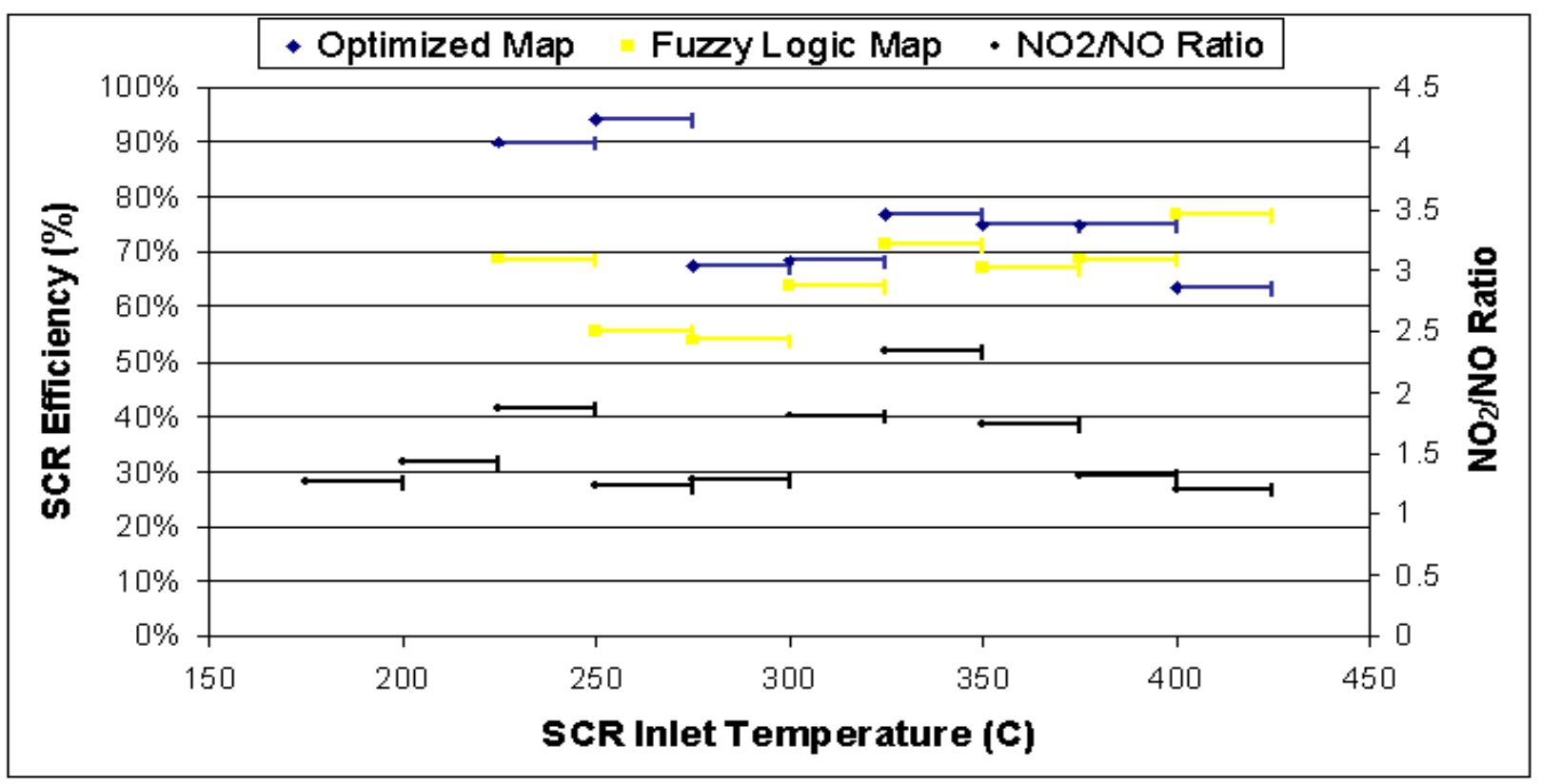

Figure 71 - SCR efficiency based on ranges of temperature for an ETC cycle

Adding a trendline to the data from Figure 71 gives the same type of SCR model created before for the FTP, but for the ETC instead. The model is shown in Figure 72 below and is representative of the SCR behavior. It could be combined with the data from the FTP to create an even better SCR model, which may be used to improve the fuzzy logic method. Combining the data for the various test cycles would give a wide temperature range for the model that would be more representative of the engine operational range. The ETC model is shown below. 


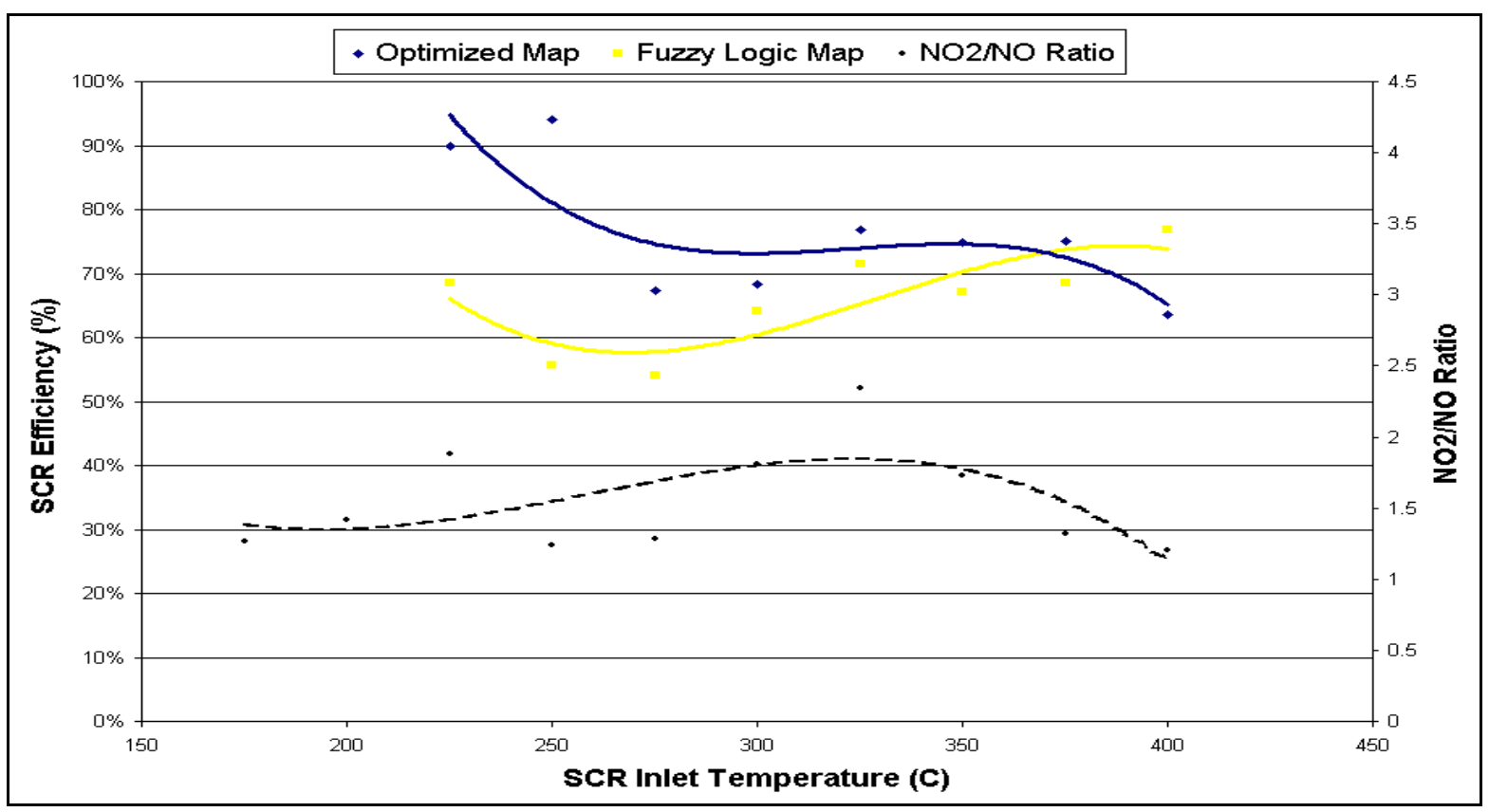

Figure 72 - SCR efficiency over the ETC temperature range

Figure 72 shows that the fuzzy logic map has lower SCR efficiency at lower temperatures. This is a direct result of the SCR efficiency prediction used within the fuzzy logic program. At low temperatures, the SCR is not able to convert $\mathrm{NO}_{\mathrm{x}}$ as efficiently. The fuzzy logic program takes this into account when creating the injection map, and is the reason the fuzzy logic map does not create any significant ammonia slip values. The optimized map injects an excess of ammonia at low temperatures during the FTP cycle. This creates higher $\mathrm{NO}_{\mathrm{x}}$ conversion but also increases $\mathrm{NH}_{3}$ slip and adsorption. When the temperature increases, the excess adsorbed by the catalyst is released and a large $\mathrm{NH}_{3}$ slip value is observed. 


\section{Conclusions and Recommendations}

\subsection{Conclusions}

The main objective of this study was to create a fuzzy logic model for controlling urea dosage during transient operation of the engine. In addition to the fuzzy logic urea map, two other maps, namely the optimized map and the average $\mathrm{NO}_{\mathrm{x}}$ map were also developed, qualified and tested. The program was implemented with an open loop urea map control strategy, without the use of $\mathrm{NO}_{\mathrm{x}}$ or $\mathrm{NH}_{3}$ sensors. The final fuzzy logic urea map created was able to reduce $\mathrm{NO}_{\mathrm{x}}$ by $57 \%$ over the FTP cycle and $60 \%$ over the ETC cycle. This reduction was achieved without causing any significant ammonia slip. The optimized and average $\mathrm{NO}_{\mathrm{x}}$ urea maps reduced $\mathrm{NO}_{\mathrm{x}}$ by $67 \%$ and $66 \%$ over the FTP cycle, but also resulted in large peaks of ammonia slip during the LAFY section. The $\mathrm{NH}_{3}$ slip seen during the FTP had a large peak of $30 \mathrm{ppm}$ but the average

$\mathrm{NH}_{3}$ slip over the entire cycle was less than $10 \mathrm{ppm}$, which was deemed acceptable. The optimized map was also used on the ETC cycle and $\mathrm{NO}_{\mathrm{x}}$ was reduced by $65 \%$ with no significant $\mathrm{NH}_{3}$ slip. The urea maps created for this study were cycle independent and may be used to control $\mathrm{NO}_{\mathrm{x}}$ emissions for any transient mode of engine operation.

The optimization method gave valuable insight into the SCR system. From the optimization testing, it was seen that injecting stoichiometric values of $\mathrm{NH}_{3}$ is inadequate to achieve high levels of $\mathrm{NO}_{\mathrm{x}}$ reduction. This is due to the efficiency of hydrolysis reactions, incomplete vaporization, pump injection error, $\mathrm{NH}_{3}$ adsorption and undesirable $\mathrm{SCR}$ reactions. Incomplete vaporization was the major limiting factor. Urea was seen to condense and pool prior to the SCR inlet resulting in a large loss of available $\mathrm{NH}_{3}$ for reaction. A scaling factor was determined to correct for this and was used in both the average $\mathrm{NO}_{\mathrm{x}}$ and fuzzy logic methods. The average $\mathrm{NO}_{\mathrm{x}}$ method was able to significantly reduce the investment of time, costs and testing needed to create a high $\mathrm{NO}_{\mathrm{x}}$ reduction urea map. The fuzzy logic method was able to predict an SCR efficiency that accurately represented the condition of the SCR system, which allowed for the successful reduction of $\mathrm{NO}_{x}$ without $\mathrm{NH}_{3}$ slip. The fuzzy logic program was seen to be a very robust system that could handle large variations of input values and still produce accurate outputs. The open loop urea map approach used in conjunction with fuzzy logic techniques was shown to be a legitimate control strategy that could be adapted in the future to further optimize $\mathrm{NO}_{\mathrm{x}}$ reduction by SCR systems. 
Temperature was shown to play an important role in the behavior of the SCR system. At low temperatures, the catalyst was able to adsorb a large amount of $\mathrm{NH}_{3}$, while at very high temperatures adsorption becomes negligible. The SCR efficiency was shown to have a large dependence on the temperature. Higher temperatures of the catalyst allowed for higher conversion efficiencies of $\mathrm{NO}_{\mathrm{x}}$. The efficiency was also shown to depend on the $\mathrm{NO}_{2} / \mathrm{NO}$ ratio but to a lesser extent than the temperature. The optimized and average $\mathrm{NO}_{\mathrm{x}}$ methods did not account for the temperature of the system while the fuzzy logic method did. The $\mathrm{NH}_{3}$ slip caused by the optimized and average $\mathrm{NO}_{\mathrm{x}}$ maps during the LAFY section of the FTP was a direct result of over-injection of urea at low system temperatures.

\subsection{Recommendations}

To improve the urea maps created, a more in depth study of the adsorption/desorption of the catalyst should be undertaken. By having a sensor inside the SCR to monitor the actual catalyst brick temperature, it would be possible to create a more accurate model that better takes into account the adsorption/desorption of ammonia. This would allow for improved control of the $\mathrm{NH}_{3}$ slip throughout each cycle, especially the FTP. Also more research should be done regarding the losses of the system and where they originate. This would allow for more accurate scaling of the stoichiometric $\mathrm{NH}_{3}$ amount. More accurate urea injection by the pump would be very beneficial and may be achieved by decreasing the size of the urea injection step. The step used for this study was $0.36 \mathrm{~kg} / \mathrm{hr}$. At low $\mathrm{NO}_{\mathrm{x}}$ levels, this step size can create $\mathrm{NH}_{3}$ slip due to over-injection of urea. Decreasing the step size would also help to smooth out the urea maps by reducing the magnitude of the difference in urea injection values between two consecutive points within the maps.

The fuzzy logic program can also be improved to increase the accuracy of urea injection. Some possible changes could be the size of the inference rule matrix and number of membership functions. Increasing the number of membership functions would allow for a larger inference rule matrix. This could significantly improve the SCR prediction model. Also the inference rules used were based upon the SCR model shown in Figure 42, which may be different than the actual behavior of the SCR system used in this study. The SCR model created from FTP and ESC data and shown in the results section would allow for a better model of the system. The membership function shapes could also be changed to a bell shaped MF to eliminate any 
discontinuities in the command produced. Another improvement could be obtained by using both the FTP and ETC data together in order to create the SCR efficiency model and fuzzy logic urea maps. This would input many more points of transient operation to allow for a more accurate representation of the system. 


\section{References}

1. Walker, Andrew P., Allanson, Ronny, Blakeman, Philip G. and Lavenius, Mats. "The Development and Performance of the Compact SCR-Trap System: A 4-way Diesel Emission Control System.” SAE Paper No. 2003-01-0778.

2. Willems, Frank, Cloudt, Robert, van den Eijnden, Edwin. "Is Closed-Loop SCR Control Required to Meet Future Emission Targets?” SAE Paper No. 2007-01-1574.

3. "Health and Environmental Impacts of $\mathrm{NO}_{\mathrm{x}}$." United States Environmental Protection Agency. 23 June 2008. <http://www.epa.gov/airprogm/oar/urbanair/nox/hlth.html>.

4. Pulkrabek, Willard W. "Engineering Fundamentals of the Internal Combustion Engine." $2^{\text {nd }}$ ed. Upper Saddle River, NJ: Pearson Prentice Hall, 2004.

5. Tree, Dale R. and Cooley, William B. "A Comparison and Model of $\mathrm{NO}_{\mathrm{x}}$ Formation for Diesel Fuel and Diethyl Ether.” SAE Paper No. 2001-01-0654.

6. Borman, Gary L., and Ragland, Kenneth W. "Combustion Engineering." 1st ed. Madison, WI: WCB/McGraw-Hill, 1998.

7. Clark, Nigel and Thompson, Gregory. "Selective $\mathrm{NO}_{\mathrm{x}}$ Recirculation for Stationary LeanBurn Natural Gas Engines.” Technical Progress Report. West Virginia University. 28 Dec 2005.

8. Renshan, Liu and Zhang, Chao. "A Numerical Study of $\mathrm{NO}_{\mathrm{x}}$ Reduction for a DI Diesel Engine with Complex Geometry.” Journal of Energy Resources Technology. Vol. 126. March 2004.

9. Rente, T., Gjirja, S. and Denbratt, I. "Experimental Investigation of the Effect of Needle Opening Pressure (NOP) on Combustion and Emissions Formation in a Heavy Duty DI Diesel Engine.” SAE Paper No. 2004-01-2921.

10. Gieshoff, J., A. Schafer-Sindlinger, and P.C. Spurk. "Improved SCR Systems for Heavy Duty Applications.” SAE Paper No. 2000-01-0189.

11. Miller, William R. and Klein, John T. "The Development of Urea-SCR Technology for US Heavy Duty Trucks.” SAE Paper No. 2000-01-0190.

12. Kim, Jeong Y., Cavataio, Giovanni and Patterson, Joseph E. "Laboratory Studies and Mathematical Modeling of Urea SCR Catalyst Performance.” SAE Paper No. 2007-011573. 
13. Huang, S.C., R. C. Yu, A.S. Cole and B.J. Stroia. "Development of Diesel Exhaust Aftertreatment System for Tier II Emissions.” SAE Paper No. 2002-01-1867.

14. Penetrante, Bernie M., Brusasco, Raymond C. and Wander, Joseph D. "Plasma-Assisted Catalytic Reduction of $\mathrm{NO}_{\mathrm{x}}$ from Stationary Engines.” SERDP Project CP-1077. Air Force Research Laboratory. 15 Jul 2001.

15. "Diesel Oxidation Catalyst." DieselNet. 2002. 16 Jul 2008.

$<$ http://www.dieselnet.com/tech/cat_doc.html $>$.

16. “Diesel Particulate Filter.” DieselNet. 2001. 16 Jul 2008.

$<$ http://www.dieselnet.com/tech/dpf_top.html $>$.

17. Song, Qingwen and Zhu, George. "Model Based Closed Loop Control of Urea SCR Exhaust Aftertreatment System for a Diesel Engine.” SAE Paper No. 2002-01-0287.

18. "Smart $\mathrm{NO}_{\mathrm{x}}$ Sensor." Siemens VDO/NGK. 7 Jul 2008. <http://www.siemensvdo.com>.

19. Perhinschi, Mario G. Class Notes/Handouts. Artificial Intelligence Techniques in Engineering. February 2007.

20. Kaehler, Steven D. “Fuzzy Logic-An Introduction.” Encoder Newsletter. March 1998. Seattle Robotics Society. 10 Jul 2008. <http://www.seattlerobotics.org/encoder/Mar98/fuz>.

21. Ardanese, Michelangelo. "Simple Strategy-Based Technique to Reduce Emissions from SCR-equipped Heavy-Duty Diesel Engines over Different Engine-Out Calibrations.” Ph.D. Dissertation, Dept. of Mechanical and Aerospace Engineering, West Virginia University. Morgantown, WV. August 2008.

22. Ardanese, Raffaello. "Control of $\mathrm{NO}_{\mathrm{x}}$ and PM Emissions from SCR-equipped 2010 Compliant Heavy Duty Diesel Engines over Different Engine-Out Calibrations.” Ph.D. Dissertation, Dept. of Mechanical and Aerospace Engineering, West Virginia University. Morgantown, WV. August 2008.

23. "Heavy-Duty FTP Transient Cycle.” DieselNet. 1999. 23 Jul 2008. $<\mathrm{http}: / /$ www.dieselnet.com/standards/cycles/ftp_trans.html $>$.

24. “AVL 8-Mode Heavy Duty Cycle.” DieselNet. 2000. 23 Jul 2008. $<$ http://www.dieselnet.com/standards/cycles/avl_8mode.html $>$.

25. Chi, John N. and DaCosta, Herbert F.M. "Modeling and Control of a Urea-SCR Aftertreatment System.” SAE Paper No. 2005-01-0966.

26. "SCR Dosage Urea System Calibration.” Volvo Presentation, 2008. 24 Jul 2008. 


\section{Appendix A - Fuzzy Logic Control Code}

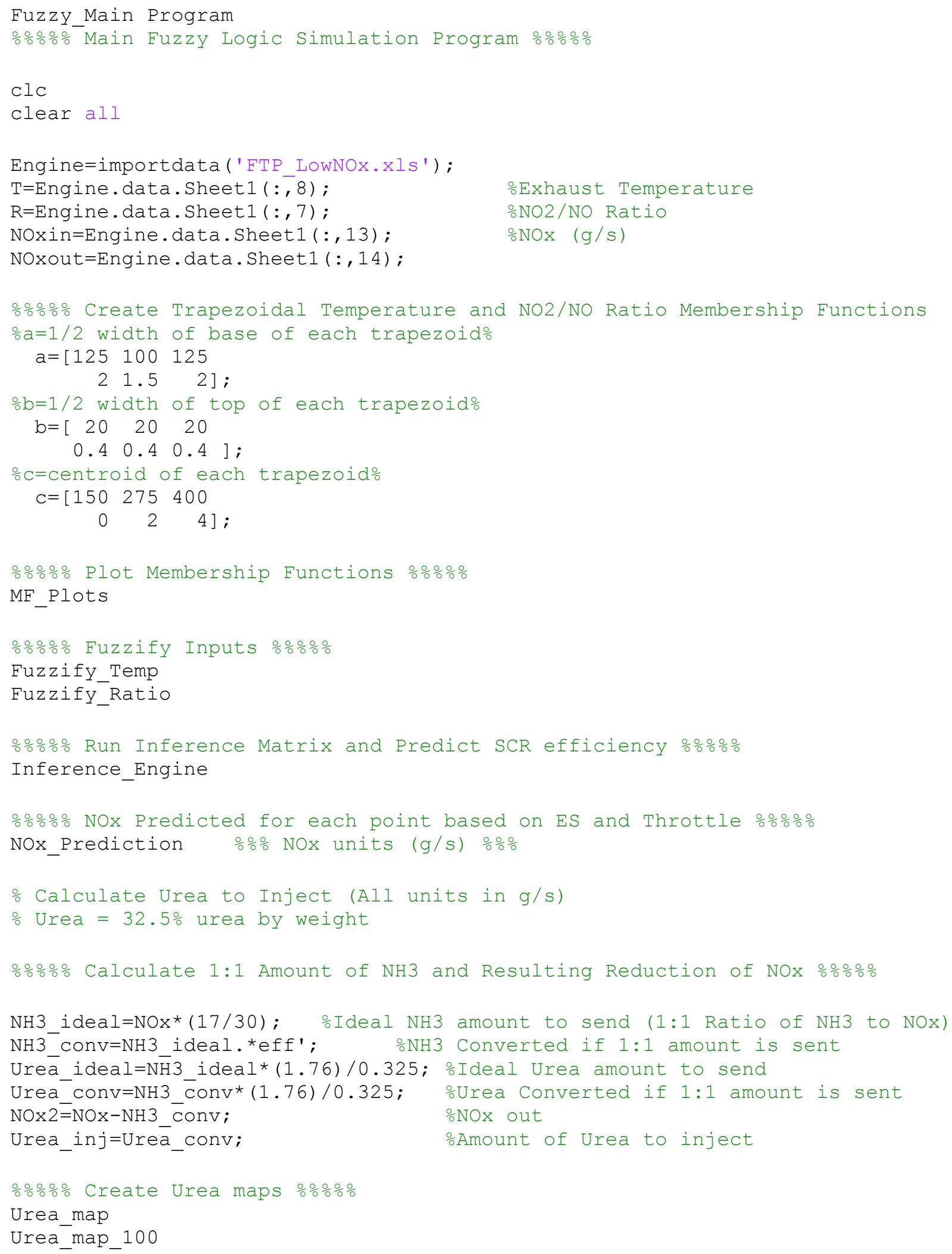


oCalculate predicted percent reduction of $\mathrm{NOx}$

$\mathrm{N} 1=\operatorname{sum}(\mathrm{NOx}) ;$

$\mathrm{N} 2=\operatorname{sum}(\mathrm{NO} \times 2)$;

Calculate Predicted Reduction Percentage of NOx

ReductionPerc $=((\mathrm{N} 1-\mathrm{N} 2) / \mathrm{N} 1) * 100$;

\section{Fuzzify_Temp.m}

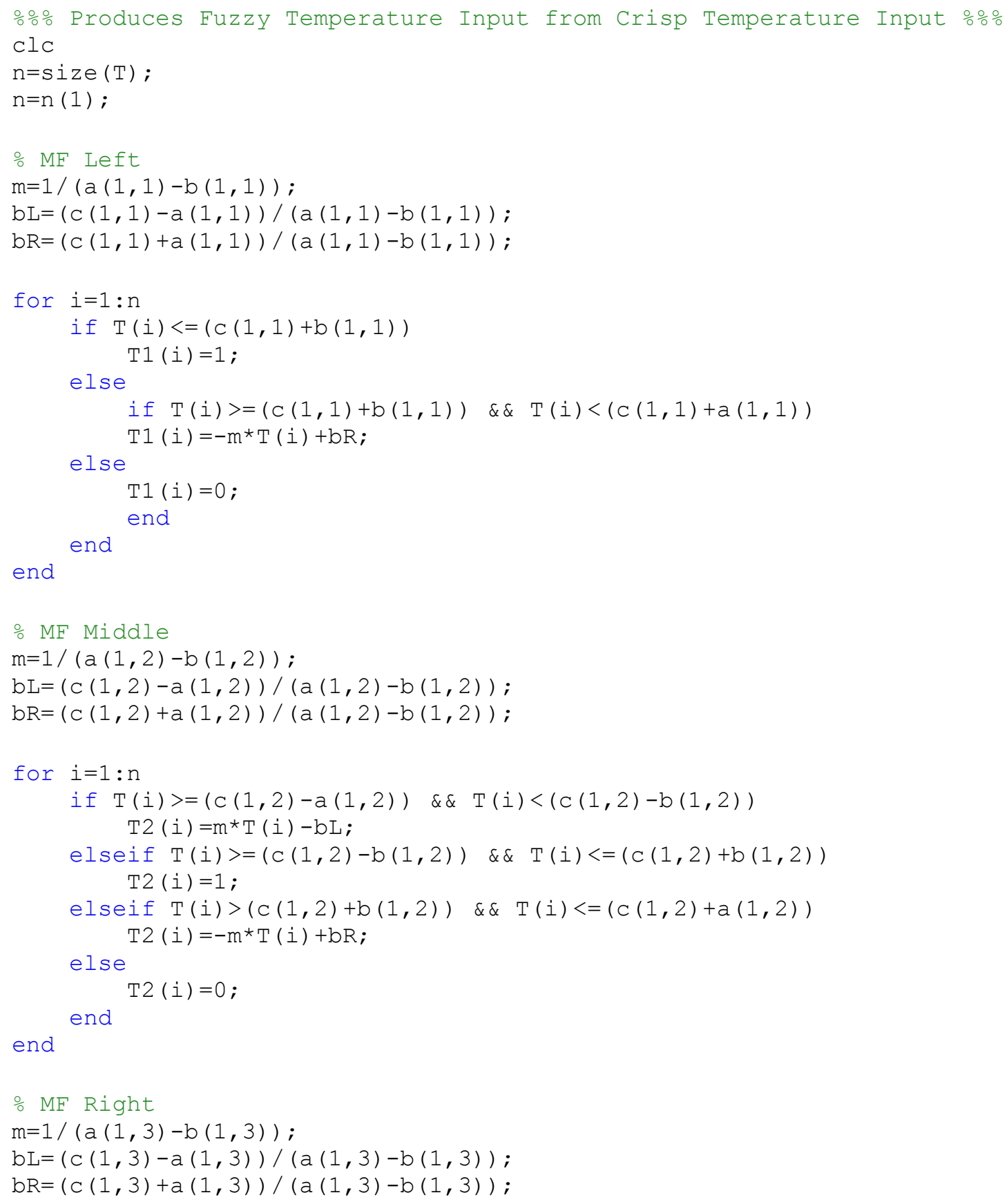




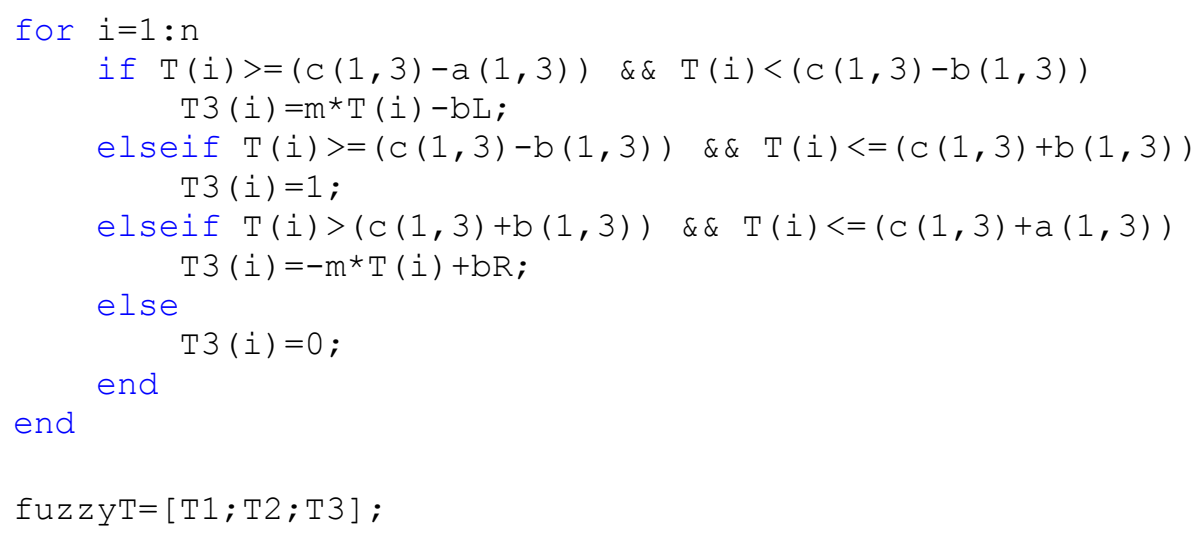

\section{Fuzzify_Ratio.m}

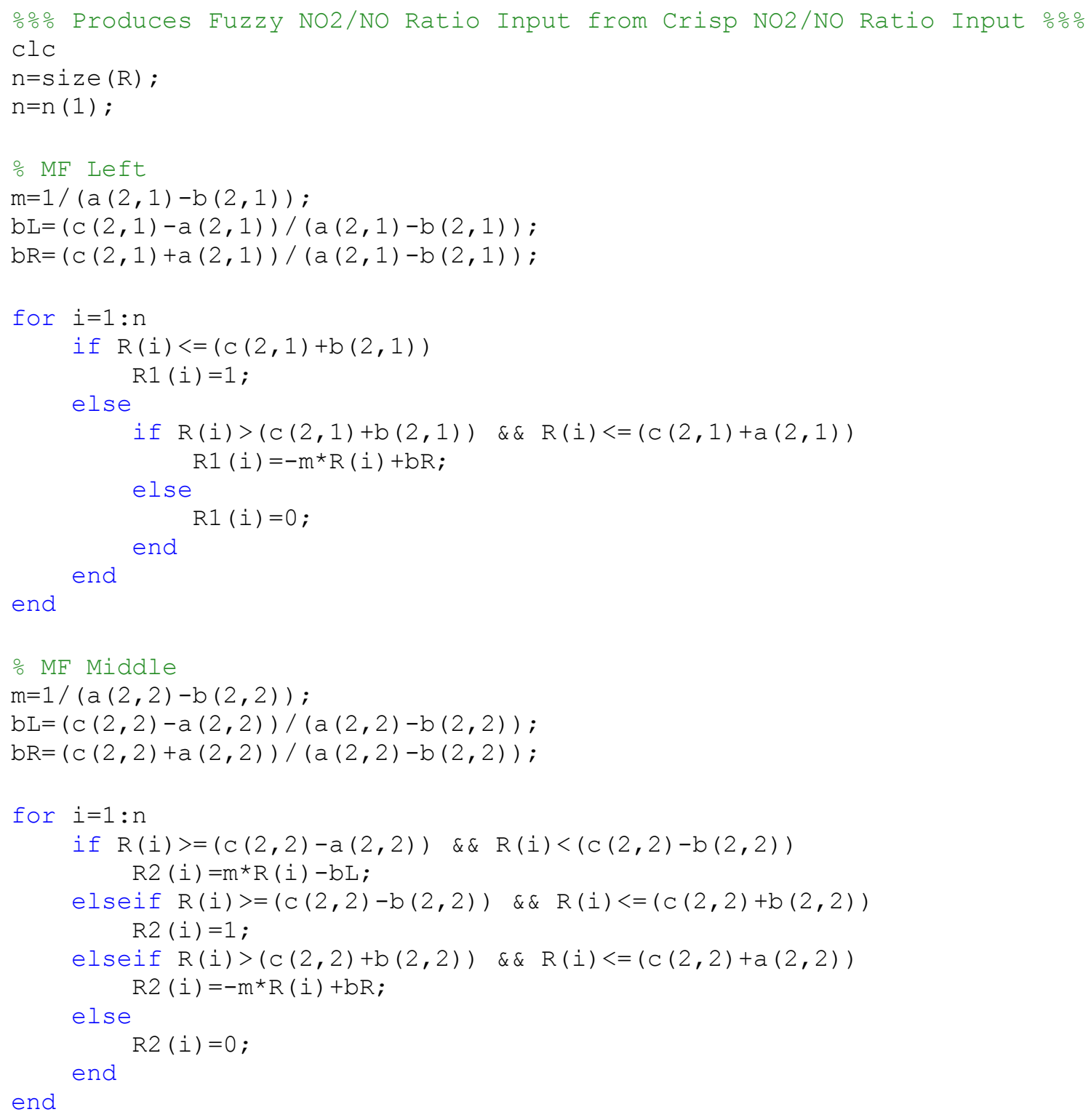




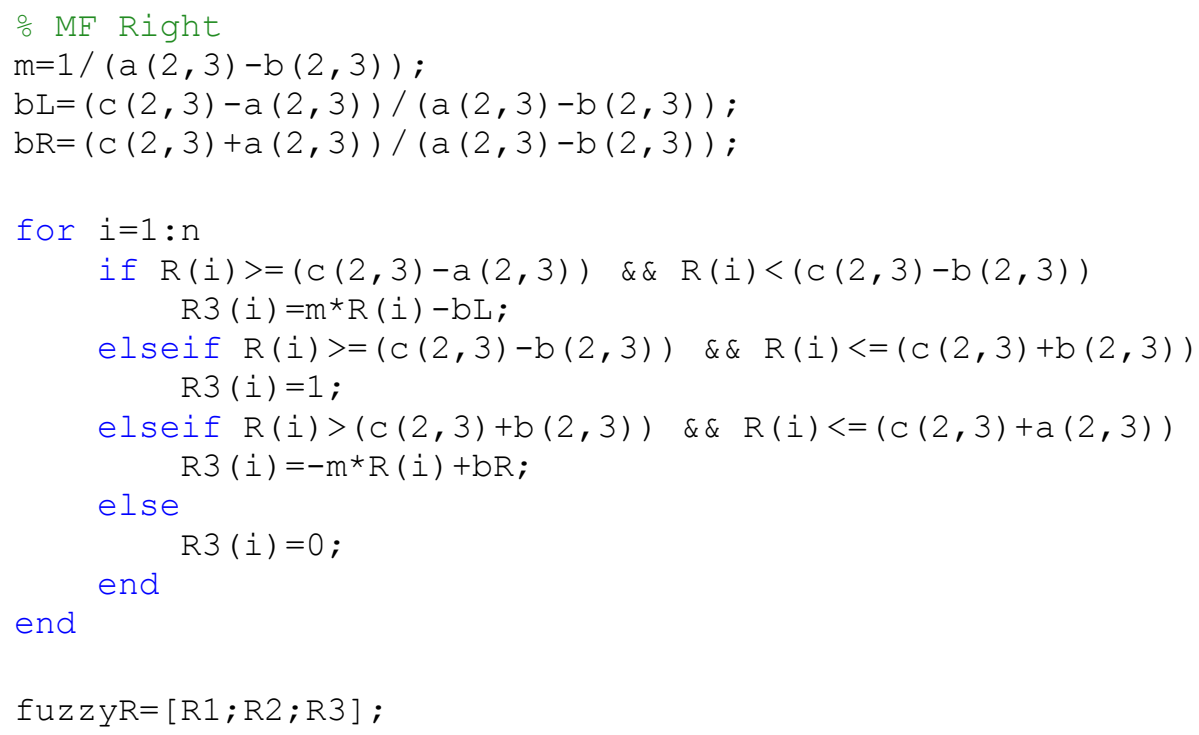

\section{Inference_Engine.m}

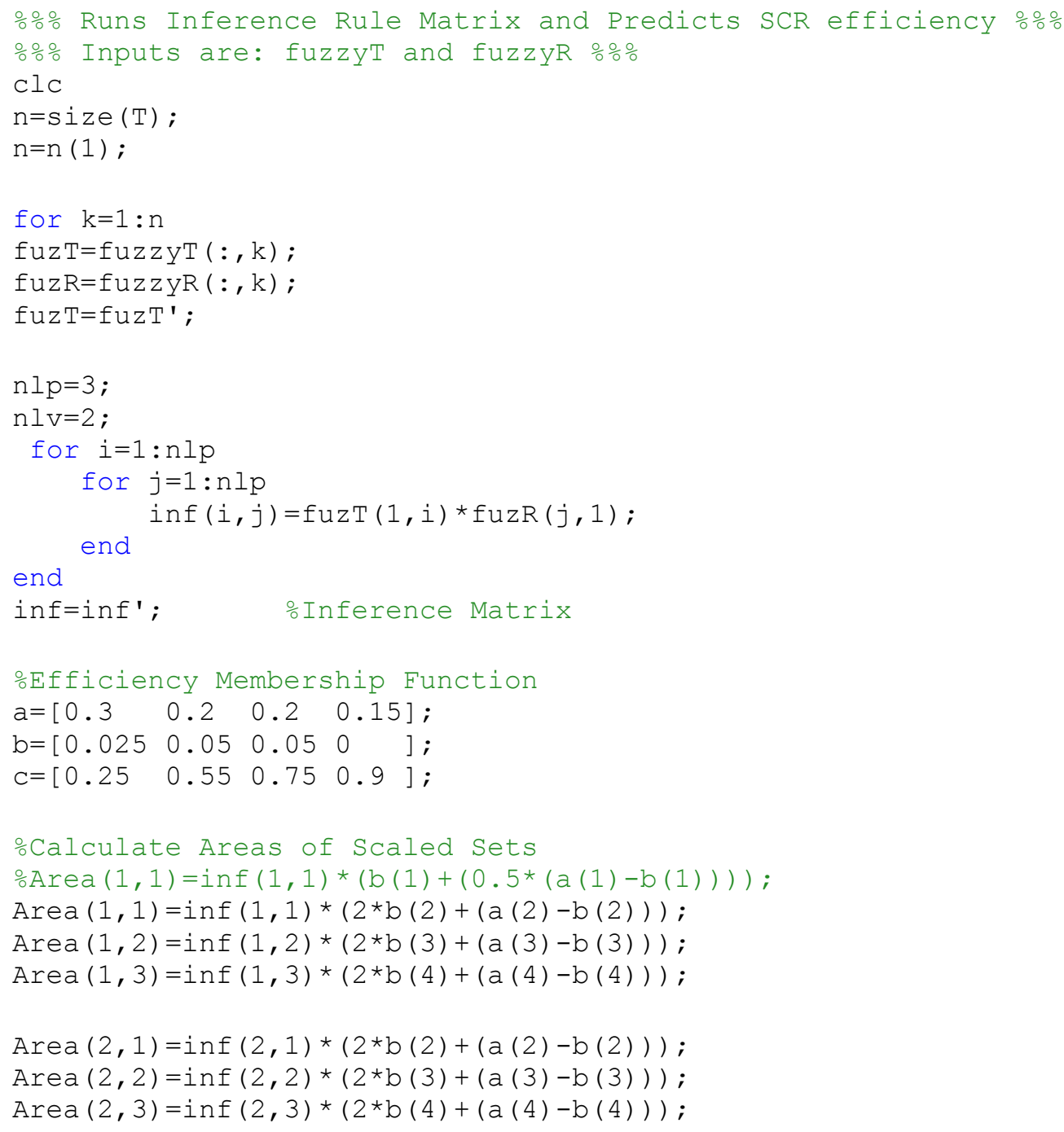




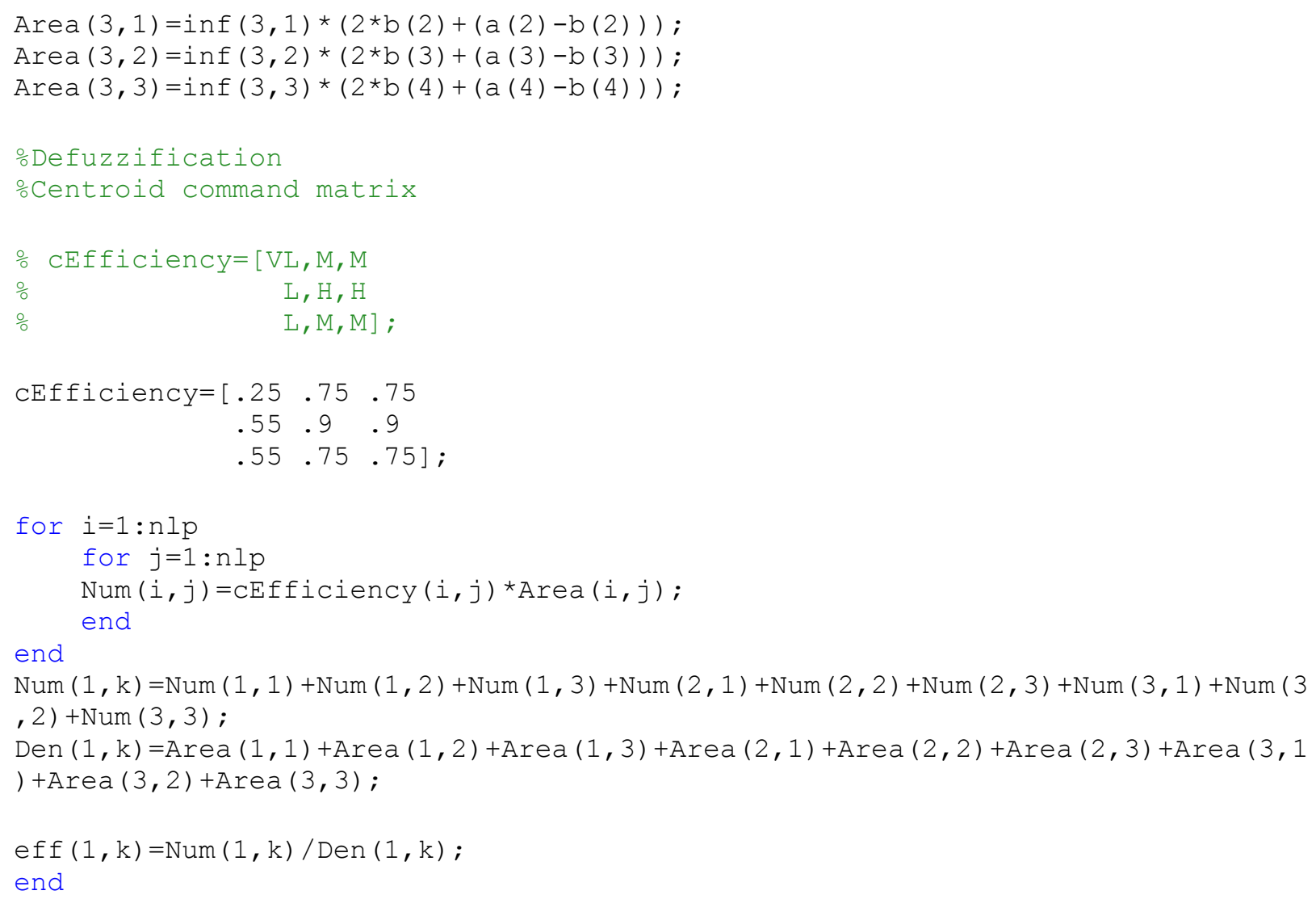

\section{$\mathrm{NO}_{\mathrm{x}_{-}}$Prediction.m}

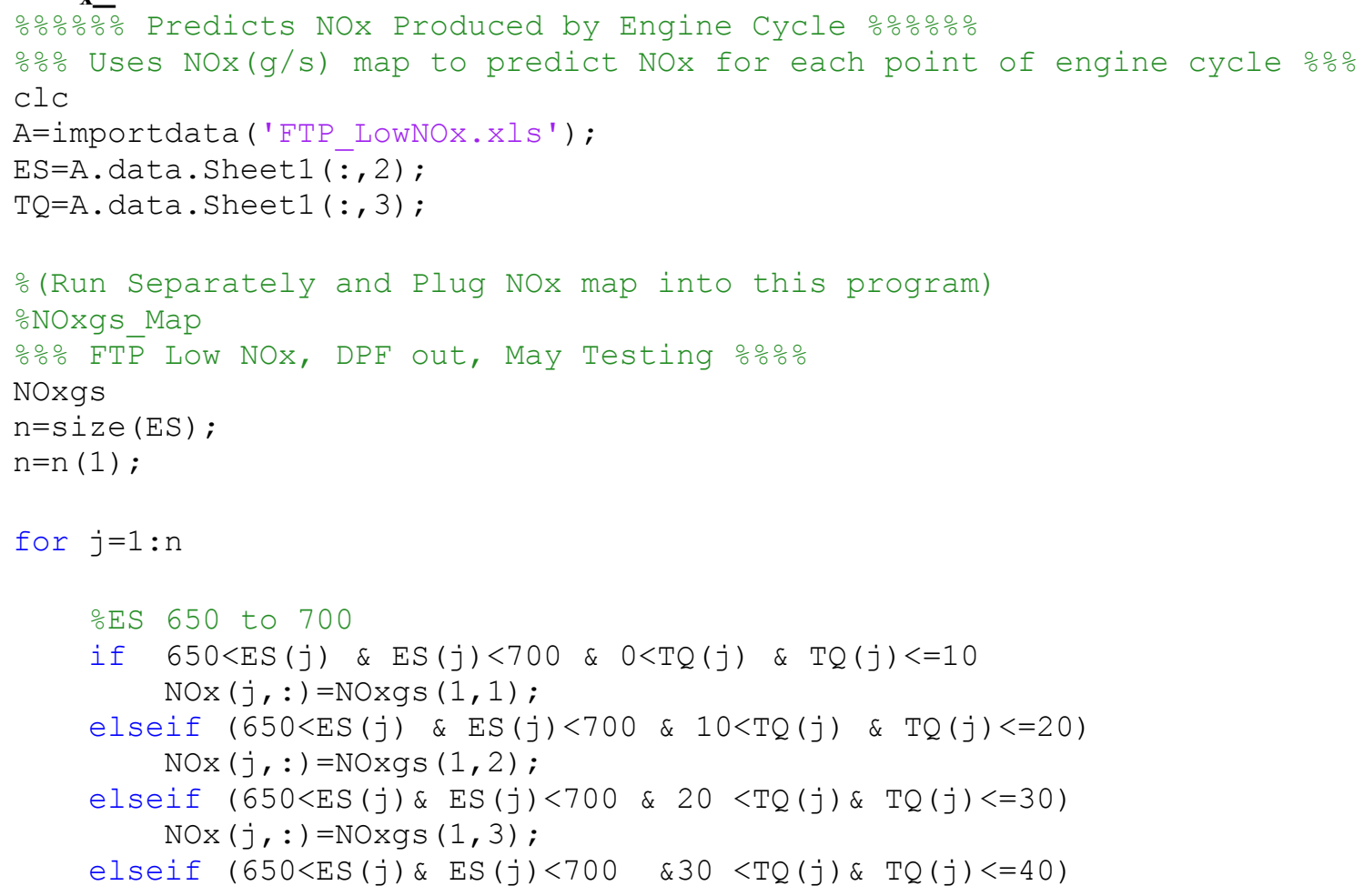




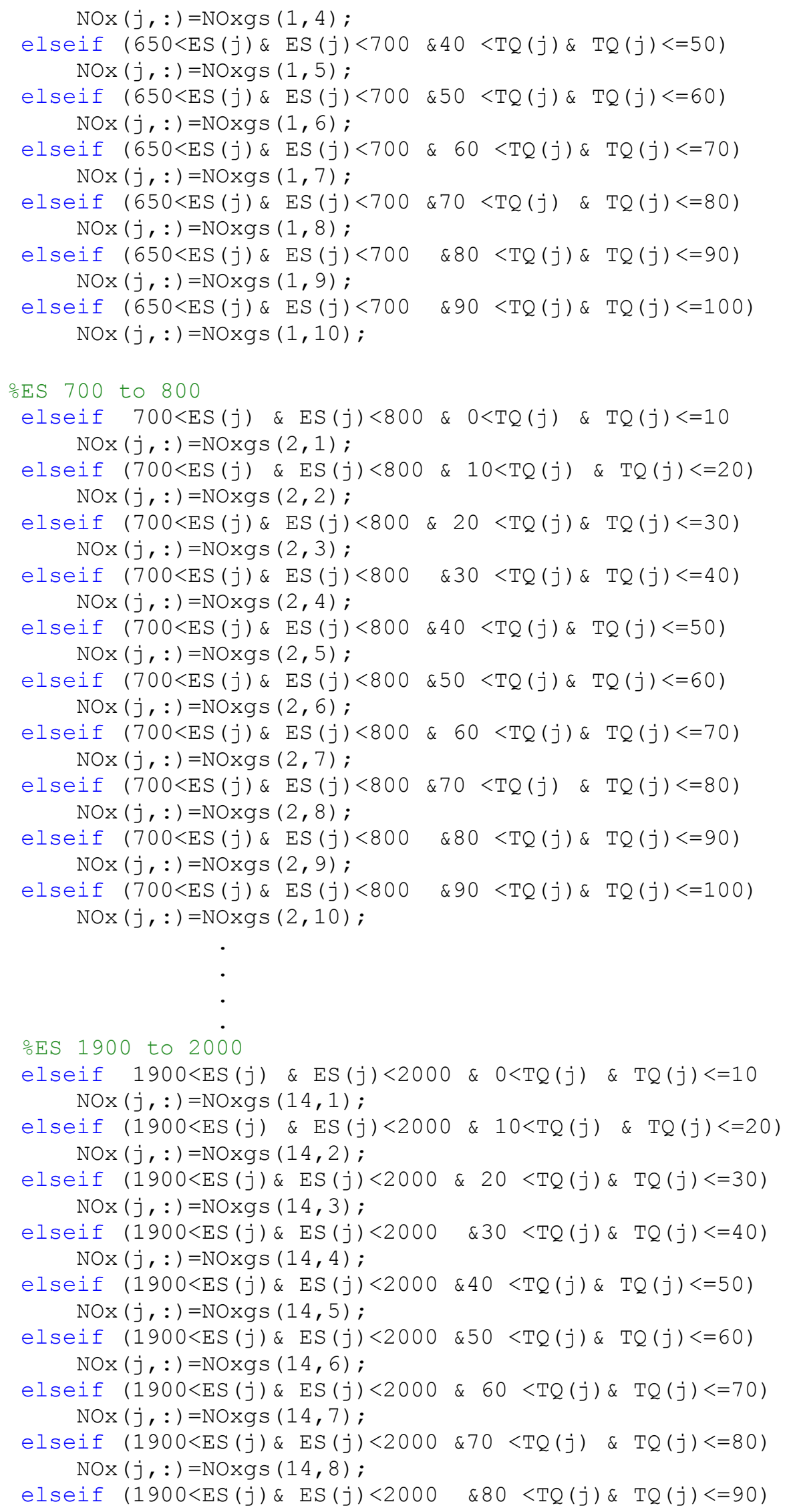




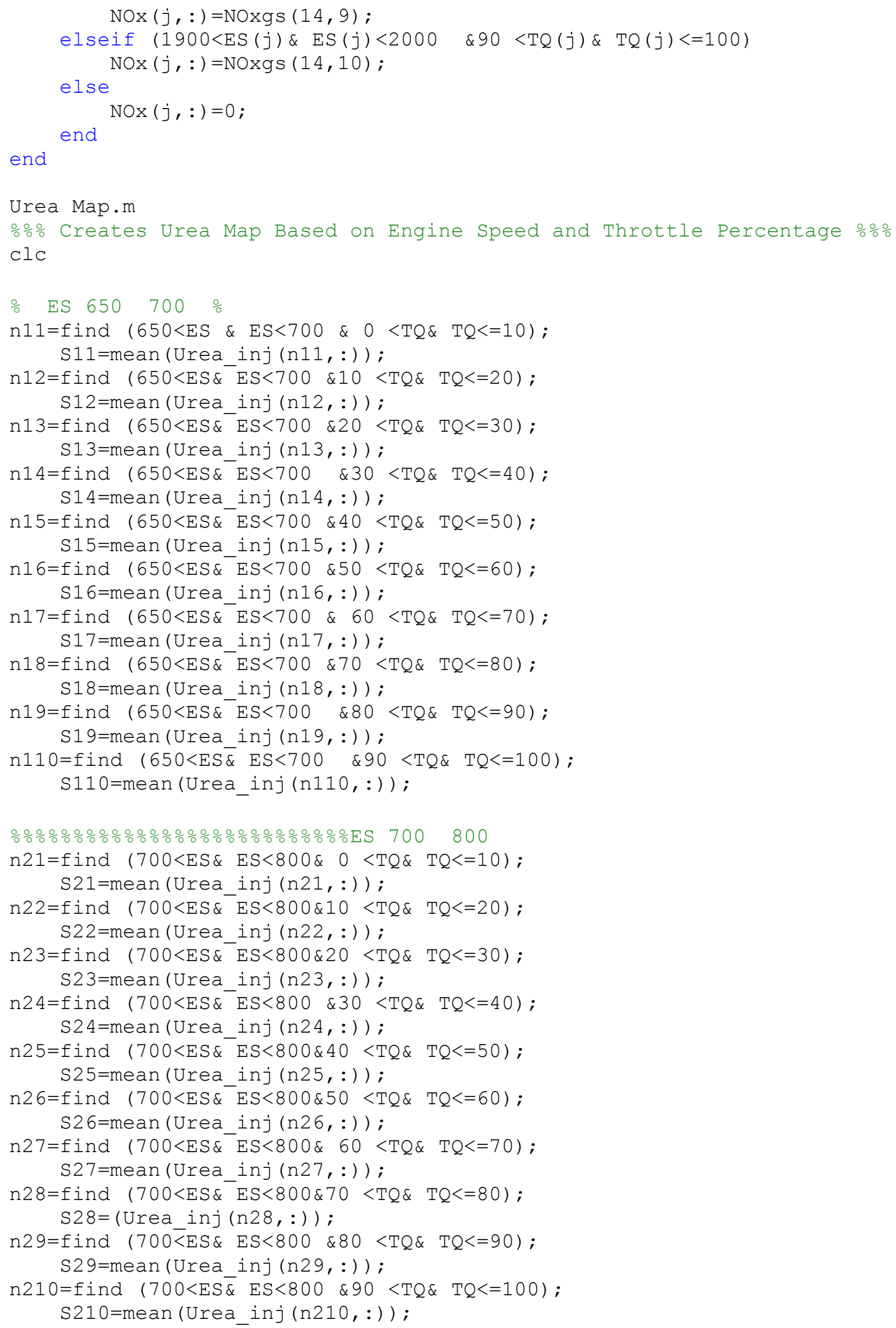




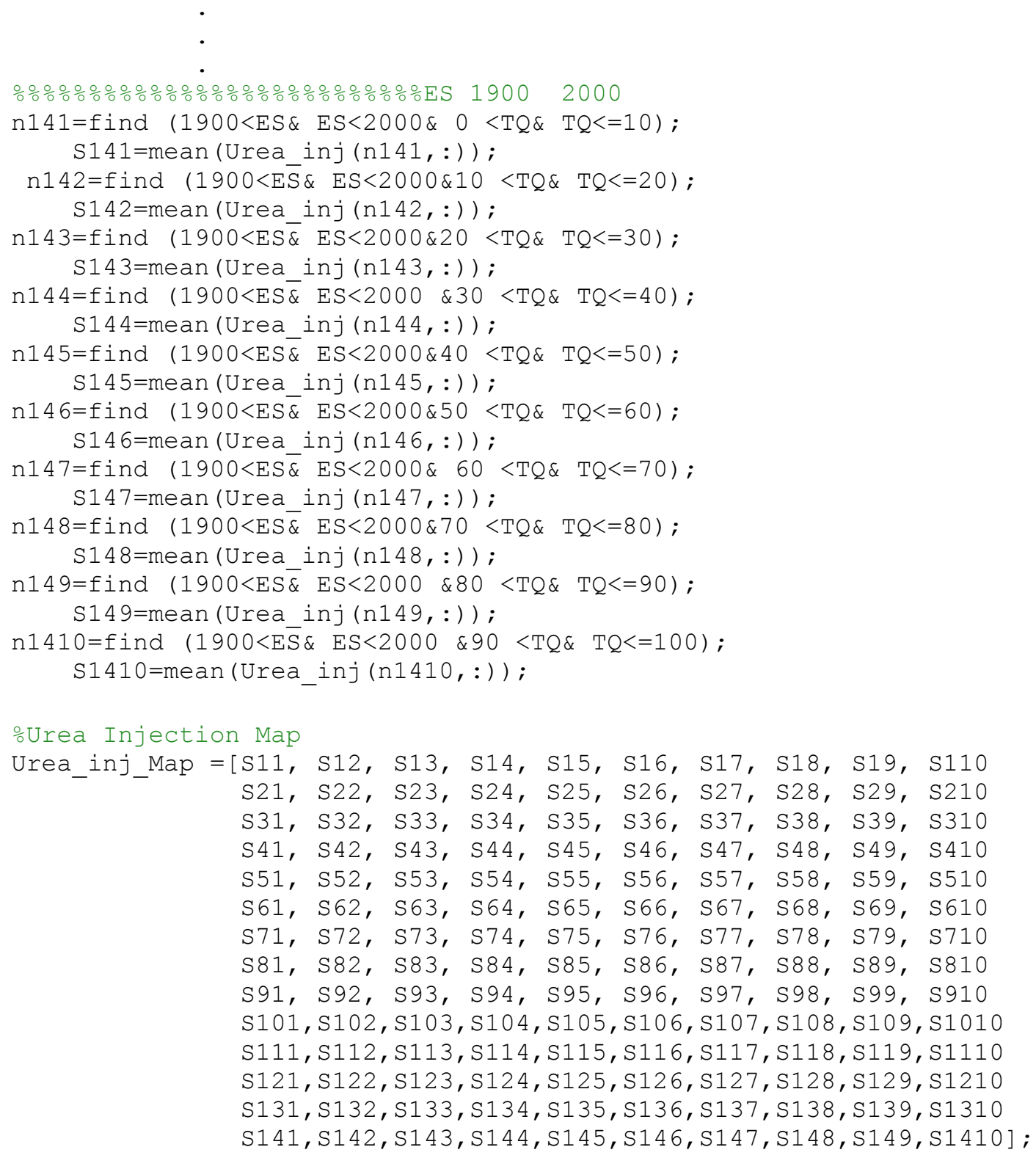




\title{
Appendix B - CANalyzer Control Code
}

\author{
Main \\ variables \{ \\ msTimer SendADS_CMD1; \\ msTimer SendAMB_COND; \\ word UreaMassflow $=0$; \\ int HeatingEnable $=0$; \\ byte DosValve $=2$; \\ int Timer_ADS_CMD1_Value $=50$; \\ int Timer_AMB_COND_Value $=500$; \\ word EngineSpeed $=0$; \\ word EngineSpeedstep $=1000 ; / *$ EngineSpeedstep $=1000 ; * /$ \\ word DiagPGN = 0xfecb; \\ dword mPage; // menu page \\ word UreaStep $=2400 ; / / 0.36 \mathrm{~kg} / \mathrm{h}$ \\ word timstep $=1$; \\ int tim $=0$; \\ word AmbTemp = 9500; /* 9536 = 25 C default*/ \\ word AmbTempStep $=160 ; / * 160=5 \mathrm{C} /$ step */ \\ byte AfterrunDelay $=0$; \\ byte VehicleType $=7$; \\ byte $\mathrm{ACP} 1=0$; \\ byte U_Cat_TempU $=0$; \\ int $x$ index $=\overline{1} 5$; \\ int yindex $=11$; \\ /*durability*/ \\ float noxc; \\ int noxtable[15][11] $=\{$ \\ $\{0,0,0,0,0,0,0,0,0,0,0\}$, \\ $\{0,0,1,1,1,0,0,0,0,0,0\}$, \\ $\{1,1,1,1,1,1,1,1,1,1,1\}$, \\ $\{1,1,1,1,1,1,1,1,1,0,0\}$, \\ $\{1,1,1,2,2,2,1,1,2,1,1\}$, \\ $\{1,1,2,2,2,2,2,2,2,2,0\}$, \\ $\{0,0,2,2,2,1,1,1,1,2,1\}$, \\ $\{0,0,1,1,1,1,1,1,2,2,1\}$, \\ $\{1,1,1,1,1,1,1,1,2,2,2\}$, \\ $\{1,1,1,1,1,2,2,2,3,3,1\}$, \\ $\{1,1,2,2,2,2,2,3,3,4,1\}$, \\ $\{1,1,2,2,3,3,3,3,3,2,1\}$, \\ $\{1,1,2,2,3,3,3,3,3,4,4\}$, \\ $\{1,1,2,2,3,3,2,2,2,3,0\}$, \\ $\{1,1,2,2,3,3,3,3,3,0,0\}$
}




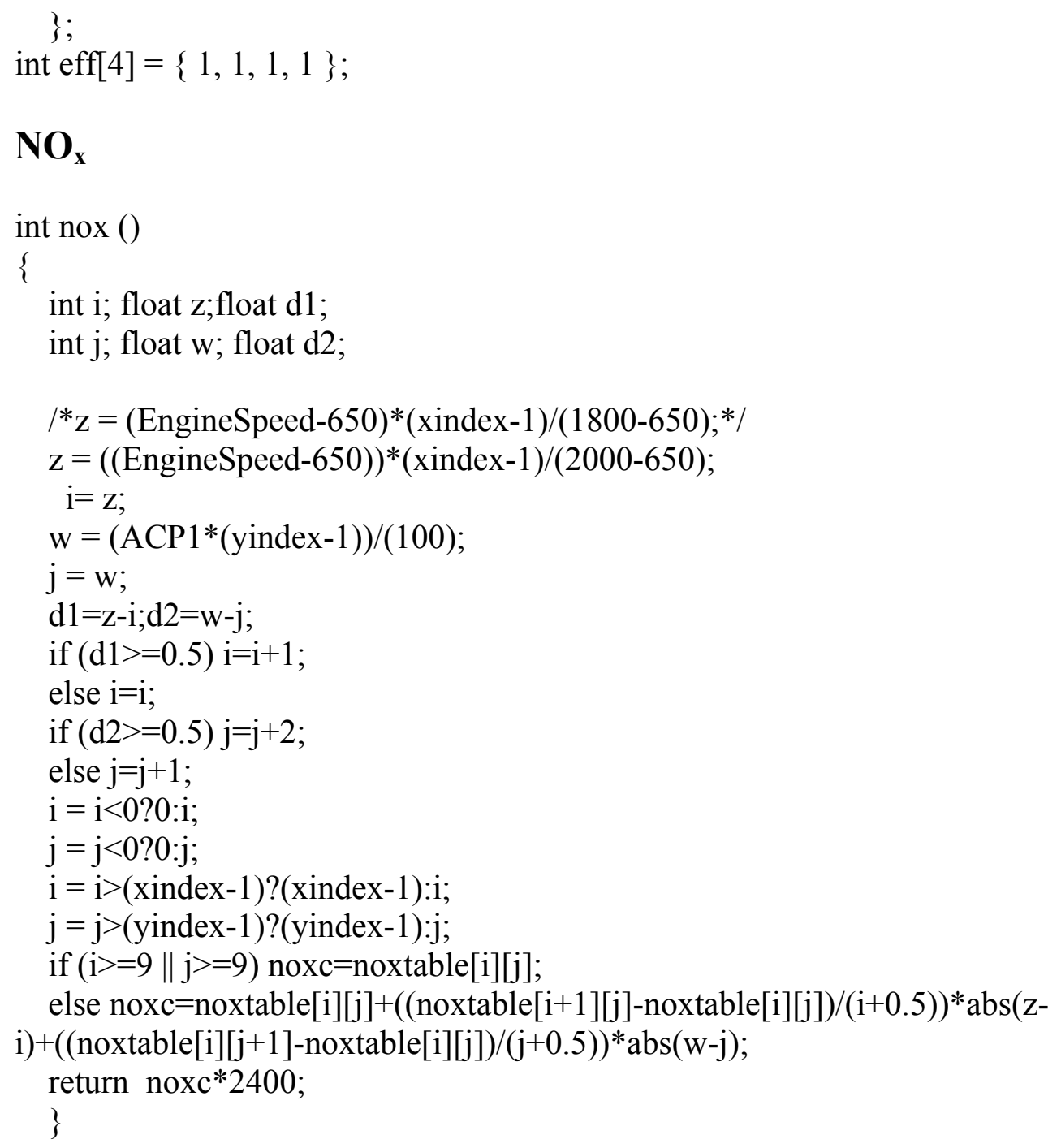

\section{SCR efficiency}

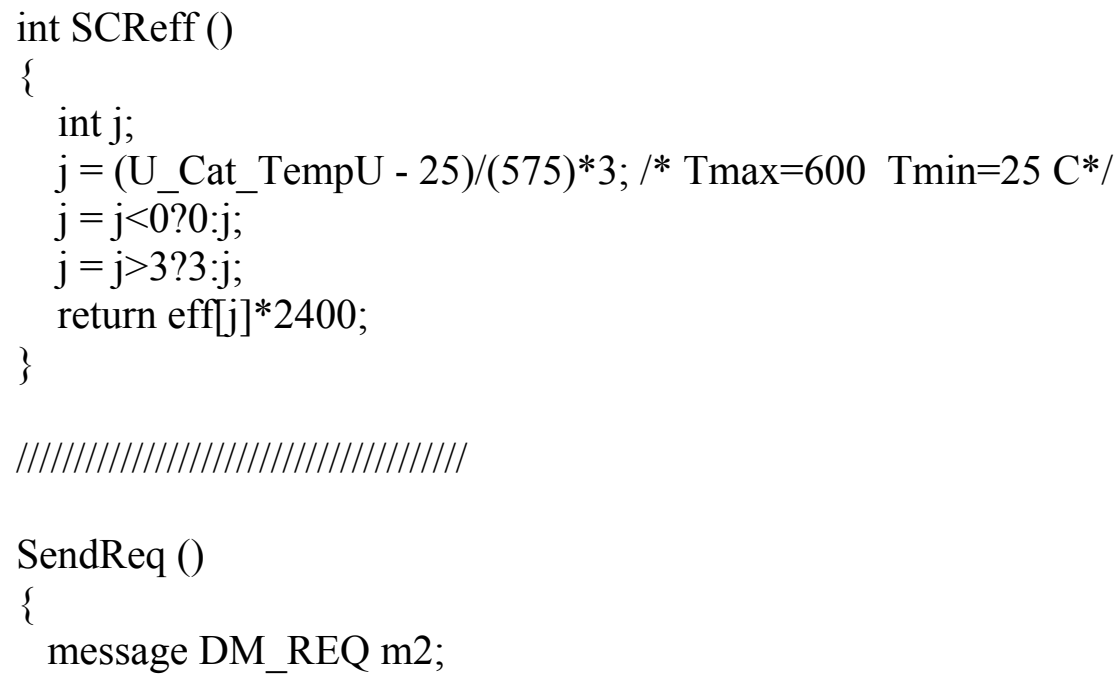




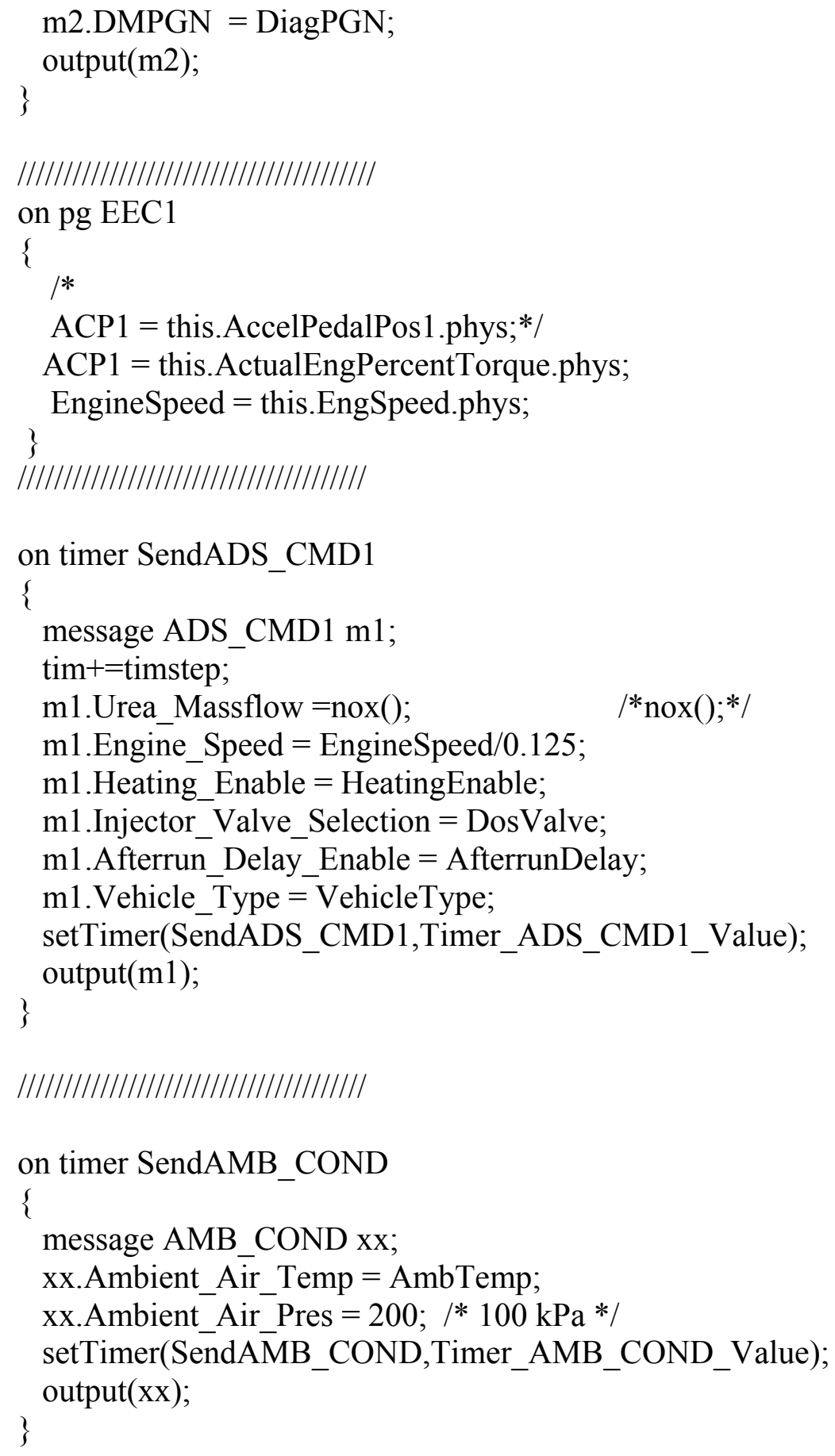

\section{Display Graphics}

Display()

\{

writeclear(mPage);

// writeTextBkgColor(mPage, $0,0,0)$;

// writetextcolor(mPage,255,255,32); 
// writelineex(mPage,4,"\%lf Heat:\%ld rpm:\%ld Amb temp:\%ld C \%ldkg/h Afterrun:\%ld", (UreaMassflow* 4.166666666667e-5), HeatingEnable, EngineSpeed/8, AmbTemp/32-

273,3+DosValve*3,AfterrunDelay);

// writeTextBkgColor(mPage,96,96,224);

// writetextcolor(mPage,255,255,255);

writelineex(mPage,4,"*** UDS Control Script Menu ***");

writelineex(mPage,4," e - Toggle engine speed");

writelineex(mPage,4," y/u - Vehicle type +/- \%ld",VehicleType);

writelineex(mPage,4," h/t - Toggle el/tank heating");

writelineex(mPage,4," j/n - Urea massflow +/- \%lf g/s", (UreaStep * 4.166666666667e-5));

writelineex(mPage,4," a - Toggle afterrun delay");

writelineex(mPage,4," 1/k - Ambient temp +/- \%ld C",AmbTempStep/32);

writelineex(mPage,4,"3,6,9 - Select dosing valve");

writelineex(mPage,4,"v,g,b - Request DM2,DM3,DM11");

writelineex(mPage,4," AccelPedalPosition \%ld",ACP1 );

writelineex(mPage,4," xindex \%ld",EngineSpeed ); 